\title{
Induction of myosin cross-reactive antibody and cytolytic T cell responses in mice with Streptococcus pyogenes
}

\author{
Cynthia Ann Cunningham \\ West Virginia University
}

Follow this and additional works at: https://researchrepository.wvu.edu/etd

\section{Recommended Citation}

Cunningham, Cynthia Ann, "Induction of myosin cross-reactive antibody and cytolytic T cell responses in mice with Streptococcus pyogenes" (2000). Graduate Theses, Dissertations, and Problem Reports. 1230. https://researchrepository.wvu.edu/etd/1230

This Dissertation is protected by copyright and/or related rights. It has been brought to you by the The Research Repository @ WVU with permission from the rights-holder(s). You are free to use this Dissertation in any way that is permitted by the copyright and related rights legislation that applies to your use. For other uses you must obtain permission from the rights-holder(s) directly, unless additional rights are indicated by a Creative Commons license in the record and/ or on the work itself. This Dissertation has been accepted for inclusion in WVU Graduate Theses, Dissertations, and Problem Reports collection by an authorized administrator of The Research Repository @ WVU.

For more information, please contact researchrepository@mail.wvu.edu. 


\title{
Induction of Myosin Cross-Reactive Antibody and Cytolytic T Cell Responses
} in mice with Streptococcus pyogenes

\author{
Cynthia A. Cunningham \\ Dissertation submitted to the School of Medicine \\ at West Virginia University \\ in partial fulfillment of the requirements \\ for the degree of
}

Doctor of Philosophy

in

Immunology

\author{
Meenal Elliott, Ph.D., Chair \\ Christopher Cuff, Ph.D. \\ Jim Mahaney, Ph.D. \\ Rosana Schafer, Ph.D. \\ Jim Sheil, Ph.D.
}

Department of Microbiology and Immunology

Morgantown, West Virginia 2000

Keywords: Streptococcus pyogenes, M protein, myosin, and autoimmunity 


\begin{abstract}
Induction of Myosin Cross-Reactive Antibody and Cytolytic T Cell Responses in mice with Streptococcus pyogenes
\end{abstract}

\title{
Cynthia Cunningham
}

Impetigo and pharyngitis are two common suppurative infections in man elicited by Streptococcus pyogenes that lead to autoimmune complications in susceptible individuals. Although the underlying mechanisms for the onset of post-streptococcal autoimmunity have yet to be established, experimental information gained thus far suggests that the resultant pathology is a consequence of immunological cross-reactivity between streptococcal antigens, namely the anti-phagocytic factor M protein and host proteins, specifically myosin. Experimental animal model systems developed to date have predominantly relied on the immunization of adult animals with $\mathrm{M}$ protein emulsed in adjuvant. In the laboratory we have undertaken studies with mice to examine the capacity of $S$. pyogenes as whole organism without adjuvant to elicit autoreactive $\mathrm{B}$ and $\mathrm{T}$ lymphocytes.

We have observed that immunizing mice with heat-killed preparations of S. pyogenes as neonates, but not adults, induces the production of host cross-reactive serum antibodies akin to those documented in cases of post-streptococcal autoimmunity. Western blot analysis of monoclonal antibodies generated from mice immunized with $S$. pyogenes suggests that antibodies induced in neonatal mice preferentially recognize the cardiac isoforms of mouse skeletal myosin, whereas, antibodies derived from adult mice primarily recognize determinants shared by all isoforms of mouse skeletal myosin. In addition, we have demonstrated the ability of neonatal, but not adult, mice to mount a myosin-reactive $\mathrm{CD} 8^{+}$cytotoxic $\mathrm{T}$ cell response following immunization with $S$. pyogenes. Our observations indicate that the response is additionally dependent on the genetic background of mice, the route of immunization, and requires $\mathrm{M}$ protein.

In summation, our results suggest that in susceptible individuals exposure to $S$. pyogenes early in life may serve as a priming event and following a subsequent event later in life, possibly re-exposure to S. pyogenes, allow the initiation of the pathology associated with poststreptococcal autoimmunity. These results contribute to the understanding of the development of the mechanisms of post-streptococcal autoimmune complications and may ultimately contribute to the development of effective diagnostic intervention strategies. 


\section{Dedication}

I dedicate this dissertation to my parents, James and Judith McDaniel, whose example and uncompromising devotion and support have given me the courage to accept challenges and the strength to accomplish my goals. 


\section{Acknowledgements}

I would like to thank my advisor, Dr. Meenal Elliott, for not only providing the opportunity and challenge to advance my education but more importantly for bestowing me her friendship. I would also like to thank my committee members, Dr. Christopher Cuff, Dr. Rosana Schafer, Dr. Jim Sheil and Dr. Jim Mahaney for generously allotting their time, advice and encouragement.

I thank my family for their love and support; my parents for their understanding and encouragement and especially my brothers, Roger and Timothy, for maintaining my sense of humor. I thank my husband, James Cunningham, for accepting my desire to pursue this degree and providing the necessary support when I needed it most.

I would like to thank the friends whom I have made along the way. Their companionship has not only enriched my life but also made the darkest hours more bearable.

Finally, I would like to thank the late Dr. Thomasina Redd. Through her example and guidance she was the catalyst who spurred my interest in pursuing this degree and instilled within me the confidence to achieve it. 


\section{Table of Contents}

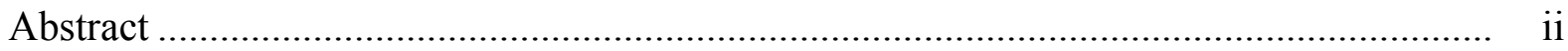

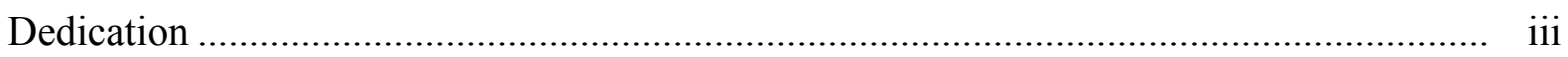

Acknowledgement .................................................................................................... iv

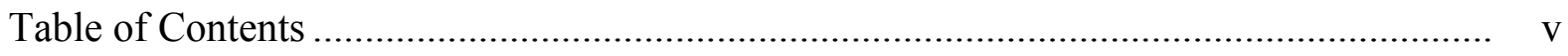

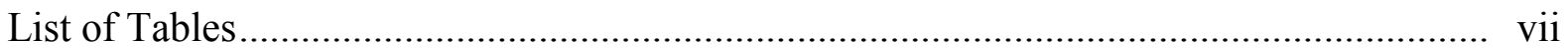

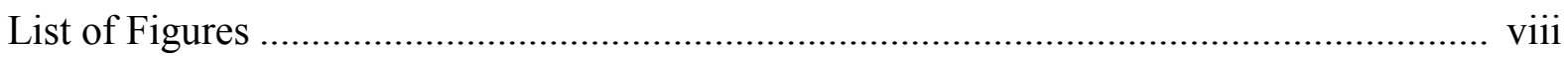

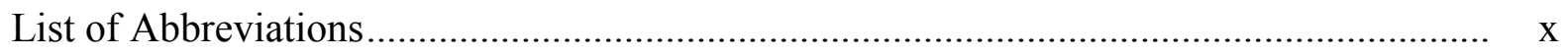

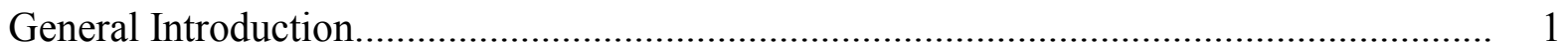

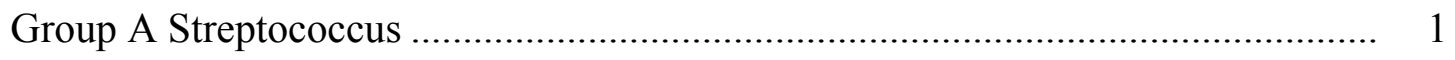

Acute Rheumatic Fever and other Post-streptococcal Autoimmune Sequelae ......... 18

Overview of Our Studies ................................................................................ 37

Antibodies Induced by Heat-Killed Streptococcus pyogenes in Neonatal

BALB/c Recognize Isoforms of Mouse Skeletal Myosin ..................................................... 46

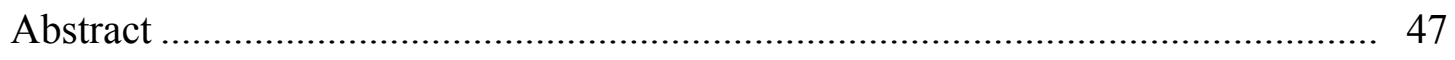

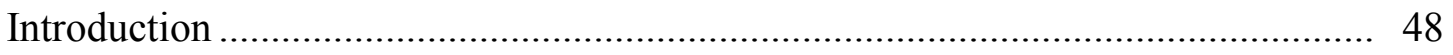

Material and Methods............................................................................................. 51

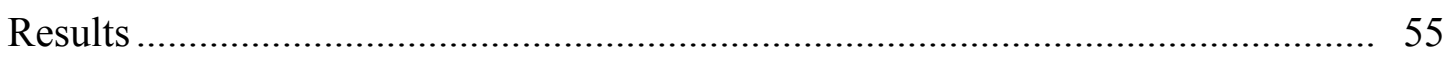

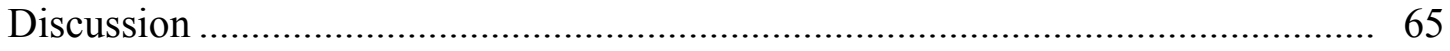

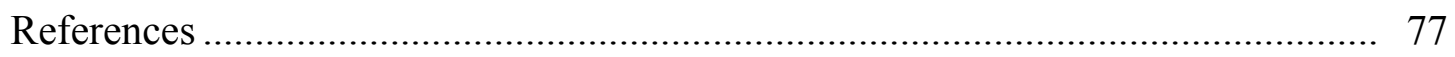

Induction of Myosin-Reactive CTL in Mice following Immunization with Heat-Killed Streptococcus pyogenes ....................................................................... 81

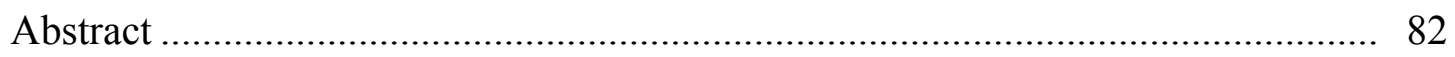

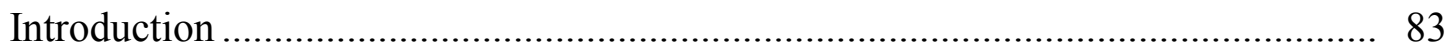




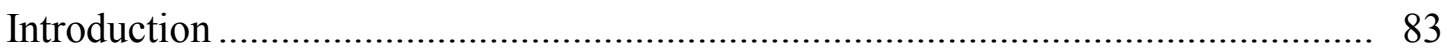

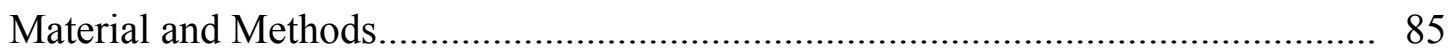

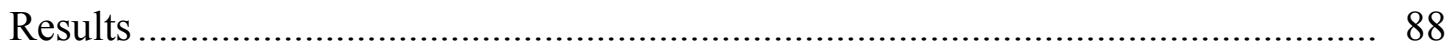

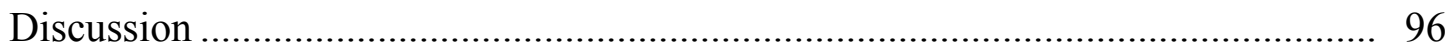

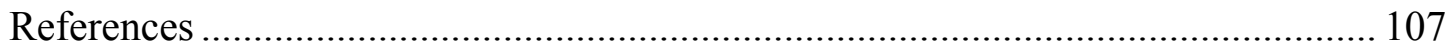

Myosin-Reactive CTL are Induced in Neonatal Mice by the

C-Terminal Conserved Region of the Streptococcal M protein............................................. 111

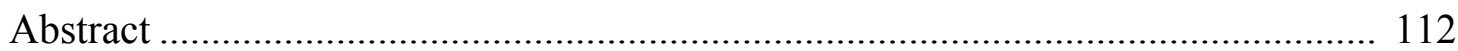

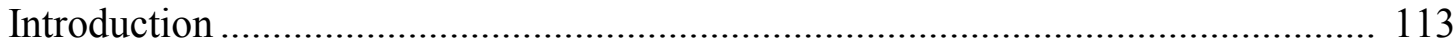

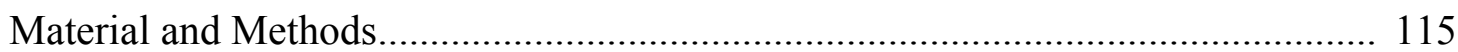

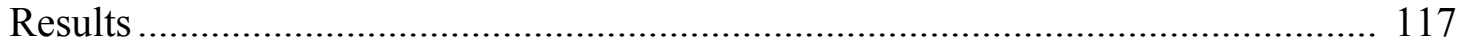

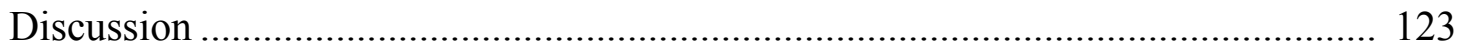

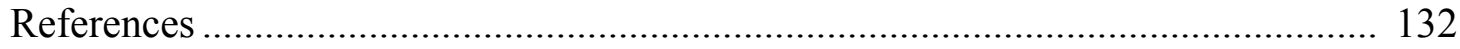

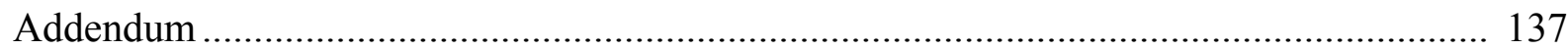

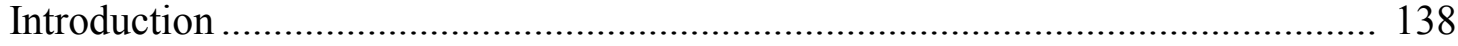

Material and Methods.......................................................................................... 139

Results and Discussion................................................................................... 141

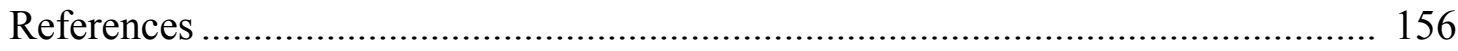

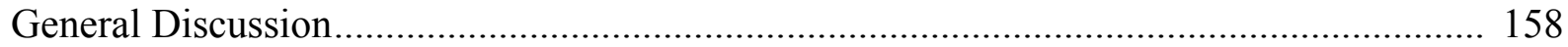

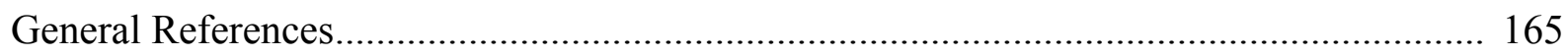




\section{List of Tables}

General Introduction

Table 1. Major virulence factors of Streptococcus pyogenes and their potential role in infection and pathogenesis

Antibodies Induced by Heat-Killed Streptococcus pyogenes in Neonatal

Versus Adult BALB/c Recognize Distinct Isoforms of Mouse Skeletal Myosin

Table 1. Summary of hybridomas obtained following distinct immunization strategies.

Table 2. Binding of myosin components by monoclonal antibodies induced by GAS.

Table 3. Patterns for cross-recognition of endogenous MyHC by antibodies against GAS

Addendum

Table 1. Potential role of genetics in the elicitation of a myosin-specific CTL response following neonatal immunization with $S$. pyogenes 


\section{List of Figures}

General Introduction

Figure 1. Schematic representation of M6 protein

14

Antibodies Induced by Heat-Killed Streptococcus pyogenes in Neonatal

Versus Adult BALB/c Recognize Distinct Isoforms of Mouse Skeletal Myosin

Figure 1. Antibody responses in BALB/c mice

immunized with heat-killed GAS.

Figure 2. Western blot analysis of mouse MyHC with antibodies raised against human and rat $\mathrm{MyHC}$

Figure 3. Western blot analysis of $\mathrm{MyHC}$ isoforms from hindlimbs and diaphragm with mouse monoclonal antibodies induced by GAS

Figure 4. Western blot analysis of mouse cardiac MyHC with mouse monoclonal antibodies induced by GAS.

Induction of Myosin-Reactive CTL in Mice following Immunization with Heat-Killed Streptococcus pyogenes

Figure 1. Analysis of cytolytic T cell responses induced in adult primed $\mathrm{BALB} / \mathrm{c}$ animals.

Figure 2. Analysis of myosin-specific CTL responses in BALB/c mice challenged as neonates with heat-killed $S$. pyogenes

Figure 3. Kinetics of the myosin-specific CTL response elicited in $\mathrm{BALB} / \mathrm{c}$ mice primed as neonates with heat-killed $S$. pyogenes

Figure 4. The role of age in the induction of a myosin-specific CTL response 104

Figure 5. Requirement of $\mathrm{M}$ protein during neonatal exposure of $S$. pyogenes for the induction of a myosin-specific CTL response

Figure 6. CTL activity of $\mathrm{CD}^{+}$enriched splenocytes before and after culturing with recombinant streptococcal $\mathrm{M}$ protein

Myosin-Reactive CTL are Induced in Neonatal Mice by the

C-Terminal Conserved Region of the Streptococcal M protein

Figure 1. Electrophoretic separation of mouse myosin 
Figure 2. Cytolytic activity against myosin primed in neonatal mice requires $\mathrm{M}$ protein

Figure 3. Priming of myosin-specific CTL responses in mice with non-rheumatogenic strains of $S$. pyogenes

Figure 4. Priming of myosin-specific CTL response in neonatal mice with the conserved region of $\mathrm{M}$ protein

Figure 5. Priming of a myosin-specific CTL response in adult mice with the conserved region of $\mathrm{M}$ protein

Addendum

Figure 1. C57B1/6 mice are capable of eliciting a myosin-specific response following neonatal i.p. challenge with $S$. pyogenes

Figure 2. M protein is required but not exclusively responsible for the myosin-reactive CTL response

Figure 3. The myosin-reactive CTL response can not be elicited by the intranasal route of immunization

Figure 4. Intranasal immunization with S. pyogenes during the neonatal period primes for a systemic myosin-reactive CTL response

Figure 5. Role of B lymphocytes in the elicitation of the myosin-reactive CTL response 


\section{List of Abbreviations}

\begin{tabular}{|c|c|}
\hline GN & Acute glomerulonephritis \\
\hline $\mathrm{AH} \ldots . . .$. & Adult heart ventricle \\
\hline APC.. & Antigen presenting cell \\
\hline ARF.. & Acute rheumatic fever \\
\hline BSA.. & Bovine serum albumin \\
\hline CTL & Cytotoxic T lymphocyte \\
\hline ELISA & $\begin{array}{l}\text { Enzyme-linked immunosorbance } \\
\text { assay }\end{array}$ \\
\hline EMB . & Embryonic \\
\hline GAS.. & Group A streptococcus \\
\hline GAST . & Adult gastrocnemius \\
\hline GlcNAc. & $\mathrm{N}$-acetyl- $\beta$-D-glucosamine \\
\hline 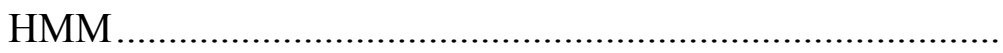 & Heavy meromyosin \\
\hline LMM . & Light meromyosin \\
\hline …................. & Lipoteichoic acid \\
\hline mAb... & Monoclonal antibody \\
\hline MHC.. & Major histocompatibility complex \\
\hline 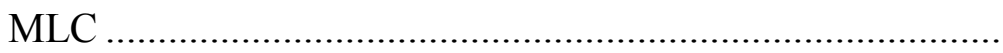 & Myosin light chain \\
\hline 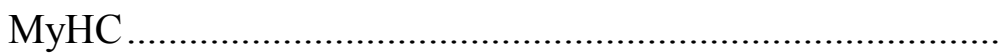 & Myosin heavy chain \\
\hline $\mathrm{NH}$ & Neonatal heart \\
\hline $\mathrm{NN}$ & Neonatal \\
\hline (2) & Systemic lupus erythematosus \\
\hline SOL & Adult soleus \\
\hline 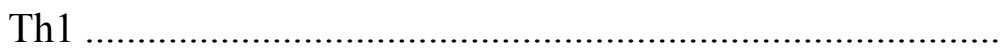 & T helper type 1 lymphocyte \\
\hline & T helper type 2 lymphocyte \\
\hline
\end{tabular}




\section{General Introduction}

Introduction. Streptococcus pyogenes is a group A, beta hemolytic gram-positive cocci that is the causative agent of several infectious manifestations in man. Streptococcal infections are typically controlled by a protective antibody response with or without the aid of antibiotics, however, a certain small percentage of children worldwide who do not receive proper timely antibiotic treatment will develop autoimmune sequelae. Much research has been devoted to understanding the underlying mechanisms that initiate these autoimmune complications and, although no clear answers have been found, it is becoming increasingly evident that characteristics of the host may play just as important of a role as the infectious organism. Because GAS infections are prevalent and may subsequently result in invasive or autoimmune complications, the development of an efficacious vaccine is becoming increasingly important. Despite the significance of information gained thus far, research into all facets of poststreptococcal autoimmune scenarios has been hindered by the lack of a complete autoimmune animal model system. This chapter will discuss both historic and current research, as well as, the contributions of the research conducted in our laboratory, towards the advancement of the understanding of the relationship between host and organism and of the understanding of the subsequent autoimmune complications.

\section{Group A Streptococcus}

Historical Perspective. Streptococci first came into our acquaintance around the late 1870's, during the time that Louis Pasteur was beginning to develop the germ theory of disease.

Refusing to accept the currently reigning ideology of diseases being the result of spontaneous generation, Pasteur began to focus his attention on puerperal fever, which at that time was a very 
prevalent cause of maternal and neonatal deaths following childbirth. Upon examining samples acquired from women with puerperal sepsis, he repeatedly encountered chained or paired microorganisms. Although it was these microorganisms that Pasteur implicated as the causative agent, it was not until 1879 when he introduced this theory at the Academy of Medicine meeting streptococci received recognition (reviewed in Stollerman 1975; Horaud et al. 1997). Two years later Billroth and Ehrlich officially identified the organism and named them Streptococcus (rev. in Stollerman 1975; Horaud et al. 1997). Since its introduction Streptococcus has made historically significant contributions to the study of genetics and antibacterial chemotherapy. Experiments performed in the late 1930's demonstrated the ability to clear streptococcal infections with chemical compounds later identified as sulfonamides and providing the first series of antibacterial chemotherapeutic agents (reviewed in Horaud et al. 1997). About the same time, McCarty employed Streptococcus as the experimental agent to demonstrate and define bacterial transformation for the first time (reviewed in Horaud et al. 1997). The focus of more recent history of Streptococcus has been primarily towards the relationship with human diseases. Probably one of the most celebrated pioneers in streptococcal research is Dr. Rebecca Lancefield. Her most notable contributions began in the 1920's with the definition of streptococcal subgroups based on cell wall carbohydrate moieties and later changed the course of streptococcal research with the identification of M protein as the major anti-phagocytic factor (Lancefield 1962). Other notable investigators include Rammelkamp, Edward Kaplan, James Dale, Edwin Beachey, John Zabriskie, Vincent Fischetti and Mclean McCarty. By expanding on Lancefield's initial work these researchers, among others too numerous to mention, have been able to elucidate aspects of streptococcal virulence and the impact of Streptococcus and streptococcal related diseases, both primary and sequelae, on the human condition. 
Group A streptococcal infections. S. pyogenes is a human pathogen associated with several suppurative infections of the skin and throat, as well as, a number of autoimmune diseases including acute rheumatic fever and acute glomuleronephritis. While the most prevalent infections are pharyngitis and impetigo, GAS is associated with several, more invasive infections including scarlet fever, streptococcal toxic shock syndrome, cellulitis, erysipelas, necrotizing faciitis and gangrene (Stevens 1992; Schlievert et al. 1996). Pharyngitis, or strep throat as it is commonly known, and impetigo are superficial infections that are easily controlled with antibiotics, however, these infections may lead to more serious invasive infections such as those listed above or to autoimmune complications. Streptococcal pharyngitis is characterized by a sore throat and fever that onsets within 72 hours of initial infection. With the aid of antibiotics, symptoms generally subside within 7 - 10 days and most organisms are cleared, however, in untreated cases the organism may be present up to 4 weeks post infection. This merits concern, considering that up to $40 \%$ of all cases are mild to asymptomatic and may not warrant treatment, thus allowing the spread the organism and creating greater risk of further complications, whether invasive or autoimmune (Kehoe 1991; Stevens 1992). Impetigo is characterized by pustular skin lesions most likely found on the extremities and usually is preceded by skin colorization and mild trauma to the affected area. Typically, pharyngeal infections are cleared by a vigorous host response that results in lifelong type-specific immunity while impetigo does not. Additionally, streptococcal pharyngitis may appear in any individual over the age of 5 years, while impetigo typically reaches peak at two to five years of age.

Phage transformed streptococcal organism produce a set of exotoxins and are known to induce scarlet fever, a disease characterized by pharyngitis and a rash around the trunk and neck that spreads to the extremities. Most often this infection occurs in children ranging in age from 
two to ten years. Other streptococcal invasive infections, necrotizing faciitis, myositis, gangrene, are the result of deep tissue infection and exhibit high mortality rates. These infections usually occur in immunocompromised individuals or healthy individuals following a trauma or underlying illness. The most recently identified and potentially most serious invasive GAS infection is streptococcal toxic shock syndrome. Unlike the other invasive infections these disease occurs in patients between the ages of 20 and 50 who were otherwise healthy (Scwartz et al. 1990).

Another potential complication of streptococcal infections is the development of autoimmune disorders, which include acute rheumatic fever, acute glomerulonephritis, Syndenham's chorea, psoriasis, and Kawasaki's disease. Post-streptococcal autoimmunity differs from other cross-reactive antibody associated diseases such as SLE in that, antibodies in post-streptococcal sequelae bind directly to the tissue site while in SLE the antibodies form immunocomplexes with the autoantigen (DNA) that in turn bind to the tissue site (Chan et al. 1999; Maddison 1999). ARF is an autoimmune complication that primarily affects the heart and joint tissue and appears in a small percentage of children ranging in age from 5 to 15 years approximately three to four weeks following untreated GAS nasopharyngeal infection. AGN is also predominantly a childhood disease, however, it is characterized by renal tissue pathology and typically follows impetigo. Unlike AGN and ARF, psoriasis is an inflammatory skin disease that appears to be indiscriminant with age. These diseases have been shown to follow or be exacerbated by a streptococcal infection and will receive more attention later in the review. Virulence factors promoting adherence and colonization. Upon entering the host, the organism typically initiates colonization by adhering to host cell epithelium. S. pyogenes has at least eleven potential candidates to carry out this action (Hasty and Courtney 1996); however 
only five such factors have been well characterized which include lipoteichoic acid (Beachey and Simpson 1982; Beachey et al. 1983; Caparon et al. 1991), fibronectin binding protein (Hasty and Courtney 1996), M protein (Caparon et al. 1991; Kehoe 1991; Okada et al. 1994), protein F (Hasty and Courtney 1996) and the hyaluronic acid capsule (Schrager et al. 1998). Of course, other factors that have not yet been characterized cannot be discounted. Protein F and fibronectin binding protein interact with fibronectin on pharyngeal epithelial cells (Kehoe 1991; Hanski and Caparon 1992) and purified preparations of these proteins have been shown to inhibit adhesion of GAS to epithelial cells in vitro (Speziale et al. 1984; Kehoe 1991). Lipoteichoic acid is believed to mediate adherence to host epithelium and buccal cells (Simpson and Beachey 1983) through the formation of a complex with $\mathrm{M}$ protein and binding via its lipid moiety to fibronectin on the epithelial cells (Beachey and Simpson 1982).

The standard model of adhesion suggests that during the process of its release from the cell LTA forms a surface protein-LTA complex where the lipid ends of LTA protrudes outwards to permit the binding to fibronectin on the surface of epithelial cells (Beachey et al. 1983). However, Caparon et al. (Caparon et al. 1991) have presented evidence indicating that M protein does not interact with LTA but instead M protein promotes the formation of aggregates or microcolonies. This suggests that while M protein does not initiate adherence, it directly promotes or enhance adherence that ultimately aides in counteracting attachment inhibition mediated by secretory IgA (Williams and Gibbons 1972). While it is generally agreed that M protein itself does not play a direct role in adhesion to epithelial cells (Caparon et al. 1991; Okada et al. 1994; Hasty and Courtney 1996), certain serotypes of M protein can mediate binding to human laryngeal epithelial Hep-2 cells and keratinocytes through CD46 (Okada et al. 1994; Okada et al. 1995). However, the significance of this interaction remains in question since Schrager et al. 
(1998) demonstrated that the hyaluronic acid capsule physically inhibits M protein binding to keratinocytes while mediating binding through CD44. Despite the ambiguity of the roles of the various adhesion factors it might be inferred that the availability of such a variety is an indication of the organism's ability to adapt to various host conditions. Further, instead of dependence on one key adhesion factor, each factor may play a minor role, as necessary, in the overall goal of adhesion.

Host immune response to group A streptococcal infections. Upon bypassing the physical barriers and entering the host, the organism may initiate an inflammatory response resulting in the influx of the necessary effector cells of the immune system (phagocytes and lymphocytes) and serum proteins with effector function, most importantly antibody and complement. The most effective defense against an extracellular organism such as GAS is phagocytosis and the activation of the complement system either through the alternative and classical antibody mediated pathways. Phagocytosis can be directed under two mechanisms; first, phagocytic macrophages possess receptors for certain bacterial polysaccharides and upon recognition may directly mediate phagocytosis, and second, phagocytic activity is greatly enhanced with opsonic help of antibodies and complement.

The complement system is composed of two pathways; antibody mediated classical pathway and the less specific alternate pathway (Winkelstein 1981). Activation of the alternate pathway is initiated by the binding of complement factor $\mathrm{C} 3 \mathrm{~b}$ to the outer surface of the organism, while the classical pathway is activated by antibody binding to the pathogen or the formation of antigen-antibody complexes. While the initial events of the two pathways differ they eventually overlap with factor $\mathrm{C} 3 \mathrm{~b}$. Involvement of factor $\mathrm{C} 3 \mathrm{~b}$ leads to the splicing of factor $\mathrm{C} 5$ into $\mathrm{C} 5 \mathrm{a}$ and $\mathrm{C} 5 \mathrm{~b}$, where $\mathrm{C} 5 \mathrm{a}$ is a major chemotatic agent and $\mathrm{C} 5 \mathrm{~b}$ will initiate the 
formation of the membrane attack complex. Activation of the complement cascade will ultimately allow for two potential outcomes, lysis or phagocytosis. First, binding of $\mathrm{C} 3 \mathrm{~b}$ to the organism as an event of either pathway can initiate the formation of the membrane attack complex resulting in membrane permeation and subsequent cellular lysis. Secondly, the bound antibody and $\mathrm{C} 3 \mathrm{~b}$ function as a major opsonin thereby enhancing phagocytic uptake of the organism by monocytes, macrophages, or neutrophils.

The antibody response to GAS plays a pivotal role in controlling GAS infection, not only as a means to induce phagocytosis as discussed above but also to hinder attachment to mucosal surfaces or neutralize bacterial toxic factors that may have potentially deleterious effect upon the host. Antibody titers against a number of extracellular streptococcal antigens, including the group specific carbohydrate, streptolysin O (SLO), DNase B and C5a peptidase have proven effective in confirming recent infection. Typically, the geometric mean titers of anti-SLO in sera from children tend to level at the age of three, while the mean titer of anti-DNase B and anti-C5a peptidase reach maximum levels around the age of six and nine, respectively (O'Connor et al. 1991). Typically, the antibody response to these antigens is dominated by the IgG subclass; however, a secretory IgA response to C5a peptidase has been demonstrated (O'Connor et al. 1991). The group specific carbohydrate is considered the immunodominant antibody epitope; however, the response is primarily mediated by IgM subclass (Emmrich et al. 1985). Because of the central role in pathogenesis of streptococcal diseases, the response to $\mathrm{M}$ protein has received the most attention. Antibodies to M protein opsonize streptococci for phagocytosis (Maxted 1956) and usually provide serotype specific immunity against infection by strains of the same M protein serotype (Lancefield 1962; Quinn et al. 1985). Despite the protective value of these typespecific antibodies, detection in patient sera following infection is highly variable, with $<20 \%$ to 
70\% of patients exhibiting detectable levels (Siegel et al. 1961; Quinn et al. 1985). The site of infection also influences the antibody response. Unlike the throat infection, a very poor serotypespecific response is generated following skin infection (El Kohly et al. 1980). This trend has also been demonstrated for antibody responses against SLO, while the antibody response against DNase B is good regardless of infection site (Kaplan et al. 1970).

While the importance of antibodies in GAS infections is well documented, adequate information regarding the $\mathrm{T}$ lymphocyte response has been lacking. Historically, $\mathrm{T}$ cell help has been shown to be a requirement for the antibody response against GAS (Braun et al. 1972), while anamnestic cellular responses can be demonstrated in vitro with a patient's peripheral blood lymphocytes. More recently the $\mathrm{CD} 4^{+} \mathrm{T}$ cell response against $\mathrm{M}$ protein has received the most attention in attempts to develop a protective serotype non-specific vaccine. Research led by Good (Pruskakorn et al. 1992; Pruskakorn et al. 1994a; Pruskakorn et al. 1994b) and Kehoe (Robinson et al. 1993; Rossiter et al. 1994) have shown that antigen-specific T cell responses against $\mathrm{M}$ protein are protective in mice, and the immunodominant epitopes have been mapped. While the role of the $\mathrm{CD} 4^{+} \mathrm{T}$ cell population is appreciated in the protective immune response, information regarding the role, if any, $\mathrm{CD} 8^{+} \mathrm{T}$ cells play has been lacking. Evidence has been presented to indicate that GAS may enter host epidermal cells (Hagman et al. 1999), however GAS is typically an extracellular organism. While the ability of an exogenous antigen like GAS to enter the class I processing and presentation pathway is not completely understood, several mechanisms have received extensive attention elsewhere (Yewdell et al. 1999, Heath and Carbone 1999). Rock et al. (Rock et al. 1993; Kovacsovics-Bankowski and Rock 1995) and Harding et al. (Pfeifer et al. 1993; Harding 1996) have shown that extracellular particulate antigens, whether protein coated beads or extracellular bacteria, can be processed and presented 
via class I by activated macrophages in vitro. This activity has also been demonstrated for dendritic cells (Svensson et al. 1997) and B cells (Ke and Kapp 1996). Cross-priming (Bevan 1976) is an aspect of class I presentation of exogenous antigen that has received extensive attention and yielded the most recent insight regarding potential mechanisms and requirements (Bennett et al. 1997, Bennett et al. 1998). Accordingly, APC may uptake high-dosage antigen or apoptotic cells (Kurts et al. 1998) and present the cell bound antigen via class I MHC under conditions that require signaling through CD40 by CD4+ T helper cells (Bennett et al. 1997, Bennett et al. 1998). Therefore, while providing means for class I presentation of tissueassociated antigens for immunological surveillance, this phenomenon may also serve as a means for extracellular infectious agents to access this presentation pathway.

Virulence factors involved in evasion of host immune responses. Streptococcus pyogenes is able to evade phagocytosis with an arsenal of somatic and secreted virulence factors. The hyaluronic acid capsule is considered an important virulence factor, since strains lacking the capsule are generally more readily phagocytosed and in turn much less infectious (Husmann et al. 1997). The capsule is believed to inhibit phagocytic uptake through steric interactions, physical repulsion due to a net negative charge, or other potential mechanisms (Whitnack et al. 1981). Being composed of equimolar concentrations of $\mathrm{N}$-acetyl glucosamine and glucuronic acid, components ubiquitously found in connective tissue component of the host (Kendall et al. 1937), the capsule may potentially provide a protective mask over the organism, diminishing recognition for the phagocytic process. Beyond the physical barrier provided by the capsule, other virulence factors, notably M protein and C5a peptidase, are able to directly interfere with the host immune response. M protein is able to prevent non-immune opsonization by binding factor H (Horstmann et al. 1988; Horstmann et al. 1992) and more preferably factor H-like 
protein 1 (FLH-1), the alternative splice product of the factor H gene (Zipfel et al. 1999). Factor $\mathrm{H}$ and FLH-1 are important regulators of the complement system that enact their functions by splicing C3b and controlling the stability of C3 convertase (Zipfel et al. 1999). This prevention is further augmented by C5a peptidase whose primary activity is to selectively cleave a six amino acid peptide from the carboxy-terminus of the complement component $\mathrm{C} 5$ thereby preventing chemotatic signaling necessary for the immune response (Wexler et al. 1985).

Although their function remains undetermined, another potential virulence aspect of GAS is the family of immunoglobulin-binding proteins (IGPs) (Cleary and Retnoningrum 1994). This family of cell associated proteins includes the M-like protein and a set of other proteins that are classified as type IIa or type IIb, where IIa binds human IgG1, IgG2, and IgG4 and IIb binds only IgG3 (Cleary and Retnoningrum 1994). Also, a set of these family members demonstrates IgA binding capabilities (Bessen 1994). While these proteins have been shown to bind immunoglobulin and could potentially help to mask the organism from phagocytosis, it has been hypothesized that the immunoglobulin-binding proteins function as sensory protein allowing the organism to regulate its virulence genes and thus alter the course of infection (Cleary and Retnoningrum 1994; Boyle 1995).

\section{Other virulence factors involved in promoting infection and pathology. Group A}

streptococcus produces a battery of secreted factors that serve to promote the endurance and spread of infection. While the secreted factors serve to protect the organism, they are also more apt to elicit cytopathic effects upon host tissue. One set of factors serves to facilitate the spread of infection by removing physical barriers. Within this set are the enzymes hyaluronidase (Kehoe 1991) and streptokinase (Kehoe 1991; Husmann et al. 1997) and the surface plasmin binding protein (Speziale et al. 1984). Hyaluronidase removes hyaluronic acid, an important 
Table 1. Major virulence factors of Streptococcus pyogenes and their potential role in infection and pathogenesis

\begin{tabular}{|c|c|c|c|}
\hline Component & Location & Function & Adverse Activity in Host \\
\hline $\begin{array}{l}\text { Hyaluronic Acid } \\
\text { Capsule }\end{array}$ & capsule & $\begin{array}{l}\text { Anti-phagocytic } \\
\text { factor } \\
\text { Adhesion }\end{array}$ & \\
\hline N-acetyl glucosamine & $\begin{array}{l}\text { cell wall } \\
\text { capsule }\end{array}$ & & $\begin{array}{l}\text { GlcNAc is a B cell mitogen } \\
\text { Persistent Ab titers to } \\
\text { GlcNAc } \\
\text { Antibody cross-reactivity } \\
\text { between GlcNAc and myosin }\end{array}$ \\
\hline Cell Membrane & & & $\begin{array}{l}\text { Induces cross-reactive } \\
\text { antibodies in animals }\end{array}$ \\
\hline $\begin{array}{l}\text { Lipoteichoic acid } \\
\text { (LTA) }\end{array}$ & cell wall & Adherence & $\mathrm{B}$ and/or $\mathrm{T}$ cell mitogen \\
\hline Protein F & cell wall & Adherence & \\
\hline M protein & cell wall & $\begin{array}{l}\text { Anti-phagocytic } \\
\text { factor }\end{array}$ & $\begin{array}{l}\text { Superantigen for human T } \\
\text { cells } \\
\text { Host cross-reactive } \\
\text { antibodies } \\
\text { Induces host-reactive CTL } \\
\text { responses in vitro }\end{array}$ \\
\hline M-like protein & cell wall & Sensory proteins? & $\begin{array}{l}\text { Bind immunoglobulin and } \\
\text { other plasma proteins }\end{array}$ \\
\hline $\begin{array}{l}\text { Streptolysin O(SLO) } \\
\text { Streptolysin S (SLS) }\end{array}$ & secreted & $\begin{array}{l}\text { Mediates lysis of } \\
\text { eucaryotic cells }\end{array}$ & $\begin{array}{l}\text { SLO has cardiotoxic effects } \\
\text { SLS suppresses T cells }\end{array}$ \\
\hline $\begin{array}{l}\text { Pyrogenic exotoxins } \\
\text { SPE A, B, C }\end{array}$ & secreted & $\begin{array}{l}\text { Fever induction } \\
\text { Cytotoxic } \\
\text { Septic shock }\end{array}$ & $\begin{array}{l}\text { PBL mitogen } \\
\text { Suppress antibody response } \\
\text { Scarlet fever rash }\end{array}$ \\
\hline Hyaluronidase & cell surface & Tissue invasion & Cleaves hyaluronic acid \\
\hline C5a peptidase & cell surface & $\begin{array}{l}\text { Anti-phagocytic } \\
\text { factor }\end{array}$ & \\
\hline
\end{tabular}

The above information was obtained from the following: Whitnack et al. 1981; Goldstein et al. 1967; Cunningham and Russell 1983; Hasty and Courtney 1986; Horstmann et al. 1988; Hosein et al. 1979; Boyle 1995; Thompson et al. 1970; Hryniewicz et al. 1978, Bohach et al. 1989; Kehoe 1991; Wexler 1985 et al. 1985. 
connective tissue component, thereby permitting tissue penetration (Kehoe 1991). GAS removes fibrin clots either directly with streptokinase or indirectly with plasmin-binding proteins that bind plasmin, the key fibrinolytic enzyme (Lottenberg et al. 1987). This binding not only allows plasmin to remain enzymatically active but also prevents it from regulation by its inhibitor, $\alpha-2$ plasma inhibitor (Lottenberg et al. 1987).

Other secreted factors include streptolysin O (SLO) (Thompson et al. 1970, Halbert et al. 1961), streptolysin S (SLS) (Hryniewicz et al. 1978), and the pyrogenic exotoxins (SPE A, B, C). SLO is capable of lysing a wide range of eucaryotic cells, most notably cardiocytes and hepatocytes, by binding to the cell membrane to form a ring structure that allows high molecular weight cytoplasmic proteins to leak out (Thompson et al. 1970). SLO is very antigenic and antiSLO antibody titers are a useful diagnostic indicator for recent GAS infection. Because it is cardiotoxic and highly immunogenic, a potential model for rheumatic fever suggests that SLO is carried to the cardiac tissue by circulating immune complexes of SLO and antibody however, supporting in situ data has been lacking (Halbert et al. 1961). SLS is a non-antigenic extracellular product that has been shown to be lytic for eucaryotic cells, including both red and white blood cells (Hryniewicz et al. 1978). SLS has been shown to lyse both the cell membranes and granules of phagocytes that lead to local tissue damage and a local inflammatory response. Other well-characterized secreted virulence factors are the pyrogenic exotoxins, SPE A, B, and C. Based on their shared biological activities these proteins belong to a family of pyrogenic toxin superantigens (Bohach et al. 1989). SPE A and SPE C are encoded by a bacteriophage and expression of the SPE A gene has been shown to be associated with strains that can cause severe invasive infections (Schlievert et al. 1996). The primary effect of these exotoxins is to elicit fever however, they have been shown to cause a wide array of problems: inducing the 
characteristic rash of scarlet fever, myocardial and hepatic necrosis, decrease in antibody synthesis, and acting as a superantigen for T cells (Marrack and Kappler 1990; Schlievert et al. 1996).

Streptococcal M protein and the M protein family. Of all the virulence factors produced by $S$. pyogenes, $\mathrm{M}$ protein is considered most important. This is not only by virtue of its antiphagocytic properties but also due to its structural and antigenic diversity (Manjula and Fischetti 1980; Phillips et al. 1981; Manjula et al. 1985), its ability to induce a protective antibody response (Lancefield 1962; Quinn et al. 1985; Pruskakorn et al. 1992) and its potential to elicit host cross-reactive immune responses (Kingston and Glynn 1971; Krisher and Cunningham 1985; Dale and Beachey 1987; Huber and Cunningham 1996). Because of these properties M protein has garnered much attention from the research community as a vaccine candidate for GAS infections and to understand the role the protein has in post-streptococcal autoimmune sequelae.

M protein is a dimeric alpha helical coiled-coil protein that extends approximately $60 \mathrm{~nm}$ from the surface of the organism (Phillips et al. 1981). The protein is able to maintain this coiled-coil conformation due to a seven residue periodicity of non-polar amino acids found throughout the molecule, with the notable exception of the wall and membrane-spanning region and the short random sequence at the extreme amino terminus (Manjula and Fischetti 1980; Manjula et al. 1985). Within this periodicity the first and fourth residues are hydrophobic in nature forming the core residues of the coil, the fifth is typically a basic residue, and an acidic residue can be usually be found in the last position (Manjula and Fischetti 1980; Manjula et al. 1985). While the periodicity is conserved, $\mathrm{M}$ protein does contain residual interruptions, especially of the hydrophobic residues at the first and fourth positions of the heptad repeat, 


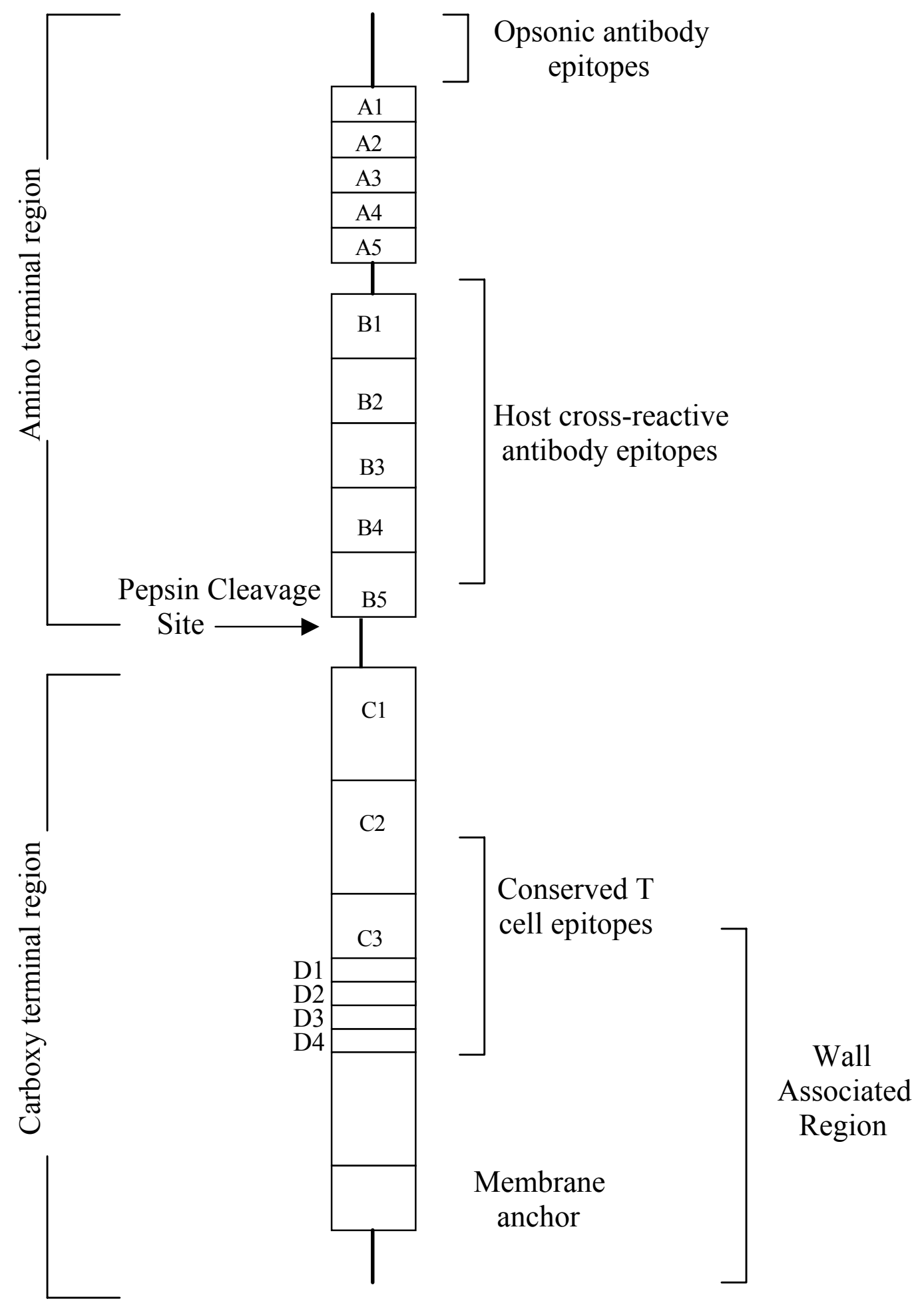

Figure 1. Schematic representation of M6 protein Adapted from: Robinson, J. H., Immunol. Today 13:362, 1992 
allowing flexibility (Phillips et al. 1981; Fischetti 1989). Based on these amino acid irregularities within the heptad repeat, the central portion of the protein can be divided into three subregions which correlate with the A, B and C sequence repeat regions (Fischetti 1989).

The N-terminal region of $\mathrm{M}$ protein contains a significantly higher net negative charge than the C-terminal region (Fischetti 1989), which may hinder contact between GAS and phagocytes due to electrostatic repulsion since phagocytes have a net negative surface charge (Lichtman and Weed 1970; Manjula et al. 1985). The negative charge of the outer surface may also be a factor in the protective antibody response against $\mathrm{M}$ protein since it has been demonstrated that opsonic antibodies against $\mathrm{M}$ protein are more basic that non-opsonic antibodies thereby eliminating the net negative charge upon binding (Fischetti 1983; Fischetti 1989).

Despite the relatively conserved coiled-coil structural conformation, $\mathrm{M}$ protein is able to maintain antigenic diversity. M protein contains three regions of tandem repeats designated as A, $\mathrm{B}$ and $\mathrm{C}$, where the $\mathrm{A}$ and $\mathrm{B}$ region are found in the amino terminal portion and the $\mathrm{C}$ region is within the more conserved carboxy region (Hollingshead et al. 1986; Fischetti 1989). Due to naturally occurring insertional or deletional recombination events the number and size of repeats within these regions may vary between the various M proteins, even among different strains or isolates of the same serotype (Fischetti et al. 1985). Sequence analysis of the various M genes indicates that the exposed amino terminus is the highly variable and the carboxy terminus is more conserved among the different serotypes (Fischetti et al. 1985). It is the extensive variability of the amino terminus for which serological typing is conferred, and so far over 100 distinct $\mathrm{M}$ protein serotypes have been identified. Epidemiological studies have indicated that 
the serotype of the M protein is an important factor in the incidence of GAS infections and sequelae (Berrios et al. 1986; Stollerman 1991; Johnson et al. 1992). GAS serotypes that are associated with nasopharyngeal infections do not typically cause skin infections and the reverse typically holds true as well, although there are certain serotypes that can infect both areas. Furthermore, with a few exceptions, GAS serotypes that are associated with rheumatic fever typically cause nasopharyngeal infections while serotypes that cause skin infections are associated with glomerulonephritis (Veasy and Hill 1997). Detailed antibody reactivity studies indicate that antigenic differences exist within the conserved carboxy region as well, suggesting that most M protein serotypes may be placed in one of two major classes of M protein (Bessen et al. 1989; O'Toole et al. 1992). Nearly all serotypes of GAS that have been associated with ARF have been shown to express class I M protein (Bessen et al. 1989). Therefore, GAS serotypes associated with rheumatic fever express $\mathrm{M}$ proteins that are antigenically distinct from the other non-rheumatic serotypes.

$\mathrm{M}$ protein is a member of the $\mathrm{M}$ protein family, which includes structurally related M-like proteins (Boyle 1995). The family is a large group of fibrous alpha-helical surface proteins that share similar carboxy terminal halves, including the repeats of the $\mathrm{C}$ region and two non-adjacent domains of the cell wall and membrane spanning portion, while maintaining high variability within the amino-terminal halves (Bessen and Fischetti 1990; Nilson et al. 1995). Both M protein and M-like protein bind one or more of several different plasma proteins including immunoglobulin, fibrinogen, plasminogen, albumin, and complement components and $\beta 2$ microglobulin, however, only M protein exhibits anti-phagocytic activity (Cedervall et al. 1995). Many GAS may express more than one protein from this family (Cedervall et al. 1995), however, with the exception of $\mathrm{M}$ protein, their overall role in bacterial pathogenesis has not been 
completely understood. It has been observed that GAS isolates exhibiting IgA binding activity are much more likely to be found in wound and deep tissue infections than in nasopharyngeal sites (Bessen and Fischetti 1990; Bessen 1994). Also, binding of the various plasma proteins has been shown to stabilize the dimer structure of the M-like proteins at physiological temperatures (Nilson et al. 1995).

The most important aspect of $\mathrm{M}$ protein is the ability to inhibit non-immune opsonization either by binding the complement control protein factor $\mathrm{H}$, as already described above, or binding plasma fibrinogen (Bessen and Fischetti 1990; Dale et al. 1996). It has been suggested that the interaction with plasma fibrinogen masks $\mathrm{C} 3 \mathrm{~b}$ binding sites on the streptococcal surface, thereby preventing activation of the alternative complement pathway and subsequent phagocytosis by neutrophils (Dale et al. 1996). Also, fibrinogen has been shown to interact with the aminoterminus of M protein (Ryc et al. 1989) and prevent antibody binding to that particular area, which is especially advantageous considering the immunodominant antibody epitope of M protein is located within the B repeat region of the amino terminus (Fischetti and Windels 1988). Despite the effective protective mechanism of binding to either fibrinogen or factor $\mathrm{H}, \mathrm{M}$ protein cannot prevent subsequent immune opsonization. Opsonic antibodies are directed against the 10 or so amino acids of the extreme amino terminus, an area not bound by fibrinogen (Fischetti and Windels 1988). However, GAS may still maintain a slight advantage because the production of opsonic antibodies is not only delayed but also made in much lower titers as compared to nonopsonic antibodies (Jones and Fischetti 1988). Furthermore, the protective antibody response to GAS is serotype specific and cannot protect the host against infection from other serotypes.

Immunity to GAS is highly dependent on the production of opsonic antibodies against M protein; therefore, $\mathrm{M}$ protein has become a potential vaccine candidate for GAS. In addition to 
the problem of serotype specificity of the opsonic antibody response as mentioned above, $\mathrm{M}$ protein contains epitopes that have the potential to elicit deleterious autoimmune responses as will be discussed later in the review. Extensive work contributed by groups led by either Good (Pruskakorn et al. 1992; Pruskakorn et al. 1994a; Pruskakorn et al. 1994b) or Kehoe (Robinson et al. 1993; Rossiter et al. 1994; Delvig et al. 1997), have delved into the problem of identifying a M protein peptide that will elicit a serotype non-specific opsonic antibody response along with a strong helper T cell response to promote memory. CD4 T cell epitopes have been mapped throughout the length of select M protein serotypes; however, in order to avoid serotype specific responses efforts have been focused primarily on the conserved carboxy region (Robinson et al. 1993; Rossiter et al. 1994). Good et al. (Pruskakorn et al. 1994b) have described one particular epitope derived from the conserved region of M5 that is capable of inducing bactericidial antibodies as well as a helper T cell response to multiple GAS serotypes, however the antibody response was less effective in killing than serotype specific antibodies. In addition, human $\mathrm{CD}^{+}$ T cell lines specific for this peptide also demonstrated proliferative responses to mammalian myosin (Pruskakorn et al. 1994a).

\section{Acute Rheumatic Fever and Other Post-streptococcal Autoimmune Sequelae}

History and epidemiology. For over three hundred years ARF has been under the scrutiny of the medical establishment, however, complete appreciation of the disease pathology did not come until within the last century. During the early period Guillaume de Baillou distinguished ARF from other causes of rheumatism and Thomas Syndenham described the acute chorea that bears his name, however neither one connected these symptoms to a disease of the heart (reviewed in 
Stollerman 1975; Read and Zabriskie 1977a). Although the first definitive descriptions of cardiac lesions of acute rheumatic fever were being published as early as the early eighteenth century, it took over one hundred years before cardiac involvement in rheumatic fever was appreciated. It was at this time that William Wells, the man credited for the first description of the subcutaneous nodules in cases of rheumatic fever, presented a clinical study detailing heart pathology of a series of true cases of rheumatic fever (Stollerman 1975; Read and Zabriskie 1977a). This was followed by the eloquent studies of Jean-Baptiste Bouillaud, the 'Father of rheumatic heart disease' who in 1836 gave the first detailed auscultation methods for diagnosing acute rheumatic fever (Stollerman 1975; Read and Zabriskie 1977a). While several manifestations of rheumatic fever were being described separately during this time, it was Walter Cheadle who in 1889 comprehensively described, for the first time, all the symptoms of ARF as a syndrome and his definition has not deviated much even to this day (Read and Zabriskie 1977a). His classification of the symptoms into phase correlates with major and minor Jones' criteria still used today for diagnosis (Dajani 1992).

The symptoms of rheumatic fever, glomerulonephritis and psoriasis have been known to man for several hundred years. Clinicians knew that outbreaks of rheumatic fever and glomerulonephritis almost invariably followed epidemics of scarlet fever, however, confirmation of the diseases being linked to an infectious entity did not come until the early part of this century. While the relationship of antecedent sore throat and rheumatic fever was first being described in 1880 by Fowler, it was not appreciated until 1907, when Bela Schick developed the concept of rheumatic fever being a complication of a bacteria infection (Stollerman 1975; Read and Zabriskie 1977a). Schick also drafted the concept of the latent period between the initial infection and the sequelae, which was corroborated about the same time by Poyton and Payne 
and yet again by Coombs in 1924 (Veasy and Hill 1997). These studies were soon followed by four important studies that provided final evidence supporting the relationship between group A streptococcus pharyngitis and ARF. During the early 1930's Rebecca Lancefield defined subgroups of streptococci based on the cell wall carbohydrate and identified the GAS as the most important human pathogen (Lancefield 1962). Also in the 1930's, two independent epidemiological studies, conducted by Coburn (1935) in the United States, and Collis (1932) in England, confirmed the relationship between streptococcal pharyngitis and the development of ARF. The final evidence came from studies conducted by a group led by Rammelkamp, which demonstrated that rheumatic fever could be prevented by treating streptococcal pharyngitis with penicillin (rev. in Stollerman 1975). Correlation between streptococcal throat and skin infections and glomerulonephritis soon followed in 1929 and 1940, respectively. Although psoriasis does not epidemiological correlate to scarlet fever as does ARF and AGN, the relationship with antecedent streptococcal sore throat and development of psoriasis was confirmed in 1916.

Probably one of the most interesting aspects of ARF is its changing nature. Once one of the major causes of death in children in this country, it has now become an occasional outbreak, while still remaining a serious threat to children in more under-developed countries (Gordis 1985). During the beginning of this century ARF was the leading cause of death for adolescents and heart disease for individuals under the age of forty in the United States (Homer and Shulman 1991). At this time, ARF had a reported annual incidence of 100 to 200 cases out of 100,000 population and a death rate of 25 to 30 per 100,000 population that seriously outnumbered deaths related to other infectious diseases including polio, measles, and diphtheria (Homer and Shulman 1991). However, by the 1940 's the incidence had declined to about 50 per 100,000 population and continued a steady decline to an incidence rate of 0.5 per 100, 000 by the early 1980 's 
(Gordis 1985; Griffiths and Gersony 1990). This steep decline led some in the medical establishment to predict the eventual disappearance of the disease in the United States; however, in recent years ARF has had an unexpected resurgence. Isolated outbreaks have been reported in Utah (Veasy et al. 1987), Ohio (Congeni et al. 1987), Pennsylvania (Wald et al. 1987), New York (Giardina and Heaton 1988; Griffiths and Gersony 1990), and Tennessee (Westlake et al. 1990). West Virginia also had an increased incidence rate in recent years (Hoffman et al. 1997).

AGN appears to be following a similar epidemiological path as ARF, in that by the 1950's the incidence had declined considerably in the United States and Europe, but it continues to be a major childhood threat in less developed countries (Ayoub and Chun 1990). Like ARF, AGN is predominantly a childhood disease, where $60 \%$ of all cases occur in the 2 to 12 year age range and less than $5 \%$ occurring in children under 2 years of age (Richards 1991). Typically, AGN occurs in the presence of a nephritogenic strain of GAS with an overall attack rate of $15 \%$ regardless of infection site (Stetson et al. 1955), however, nephritogenic strain of M49 serotype has been shown to give a $25 \%$ and $5 \%$ risk of AGN development following skin or throat infection, respectively (Anthony et al. 1969). Psoriasis, on the other hand, does not demonstrate such age discrimination and affects about $2 \%$ of the Western population.

Predicting the manner of these diseases has proven difficult due to the interplay of several important epidemiological factors, both environmental and host related. In the past, the major environmental factor has been socioeconomic status, where ARF has been a disease associated with crowded, impoverished urban areas and in many under-developed countries this trend still holds true. The incidence decline witnessed during the past fifty years in the United States has been widely attributed to better living standards, whether better nutrition, hygiene or housing (Land and Bisno 1983; Gordis 1985). While socioeconomic conditions are important they alone 
cannot explain the changes in the United States. Recent outbreaks have occurred in mostly middle-class suburbanian and rural areas instead of the predicted urban areas (Wald et al. 1987; Westlake et al. 1990; Veasy and Hill 1997). The decline in ARF incidence may also be attributed to the introduction and widespread use of antibiotics. Penicillin has been shown to be important in preventing onset and recurrences of ARF as well as decrease the morbidity. However, the incidence of ARF began decreasing before widespread use of penicillin and about one-third of ARF cases follow mild or asymptomatic pharyngitis that receive no medical attention.

Clinical aspects of ARF and other post-streptococcal autoimmune complications. The clinical presentation of ARF primarily involves three major organs systems; the heart, joints and nervous system and diagnosis is usually made predominately on the basis of Jones' criteria (Dajani 1992). Systemic manifestations may include one or more of the following; polyarthritis, carditis and chorea, and usually occur simultaneously with skin manifestations that include erythema marginatum and subcutaneous nodules. The polyarthritis of ARF is the most common but least specific symptom involving the larger joints and is characteristically asymmetric and migratory in nature. Syndemham's chorea is the result of an inflammation of the central nervous system specifically involving the basal ganglia and caudate nuclei (Ayoub and Chun 1990). It is a delayed manifestation appearing up to 3 months after the onset of ARF in about $20 \%$ of ARF patients and in some cases may be the only manifestations (Ayoub and Chun 1990).

Rheumatic carditis associated with ARF is a pancarditis affecting the endocardium, myocardium, and pericardium at varying degrees, however the hallmark of rheumatic carditis is valvulitis where the inflammation leads to mitral valve insufficiency and potentially valve stenosis. Another hallmark characteristic of ARF is the granulomatous lesions known as 
Aschoff's nodules or bodies that were first described in 1904 by Ludwig Aschoff and can be found in interstitium of myocardium, atrial endocardium and heart valves. While these lesions are considered one of the major indicators of ARF, doubt still remains about their composition and, more important, their role in the disease process. Histological analysis reveals that Aschoff's bodies are predominately derived from injured heart muscle cells trying to undergo regeneration, otherwise known as Anitschkow cells (Wagner 1960). It has been inferred that these Anitschkow cells are responsible for the scarring of heart tissue associated with ARF (Stehbens and Zuccollo 1999). Established Aschoff's lesions are not directly stained with typical lymphocyte and macrophage reagents, however the damage could be the result of inflammatory cytokines produced during multiple phases of infiltration of macrophages followed by $\mathrm{T}$ and $\mathrm{B}$ lymphocyte infiltration (Kemeny et al. 1989; Fraser et al. 1997). In regard to their role in the disease process, Aschoff himself argued that the cardiac failure associated with this disease is due to weakness resulting from changes in the myocardium more so than by valvular lesions (Stollerman 1975). Furthermore, the persistence of Aschoff bodies in the asymptomatic patient with clinically inactive rheumatic heart disease may actually represent a low-grade chronic inflammatory process that has little to do with the functional state of the myocardium (Stehbens and Zuccollo 1999).

Other autoimmune complications of streptococcal infection that have received much attention from the research community include acute glomerulonephritis and psoriasis. Psoriasis is an inflammatory skin disease characterized by lesions that are sharply demarcated reddish plaques of various size and cover with scaling. These symptoms are due to reversible keratinocyte hyperproliferation giving rise to the increased epidermal turnover or scaling (England et al. 1997; Prinz 1997). In greater than 10\% of patients these symptoms are also 
accompanied by joint involvement which may lead to severe arthritis. AGN is characterized by renal tissue involvement and glomerular injury is evidenced by the sudden appearance of hematuria and proteinura that is often accompanied with edema (Richards 1991). Hematuria in varying degrees is present in all patients with up to $90 \%$ exhibiting proteinura (Zarconi and Smith 1988; Richards 1991). Typically, 60 - 70 percent of these patients display hypertension and edema. Renal biopsies of patients demonstrate diffuse proliferation of endothelial and mesangial cells accompanied by polymorphonuclear cell infiltrate (Zarconi and Smith 1988). Other microscopic finds include diffuse antibody and complement deposits, which are believed to be the cause of the symptoms and pathology.

\section{Role of humoral immune response in pathology of post-streptococcal acute rheumatic}

fever. Although the underlying mechanisms of pathology have yet to be truly understood, ARF has long been considered an autoimmune event. This suspicion has been based upon several factors, including the latent period between initial infection and the onset of ARF, the ability to prevent such an event with effective penicillin treatment, and most importantly, the exaggerated antibody responses exhibited by ARF patients. One of the earliest and most sustaining theories suggested that susceptibility to the disease might be due to immune hyperresponsiveness (rev. Ayoub 1991). This theory eventually became contested when Cavelti described heart-reactive antibodies for the first time, putting forth the idea that autoimmune mechanisms may be involved in the pathogenesis of ARF (Cavelti 1945).

Early evidence suggesting that antibodies may play a role in pathology was presented first by Kaplan, who confirmed the presence of heart reactive serum antibodies in ARF patients and also found diffuse antibody and complement deposits throughout the myocardium that was localized primarily at edges of cardiac myofibers (Kaplan 1960; Kaplan et al. 1964b). Kaplan 
then followed up this work by demonstrating for the first time that antibodies raised against GAS cross-react with cardiac tissue (Kaplan 1963; Kaplan and Suchy 1964a). About the same time, Goldstein et al. (1967) demonstrated that antibodies to GAS cell wall polysaccharide GlcNAc cross-react with heart valve glycoproteins and Zabriskie and Freimer (Zabriskie and Freimer 1966) described an antibody cross-reaction between GAS membranes and myocardial sarcolemma. Seven years later Beachey and Stollerman (Beachey and Stollerman 1973) demonstrated that $\mathrm{M}$ protein was capable of absorbing heart-reactive antibodies from human sera. Since then, it has been repeatedly shown that ARF patients typically exhibit high titers of anti-streptococcal antibodies in their sera against $M$ protein and GlcNAc that cross-react with cardiac myosin (van de Rijn et al. 1977; Cunningham and Russell 1983; Cunningham et al. 1989). Antibody cross-reaction has also been implicated in other aspects of ARF, including chorea. A study of a group of patients with chorea found that almost half of the patients exhibited antibodies reactive with the cytoplasm of neurons in the subthalamic and caudate nuclei (Husby et al. 1976).

Although these antibodies have been extensively described and antibody deposits have been consistently found in histological sections (Kaplan 1960; Kaplan et al. 1964b; Kemeny et al. 1989), their role on the course of the disease remains largely unknown. The anti-streptococcal carbohydrate antibodies are typically of the $\operatorname{IgM}$ isotype and have been shown to be capable of mediating complement lysis in vitro (Prehm et al. 1995). Research conducted by the laboratories of Ayoub (Dudding and Ayoub 1968; Shulman et al. 1974a) and Eichbaum (1995), observed that ARF patients with heart problems have persistently high titers of anti-streptococcal antibody compared to controls and ARF patients without cardiac problems suggesting ARF patients have an exaggerated humoral immune response. Observations have been made in ARF patients that a 
sustained rise in the anti-streptococcal antibody titer that cross-reacts with cardiac tissue has been shown to precede an attack of ARF (Kaplan and Frengley 1969). Furthermore, sufficient evidence has been presented to show that streptococcal infections are capable of inducing crossreactive antibody responses in both humans and laboratory animals (Zabriskie and Freimer 1966; van de Rijn et al. 1977; Cunningham et al. 1988). However, it is difficult to assign a primary role for the cross-reactive antibodies since evidence that can ascribe pathogenic potential to such antibodies is lacking (Neu et al. 1993) and because normal healthy individuals exhibit low levels of self-reactive natural antibodies in their sera without any resultant complications (Klinman et al. 1988).

Also, it may be postulated that these antibodies are secondary to the disease process, being the result of antigen release due to organ specific inflammation and damage and not due so much to direct cross-reactivity (Neu et al. 1993). Patients who have sustained cardiac injury or surgery exhibit myosin reactive antibodies in their sera, however these antibodies do not crossreact with GAS determinants (Kennedy and Das 1976). Likewise, antibodies raised against bovine heart valve homogenates were not cross-reactive to GAS polysaccharide (KaspGrochowska et al. 1972a). Upon histological staining of human heart and kidney tissue with this bovine heart antisera and anti-streptococcal sera they found that the bovine heart sera reacted to connective tissue and basement membrane while the anti-streptococcal sera reacted to cellular components of both myocytes and fibroblasts in the heart and the glomerular tufts of the kidney (Kasp-Grochowska et al. 1972b). Demonstration of this cross-reactivity leads to another interesting facet of the autoimmune response; a bacterial carbohydrate is capable of eliciting antibodies that can cross-react with protein determinants. Cunningham et al. $(1983 ; 1984 ; 1986$; 1992) have developed an extensive panel of murine and human monoclonal antibodies that cross- 
react with GAS group specific carbohydrate (GlcNAc) and mammalian proteins including myosin and keratin. In addition, they have shown that this cross-reaction cannot be inhibited with the removal of carbohydrate from the proteins with n-acetyl-muraminidase treatment (Shikhman and Cunningham 1994). Harris et al. (1997) demonstrated that monoclonal antibodies against GAS polysaccharide were capable of isolating cross-reactive peptides from a panel of phage display libraries. Since the peptides binding to these antibodies appeared to be specific they suggested that distinct mechanisms exist for carbohydrate and peptide recognition and that cross-reactive peptides may be found for most anti-carbohydrate antibodies (Harris et al. 1997).

\section{Involvement of cellular immune response in pathology of post-streptococcal autoimmune}

diseases. The group led by Zabriskie (Read et al. 1974) was among the first to note a relationship between cell-mediated immune responses to streptococcal antigens and attacks of ARF in humans. Histological sectioning and staining of biopsied cardiac tissue reveals that pathology is primarily due to lymphocytic infiltrates (Raizada et al. 1983; Kemeny et al. 1994) however, the question remains as to how and why these cells are recruited. In both active and chronic cases of ARF, these infiltrates are found to be mostly macrophages and $\mathrm{T}$ lymphocytes of which the $\mathrm{CD} 4^{+}$population outnumbers the $\mathrm{CD} 8^{+}$population 4:1 (Kemeny et al. 1994). Phenotypic and cytokine profiles of peripheral blood lymphocytes (PBL) of ARF patients compared to controls indicate that ARF patients exhibit hyperimmune responses where there is a sustained increase in the number and percentage of $\mathrm{CD}^{+} \mathrm{T}$ cells and $\mathrm{B}$ cells but a decrease in the percentage of CD8 ${ }^{+} \mathrm{T}$ cells (Lueker et al. 1975; Williams et al. 1982; Cairns 1988; Bhatia et al. 1989; Alarcon-Riquelme et al. 1990; Morris et al. 1993a; Morris et al. 1993b). 
Several studies have suggested that during the acute phase of disease, the numbers and percentages of $\mathrm{CD} 4^{+} \mathrm{T}$ cells were increased, returning to normal during convalescence while the $\mathrm{CD}^{+} \mathrm{T}$ cells were decreased during the acute phase and increased during recovery (Cairns 1988; Alarcon-Riquelme et al. 1990; Bhatnagar et al. 1999). This increased percentage in peripheral $\mathrm{CD}^{+}$lymphocytes has been shown to correlate with the increased percentage of peripheral CD25 $5^{+}$(IL-2R) cells (Morris et al. 1993a; Morris et al. 1993b). Furthermore, the increases in both $\mathrm{CD} 4{ }^{+}$and $\mathrm{CD} 25^{+}$cells correlate to the increased production of IL-2 in ARF patients (Narin et al. 1995). In addition to increased IL-2 levels (Morris et al. 1993b; Narin et al. 1995), acute phase patients exhibit increased levels of inflammatory cytokines, including IL-1 (Morris et al. 1993b; Narin et al. 1995), IL-6, IL-8 (Kutukculer and Narin 1995; Yegin et al. 1997), and TNF- $\alpha$ (Miller et al. 1989; Yegin et al. 1997). The results of these studies have led to the proposal suggesting that the pathological outcome of $\mathrm{ARF}$ is a $\mathrm{CD} 4^{+}$lymphocyte-driven hyperimmune response with convalescence mediated by $\mathrm{CD} 8^{+}$lymphocytes down-regulating the deviant immune responses (Cairns 1988; Alarcon-Riquelme et al. 1990; Bhatnagar et al. 1999). However, extensive studies with experimental autoimmune myocarditis indicate that $\mathrm{CD} 4^{+} \mathrm{T}$ cells are necessary to initiate the response but $\mathrm{CD} 8^{+} \mathrm{T}$ cells mediate the pathological outcome and recovery (Rose et al. 1990; Neu et al. 1993; Smith and Allen 1993).

In addition to an overzealous immune response, several reports have indicated that ARF patients exhibit cross-reactive autoimmune cellular responses. el-Demellawy et al. (1997) demonstrated that PBL from ARF patients recognize a $50 \mathrm{kDa}$ and $54 \mathrm{kDa}$ protein of myocardial extracts and that pre-culturing with GAS extracts may intensify the proliferative response. Cloning of lymphocyte infiltrates has yielded conflicting results. Guilherme et al. (1995) have been able to isolate clones that cross-reacted with $\mathrm{M}$ protein and myosin however; Yoshinaga et 
al. (1995) could not. Cloning of PBL from active and chronic cases of ARF has given no clearer answer either. The T cell lines produced by Pruksakorn et al. (1994a) that cross-reacted between M protein and myosin were isolated from healthy individuals. While this study may not confirm the presence of cross-reactive lymphocytes, it does indicate that precursor myosin reactive $\mathrm{T}$ cells can exist in the periphery. Furthermore, the T cell lines developed from ARF patients in the Yoshinaga study reacted only with lysates of streptococcal strains associated with ARF but not strains associated with nephritis or non-pathogenic streptococci (Yoshinaga et al. 1995). While the $\mathrm{T}$ cell data may not provide conclusive support for a cross-reactive immune response, it at least underscores the notion that these patients exhibit hyperimmune responsiveness.

While ample evidence has been provided indicating a role for the $\mathrm{T}$ lymphocyte compartment in rheumatic fever, the question of tissue-specific recruitment remains. Fibroblasts of biopsied tissue from ARF patients, but not normal controls or patients of other potentially fatal cardiac diseases, were shown to have aberrant increases in MHC class II molecule expression, and therefore have the potential to act as antigen present cells (Amoils et al. 1986). In support of this data, histological analysis by Raizada et al. (1983) demonstrated that $\mathrm{CD}^{+} \mathrm{T}$ infiltrates were closely positioned to cardiac fibroblasts and collagen fibrils. Studies conducted with the myosininduced myocarditis murine model indicate the resident APC in the normal myocardium express MHC class II and can present myosin to primed T cells in vitro (Smith and Allen 1992; Donermeyer et al. 1995). In addition, myosin immunization activates endothelial ICAM-1 expression which upregulates expression of class II MHC and Class I MHC on cardiac interstitial cells and myofibers, respectively (Pummerer et al. 1991; Pummerer et al. 1996).

Kotb (1998) has suggested that $\mathrm{T}$ cell responses initiated against microbial antigens and superantigens can generate high levels of inflammatory cytokines that ultimately lead to 
localized tissue destruction and subsequent release of self-antigen that allows for the expansion of autoreactive T cells. S. pyogenes produces several superantigens, including pyrogenic exotoxins (SPE), LTA, and M protein. In vitro and in vivo studies have demonstrated that streptococcal proteins, especially the M protein, can induce the differentiation of human and rabbit cytotoxic T lymphocytes with the capacity to kill myocardial cells and cell lines (Dale et al. 1981; Dale and Beachey 1987; Kotb et al. 1989). Certain serotypes of M protein that have been associated with ARF have been shown to have superantigenic effects on particular subsets of human lymphocytes (Tomai et al. 1990; Tomai et al. 1991; Tomai et al. 1992; WatanabeOhnishi et al. 1994), however, this has not been correlated to V $\beta$ gene usage in ARF patients (Abbott et al. 1996).

Role of the immune response in other post-streptococcal autoimmune sequelae. Due to pathological manifestations and histological findings psoriasis has been suspected to be an autoimmune disorder, in that, extensive granulocytic and $\mathrm{T}$ lymphocytic infiltrates, as well as antibody deposits, can be found throughout the dermis and epidermis (Bjerke et al. 1978; Baker et al. 1984a). Lesional eruptions coincide with an influx of activated macrophages and $\mathrm{CD} 4^{+} \mathrm{T}$ cells while disease resolution is associated with the influx of $\mathrm{CD}^{+} \mathrm{T}$ cells (Bjerke et al. 1978; Baker et al. 1984a; Baker and Fry 1992). Infiltrating T cells have been observed in close proximity to class II MHC-bearing dendritic cells (Baker et al. 1984b). Psoriatic pathology has been induced in uninvolved psoriatic skin transplants on SCID mice following injection of activated mononuclear cells (Gottlieb et al. 1996). Further, immunoregulatory agents cyclosporin A and anti-CD4 antibody clinically alleviate symptoms (Griffiths et al. 1986; Morel et al. 1992). Studies have demonstrated the capacity of psoriatic $\mathrm{T}$ cells to be mitogenic to keratinocytes in vitro (Prinz et al. 1994; Bata-Csorgo et al. 1995) and T cell stimulating 
cytokines IL-2 and IFN- $\gamma$ exacerbate skin lesions in vivo (Lee et al. 1988; Fierlbeck and Rassner 1990). T cells isolated from lesions also produce TNF- $\beta$, IL-3, and IL-5 (Vollmer et al. 1994), however it is IFN- $\gamma$ that is believed to play the central role (Baker et al. 1988; Scheynius et al. 1992; Prinz et al. 1994). IFN- $\gamma$ along with TNF- $\alpha$ and $\beta$, induce ICAM-1 and MHC II expression on keratinocytes witnessed in vivo (Vollmer et al. 1994).

The relationship between GAS throat infections and psoriasis has long been established; only recently has direct supporting evidence emerged. Psoriatic patients have been shown to exhibit circulating autoreactive antibody (Perez-Lorenzo et al. 1998), especially to keratins (Shikhman and Cunningham 1994; Sigmundsdottir et al. 1997; Valdimarrson et al. 1997) but, as with ARF, no direct association with pathology can be demonstrated. Circulating T cells from psoriatic patients demonstrate the ability to respond to streptococcal M protein peptides that share sequence homology to keratin (McFadden et al. 1991; Sigmundsdottir et al. 1997). T cell lines derived from psoriatic lesions display specific responses to streptococcal antigens (Baker et al. 1993). While direct cross-reactivity has been demonstrated, others have postulated a role for streptococcal superantigens including M protein and SPE (Leung et al. 1995a; Leung et al. 1995b; Valdimarrson et al. 1997).

Unlike ARF and psoriasis, cell mediated immunity is lacking in AGN (Rajajee et al. 1984). Therefore, the resultant pathology of AGN is believed to be due to an elevated antibody response resulting in antibody and complement deposition and the subsequent inflammatory response. The mechanisms under investigation include antibody-antigen complexes that build up in the target tissue (Nordstrand et al. 1996), direct antibody cross-reactivity (Lange 1995), and streptococcal antigen deposition (Holm 1988; Nordstrand et al. 1998). Dillon et al. (1974) were among the first to provide supporting evidence when they reported that patients with AGN 
demonstrate elevated antibody titers to DNase B but not SLO as compared to controls and that following skin infections the anti-DNase B titers rose more often and persisted longer than the anti-SLO titers. More recently, Mori et al. (1997) found that IgG titers against M12 C region but not the $\mathrm{AB}$ region were higher in AGN patients and persisted after the SLO and streptokinase titers returned to normal.

In addition to the elevated antibody response witnessed in AGN patients, it is believed that antibody cross-reactivity may play a role as well. Markowitz and Lange were the first to observe immunologic cross-reactivity between the streptococcal glycoprotein and the glomerular basement membrane (Markowitz and Lange 1964). Several groups have since demonstrated in a variety of in vitro systems the cross-reactivity between anti-streptococcal antibodies and kidney basement membrane (Fitzsimons et al. 1987; Kraus and Beachey 1988; Kraus et al. 1990). Antibody cross-reactivity and corresponding pathology have also been demonstrated in vivo with laboratory animals (Fitzsimons and Lange 1991; Lange 1995). Histological findings indicate that although $\operatorname{IgM}$ and $\mathrm{IgG}$ are present, C3 arrives first and is the major immune deposit found in the kidney (Nordstrand et al. 1996). A possible explanation may be that the localization of streptokinase to glomeruli causes subsequent deposition of complement as an effect of the ability of streptokinase to convert plasminogen to plasmin (Holm 1988; Nordstrand et al. 1998). Immune complexes are believed to have a role in the later stage of disease since C 3 deposition is followed by IgG deposition in humans (Sorger 1986).

Potential role of streptococcal $M$ protein in autoimmunity. Epidemiological studies indicate the association of particular streptococcal serotypes with systemic infection and sequelae (Berrios et al. 1986; Johnson et al. 1992). Several groups have demonstrated the ability of M protein to induce antibodies that cross-react with various host coil-coiled proteins (Hosein et al. 
1979; Dale and Beachy 1985a; Dale and Beachy 1985b; Cunningham et al. 1988; Kraus et al. 1990; Vashishtha and Fischetti 1993). The alpha helical coiled-coil feature of M protein is not a common conformation for most bacterial surface proteins; however, the conformation is prevalent among mammalian proteins. Research conducted by laboratory of Fischetti (Manjula and Fischetti 1980; Manjula et al. 1985) have shown that M protein, especially those serotypes associated with autoimmune sequelae, shares extensive amino acid sequence and physicochemical similarities with coiled-coil mammalian proteins, notably myosin heavy chain, tropomyosin, and type I keratins. Furthermore, the coiled-coil in the B region is characteristically more similar to mammalian coiled-coil proteins, especially myosin (Manjula and Fischetti 1986) and the B region contains the immunodominant antibody epitopes (Fischetti and Windels 1988). These examples of shared homology, especially in regions of immunodominancy, provide an explanation for the ability of M protein to induce a host-crossreactive antibody response. Independent studies by Dale and Beachey et al. (1985a; 1985b; Kraus et al. 1990), Cunningham et al. (1988; 1992), and Fischetti et al. (Vashishtha and Fischetti 1993) have demonstrated in experimental animals the ability of M protein to elicit antibodies that cross-react with mammalian coiled-coil proteins; notably myosin, tropomyosin, keratin and actin.

Experimental evidence indicating a role for $\mathrm{M}$ protein in inducing a host cross-reactive cellular response has been conflicting (Robinson et al. 1993; Pruskakorn et al. 1994a; Guilherme et al. 1995; Yoshinaga et al. 1995; Huber and Cunningham 1996). In vitro and in vivo studies have shown that $\mathrm{M}$ protein has the potential to induce cytotoxic $\mathrm{T}$ cell responses that have the capacity to kill myocardial cells (Friedman et al. 1971; Yang et al. 1977; Dale and Beachey 1987; Kotb et al. 1989; el-Demellawy et al. 1997). Dale and Beachey et al. (1987; Kotb et al. 1989) have demonstrated this for human lymphocytes, and Yang et al. (1977) and Friedman et al. 
(1971) were able to actively immunize laboratory animals with GAS and demonstrate lytic activity to heart cultures. However, several groups that have been able to demonstrate the antigenicity of $\mathrm{M}$ protein have not been able to induce such cross-reactive responses (Robinson et al. 1993; Pruskakorn et al. 1994a).

Peptic extracts of M protein from rheumatogenic strains of GAS (M5, M6, M18, M19, and M24) have been shown to have superantigenic potential for human cord blood T cells and peripheral blood lymphocytes (Dale et al. 1981; Dale and Beachey 1987; Tomai et al. 1991; Watanabe-Ohnishi et al. 1994). Work initiated by Dale et al. $(1981 ; 1987)$ and carried on by Kotb et al. (Tomai et al. 1991; Tomai et al. 1992; Watanabe-Ohnishi et al. 1994) demonstrated that peptic extracts of $\mathrm{M}$ protein (pepM) from rheumatogenic strains of GAS (M5, M6, M18, M19, and M24) are all superantigens for human T cells with all sharing a specificity for V $\beta 4$, however, each serotype has its own unique set of $\mathrm{V} \beta$ specificity which is also distinct from those reported for streptococcal pyrogenic exotoxins. Furthermore, phenotypic analysis of psoriatic lesional T cells indicates an increase in V $\beta 2$ expressing T cells (Lewis et al. 1993), as well as, Vß1, 8, 12 (Abe et al. 1991; Lewis et al. 1993). This led to the hypothesis that the superantigenicity of $\mathrm{M}$ protein may play a role in the pathogenesis of post-streptococcal autoimmune diseases (Tomai et al. 1990; Watanabi-Ohnishi et al. 1995). The superantigenic ability of $\mathrm{M}$ protein has been questioned as other groups have been unable to repeat this response with recombinant protein (Degnan et al. 1997) or have demonstrated the superantigenicity is due to exotoxin contamination (Fleischer et al. 1992). Furthermore, while patients with invasive GAS infections have abnormalities in the $\mathrm{V} \beta$ repertoire of peripheral blood $\mathrm{T}$ cells consistent with superantigen stimulation by streptococcal proteins (Watanabi-Ohnishi et al. 1995), namely the exotoxins, a study of the V $\beta$ repertoire of ARF patients did not show any such abnormalities 
(Abbott et al. 1996). While indicating that superantigen responses are not a primary mechanism of autoimmune sequelae, it does not rule out the possibility that superantigens may exacerbate existing autoimmune responses.

\section{Influence of host genetic factors on susceptibility to ARF and other post-streptococcal}

autoimmune disorders. It has been long suspected that genetic or heredity factors play a very important role in the susceptibility to rheumatic fever. Although this theory first came into existence in the late eighteenth century when Sir Arthur Newsholme conducted the first epidemiological study of rheumatic fever, tangible scientific evidence has not been forthcoming. Evidence exists for the genetic control of the immune response to GAS (Greenberg et al. 1980; Greenberg et al. 1981). Greenberg et al. found that the immune response to streptococcal antigens is controlled by two HLA-linked genes (Greenberg et al. 1981) and is inherited in an autosomal dominant manner (Greenberg et al. 1980). In addition, Hafez et al. discovered a relationship between HLA expression and the immune response to carbohydrates where a recessive trait exists for hyper-responsiveness to carbohydrates (Hafez et al. 1990). Several groups have attempted to correlate susceptibility to post-streptococcal autoimmune disorders to genetic factors, particularly race and HLA antigen expression, for over twenty years and although correlations have been made they are not without contradictions. In fact, the pioneering immunogenetic study conducted in 1973 by Falk et al. (1973), which reported a reduced frequency in HLA-A3 in ARF patients, was contradicted two years later by Caughey et al. (1975) who saw an increased frequency of HLA-A3, as well as HLA-A8, in RF patients. Another class I HLA antigen that has received attention is HLA-B5. Greenberg et al. (1975) were the first to note that lymphocytes from HLA-B5 individuals were more responsive in vitro to streptococcal antigens than their non-HLA-B5 bearing counterparts. Furthermore, an association has been 
made between the presence of elevated immune complex levels and the presence of HLA-B5 in RF patients (Yoshinoya and Pope 1980). Yet, the frequency of HLA-B5 was found to be reduced in RF families (Read et al. 1977b). Similar studies conducted with psoriatic patients indicate that HLA-Cw6, B13, and Bw57 appear to confer susceptibility (Christophers 1996).

The difficulties in demonstrating susceptibility linkage to HLA class I genes have also been encountered by several groups who undertook studies beginning in the 1980s that delved into the linkage to HLA class II genes. Most likely the greatest challenge has been due to population diversity and ethnicity. Association with HLA-DR4 was reported in Caucasians populations in the U.S. (Anastasiou-Nana et al. 1986; Ayoub et al. 1986) and Saudia Arabia (Rajapakse et al. 1987). HLA-DR1 was found associated with black populations in South Africa (Maharaj et al. 1987) whereas HLA-DR2 was implicated in susceptibility in RF in black Americans (Ayoub et al. 1986). In Brazilian patients of mixed background (Guilherme et al. 1991) HLA-DR7 and DR53 were found in higher frequencies. Interestingly, psoriasis a predominantly a Caucasian disease, seems to have an association with HLA-DR7 as well (Christophers 1996). This data may be interpreted as indicating that the real susceptibility gene for RF is not represented by any of these markers but instead by another genes present in HLA complex that could display various linkage patterns with HLA-DR and DQ (Gerbase-DeLima et al. 1994). Another potential explanation is that the HLA genes do not play a significant role in dictating susceptibility (Ertug 1993). Either way more substantiated scientific evidence is necessary.

Another potential indicator for susceptibility to ARF is the expression of a B cell alloantigen recognized by the D8/17 monoclonal antibody, an antibody produced in mice against B cells from ARF patients (Patarroyo et al. 1979; Zabriskie et al. 1985; Gibofsky et al. 1991; 
Kemeny et al. 1994). Originally, Patarroyo et al. (1979) developed the alloantisera using B cells from RF patients and noted the existence of a surface marker on peripheral blood mononuclear cells stimulated with pokeweed mitogen defined by the alloantisera 883 and that this antisera reacted to over $75 \%$ of RF patients from the United States and Columbia. When the supply of alloantisera was exhausted, Zabriskie et al. repeated the immunization strategy and developed D8/17 (Zabriskie et al. 1985). Subsequent analysis found that this D8/17 reacts with an antigen on a large proportion of B cells from ARF or RHD patients from differing ethnic backgrounds at various frequencies (Gibofsky et al. 1991; Ganguly et al. 1992) and that it is not an HLA antigen (Kemeny et al. 1994). Patients with certain neurological disorders, including Syndenhams chorea, Tourette's and subgroups of obsessive-compulsive disorder, have been shown to express higher levels of the alloantigen (Swedom et al. 1997; Hollander et al. 1999). In addition, this antibody has been shown to recognize helical coiled-coil structures (Gibofsky et al. 1991), cardiac, skeletal, and smooth muscle, epithelia and hepatocytes, and more specifically, to M6 M protein, vimentin and myosin (Kemeny et al. 1994).

\section{Overview of our studies}

Introduction. Unlike most autoimmune diseases the precipitating event for ARF, streptococcal pharyngitis, is known. Extensive examination of patients and in vitro experimentation have given credence to the theory that $\mathrm{ARF}$ is an autoimmune sequelae. But despite the overwhelming evidence indicating that group A streptococcus can induce cross-reactive autoimmune responses, the underlying mechanisms of rheumatic fever remain elusive. One of the greatest challenges facing researchers studying this phenomenon is reconciling the data demonstrating the ability of streptococcal antigens to consistently induce cross-reactive immune 
responses in vitro with the reality that this disease affects only a certain small percentage of the population and not all of these patients consistently exhibit abnormal cross-reactive immune responses. Modern medicine has been able to dampen the threat of autoimmune complications with the advent of prophylatic penicillin treatment, however the ability to predict and ultimately prevent and treat the acute autoimmune illness still remains an elusive goal. Identification of susceptible individuals has proven difficult with no clear genetic marker in sight creating a greater need for prevention. Extensive research has been applied to the development of a GAS vaccine with the predominance of research targeted towards the major immunodominant antigen M protein. Despite the promise of inducing protective immunity with such a vaccine, $M$ protein has been shown to induce host cross-reactive immune responses that may ultimately prove detrimental to the individual. The ability to confirm the circumstantial evidence obtained thus far against M protein would be greatly improved with the development of a post-streptococcal autoimmune animal model.

Based on our observation that neonatal mice immunized with $S$. pyogenes exhibit lifelong host cross-reactive antibody responses reminiscent of ARF patients, we have decided to take advantage of this immunization strategy and develop a mouse model for post-streptococcal autoimmune diseases. Research outlined in the following chapters will include work devoted to characterizing the antibody and $\mathrm{T}$ lymphocytic immune responses following neonatal immunization with $S$. pyogenes in an attempt to determine the extent to which GAS may induce immune responses to mammalian proteins, namely muscle myosin. The data presented within the subsequent chapters focuses primarily on the antibody and CTL responses elicited following immunization with heat-killed S. pyogenes. Due to unforeseen problems within our system, mostly the mitogenicity of streptococcal M protein, we were unable to evaluate autoreactive 
$\mathrm{CD}^{+} \mathrm{T}$ cell responses. In the future methodical approaches will be undertaken to identify antigen-specific $\mathrm{CD} 4^{+}$cells.

Capacity of the neonatal immune system. Although we have been able to elicit host crossreactive immune responses in our neonatally challenged mice, controversy exists regarding the extent to which neonates are capable of mounting a productive immune response following antigenic exposure. Over forty years ago Medawar and colleagues provided the first experimental evidence suggesting that the neonatal immune system is uniquely susceptible to tolerance induction (Billingham et al. 1953), an understanding which has provided an excellent explanation and time-frame for the development of self tolerance. Since this observation, two major hypotheses have emerged attempting to explain the mechanisms of this phenomenon. The first hypothesis suggests that experimental neonatal tolerance occurs by negative selection much in the same manner as natural negative selection occurs (Morrissey et al. 1983), while the second suggests that neonatal tolerance is due to the generation of a $\mathrm{T}$ cell response biased towards a predominantly suppressive Th2 response (Singh et al. 1996; Adkins and Du 1998). However, recent evidence has been put forth to contradict these hypotheses by suggesting that under the proper conditions neonates are capable of eliciting a normal protective Th1-type immune response comparable to the more immunologically mature adult animal.

Adkins et al. (1994) and Singh et al. (1996) demonstrated that neonatal antigen exposure of soluble protein or peptide in complete Fruends adjuvant, respectively; can induce a primary $\mathrm{T}$ cell response that is split between a Th1 and Th2 response but becomes biased towards a Th2 response upon secondary challenge, as determined by antibody and cytokine profiles. Forsthuber et al. (1996) demonstrated that immunizing neonatal mice with protein in incomplete Fruends' adjuvant can induce a Th1 type response that may be recalled when the animal is an adult, 
provided that the booster contains complete Freunds' adjuvant. In contrast, Pertmer and Robinson (1999), while able to induce similar Th1 immune responses with a DNA vaccine of influenza hemagglutinin, were unable to induce antibody responses to the protein until two weeks of age. In regard to eliciting protective CTL responses, Sarzotti et al. (1996) and Siegrist et al. (1998) demonstrated the ability of neonatal mice to mount a protective CTL response using two distinct viral models. Furthermore, Pilarski et al. (1977) found that mice have detectable anti-allogenic CTL responses within three days of birth.

While it has been repeatedly demonstrated that neonatal mice have a tendency to elicit a deviant (Th2) immune response upon antigenic challenge, questions still remain as to the cause. An obvious explanation would be the immunological immaturity of the neonatal immune system. In support of this argument, murine $\mathrm{T}$ cells have TCR with limited $\mathrm{N}$ region addition that restricts the diversity of the TCR during the neonatal period (Feeney 1991). However, neonatal T cells have been shown to express receptors for cytokines and costimulatory molecules in similar amounts as the adult animal (Adkins et al. 1994). Furthermore, neonatally thymectomized mice produce a Th1 response upon challenge with soluble protein, suggesting that $\mathrm{T}$ cells have fully mature capacity as early as day one of life (Adkins and $\mathrm{Du}$ 1998). Other potential explanations include deficiencies in production of key cytokines (Adkins et al. 1994; Adkins and Du 1998; Arulanandam et al. 1999) or antigen processing and presentation (Levin and Gershon 1989; Ridge et al. 1996). Typically neonatal mice produce larger amounts of IL-4, a Th2 cytokine, as compared to adult mice (Singh et al. 1996; Adkins and Du 1998). Adkins et al. (1994; 1998) found neonatal mice compared to adult mice, exhibit a more rapid kinetics and produce higher levels of cytokines, namely IL-2, IL-4 and INF- $\gamma$ and that in vitro IL-6 enhances the ability of neonatal T cells to respond to secondary stimuli. Arulanandam et al. (1999) 
demonstrated that upon antigenic challenge neonatal mice have decreased IL-12 production compared to adult animals, and the addition of IL-12 in the immunization to neonatal mice will enhance the Th1 response. Deficiencies exist for neonatal antigen processing and presentation as well. Levin and Gershon (1989) found that neonatal spleen cells exhibit inadequate antigen processing and presentation of soluble antigen in vitro. Interestingly, the deficiencies of neonatal spleen cell antigen presentation cannot be ascribed to suppressive cells or factors since neonatal cells actually produce ample amounts of soluble proliferative factors (Levin and Gershon 1989). This observation has led Levin and Gershon (1989) to suggest that the problem lies somewhere in the initial stages of this event. However, Morris et al. (1992) demonstrated that neonatal splenic B cells are capable of binding, internalizing, and degrading radiolabeled antigen. While neonatal B cells may express nearly adult levels of MHC class II and necessary costimulatory molecules, and the neonatal lymph node environment may support $\mathrm{T}$ and $\mathrm{B}$ cell collaboration, neonatal B cells are unable to differentiate or induce IL-2 production in T cells (Morris et al. 1992; Astori et al. 1998). Additionally, neonatal dendritic cells demonstrate a limited ability to induce either adult or cord blood $\mathrm{T}$ cells to proliferate in response to $\mathrm{T}$ cell mitogens PHA and Con A. However, this may be overcome with increased doses of mitogen or cell number (Petty and Hunt 1998). Yet, neonatal dendritic cells may maintain some degree of functionality compared to spleen APC since Ridge et al. (1996) found that dendritic cells were capable of eliciting immune responses in neonatal mice; whereas, a mixed spleen population induced tolerance.

Characterization of myosin cross-reactive monoclonal antibodies. The cross-reactivity between streptococcal antigens and mammalian myosin has long been established (Cunningham et al. 1984, Dale and Beachey 1985a, Manjula et al. 1985). The first chapter discusses work 
conducted in the laboratory characterizing the myosin cross-reactive antibody response in $\mathrm{BALB} / \mathrm{c}$ mice as a result of neonatal S. pyogenes immunization. Monoclonal antibodies were produced from mice immunized as adults or neonates with streptococcal strain D471 (serotype M6), its M- variant UAB152, and J17A4 (non-typable). This immunization scheme allowed for examination of the cross-reactive antibody response induced in mice as a function of age and $\mathrm{M}$ protein. In ELISA analysis, these monoclonal antibodies demonstrated cross-reactivity to several mammalian antigens, including keratin, DNA and commercially prepared rabbit myosin. These results are in agreement with similar work conducted by Cunningham et al $(1984 ; 1986$; Shikhman and Cunningham 1994); and our study takes such analysis a step further.

Extensive Western blotting analysis was undertaken to determine the reactivity against mouse myosin isolated from both cardiac and skeletal sources. We found that antibodies derived from mice immunized as neonates with $S$. pyogenes preferentially recognized the cardiac isoforms of myosin, whereas, antibodies derived from adult immunized mice display no such discrimination of the skeletal myosin isoforms. This suggests that exposure to GAS at a young age may selectively induce a cross-reactive antibody response to the cardiac isoforms of myosin and could therefore play a potential role in the cardiac pathology associated with acute rheumatic fever without the destruction of other muscles in the body.

\section{Neonatal immunization with $S$. pyogenes induces myosin-reactive cytolytic $T$ cell responses}

in BALB/c mice. Once we ascertained the extent to which S. pyogenes could induce an autoreactive antibody response, experiments were undertaken to determine if immunization with $S$. pyogenes could induce a $\mathrm{T}$ cell response against myosin as well. BALB/c were immunized as adults or neonates with S. pyogenes strain D471, its M- variant UAB152, recombinant M6 M protein, or the control antigen cytochrome c. BALB/c mice immunized as adults with D471 
mounted a poor CTL response against streptococcal M protein and no CTL response against mammalian myosin; whereas, mice immunized with the same vaccine within three days of birth and boosted at 5 - 6 weeks of age mounted a measurable CTL responses against both streptococcal $\mathrm{M}$ protein and mammalian muscle myosin that was inhibitable by the addition of anti-CD8 antibodies in the assay. The CTL response against myosin, but not M protein, appeared to be dependent upon the age of initial exposure to the vaccine D471, in that the response against myosin was detected only in mice primed up to 22 days of birth but not after. Our results suggest that immunization with a rheumatogenic strain of $S$. pyogenes can induce age dependent myosinreactive CTL responses providing further evidence to the competence of this immunization strategy as a suitable mouse model system for studying childhood post-streptococcal autoimmune complications.

\section{Role of streptococcal $M$ protein and its C-terminal conserved region in inducing myosin-}

reactive CTL responses in neonatal mice. Experiments discussed in chapter three were designed to determine if the induction of a myosin-reactive CTL response is exclusive to rheumatogenic serotypes of S. pyogenes (D471). Additionally, we wanted to determine if the more conserved carboxy terminal region is responsible for eliciting the myosin-reactive CTL response. These experiments were designed around the findings by Bessen et al. (Bessen et al. 1989; O'Toole et al. 1992) suggesting that most M protein serotypes may be placed in one of two major classes of M protein and that nearly all serotypes of GAS that have been associated with ARF have been shown to express class I M protein. Also, this portion of $\mathrm{M}$ protein is under consideration as a vaccine candidate (Robinson et al. 1993; Pruskakorn et al. 1994a; Pruskakorn et al. 1994b). 
For the first set of experiments neonatal BALB/c mice were immunized with nonrheumatogenic streptococcal strains of GAS that included B737 (M49), H3 (M12) and J17A4. To address the role of the c-terminal region, mice were immunized with recombinant protein consisting of the carboxy terminal region of MP (C6), the variable amino-terminal region of M protein (AB6) or D471 treated with pepsin to cleave away the variable amino terminus of $\mathrm{M}$ protein (D471*).

We found that all strains of GAS tested were capable of eliciting a myosin-reactive CTL response. Only J17A4 elicited a myosin-reactive CTL response comparable to that elicited by D471. In addition, only these two strains elicited responses that preferentially recognized mouse neonatal cardiac myosin. This myosin-reactive cytolytic response was seen in conjunction with a response against the carboxy-terminal conserved region of $\mathrm{M}$ protein and mice primed with $\mathrm{C} 6$ or D471* elicited a response to myosin, whereas, mice treated with AB6 did not. These results suggest that the carboxy terminal region of M protein contains an epitope that is capable of inducing a myosin-reactive CTL response in $\mathrm{BALB} / \mathrm{c}$ mice.

Induction of the myosin-reactive CTL responses in mice with heat-killed $S$. pyogenes: The role of age, haplotype, route of immunization and presence of B lymphocytes. To complete the $\mathrm{BALB} / \mathrm{c}$ studies we demonstrated the obligate role of M protein in the induction of a CTL response against myosin following neonatal immunization with heat-killed S. pyogenes. Specifically, we demonstrate that the M protein must be cell bound because immunization with a combination of an $\mathrm{M}$ protein streptococcal mutant and recombinant protein does not allow for the development of a myosin-reactive CTL response. Also, in chapter four we undertook a preliminary study to determine what role, if any, genetic factors play in the develop of myosinreactive CTL response we have measured following neonatal S. pyogenes exposure, mice of the 
same MHC haplotype as BALB/c (DBA/2J) or of differing haplotypes, $\mathrm{C} 57 \mathrm{Bl} / 6$ and $\mathrm{CBA} / \mathrm{J}$. Our results suggested that mice of the $\mathrm{H}-2^{\mathrm{d}}$ background (BALB/c and DBA/2J), as well as, mice of the $\mathrm{H}-2^{\mathrm{b}}$ background (C57Bl/6) are capable of eliciting myosin-reactive CTL responses following neonatal exposure with $\mathrm{D} 471$, whereas $\mathrm{CBA} / 2 \mathrm{~J}\left(\mathrm{H}-2^{\mathrm{k}}\right)$ were incapable. Although not conclusive, these results suggest that genetic factors can potentially play a role in determining the ability of the host to develop potentially deleterious auto-reactive CTL responses following exposure to $S$. pyogenes. The final set of experiments undertaken and presented in chapter four were performed to determine what effect the route of immunization and the presence of B lymphocytes has on the ability of mice to elicit a myosin-reactive response following neonatal $S$. pyogenes exposure. Experiments were performed with $\mathrm{BALB} / \mathrm{c}$ and $\mathrm{C} 57 \mathrm{~B} 1 / 6$ wild type and immunoglobulin heavy chain knock-out $\left(\operatorname{Igh}^{-/}\right)$mice. The results suggest that intranasal immunization alone does not elicit an immune response to M protein or myosin, either locally or systemically, regardless of the age of immunization. However, if the mice are immunized as neonates intranasally with $S$. pyogenes vaccine and boosted intraperitoneally with recombinant M protein a CTL response is generated against both $\mathrm{M}$ protein and myosin suggesting that intranasal exposure during the neonatal period can prime a systemic autoimmune response. Assays conducted with $\mathrm{C} 57 \mathrm{Bl} / 6$ $\mathrm{Igh}^{-/-}$mice indicate that the lack of the B cell compartment has no direct effect upon the development of a CTL response against either M protein or myosin following neonatal immunization with vaccine. 
Antibodies induced by heat-killed Streptococcus pyogenes in neonatal BALB/c mice recognize cardiac isoforms of mouse skeletal myosin.

Cynthia Cunningham, Malini Pearce and Meenal Elliott 


\begin{abstract}
Antibodies recognizing mammalian cardiac myosin are a hallmark of acute rheumatic fever, an autoimmune complication of pharyngitis caused by the group A streptococcus. Previous reports demonstrate that antibodies reactive toward mammalian myosin can be induced in adult mice following systemic immunization with membrane fractions of GAS or purified streptococcal M protein, albeit with no pathological consequences. Here, we show that antibodies capable of binding mammalian myosin are induced and persist for several months in sera of BALB/c mice immunized within one week of birth with heat killed GAS. We have constructed representative hybridomas to permit characterization and comparison of myosinreactive antibodies induced following immunization of neonatal versus adult mice. Employing western blot analyses we demonstrate that most of the myosin-reactive antibodies induced in neonatal mice cross-react with the group-specific determinant $\mathrm{N}$-acetylglucosamine and recognize primarily the cardiac isoforms of mouse myosin. In contrast, antibodies derived from adult mice immunized with GAS and boosted with recombinant M protein or mouse myosin recognize determinant(s) shared by most isoforms of mouse skeletal myosin. These findings reveal that different classes of myosin-reactive antibodies can be induced by antigens associated with the group A streptococcus depending on the age at exposure. We propose that antibodies recognizing cardiac myosin induced by the group A streptococcus early in ontogeny are likely to play a key role in the pathogenesis of rheumatic fever.
\end{abstract}




\section{INTRODUCTION}

Streptococcus pyogenes, a $\beta$-hemolytic group A streptococcus, is a causative agent of several suppurative skin and mucosal infections in humans. In a small percentage of children, streptococcal pharyngitis may be followed within 3 to 4 weeks by acute rheumatic fever, a disease characterized by fever, polyarthritis and/or carditis $(1,2)$. In a significant number of patients, mitral valve involvement occurs and is characterized by stenosis and/or regurgitation of valve, which can be fatal (1 - 3). Biopsy and autopsy may reveal thickening and calcification of the mitral valve leaflets and shortening of the supporting papillary muscles $(3,4)$. Frequently, granulomatous lesions called 'Aschcoff nodules' are found within the mitral valve and the pericardium $(2,4)$. Additionally, antibody deposits may be found within the valve leaflets and the myocardium $(1,2)$. Individuals presenting with ARF display elevated titers of antistreptococcal antibodies; some of these cross-react with cardiac myosin (5). ARF, when not fatal, resolves itself but can recur with recurring streptococcal pharyngitis. Therefore, the treatment for $\mathrm{ARF}$ is geared towards preventing the recurrence of streptococcal pharyngitis, thereby preventing the recurrence of ARF. Long-term penicillin prophylaxis is prescribed for ARF patients and is very effective $(2,6)$. Timely intervention of streptococcal pharyngitis in children with penicillin treatment has also effectively reduced the incidence of ARF in developed nations (7). Due to the reduced incidence of ARF and the lack of suitable animal model systems, the mechanism of ARF and the mechanism of penicillin intervention remain a mystery.

In both humans and mice the protective antibody response against GAS is directed primarily against the group specific carbohydrate $\mathrm{N}$-acetyl- $\beta$-D-glucosamine and the antiphagocytic virulence factor, $\mathrm{M}$ protein $(8-10)$. The induction of heart-cross-reactive antibodies 
in ARF is thought to involve antigen mimicry by the pathogen in susceptible individuals $(1,2$, 11, 12). Antibodies cross-reactive with mammalian myosin can be induced in laboratory mice following immunization with preparations of streptococcal membranes as well as purified $\mathrm{M}$ protein (13), arguing in favor of a direct role of the pathogen in the induction of a cross-reactive humoral immune response.

Mammalian myosins can be divided into three distinct families, the skeletal muscle myosins, the smooth muscle myosins and the non-muscle myosins. Each family consists of distinct isoforms of heavy and light chains, encoded by distinct genes (14). Each muscle expresses one or more isoforms of the appropriate family of myosins (14 - 17); the expression of distinct isoforms in a given muscle may also change as a function of age $(16,17)$. The various isoforms of myosin display high degree of conservation across species at the amino acid as well as at the nucleotide level (14). Antibodies against streptococcal antigens such as M protein have been shown to cross-react with the skeletal muscle myosins and not the smooth or non-muscle myosins. Studies employing synthetic peptides both of M protein and human cardiac myosin have been instrumental in localizing the cross-reactive epitopes shared by these two proteins (18, 19). The putative myosin epitope mapped in these studies LRRDLD is shared by heavy chains of all isoforms of the skeletal muscle myosins. It is not clear how antibodies recognizing this epitope would induce pathological damage of joints and the heart and spare other skeletal muscles of the body. Furthermore, in the adult inbred mouse model, myosin-reactive antibodies induced by M protein do not lead to pathology similar to that observed in ARF. Therefore, their relevance to pathogenesis of ARF remains unclear.

Here we demonstrate that antibodies against mammalian skeletal myosin can be induced by heat-killed GAS in the absence of any adjuvant in neonatal but not adult mice. We have 
developed panels of monoclonal antibodies reactive toward mouse myosin from BALB/c mice immunized as neonates with GAS and from adult mice immunized with GAS and boosted with M protein or myosin. The current study presents a comparison of the monoclonal antibodies within these panels with respect to their ability to distinguish between distinct isoforms of autologous myosin. We find that antibodies induced by GAS in neonatal mice bind primarily to cardiac specific isoforms of mouse skeletal myosin while those induced in adult mice recognize an epitope shared by most isoforms of skeletal myosin. These results suggest that antibodies induced by GAS early in life are distinct from the myosin-reactive antibodies described heretofore. Their potential role in the pathogenesis of ARF is discussed. 


\section{MATERIALS AND METHODS}

Mice and immunizations: BALB/c mice were purchased from Jackson Laboratories, Bar Harbor, ME and bred at the WVU-OLAR. Newborn mice were immunized intraperitoneally with $10^{7}$ heat-killed GAS of the appropriate strain in $50 \mu$ l volume. Adult mice were immunized intraperitoneally with $10^{8}$ bacteria of appropriate strain or $50 \mu \mathrm{g}$ of recombinant M6 protein or myosin extracted from gastrocnemius muscle of BALB/c mice.

Bacteria: GAS strain J17A4 was obtained from ATCC, strain D471 was a gift of Dr. Susan Hollingshead, UAB, Birmingham AL. Both strains were grown in Todd-Hewitt broth, heatkilled by incubation at $60^{\circ} \mathrm{C}$ for 1.5 hours, washed extensively with $0.85 \%$ saline, resuspended in $0.85 \%$ saline. The cell concentration was estimated by measuring absorbance at $600 \mathrm{~nm}$. Heatkilled J17A4 was treated with pepsin at pH 2 for 30 minutes at $37^{\circ} \mathrm{C}$ as described (20) to cleave surface proteins and thereby expose the group A carbohydrate. The preparation was neutralized by the addition of $\mathrm{NaOH}$, washed with and resuspended in $0.85 \%$ saline. Bacteria were stored frozen at $-20^{\circ} \mathrm{C}$ in aliquots of $10^{9} / \mathrm{ml}$.

Antigens: N-acetyl- $\beta$-D-glucosamine coupled to BSA (GlcNAc-BSA) was a gift of Dr. Madeleine Cunningham, University of Oklahoma Health Science Center, Oklahoma City, Oklahoma. Rabbit muscle myosins (whole myosin, MyHC, MLC, HMM and LMM) were purchased from Sigma chemical company (St. Louis, MO). Recombinant M6 protein was prepared as follows: Plasmid TR06 containing codons 1 to 412 of the emm6 mature peptide cloned in pET20b(+) was a gift from Dr. Susan Hollingshead. This plasmid was expressed in $E$. coli strain BL21:DE3 (pLysS). The M6 protein was induced with 1mM IPTG (Sigma Chemical Company) for $1.5 \mathrm{hrs}$. Periplasmic extracts were prepared by washing cells with one-half 
volume of TSE (150 mM Tris, $20 \%$ Sucrose, $1 \mathrm{mM}$ EDTA) followed by a 20 minute osmotic shock with one-tenth volume $5 \mathrm{mM} \mathrm{MgSO}_{4}$ followed by centrifugation at $10,000 \mathrm{~g}$. The M6 protein was purified from the periplasmic extract by affinity chromatography employing $\mathrm{Ni}$ NTA-Sepharose (Qiagen). The protein was checked by SDS-PAGE for purity and stored frozen at $-20^{\circ} \mathrm{C}$. Myosin extracts from muscles of $\mathrm{BALB} / \mathrm{c}$ mice were prepared essentially as described (21). Briefly, hind limb muscles, diaphragm and hearts were dissected from BALB/c mice of appropriate ages. All hind limb muscles were pooled in the case of embryonic, newborn or 7 day old mice. Adult hearts were separated into atria and ventricles. Muscles were minced on ice in four volumes/wt of cold extraction buffer $\left(0.3 \mathrm{M} \mathrm{NaCl}, 0.1 \mathrm{M} \mathrm{NaH}_{2} \mathrm{PO}_{4}, 0.05 \mathrm{M} \mathrm{Na}_{2} \mathrm{HPO}_{4}, 10\right.$ mM EDTA and $1.4 \mathrm{mM} \beta$-mercaptoethanol). Following a 30-minute incubation on ice, cellular debris was removed by centrifugation at $13,000 \mathrm{~g}$ for $30 \mathrm{~min}$ at $4^{\circ} \mathrm{C}$. Supernatants were then diluted with an equal volume of a storage solution ( $40 \mathrm{mM}$ sodium pyrophosphate, $50 \%$ glycerol) and stored at $-20^{\circ} \mathrm{C}$. Protein concentrations were determined employing a kit (DC Protein Assay, Bio-Rad).

Monoclonal antibodies: Splenocytes harvested from experimental mice were fused with P3.X63.Ag8.653 mouse myeloma by standard procedures (22). Hybridoma supernatants were screened for binding to BSA, GlcNAc-BSA, M6 protein and rabbit whole myosin by ELISA. All supernatants reacting strongly with BSA were eliminated from further analysis. Selected hybridoma wells were subcloned by limiting dilution. Subclones were screened by ELISA. Positive clones were expanded by bulk culture in RPMI 1640 (Life Technologies) supplemented with $10 \%$ FCS (Hyclone laboratories) and $2 \times 10^{-5} \mathrm{M} \beta$-mercaptoethanol. All selected clones described here expressed IgM heavy chains and $\kappa$ light chains. Hybridoma clones A4.840, BFF3, BA-G5, F1.652, N2.261, N3.36, and SC-71 were obtained from ATCC. These were cultured 
as above for collection of supernatants. All supernatants were stored frozen at $-20^{\circ} \mathrm{C}$ until use. Antibodies NOQ7.4D and hsm-V were purchased from Sigma Chemical Co.

ELISA Analysis: Protein was adsorbed onto 96 well assay plates (Costar) at $1 \mu \mathrm{g} / \mathrm{ml}$ protein in $0.1 \mathrm{M}$ borate saline (overnight at $4^{\circ} \mathrm{C}$ or $3 \mathrm{hrs}$ at $37^{\circ} \mathrm{C}$ ). Wells were blocked with $1 \%$ BSA in PBS for 1 hour at room temp and following a wash with PBS, undiluted hybridoma supernatants or serial dilutions of serum samples were added to the wells (overnight at $4^{\circ} \mathrm{C}$ or $37^{\circ} \mathrm{C} 3 \mathrm{hrs}$ ). Plates were washed and goat anti-mouse IgM or goat anti-mouse IgG antibody conjugated with alkaline-phosphatase (Southern Biotechnology Associates) was added. Phosphatase substrate was added after washing plates (Sigma 105, Sigma Chemical Co.) and following the development of color, absorbance at $405 \mathrm{~nm}$ was recorded employing a microplate reader (Bio-Rad, model 3550). The binding of monoclonal antibodies to cardiac MyHC was performed as follows: Polystyrene plates were coated with antibodies NOQ7.4D or N2.261 (both IgG1 isotype). After blocking with $1 \%$ BSA in PBS, extracts from embryonic of adult hearts was added and incubated at $4 \mathrm{C}$ overnight. Plates were washed, hybridoma supernatants were added and incubated for 3 hrs at $37 \mathrm{C}$. After washing, binding was detected by the addition of goat anti-mouse IgM conjugated to alkaline phosphatase followed by phosphatase substrate.

SDS-PAGE and Western Blot analyses: Muscle extracts $(0.2 \mu \mathrm{g}-2 \mu \mathrm{g} / \mathrm{lane})$ were resolved by one of two SDS-PAGE systems. The first consisted of resolving gel containing $5 \%$ acrylamide $(\mathrm{C}=5 \%) ; 30 \%$ glycerol and a stacking gel containing 4\% acrylamide; $30 \%$ glycerol (23). Electrophoresis of this assembly was conducted at $4^{\circ} \mathrm{C}$ at $8 \mathrm{~mA}$ for 3.5 hours and $10 \mathrm{~mA}$ for an additional 5 hours using a $25 \mathrm{mM}$ tris, $192 \mathrm{mM}$ glycine, $0.1 \%$ SDS running buffer. The other system consisted of resolving gel containing $8 \%$ acrylamide $(\mathrm{C}=2 \%)$ and $30 \%$ glycerol and a stacking gel of $4 \%$ acrylamide and 30\% glycerol (24). Preparation and execution these gels were 
carried out as previously described, with the exception that EDTA was omitted from the stacking gel. In both systems, 2-mercaptoethanol was added to the running buffer of the upper reservoir at a final concentration of $10 \mathrm{mM}$. Electrophoresis was conducted in a Mini-PROTEAN II electrophoresis system (Bio-Rad). Following electrophoresis gels were either silver stained (Bio-Rad Silver Stain Plus Kit) or transferred to PVDF membranes (Bio-Rad) under semi-dry transfer conditions (Bio-Rad Trans-Blot SD Transfer Cell) at $50 \mathrm{~mA}$ per gel for one hour. The transfer was facilitated by one of two buffer systems; 10 mM CAPS (Sigma Chemical Company) with $5 \%$ methanol for $5 \% / 30 \%$ gels and $10 \mathrm{mM} \mathrm{CAPS}, 0.05 \%$ DTT, $1 \%$ methanol for $8 \% / 30 \%$ gels). Membranes were blocked with $5 \%$ non-fat milk in PBS at $4^{\circ} \mathrm{C}$ overnight. Following a wash in phosphate buffered saline (PBS), membranes were incubated with undiluted hybridoma tissue culture supernatants for one hour at room temperature followed by a 1 hour incubation with biotinylated anti-isotype antibody (Southern Biotechnology Associates, Birmingham AL) and then a 30 min incubation with streptavidin-HRP (Southern Biotechnology Associates). Membranes were washed extensively with $0.1 \%$ tween 20 in PBS after each incubation. Reactions were visualized by incubating membranes with ECL chemoluminescent reagents (Amersham) for 1 minute followed by multiple exposures to x-ray film (Fuji) ranging from 1 to 15 minutes.

\section{RESULTS}

Induction of anti-myosin antibodies in BALB/c mice

$\mathrm{BALB} / \mathrm{c}$ mice were immunized with heat killed GAS at different ages. We chose two strains for our study; D471 expresses M protein of the M6 serotype, which has been associated with rheumatic fever in humans (i.e. rheumatogenic strain), and J17A4, a non-rheumatogenic 
strain of an unknown M-type. We chose this strain to test whether M protein from rheumatogenic strains of GAS was necessary for the elicitation of anti-myosin antibodies in mice. The heatkilled preparation of J17A4 was further treated with pepsin at acid $\mathrm{pH}$, as described in materials and methods, to cleave surface exposed proteins and to maximally expose the group $\mathrm{A}$ carbohydrate. Preparations of GAS treated in this manner have been shown to induce autoreactive antibodies in mice (25). The treated preparation is known to yield a stronger antiGlcNAc antibody response in neonatal as well as adult BALB/c mice than the untreated one (M. Elliott, unpublished observations).

We gave 2-day-old mice $2 * 10^{7}$ heat-killed organisms and 6-week-old adult mice $2 * 10^{8}$ organisms by the intraperitoneal route. Neonatally immunized mice were bled at 14 days of age and then at intervals of 10 weeks. Some mice immunized as neonates were boosted at 8 weeks of age, bled at 10 weeks and every 10 weeks thereafter. Adult mice were immunized at six weeks of age, given a booster 14 days following the primary immunization, bled at 10 weeks of age and at intervals of 10 weeks thereafter. One group of adult mice was immunized with $50 \mathrm{~g}$ of purified recombinant M6 protein at 6 weeks of age and boosted at 8 weeks of age. Data shown in figure 1 represent a comparison of the levels of antibodies of the IgM subclass against three distinct antigens in the variously immunized mice as well as unimmunized control mice at $2,10,20,30,40,50,60$ and 70 weeks of age. Data are shown for serum dilution of 5,000 for Nacetylglucosamine (fig 1a), 2,500 for myosin (fig 1b) and serum dilution of 500 for M protein (fig 1c).

In adult mice immunized with D471 or J17A4, high titers of antibodies of the IgM subclass against $\mathrm{N}$-acetylglucosamine (GlcNAc) were induced within 2 weeks of immunization (fig1a). The titers dropped as a function of age to slightly above baseline and remained at this 
level through the remainder of the experiment. Levels of anti-myosin antibodies were only slightly above those in unimmunized mice (fig 1b) and did not rise over the period of the experiment. Levels of antibodies against M6 protein were increased two weeks after the second immunization but were much lower in comparison to those induced by purified recombinant M6 protein (fig 1c).

In adult mice immunized and boosted with purified M6 protein, response to M6 protein was the highest at 10 weeks of age; dropping to background levels within 30 weeks and remaining low throughout the course of the experiment. Antibodies against GlcNAc as well as myosin were elevated slightly above background in this group of mice and maintained at that level throughout the experiment (fig 1a and 1b). The significance of the latter response is not clear at this point.

In mice immunized within one week of birth with either D471 or J17A4 and boosted at 6 weeks of age with the same preparation, levels of antibodies against all three antigens were elevated at 10 weeks of age (fig $1 \mathrm{a}, \mathrm{b}$ and c). However, in both these groups, antibody levels dropped to a plateau above the baseline and remained there throughout the course of the experiment. In mice immunized within one week of birth with D471 or J17A4, levels of antibodies against GlcNAc increased slowly as a function of age (fig 1a); and continued to rise throughout the remainder of the experiment. Similarly, levels of antibodies against myosin were increased steadily in parallel (fig 1b). Levels of anti-GlcNAc as well as anti-myosin antibodies in these mice between 30 and 60 weeks were significantly higher than in all other groups. This is reminiscent of antibodies observed in ARF patients $(1,26,27)$. The levels of antibodies against M6 protein were very low in these two groups of mice throughout the course of the experiment (fig 1c). Thus, a subclass of antibodies against GlcNAc preferentially induced in neonatal mice 
by both strains of GAS was related to anti-myosin antibodies observed in their sera.

Interestingly, high titers against the respective antigens were not observed in mice immunized as neonates and boosted as adults with heat-killed GAS.

Finally, IgG antibodies against all three antigens were also present in sera of mice immunized with heat-killed GAS within one week of birth and in mice immunized with M6 protein at 6 weeks of age (results not shown). To explore the basis for the anomalous antimyosin response following immunization with GAS, we established panels of representative monoclonal antibodies.

Analysis of monoclonal anti-myosin antibodies from BALB/c mice immunized with $G A S$ by ELISA:

We chose 6 different groups of mice for construction of hybridomas (Table 1). Mice immunized with either J17A4 or D471 at 2 days of age were sacrificed at the age of 60 weeks for hybridoma construction (groups 1 and 2). Another group of 2 mice immunized with D471 at 2 days of age was boosted at 8 weeks of age and sacrificed at 10 weeks (group 3). We also generated hybridomas from adult BALB/c mice immunized with D471 and boosted with either D471 (group 4), purified recombinant M6 protein (group 5) or mouse myosin (group 6). Following an ELISA based screen, a total of 22 myosin-reactive monoclonal antibodies were recovered, all of which were of the IgM isotype. We were able to recover only one IgG antibody that was specific for M6 protein. Group 4 yielded several anti-GlcNAc antibodies and one antiM6 protein antibody confirming the serological data that GAS fails to induce myosin-reactive antibodies in adult mice. We excluded this group from further analyses. 
Previous studies have shown that myosin-reactive antibodies induced by streptococcal antigens recognize the coiled tail region of the skeletal myosin heavy chains $(13,18,19)$. We tested the 22 myosin-reactive antibodies for binding to isolated rabbit myosin heavy chains and light chains as well as purified heavy meromyosin (the head region of myosin) and the light meromyosin (the tail region). Table 2 summarizes the findings. Several things are of note: firstly, all of the antibodies in groups 1,2 and 3 reacted strongly with GlcNAc; as expected, antibodies from groups 5 and 6 displayed comparatively weaker binding to this antigen, if at all. Furthermore, while hexoseaminidase treatment of plate-bound antigens eliminated reactivity of all antibodies with GlcNAc-BSA, it did not alter binding to the myosin components (results not shown). Secondly, all of the anti-myosin antibodies reacted with MyHC; five antibodies (groups 1,2 and 3) additionally reacted with MLC. Thirdly, all antibodies reacted with LMM. Antibody 1M12 also reacted with HMM. Five antibodies (group 1 and group 2) displayed weak reactivity toward M6 protein whereas; antibodies induced in adult mice following boosters with M6 protein bound M6 very well. Additionally, two antibodies from group 6 also bound M6. Thus, many of the antibodies described here reacted with GlcNAc, M protein and myosin. Examples of antiGlcNAc antibodies reacting with both M protein and MyHC have been previously described (28); reactivity with MLC is a novel finding. None of the antibodies bound to laminin, vimentin, troponin or tropomyosin; all of the antibodies from groups 1 and 2 and two each from groups 3, 5 and 6 bound to keratin (results not shown). These binding assays were unable to identify major differences between antibodies induced in neonatal versus adult mice. Therefore, we decided to probe western blots of mouse skeletal myosins resolved to separate distinct isoforms, with our panels of antibodies. 
Resolution and identification of distinct mouse skeletal myosin isoforms:

Eight distinct isoforms of mammalian skeletal myosin heavy chains $(\mathrm{MyHC}, \mathrm{Mr}=$ 220Kda) encoded by distinct genes have been described; these are (I) embryonic, (ii) neonatal, (iii) type IIa, (iv) type IIx/IId, (v) type IIb, (vi) type I (also known as cardiac $\beta$, (vii) cardiac $\alpha$ and (viii) ocular (14). Antibodies against distinct human and rat MyHC have been established and used extensively in studies addressing the developmental regulation of myosin gene expression using western blot as well as immunofluorescent techniques (17,29-31). Since no such information about the mouse MyHC isoform expression was available, we decided to use the available antibodies and conduct these analyses at the outset.

We prepared crude myosin extracts from a variety of different muscles, from mice of different ages. The preparations were subjected to electrophoresis on polyacrylamide gels containing glycerol to permit resolution of myosin isoforms on the basis of net charge. The myosin isoforms in each sample were identified on the basis of migratory pattern by comparison with a previous study (32) in combination with western blot analysis using pre-characterized antibodies raised against human or rat myosins. Ten distinct myosin extracts representing distinct muscles of fetal to adult BALB/c mice were chosen for this study to identify and distinguish seven of the eight skeletal MyHC isoforms.

The top panel in figure 2a shows a silver stained SDS-PAGE ( $8 \%$ acrylamide, $30 \%$ glycerol) depicting six of these extracts. The embryonic isoform of skeletal myosin was present in an extract prepared from hind limbs muscles of fetal (18-day embryonic) mice (lane 1) and from hind limb muscles of newborn (12-24 hour old) mice (lane 2). Bands corresponding to this isoform were detected by antibody F1.652 $(17,29)$. 
The neonatal MyHC isoform was present in extracts from hind limb muscles of fetal mice (lane 1), newborn mice (lane 2) and 7-day-old mice (lane 3) as well as in the diaphragm of 7-dayold mice (lane 4). Bands corresponding to the NN isoform were detected by antibody N3-36 that has been shown to bind the NN, IIa, IIb and IIx/IId MyHC isoforms of human and rat origin (29, 30). Antibody SC-71 also recognized bands corresponding to this isoform in extracts of newborn and 7-day-old hind limbs; although SC-71 was shown to be specific for the type Ila isoform of rat myosin in previous studies (31). Additionally, SC-71 showed very strong reactivity toward a band co-migrating with the NN isoform within the embryonic hind limb extract. The type IIa isoform of mouse myosin was found to be most abundant in an extract of the soleus muscle (lane 5) and was detected by antibody SC-71 (fig 2d). SC-71 also detected this isoform in extract of hind limb muscles from 7-day-old mice (lane 3).

The type Ilb myosin isoform was present only in the extract prepared from the gastrocnemius muscle of adult (6 week old) mice and was detected by antibody BF-F3 raised against and shown to be specific for the rat IIb myosin (31).

The type IIx/IId isoform was detected in an extract from the gastrocnemius of adult mice (lane 6) and was detected by antibody N3.36. Antibody N3.36 also detected a band corresponding to this isoform in an extract from the diaphragm of 7-day-old mice (lane 4).

The type I isoform was present in extracts of fetal hind limbs, diaphragm and the soleus muscle (lanes 1, 4 and 5). This isoform was detected by antibody A4.840 that also recognizes the corresponding isoform of human and rat origin $(16,17,30)$.

The EMB, type IIa and type I isoforms were additionally detected by antibody N2.261 which has been shown to recognize the type $\mathrm{I} /$ cardiac $\beta$ as well as the type Ila isoforms of human and rat origin $(16,17)$. Of note is the weak reaction with a slow migrating band in the diaphragm 
extract (lane 4), On the basis of non-reactivity of N2.261 with the extract from the gastrocnemius muscle (lane 6), we adjudged this band to be type IIa MyHC. Overloading of the diaphragm extract permitted the detection of this isoform by antibody SC-71, thereby confirming its presence in this extract (results not shown).

Three extracts prepared from hearts of BALB/c mice were resolved by SDS-PAGE (5\% polyacrylamide, $30 \%$ glycerol. The abundance and migratory patterns of the two isoforms ( $\alpha$ and $\beta$ ) of cardiac myosin were displayed by silver staining of gel and are shown in the top panel of figure $2 \mathrm{~b}$. The cardiac $\beta$ isoform, which is expressed in heart ventricles, predominates in the fetal mouse heart extract (lane 1), the $\alpha$ and the $\beta$ isoforms are present at about equimolar concentrations in the hearts of newborn mice (lane 2) and the $\beta$ isoform is absent in heart ventricles of adult mice (lane 3). The cardiac $\beta$ isoform was detected by antibody A4.840 described above. The antibody BA-G5 specific for the rat cardiac $\alpha$ isoform (31) was unable to detect the corresponding isoform in our extracts (results not shown). However, both the cardiac $\alpha$ and $\beta$ isoforms were detected by N2.261. Thus the determinant recognized by the N2.261 antibody appears to be present on the EMB, type IIa, type I/cardiac $\beta$ as well as cardiac $\alpha$ isoforms of mouse myosin.

These analyses prepared us for the correct interpretation of binding patterns displayed by the panel of monoclonal antibodies generated within our laboratory. They also revealed novel antigenic differences between myosin isoforms of human, rat and mouse origin. Antibodies recovered from mice primed with GAS as neonates recognize cardiac myosin specific determinants:

All of the monoclonal antibodies described in Table 2 were screened by western blot analysis employing the myosin extracts described above. All of the antibodies reacted with 
myosin bands if the extracts were resolved on a 5\% acrylamide gel and transferred to the PVDF membrane in the presence of DTT, but failed to react if the extracts were resolved with $8 \%$ acrylamide and transferred without DTT. The EMB and the NN isoforms of MyHC within the embryonic extract and the IIx/IId and the IIb isoforms within the gastrocnemius extract migrated very close together on 5\% acrylamide gels and transferred as a single band. Since the embryonic extract contained large amounts of the EMB isoform, the reactivity with the EMB isoform was scored negative if the intensity of reaction with the band in lane 1at a position corresponding to the EMB isoform was weaker than that in lane 2. Detection of reactivity toward the IIb MyHC isoform was facilitated by the inclusion of an extract from gastrocnemius of 2-week-old mice. This extract contained primarily the $\mathrm{NN}$ and the IIb MyHC isoforms which formed a doublet on blots prepared from the 5\% acrylamide SDS-PAGE (results not shown); the faster migrating band was identified as the IIb isoform by antibody BF-F3 described above. Panels in figure 3 represent results obtained with SDS-PAGE containing 5\% acrylamide, 30\% glycerol and transferred in the presence of DTT.

Antibodies BA1-23, FD3-6-1 (group 1) and 1G19, 1L23, 1M12 and 1N24 (group 2) were derived from mice that were immunized with heat-killed GAS within the first week of life and did not receive any additional immunizations. As shown in figure 3, antibodies BA1-23, FD3-61 and 1L23 all detected the type I isoform of mouse myosin in the soleus muscle extract and showed weak reactivity toward type IIa isoform (lane 5 in corresponding panels). Binding to the type IIa isoform was not faithfully reproduced in subsequent repeats of the experiment. Antibody 1G19 recognized both type I and type IIa myosins. Antibody 1M12 detected bands in lanes 3, 5 and 6 but not in lane 4 . It also recognized the IIb isoform in western blots of $8 \%$ acrylamide gels. It was adjudged that this antibody reacted with type I (weak reaction) as well as types IIa and IIb 
myosin. Antibody $1 \mathrm{~N} 24$ recognized the $\mathrm{NN}$ as well as types I, IIa, IIb and IIx/IId MyHC isoforms resolved on both 5\% and $8 \%$ acrylamide gels. Thus, all six myosin-reactive antibodies from these two groups recognized the type $\mathrm{I} / \mathrm{cardiac} \beta$ isoform of mouse myosin, three recognized only this isoform.

Antibody 11E18 (group 3) recognized the NN, type I, and type IIa isoforms while antibodies 11L6, 11L24 additionally recognized type IIx/IId isoform. Antibodies 11N24 and 11AA23 detected the NN and type I, IIa, Ilb and IIx/IId isoforms.

Antibodies derived from mice immunized at six weeks of age with D471 and boosted with either M6 protein (group 5) or mouse hind limb myosin (group 6) were tested next. Antibodies 14A23, 14L7 and 14H15 derived from group 5 reacted with all isoforms of myosin MyHC except the EMB, but also consistently gave a high background (results not shown). Antibodies $14 \mathrm{I} 23$ and $14 \mathrm{~J} 16$ failed to detect myosin by western blot. All seven antibodies derived from group 6 displayed strong reactivity toward all isoforms of mouse myosin except the embryonic isoform and are represented here by a blot probed with antibody 15E23.

Western blot analysis of heart muscle extracts revealed that all of the antibodies described above with the exception of 11E18, 11L6 and 11L24 recognized both $\alpha$ and $\beta$ isoforms of cardiac MyHC. Antibody 11E18 (group 3) recognized only the $\beta$ isoform of cardiac MyHC; Figure 4 shows a sampling of these western blots with at least one example from each of the five experimental groups that included myosin-reactive monoclonal antibodies. Reactivity toward cardiac myosins was additionally tested in an indirect ELISA as described in materials and methods. Antibodies 11L6 and 11L24 were able to recognize MyHC from all three extracts of $\mathrm{BALB} / \mathrm{c}$ hearts in this assay (results not shown). It is possible that the epitope(s) recognized by these antibodies were lost upon dissociation of MLC from MyHC in SDS-PAGE. 
As summarized in Table 3, analyses presented above identified six distinct reactivity patterns of anti-MyHC antibodies induced in BALB/c mice. Anti-myosin antibodies recovered from mice exposed to the J17A4 strain of GAS as neonates (group 1) showed the narrowest pattern of reactivity, primarily binding the cardiac MyHC. One antibody with specificity for the cardiac MyHC was also recovered from mice immunized as neonates with the D471 strain of GAS. Two other antibodies from group 2 recognized additional $\mathrm{MyHC}$ isoforms and the fourth one recognized all but the EMB isoforms. The reactivity of one antibody from group 3 was restricted to the type I / cardiac, IIa and NN MyHC isoforms. The remainder recognized all MyHC isoforms with the exception of the EMB, by western blot and/or ELISA. Finally, antibodies from groups 5 and 6 recognized all but the EMB MyHC isoform.

Finally, western blot analyses of MLC resolved on 12\% SDS-PAGE with all antibodies failed (results not shown). Our findings demonstrate that anti-myosin antibodies resulting from immunization of $\mathrm{BALB} / \mathrm{c}$ mice with GAS can distinguish between distinct isoforms of skeletal MyHC depending on the age at primary exposure to GAS. 


\section{DISCUSSION}

We have described previously that immunization of neonatal mice with heat-killed $S$. pneumoniae induced the production of a class of anti-phosphorylcholine antibodies distinct from those produced in adult mice and which were non-protective and possibly autoreactive (39). We decided to explore whether antigens from other pathogenic bacteria could induce autoreactive and potentially pathogenic antibodies in neonatal mice. We chose GAS for two reasons: the antibody response in humans and mice against the group-specific determinant GlcNAc has been characterized $(8,9)$, and the etiologic relationship between GAS and diseases such as ARF is established $(1,2)$. A large number of prior studies demonstrate that myosin-cross-reactive antibodies are induced by GAS in ARF patients and in laboratory mice $(11-13,18,19)$. However, their role in the pathogenesis of ARF remains unclear.

The current study reveals that anti-myosin antibodies are induced and persist in BALB/c mice that have been exposed to heat-killed GAS as neonates. These antibodies react strongly with GlcNAc but show weak reactivity toward the M6 protein. While the presence of an emm gene in J17A4 has been documented (34), whether a functional M protein is expressed by this strain is unknown. Nevertheless, small amounts of surface proteins may be retained within the J17A4 preparation treated with pepsin. We have recently observed that a variant of D471 with an insertional inactivation in the emm6 gene is capable of inducing the production and persistence of anti-myosin serum antibodies in neonatal BALB/c mice. Thus, the presence of an M protein is not essential for the induction of myosin-reactive antibodies. Furthermore, we failed to observe any strain-specific differences in the serum antibody responses in BALB/c mice (this study) and in DBA/2J and C57Bl/6J mice (M. Elliott, unpublished observations). The 
reasons for failure to boost the autoreactive response induced by GAS in neonates by second immunization with GAS at 8 weeks of age are unclear. This appears to be a BALB/c strainrelated characteristic since in $\mathrm{DBA} / 2 \mathrm{~J}$ and $\mathrm{C} 57 \mathrm{Bl} / 6 \mathrm{~J}$ mice, a booster of $\mathrm{D} 471$ in mice neonatally primed with D471 leads to a prompt increase in GlcNAc- and myosin-reactive antibodies (M. Elliott, unpublished observations).

We have also demonstrated that heat-killed GAS was unable to induce anti-myosin antibodies in adult mice without additional boosters with purified M protein or myosin. Furthermore, monoclonal antibodies recovered following boosters with mouse myosin or the M6 protein, react with all isoforms of skeletal MyHC except the EMB isoform. In contrast, antibodies induced following immunization with GAS in neonatal mice show restricted reactivity, binding cardiac $\mathrm{MyHC}$ in preference to other isoforms of skeletal myosin heavy chains. The basis for binding of some of these antibodies to MLC remains unclear.

Since the cardiac myosin extracts employed in our studies were prepared from whole hearts, we expected contamination by smooth muscle myosins from blood vessels associated with the heart. Additional protein bands were found in the same molecular weight range as the cardiac skeletal myosins upon SDS-PAGE. However, we failed to detect any of these bands in western blots with the antibodies described here and with hsm-V, an antibody specific for human smooth muscle myosin (35). Therefore, we could not determine whether the antibodies described in this study could recognize smooth muscle myosins.

Upon histological examination of mice from groups 1 and 2 we failed to observe any abnormalities of the heart, joints or kidney. All mice within these two groups progressively developed alopecia of the whole body. Due to lack of evidence in favor of an immunologic mechanism, the alopecia was adjudged 'idiopathic'. Mice in all other groups maintained perfectly 
normal hair well beyond 70 weeks of age. Histological analyses were also conducted on groups of mice immunized with GAS within the first week of life and sacrificed at various times thereafter to detect signs of pathology that might have been overlooked in the absence of overt symptoms, albeit with negative results.

We have additionally observed that all but one of the antibodies from groups 1 and 2 and none from groups 3, 5 or 6 bind to hyaluronic acid and/or heparin sulfate by ELISA. Additionally, BALB/c as well as DBA/2J and C57Bl/6 mice immunized with GAS within one week of birth, but not as adults, carry persistent antibodies that bind hyaluronic acid and heparin sulfate (M. Elliott, unpublished observations). Both of these are acidic glycosaminoglycans found in the mammalian extracellular matrices. Hyaluronic acid commonly occurs at the surface of certain cells, in the serum and as a backbone in complex proteoglycans (36). Hyaluronic acid is also found on mitral valve leaflets, within the pericardium of the heart (37) where it probably functions as a lubricant. We propose that these antibodies may be multireactive like the monoclonals described here. They may bind hyaluronic acid coating the mitral valve, cardiac myocytes and resident fibroblasts. They may also gain entry into cardiac myocytes, bind to the myosins and compromise myocyte function. The lack of these symptoms in our model system suggests that mere presence of autoantibodies is not sufficient to cause pathology. Hyaluronic acid may also be responsible for the chronic stimulation of autoreactive antibodies in ARF sera and in our mouse model system.

In the current study, we immunized mice by the systemic route; attempts to detect significant amounts of autoantibodies following intranasal immunization have repeatedly failed. Additionally, in similar studies, we have observed that systemic immunization of neonatal, but not adult, mice with heat-killed GAS expressing the M protein led to the induction of myosin- 
reactive $\mathrm{CD} 8^{+} \mathrm{CTL}$ (Cunningham and Elliott, submitted for publication) as well as $\mathrm{CD}^{+}$cells (Elliott and Cunningham, unpublished observations). Despite the identification of functionally active autoreactive $\mathrm{T}$ cells, no pathology was detected in these studies.

Systemic autoimmune diseases such as SLE are thought to be primarily the result of autoantibodies (38). The pathological insult is primarily through deposition of immune complexes in basement membranes, cytokine imbalances may also contribute to the disease. Antibodies capable of binding acidic glycosaminoglycans are also detected in SLE (39); their role in the disease process is unknown. Recent studies have utilized gene targeting in combination with genetic animal models of SLE and autoimmune diabetes to establish that B cells are required for initiation of the disease $(40-42)$. In most other autoimmune diseases, the presence of autoantibodies is thought to reflect the release of sequestered autoantigen following tissue or organ damage and therefore, secondary to the disease process. In contrast, in ARF, myosin- and glycosaminoglycan- reactive antibodies appear to be induced by the pathogen and therefore are likely to be involved in the initial stages of the disease. Since convalescent patients and individuals on long-term penicillin prophylaxis continue to carry autoantibodies in their sera (5), their relevance to disease in later stages remains unclear. ARF remains one of the few diseases where a cause-effect relationship between a pathogen and pathogenesis is firmly established. Understanding the mechanism of ARF pathogenesis might lead to new insights into the mechanisms of other autoimmune diseases of man. 
In summary, we have begun to identify various components of the immune system with potential for pathogenesis and which are stimulated by GAS in neonatal but not adult mice. Despite the lack of pathology, the similarities with ARF make this model system suitable for dissecting the mechanisms of post-streptococcal autoimmune diseases. Since autoimmune diseases are thought to involve multiple events, identification of the pathogenic mechanisms in ARF will likely involve modifications to this model system in the future. 

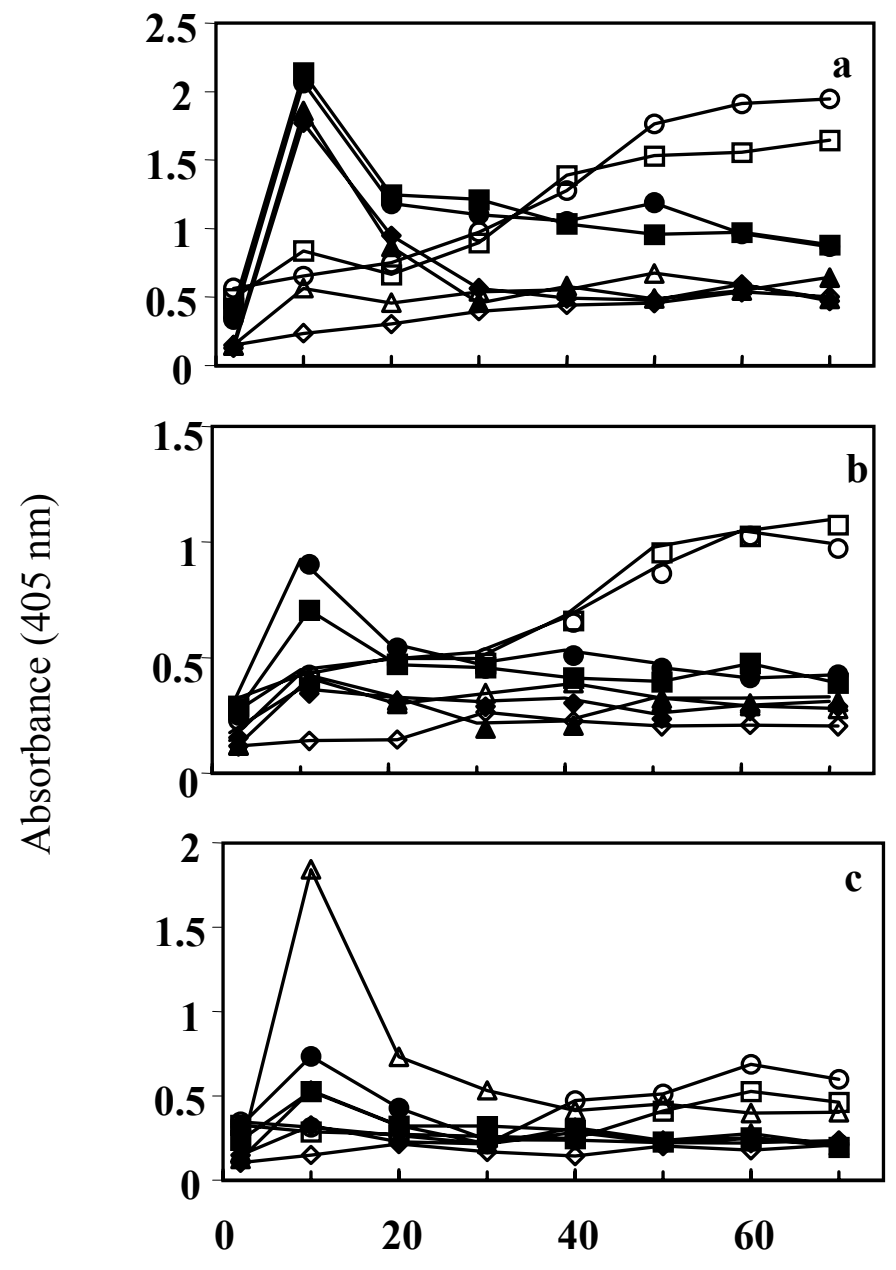

Age of mice (weeks)

Figure 1: Antibody responses in BALB/c mice immunized with heat-killed GAS. Mice were immunized as described in materials and methods. Data represent geometric means of absorbance values (Y-axis) corresponding to serum dilutions of 1:5000 (panel a), 1:2500 (panel b) and 1:500 (panel c) plotted against age of mice (in weeks) for each experimental group, with eight mice per group. Eight groups (based on the immunizing antigen and age at immunization) are as follows: unimmunized control (open diamonds), D471 at 6 and 8 weeks (filled circles), J17A4 at 6 and 8 weeks (filled squares), M6 protein at 6 and 8 weeks (open triangles), D471 at 2 and 8 weeks (filled triangles), J17A4 at 2 and 8 weeks (filled diamonds), D471 at 2 weeks only (open circles) and J17A4 at 2 weeks only (open squares). 
Table 1: Summary of hybridomas obtained following distinct immunization strategies

\begin{tabular}{|c|c|c|c|c|c|c|c|}
\hline \multirow[t]{2}{*}{ Group } & \multirow{2}{*}{$\begin{array}{l}\text { Age at } \\
\text { primary } \\
\text { immuni- } \\
\text { zation }\end{array}$} & \multirow[t]{2}{*}{$\operatorname{antigen}^{a}$} & \multirow[t]{2}{*}{$\begin{array}{l}\text { Booster } \\
\text { antigen }^{b}\end{array}$} & \multirow[t]{2}{*}{$\begin{array}{l}\text { Age at } \\
\text { fusion }\end{array}$} & \multicolumn{3}{|c|}{$\begin{array}{c}\text { numbers of monoclonal } \\
\text { antibodies reactive toward }^{c}\end{array}$} \\
\hline & & & & & GlcNAc & M6 & Myosin $^{d}$ \\
\hline 1 & $2 d$ & J17A4 & none & $60 \mathrm{wk}$ & $>100$ & 2 & 2 \\
\hline 2 & $2 d$ & D471 & none & $60 \mathrm{wk}$ & $>100$ & 4 & 4 \\
\hline 3 & $2 \mathrm{~d}$ & D471 & D471 & $10 \mathrm{wk}$ & $>100$ & 0 & 5 \\
\hline 4 & $6 \mathrm{wk}$ & D471 & D471 & $10 \mathrm{wk}$ & $>100$ & 1 & 0 \\
\hline 5 & $6 \mathrm{wk}$ & D471 & M6 & $10 \mathrm{wk}$ & 21 & 6 & 5 \\
\hline 6 & $6 \mathrm{wk}$ & D471 & Myosin & $10 \mathrm{wk}$ & 32 & 2 & 6 \\
\hline
\end{tabular}

a Heat-killed GAS of appropriate strain (J17A4 or D471) was injected by intraperitoneal route at $1-2 * 10^{7}$ to 2 day old mice and at $1 * 10^{8}$ to 6 wk old mice.

$b$ heat-killed GAS was injected at $10^{8}$ per mouse; recombinant M6 protein mouse myosin (prepared from the gastrocnemius muscle of adult mice) was injected at $100 \mu \mathrm{g}$ per mouse.

$c$ as determined by ELISA. Scoring based on absorbance at $405 \mathrm{~nm}>0.5$ units above background.

$d \quad$ whole myosin from rabbit hind limbs (Sigma Chemicals) 
Table 2: Binding of myosin components by monoclonal antibodies induced by GAS

\begin{tabular}{|c|c|c|c|c|c|c|c|}
\hline \multirow[t]{3}{*}{ Group $^{a}$} & \multirow[t]{3}{*}{$\mathrm{mAb}$} & \multicolumn{6}{|c|}{ Binding of antibodies in ELISA $^{b}$ to } \\
\hline & & \multicolumn{2}{|c|}{ GAS antigens } & \multicolumn{4}{|c|}{ Myosin components ${ }^{c}$} \\
\hline & & GlcNAc & M6 & МyHC & MLC & HMM & LMM \\
\hline \multirow[t]{2}{*}{1} & BA1-23 & +++++ & + & +++++ & +++ & -- & ++++ \\
\hline & FD3-6-1 & +++++ & + & ++++ & +++ & -- & ++++ \\
\hline \multirow[t]{4}{*}{2} & $1 \mathrm{G} 19$ & +++++ & + & +++ & -- & -- & +++ \\
\hline & $1 \mathrm{~L} 23$ & +++++ & + & +++ & +++ & ++ & +++ \\
\hline & $1 \mathrm{M} 12$ & +++++ & + & ++++ & +++ & -- & +++++ \\
\hline & $1 \mathrm{~N} 24$ & +++++ & -- & +++++ & -- & -- & ++++ \\
\hline \multirow[t]{5}{*}{3} & $11 \mathrm{E} 18$ & ++++ & -- & ++++ & +++ & -- & ++++ \\
\hline & $11 \mathrm{~L} 6$ & +++ & -- & ++++ & -- & -- & ++++ \\
\hline & 11L24 & +++ & -- & ++++ & -- & -- & ++++ \\
\hline & $11 \mathrm{~N} 24$ & +++ & -- & ++++ & -- & -- & ++++ \\
\hline & $11 \mathrm{AA} 23$ & +++ & -- & +++++ & -- & -- & +++++ \\
\hline \multirow[t]{5}{*}{5} & $14 \mathrm{~A} 23$ & ++ & + & +++ & -- & -- & ++++ \\
\hline & $14 \mathrm{~L} 7$ & -- & ++ & +++ & -- & -- & ++++ \\
\hline & $14 \mathrm{H} 15$ & + & ++++ & +++ & -- & -- & ++++ \\
\hline & $14 \mathrm{I} 23$ & ++ & +++ & +++ & -- & -- & ++++ \\
\hline & $14 \mathrm{~J} 16$ & ++ & +++ & +++ & -- & -- & +++ \\
\hline \multirow[t]{6}{*}{6} & $15 \mathrm{~A} 11$ & +++ & +++ & +++++ & -- & -- & ++++ \\
\hline & $15 \mathrm{E} 23$ & +++ & ++ & +++++ & & -- & ++++ \\
\hline & $15 \mathrm{~F} 19$ & ++ & -- & +++++ & -- & -- & ++++ \\
\hline & $15 \mathrm{~K} 6$ & + & -- & ++++ & -- & -- & ++++ \\
\hline & $15 \mathrm{~K} 20$ & + & -- & ++++ & -- & -- & ++++ \\
\hline & $15 \mathrm{~L} 12$ & ++++ & -- & +++++ & -- & -- & ++++ \\
\hline
\end{tabular}

a Groups as per Table 1, column 1

$b \quad$ absorbance values (at $405 \mathrm{~nm}$ ) are represented as follows: $0.25-0.5=+; 0.5-1.0=++; 1.0-1.5$ $=+++$; $1.5-2.0=++++;>2.0=+++++$.

c $\mathrm{MyHC}=$ myosin heavy chains, $\mathrm{MLC}=$ myosin light chains, $\mathrm{HMM}=$ heavy meromyosin, $\mathrm{LMM}=$ light meromyosin . 
a

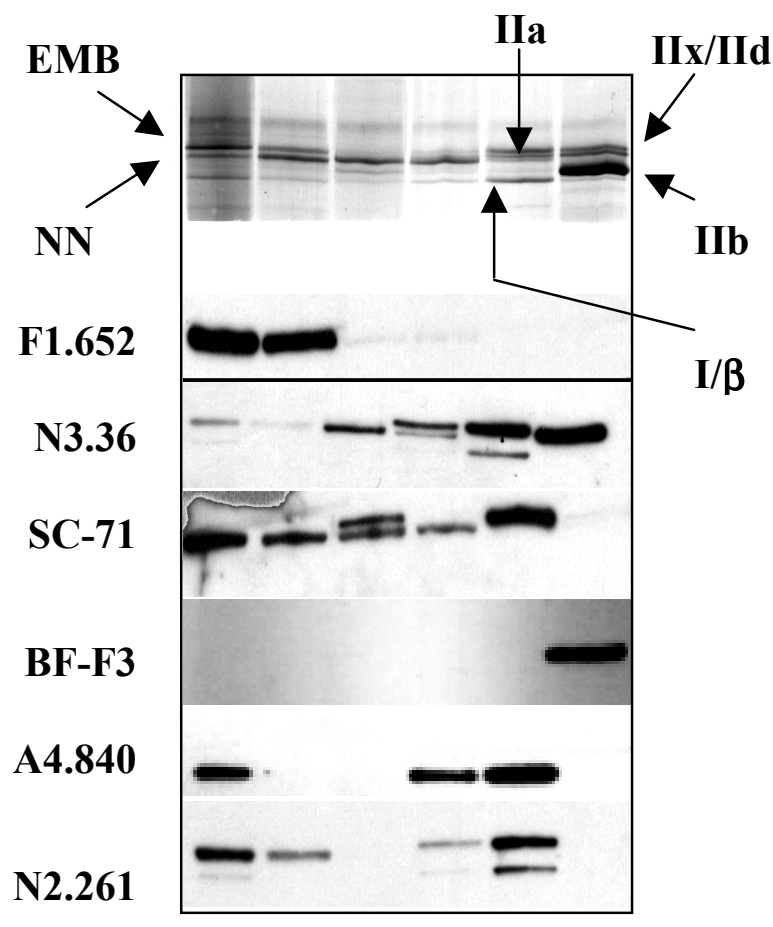

$\begin{array}{llllll}1 & 2 & 3 & 4 & 5 & 6\end{array}$

b

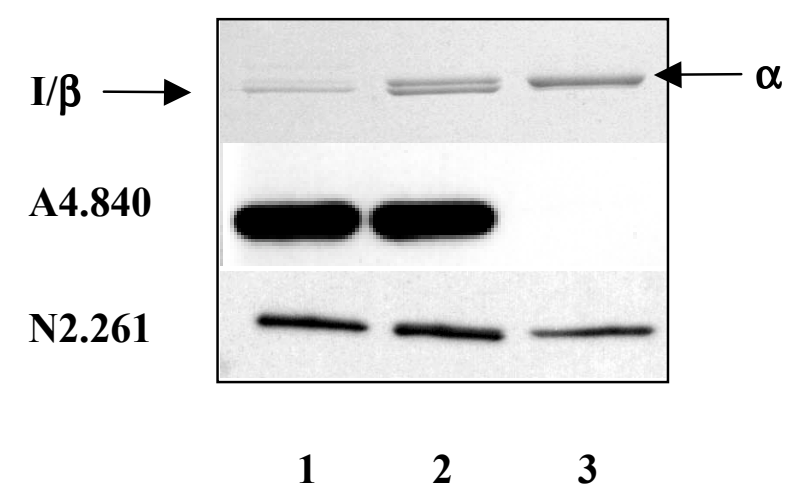

Figure 2: Western blot analysis of mouse MyHC with antibodies raised against human and rat MyHC. Myosin extracts were prepared, electrophoresed and transferred to PVDF membranes as described in materials and methods. Tissue source of myosin in lanes is as follows: figure 1a 18day-embryonic hindlimb (lane 1), 1 day hindlimb (lane 2), 7-day hindlimb (lane 3), 7-day diaphragm (lane 4), 3 week soleus (lane 5) and 5 wk gastrocnemius (lane 6). Figure 1b: 18-day embryonic heart (lane 1), 1 day heart (lane 2), and 5 week heart ventricle (lane 3). Each panel is probed with the antibody noted. 


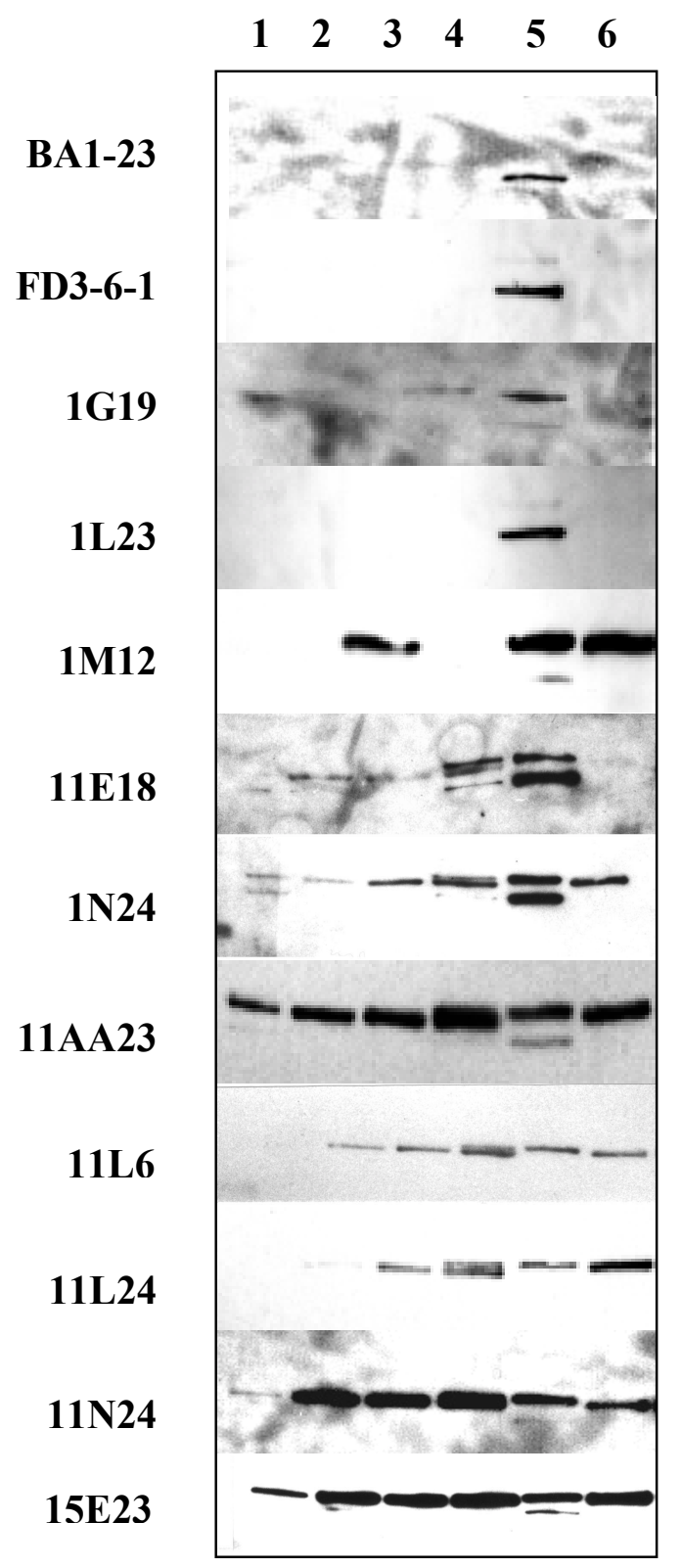

Figure 3: Western Blot analysis of MyHC isoforms from hind limbs and diaphragm with mouse monoclonal antibodies induced by GAS. Myosin extracts were prepared, electrophoresed and transferred to PVDF membranes as described in materials and methods. Tissue source of myosin in lanes is as follows: 18-day-embryonic hindlimb (lane 1), 1 day hindlimb (lane 2), 7-day hindlimb (lane 3), 7-day diaphragm (lane 4), 3 week soleus (lane 5) and 5 wk gastrocnemius (lane 6). Each panel is probed with the antibody noted. 


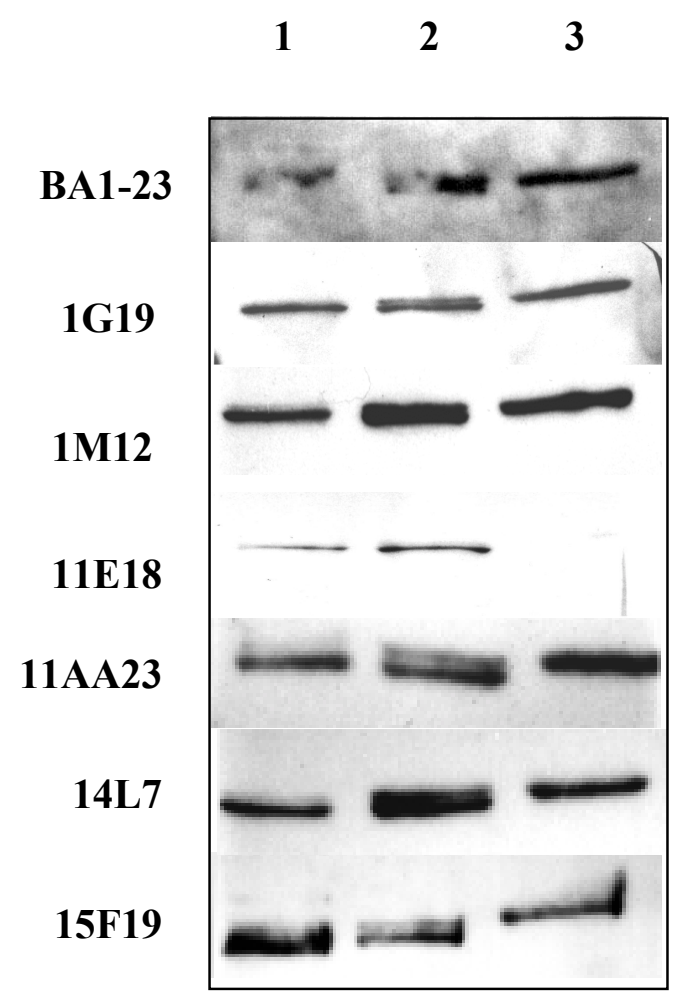

Figure 4: Western blot analysis of mouse cardiac MyHC with mouse monoclonal antibodies induced by GAS. Muscle myosin extracts were prepared, electrophoresed and transferred to PVDF membranes as described in material and methods. Tissue source of myosin in lanes is as follows: 18-day embryonic heart (lane 1), 1 day heart (lane 2), and 5 week heart ventricle (lane 3). Each panel is probed with the antibody noted. 
TABLE 3: Patterns for cross-recognition of endogenous MyHC by antibodies against GAS

\begin{tabular}{|c|c|c|c|c|c|c|c|c|c|}
\hline \multirow[t]{2}{*}{ Pattern } & \multirow{2}{*}{$\begin{array}{l}\text { \# of } \\
\text { repeats }\end{array}$} & \multirow[t]{2}{*}{ group $^{a}$} & \multicolumn{7}{|c|}{ Mouse myosin heavy chain isoform recognized ${ }^{b}$} \\
\hline & & & $\alpha$ & $\beta / I$ & IIa & $\mathrm{IIb}$ & IIx/IId & $\mathrm{Neo}$ & Emb \\
\hline 1 & 3 & 1,2 & + & + & $+/-$ & & & & \\
\hline 2 & 1 & 2 & + & $+/-$ & + & & & & \\
\hline 3 & 1 & 2 & + & + & + & + & & & \\
\hline 4 & 1 & 3 & & + & + & & & + & \\
\hline 5 & 2 & 3 & $+^{c}$ & $+^{c}$ & + & + & + & + & \\
\hline 6 & 11 & $2,3,5,6$ & + & + & + & + & + & + & \\
\hline
\end{tabular}

a Groups as per Table 1, column 1

$b$ based on detection by western blots as shown in figs 3 and 4 and indirect ELISA (for cardiac myosins).

$c$ binding as per indirect ELISA only 


\section{REFERENCES}

1. Stollerman, G. H. 1997. Rheumatic fever. Lancet. 349:935-942.

2. Haffejee, I. 1992. Rheumatic fever and rheumatic heart disease: the current status of its immunology, diagnostic criteria, and prophylaxis. Q. J. Med. 84:641-658.

3. Horstkotte, D., R. Niehues, and B. E. Strauer. 1991. Pathomorphological aspects, aetiology and natural history of acquired mitral stenosis. Eur. Heart J. 12 Suppl B:55-60.

4. Roberts, W. C. and R. Virmani. 1978. Aschcoff bodies at necropsy in valvular heart disease. Evidence from an analysis of 543 patients over 14 years of age that rheumatic heart disease, at least anatomically, is a disease of the mitral valve. Circulation. 57:803-807.

5. Kaplan M. H. 1969. Autoimmunity to heart and its relation to heart disease. Prog. Allergy. 13:408-429.

6. DaSilva, N. A. and B. A. Pereira. 1997. Acute rheumatic fever. Still a challenge. Rheum. Dis. Clin. North Am. 23:545-568.

7. Stollerman, G. H. 1995. Penicillin for streptococcal pharyngitis: has anything changed? Hosp. Pract. 30:80-83.

8. Shackelford, P. G., S. J. Nelson, A. T. Palma, and M. H. Nahm. 1988. Human antibodies to group A streptococcal carbohydrate. Ontogeny, subclass restriction, and clonal diversity. J. Immunol. 140:3200-3205.

9. Briles D. E. and J. M. Davie.1975. Clonal dominance. I. Restricted nature of the IgM antibody response to group A streptococcal carbohydrate in mice. J. Exp. Med. 141:12911307.

10. Beachey, E. H., G. H. Stollerman, R. H. Johnson, A. L. Bisno, and I. Ofek. 1979. Immunogenicity in animals and man of a structurally defined polypeptide of streptococcal M protein. Trans. Assoc. Am. Physicians. 92:346-354.

11. Gulizia, J. M., M. W. Cunningham, and B. M. McManus. 1991. Immunoreactivity of antistreptococcal antibodies to human heart valves. Evidence of multiple cross-reactive epitopes. Am. J. Pathol. 138:285-301.

12. Froude, J., et al. 1989. Cross-reactivity between streptococcus and the human tissue: a model of molecular mimicry and autoimmunity. Curr. Top. Microbiol. Immunol. 145:5-26.

13. Cunningham, M. W., J. M. McCormack, P. G. Fenderson, M. K. Ho, E. H. Beachey, and J. B. Dale. 1989. Human and murine antibodies cross-reactive with streptococcal M 
protein and myosin recognize the sequence GLN-LYS-SER-LYS-GLN in M protein. J. Immunol. 143:2677-2683.

14. Weiss, A. and L. A. Leinwand. 1996. The mammalian myosin heavy chains gene family. Annu. Rev. Cell. Dev. Biol. 12:417-439.

15. Havenith, M. G., R. Visser, J. M. Schrijvers-van Schendel, and F. T. Bosman. 1990. Muscle fiber typing in routinely processed skeletal muscle with monoclonal antibodies. Histochemistry. 93:497-499.

16. Hughes, S. M., M. Cho, I. Karsch-Mizrachi, M. Travis, L. Silberstein, L. A. Leinwand, and H. M. Blau. 1993. Three slow myosin heavy chains sequentially expressed in developing mammalian skeletal muscle. Dev. Biol. 158:183-199.

17. Condon, K., L. Siberstein, H. M. Blau, and W. J. Thompson. 1990. Development of muscle fiber types in the prenatal rat hindlimb. Dev. Biol. 138:256-274.

18. Dale, J. B. and E. H. Beachey. 1985. Epitopes of streptococcal M proteins shared with cardiac myosin. J. Exp. Med. 162:583-591.

19. Quinn, A., K. Ward, V. A. Fischetti, M. Hemric, and M. Cunningham. 1998. Immunological relationship between the class I epitope of streptococcal M protein and myosin. Infect. Immun. 66:4418-4424.

20. Krause, R. M. 1970. The search for antibodies with molecular uniformity. Adv. Immmunol. 12:1-56.

21. Margossian, S. and S. Lowey. 1982. Preparation of myosin and its subfragments from rabbit skeletal muscle. Method Enzymol. 85:55.

22. Kearney, J. F., A. Radbruch, B. Liesegang, and K. Rajewsky. 1979. A new mouse myeloma cell line which has lost immunoglobulin expression but permits the construction of antibody secreting hybrid cell lines. J. Immunol. 123:1548-1550.

23. LaFramboise, W. A., M. J. Daood, R. D. Guthrie, P. Moretti, S. Schiaffino, and M. Ontell. 1990. Electrophoretic separation and immunological identification of type 2x myosin heavy chain in rat skeletal muscle. Biochim. Biophys. Acta. 1035:109-112.

24. Talmadge, R. J. and R. Roy. 1993. Electrophoretic separation of rat skeletal muscle myosin heavy-chain isoforms. J. Appl. Physiol. 75:2337-2340.

25. Bazanova, E. A., E. V. Gnezditskaia, N. A. Borodiiuk, and E. Pyt'eva. 1989. Autoantibodies to different layers of epidermis during immunization of BALB/c mice with a culture of Group A Streptococcus treated with pepsin. Zh. Mikrobiol. Epidemiol. Immunobiol. Jun:86-90. 
26. Dudding, B. A. and E. M. Ayoub. 1968. Persistence of streptococcal group A antibody in patients with rheumatic valvular disease. J. Exp. Med. 128:1081-1098.

27. Appleton, R. S., B. E. Victorica, D. Tamer, and A. M. Ayoub. 1985. Specificity of persistence of antibody to the streptococcal group A carbohydrate in rheumatic valvular heart disease. J. Lab. Clin. Med. 105:114-119.

28. Shikhman, A. R., N. S. Greenspan, and M. W. Cunningham. 1993. A subset of mouse monoclonal antibodies cross-reactive with cytoskeletal proteins and group A streptococcal M proteins recognizes $\mathrm{N}$-acetyl- $\beta$-D-glucosamine. J. Immunol. 151:3902-3913.

29. Cho, M., S. G. Webster, and H. M. Blau. 1993. Evidence for myoblast-extrinsic regulation of slow myosin heavy chain expression during muscle fiber formation in embryonic development J. Cell Biol. 121:795-810.

30. Hughes, S. M. and H. M. Blau. 1992. Muscle fiber pattern is independent of cell lineage in postnatal rodent development. Cell 1992 68:659-671.

31. Schiaffino, S., L. Gorza, S. Sartore, L. Saggin, S. Ausoni, M. Vianello, K. Gunderson, and T. J. Lomo. 1989. Three myosin heavy chain isoforms in type 2 skeletal muscle fibres. J. Muscle Res. Cell Motil. 10:197-205.

32. Agbulut, O., Z. Li, V. Mouly, and G. S. Butler-Browne. 1996. Analysis of skeletal and cardiac muscle from desmin knock-out and normal mice by high resolution separation of myosin heavy-chain isoforms. Biol. Cell. 88:131-135.

33. Vakil, M., D. E. Briles and J. F. Kearney. 1991. Antigen-independent selection of T15 idiotype during B-cell ontogeny in mice. Dev. Immunol. 1:203-212.

34. Scott, J. R., W. M. Pulliam, S. K. Holingshead, and V. A. Fischetti. 1985. Relationship of M protein genes in group A streptococci. Proc. Natl. Acad. Sci., U. S. A. 82:1822-1826.

35. Lazard, D., X. Sastre, M. G. Frid, M. A. Glukhova, J. P. Thiery, and V. E. Kotelinsky. 1993. Expression of smooth muscle-specific proteins in myoepithelium and stromal fibroblasts of normal and malignant human breast tissue. Proc. Natl. Acad. Sci., U. S. A. 90: 999-1003.

36. Fraser, J. R., T. C. Laurent, and U. B. Laurent. 1997. Hyaluronan: its nature, distribution, functions and turnover. J. Intern. Med. 242:27-33.

37. Torii, S., et al. 1966. High content of hyaluronic acid in normal human heart valves. Nature 209:506-507. 
38. Madaio, M. P. 1999. The role of autoantibodies in the pathogenesis of lupus nephritis. Semin. Nephrol. 19:48-56.

39. Pirner, K., A. Rascu, W. Nurnberg, A. Rubbert, J. R. Kalden, and B. Manger. 1994. Evidence for direct anti-heparin-sulfate reactivity in sera of SLE patients. Rheumatol. Int. 14:169-174.

40. Chan O. T., M. P. Madaio, and M. J. Schlomchik. 1999. The central and multiple roles of B cells in lupus pathogenesis. Immunol. Rev. 169:107-121.

41. Falcone, M., J. Lee, G. PatstonE, B. Yeung, and N. Sarvetnick. 1998. B lymphocytes are crucial antigen-presenting cells in the pathogenic autoimmune response to GAD65 antigen in nonobese diabetic mice. J. Immunol. 161:1163-1168.

42. Noorchashm, H., Y. K. Lieu, N. Noorchashm, S. Y. Rostami, S. A. Greelay, A. Schlachterman, H. K. Song, L. E. Noto, A. M. Jevnikar, C. F. Barker, and A. Naji. 1999. I-Ag-7-mediated antigen presentation by B lymphocytes is critical in overcoming checkpoint in $T$ cell tolerance to islet beta cells of non-obese diabetic mice. J. Immunol. 163:743-750. 
Induction of myosin-reactive CTL in mice following immunization with heatkilled Streptococcus pyogenes

Cynthia Cunningham and Meenal Elliott 


\begin{abstract}
Cardiac myosin is one of the hypothetical target autoantigens associated with acute rheumatic fever; an autoimmune disease induced by the group A streptococcus. We have investigated the capacity of group A streptococcus to induce a cytotoxic T lymphocyte response against myosin in laboratory mice. Immunization of adult mice with heat-killed Streptococcus pyogenes strain D471 (D471) induced a CTL response directed against streptococcal M protein but not against myosin. In contrast, in newborn mice a CTL response against $\mathrm{M}$ protein as well as myosin was induced following intraperitoneal immunization with D471 or purified recombinant $\mathrm{M}$ protein, but not with a variant of D471 lacking the M protein. The capacity of D471 to prime myosin-reactive CTL was lost in mice three weeks of age and older. Myosinreactive memory CTL primed in neonatal mice by D471 could be restimulated several weeks later not only by D471 and myosin but also by purified recombinant M protein. CD8 ${ }^{+}$ splenocytes enriched from neonatal mice immunized with D471 and cultured in the presence of recombinant $\mathrm{M}$ protein lysed target cells pulsed with tryptic digest of $\mathrm{M}$ protein or myosin. Our observations establish the capacity of group A streptococcus to cross-prime and expand CTL reactive against myosin in BALB/c mice and reveal that age at primary exposure plays a critical role in determining this capacity.
\end{abstract}




\section{INTRODUCTION}

Streptococcus pyogenes, a $\beta$-hemolytic group A streptococcus, causes infections of the skin and the nasopharynx in humans (1). In addition, non-suppurative complications occur as sequelae to streptococcal infections in some individuals $(2,3)$. Acute rheumatic fever (ARF) and acute glomerulonephritis (AGN) represent some of the more serious complications as they involve damage to heart and renal tissues, respectively. The major manifestations of ARF include arthritis and carditis, the latter being mainly pericarditis, sometimes in combination Aschcoff bodies and fibrotic stenosis of the mitral valve (4). In biopsy and autopsy specimen from affected hearts in ARF, infiltrates consisting primarily of $\mathrm{T}$ lymphocytes have been noted $(5,6)$. The presence of both CD4 and CD8 bearing T cells along with some B cells has been documented (6). Detailed phenotypic and functional analyses of lymphocytes in these infiltrates have failed to elucidate their role in disease pathology. Additionally, sera from ARF patients have been shown to contain antibodies directed against cardiac antigens (7-9).

Studies utilizing lymphocytes isolated from ARF patients as well as attempts to develop animal model systems for ARF have revealed the capacity of the group A streptococcus to induce abnormal immune responses in mammalian hosts (10-12). Cross-reactions between streptococcal antigens, the $\mathrm{M}$ protein in particular, and human cardiac antigens such as myosin have been established at the level of antibody and CD4 T cell epitopes (13-15). Based on these studies and numerous other reports, it is widely accepted that the autoimmune sequelae to streptococcal infections result at least in part from elicitation of immune response against host antigens by $S$. pyogenes during the course of an infection. Pepsin extracts of $\mathrm{M}$ protein from at least 3 distinct serotypes of Streptococcus pyogenes have been shown to act as superantigens for 
$\mathrm{T}$ lymphocytes expressing specific $\mathrm{V} \beta$ genes from normal human peripheral blood $(16,17)$. It has been proposed that superantigen driven stimulation of $\mathrm{T}$ cells may further contribute to disease pathogenesis associated with $\mathrm{ARF}$ and related manifestations.

Additional attempts at understanding the mechanism of ARF have been directed at identifying cytotoxic lymphocytes capable of destroying cardiac myocytes in ARF patients. Lymphocytes isolated from valvular tissue from ARF cases have been shown to lyse cultured cardiac cells (18). Furthermore, peripheral blood lymphocytes from normal humans cultured with pepsin extracts of M protein have been shown to acquire a capacity for lysis of cultured myocardial cells in vitro (19).

Studies addressing the possible induction of cytotoxic $\mathrm{T}$ lymphocytes against host antigens following exposure to group A streptococcus have not been documented to date. Since S. pyogenes is an extracellular pathogen, CTL response against streptococcal antigens most likely do not constitute a major mechanism of defense against this organism in human hosts. Nevertheless, the presence of CD8 bearing cells in cardiac biopsy specimen from ARF patients warrants their evaluation as potential mediators of target organ damage. In the current report we demonstrate that myosin-reactive CTL are elicited by a rheumatogenic strain of Streptococcus pyogenes in neonatal but not in adult mice. Furthermore, neonatal exposure to heat-killed $S$. pyogenes induces memory for myosin-reactive CTL that can be reactivated by either $S$. pyogenes or purified recombinant $\mathrm{M}$ protein later in life. We then discuss why despite their presence, we fail to see pathological damage in the laboratory model. 


\section{MATERIAL AND METHODS}

Mice: BALB/c mice were purchased from Jackson Laboratory, Bar Harbor, ME and bred at WVU animal facility.

Antigens:

Streptococcus pyogenes strains D471 (serotype M6) and UAB152 (a derivative of D471 containing insertional inactivation of the emm6 gene) were grown from single colonies in 2 liters of Todd-Hewitt broth without aeration in the presence of $7.5 \% \mathrm{CO}_{2}$ until growth ceased. The cultures were pasteurized by incubation in a $5^{\circ} \mathrm{C}$ water bath for 1.5 hours at which point cells were centrifuged, washed 5 times with $500 \mathrm{ml}$ of $0.85 \%$ saline and resuspended in $0.85 \%$ saline. The cells were frozen at $-20^{\circ} \mathrm{C}$ in $5 \mathrm{ml}$ aliquots after adjusting the cell density to $\mathrm{OD}_{600}$ of $2.0 / \mathrm{ml}$ $\left(2 * 10^{8}\right.$ bacteria/ml). Both strains were a gift from Dr. Hollingshead (UAB).

Plasmid TR06 was gift of Dr. Hollingshead. This plasmid contains residues 1 to 413 of the

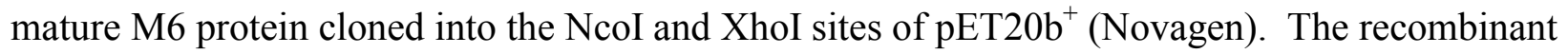
M6 protein with a carboxy-terminal His-6 tag was expressed in BL21:(DE3), pLysS by induction with Iptg for $1 \mathrm{hr}$ and was purified from periplasmic extracts by adsorption to Ni-NTA-sepharose (Qiagen).

Gastrocnemius muscles pooled from hindlimbs of 5 week old mice were placed in four volumes by weight of $0.3 \mathrm{M} \mathrm{NaCl}, 0.1 \mathrm{M} \mathrm{NaH}_{2} \mathrm{PO}_{4}, 0.05 \mathrm{M} \mathrm{Na}_{2} \mathrm{HPO}_{4}, 10 \mathrm{mM}$ EDTA, $1.4 \mathrm{mM}$ 2mercaptoethanol (20), minced fine and incubated on ice for 30 minutes with periodic mixing. Samples were centrifuged at 13,000 g for 30 minutes; supernatants were diluted 5 fold in storage buffer (40 $\mathrm{mM} \mathrm{Na}_{4} \mathrm{P}_{2} \mathrm{O}_{7}, 50 \%$ glycerol) and stored at $-20^{\circ} \mathrm{C}$. Rabbit myosin and bovine cytochrome c were purchased from Sigma Chemical Co., St. Louis, MO. 
Immunizations: Mice were immunized with $10^{7}$ heat-killed S. pyogenes per gram of body weight or soluble antigens $\mathrm{M}$ protein, myosin or bovine cytochrome $\mathrm{c}$ at the doses specified in the results section. The volumes were maintained at 50-100 $\mu 1$ (neonatal) or $200 \mu 1$ (adult) per mouse by the intraperitoneal route or in $5 \mu \mathrm{l}$ (neonatal) or $20 \mu \mathrm{l}$ (adult) per mouse divided equally between two nostrils.

Analysis of CTL responses:

Preparation of antigen peptides: M protein, rabbit myosin, mouse muscle extract and bovine cytochrome c were adjusted to a final concentration of $1 \mathrm{mg} / \mathrm{ml}$ in sterile Dulbecco's phosphate buffered saline, to which, trypsin (Sigma chemical Co., St. Louis, MO) was added at $10 \mu \mathrm{g} / \mathrm{mg}$ protein. Proteolysis was carried out for 20 hours at $37^{\circ} \mathrm{C}$ and digested samples were stored at $20^{\circ} \mathrm{C}$.

Cell cultures: Single cell suspension of splenocytes were washed extensively with incomplete RPMI following red blood cell lysis with $0.15 \mathrm{M} \mathrm{NH}_{4} \mathrm{Cl}$ lysing buffer. Cell counts and viability were monitored via trypan blue exclusion. The spleen cells were in a buffer (5mM EDTADPBS) containing pre-determined dilutions of biotinylated anti-CD45R (RA3-6B2) and antiCD4 (a mix of GK1.5 and RM4-4, Pharmingen) monoclonal antibodies. Following a 20 minute incubation on ice cells were washed and incubated with streptavidin-labeled magnetic beads (Miltenyi Biotec) for 15 minutes on ice. The stained cells were then passed through a MACS $\mathrm{CS}+$ depletion column (Miltenyi Biotec) for separation as described by the manufacturers and non-bound cells were collected for assay and culture. Efficiency of enrichment was monitored by flow cytometric analysis employing a FACScan (BDIS, San Jose CA). Typically, cells used for assay and culturing contained $<2 \% \mathrm{CD} 4^{+},<5 \% \mathrm{~B} 220^{+}$cells and $>65 \% \mathrm{CD} 8^{+}$cells. Nonbound cells were placed in culture with three to five times the number of irradiated adult spleen 
cells and tryptic digests of recombinant $\mathrm{M}$ protein or bovine cytochrome $\mathrm{c}$ for a period of five days and washed with serum-free RPMI1640 before subsequent functional assay.

Cytolytic assay: Spleens from experimental mice were processed into single cell suspensions in serum-free RPMI1640, washed once and resuspended in phenol red-free RPMI with 5\% fetal calf serum. Cultured cells were washed once in RPMI1640 prior to functional assay. P815 cells (H$2^{\mathrm{d}}$ expressing mastocytoma cell line) (21) were incubated with tryptic peptides of appropriate antigen for 30 - 60 minutes in serum-free, phenol red-free RPMI1640 at a concentration of $2 * 10^{5} / \mathrm{ml}$. Effector cells (splenocytes) were plated with the P815 cells loaded with peptides at various ratios in phenol-red free RPMI in 96-well microtiter plates for each antigen tested. Controls included target cells alone, appropriate serial dilutions of effector cells, target cells lysed with $1 \%$ Triton $\mathrm{X}-100$ and media alone. The assay plates were incubated at $37^{\circ} \mathrm{C}$ for approximately 5 hours in the presence of $7.5 \% \mathrm{CO}_{2}$. Subsequently, the plates were centrifuged for 2 minutes at $500 \mathrm{rpm}$ and $50 \mu \mathrm{l}$ of the supernatants were transferred to a new assay plate. An equal amount Promega Cytox96 assay substrate (oxidized to a colored product in the presence of LDH) was added to all wells. The absorbance was read at $490 \mathrm{~nm}$ following a 30 minutes incubation employing a multiscan (Biorad). Absorbance was proportional to the amount of LDH release by lysed cells and therefore to the amount of target cell lysis. Absorbance values for all experimental and control sets (run in triplicates) were averaged and the antigen-specific lysis was calculated as percent of maximum lysis as follows:

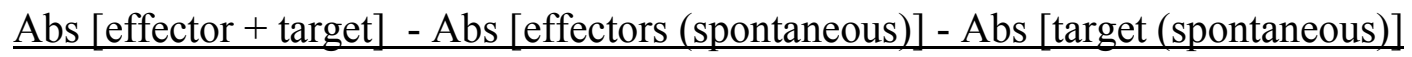
Abs [targets (maximum lysis)] - Abs [targets (spontaneous)]

Inhibition of CTL activity: Monoclonal antibodies against mouse CD4 (RL172) and CD8 (3.155) were harvested from hybridoma (ATCC) tissue culture supernatants by precipitation with 
(NH4) ${ }_{2} \mathrm{SO}_{4}$ and extensive dialysis against phosphate buffered saline, sterilized by filtration. Antibodies were titrated by staining of BALB/c spleen cells in an indirect immunofluorescence assay and flow cytometric analysis. Appropriate dilutions of antibodies were added to effector splenocytes prior to mixing with antigen-pulsed P815 cells. The remainder of assay and analysis was conducted as described above.

All statistical analyses were performed by calculating the $p$ value by ANOVA and the standard error using Microsoft Excel Analysis Toolpak. Lytic units were calculated as previously described (22).

\section{RESULTS}

$C T L$ response in adult BALB/c mice immunized with Streptococcus pyogenes:

Our initial experiments were designed to determine whether streptococcal M protein and mammalian myosin could elicit a CTL response in laboratory mice. To this end we utilized purified recombinant M protein representing a rheumatogenic strain of S. pyogenes (serotype M6, strain D471) and a crude extract of myosin obtained from the hind limbs of BALB/c mice as immmunogens. Tryptic digests prepared from the affinity-purified recombinant $\mathrm{M}$ protein and a commercially available preparation of purified rabbit hind limb myosin were then used as assay antigens. Bovine cytochrome $\mathrm{c}$ has been shown to induce CTL responses in mice when administered by the intraperitoneal route. Therefore we used this antigen as a control for our studies. Adult BALB/c mice were administered $100 \mu \mathrm{g}$ of $\mathrm{M}$ protein, myosin or bovine cytochrome $\mathrm{c}$ by the intraperitoneal route, and boosted by the same route 12 days later. Five to 7 days following the second immunization, splenocytes were harvested and assayed as described. As shown in figure 1a immunization of adult $\mathrm{BALB} / \mathrm{c}$ mice with purified recombinant $\mathrm{M}$ protein 
induced specific lysis of P815 (H-2 $\left.{ }^{\mathrm{d}}\right)$ cells loaded with tryptic peptides of M protein but not cytochrome $\mathrm{c}$ or myosin. Similarly, immunization with mouse myosin or bovine cytochrome $\mathrm{c}$ induced lysis of P815 cells in an antigen-specific manner (fig $1 \mathrm{~b}$ and c). Data shown translate into average lytic units (per $10^{7}$ effector cells) giving $20 \%$ antigen-specific lysis of 10.2, 7.3 and 8.9 for antigens M protein, myosin and cytochrome c, respectively. Lysis of EL4 (H-2 $)$ or CBA.D1 $\left(\mathrm{H}-2^{\mathrm{k}}\right)$ cells similarly pulsed with the three tryptic digests was negligible (results not shown). Thus, adult BALB/c mice display the capacity to present as well as recognize streptococcal M protein and autologous myosin in the context of class I $\left(\mathrm{H}-2^{\mathrm{d}}\right) \mathrm{MyHC}$. Furthermore, CTL response against mouse myosin in BALB/c mice can be readily measured employing peptides of rabbit myosin. These results further established that the CTL responses against the streptococcal $\mathrm{M}$ protein and mouse myosin could be easily induced and detected employing a simple non-radioactive assay.

We next sought to determine whether administration of heat-killed Streptococcus pyogenes organisms could induce a CTL response against $\mathrm{M}$ protein and against myosin which has been shown to share T-cell epitopes with M protein $(14,15)$. Adult BALB/c mice $\left(\mathrm{H}-2^{\mathrm{d}}\right)$ were administered heat-killed whole-cell preparation of S. pyogenes strain D471 (D471) by intraperitoneal route. Splenocytes harvested 7 days following two intraperitoneal immunizations with $2 * 10^{8}$ D471 given 12 days apart were harvested and assayed as described in materials and methods. As shown in fig $1 \mathrm{~d}$, the assay detected lysis of a small but significant proportion of target P815 cells loaded with tryptic peptides of recombinant M protein at the highest effector to target cell ratio. Lysis of target cells loaded with tryptic peptides of bovine cytochrome $\mathrm{c}$ or rabbit myosin was minimal even at the highest E:T ratio. Antigen-specific lysis of target cells loaded with M protein was inhibited in the presence of anti-CD8 antibodies but not anti-CD4 
antibodies confirming that lysis was induced primarily by CD8-bearing cells (fig 1e). In adult BALB/c mice immunized four times with heat-killed D471 over a 4-month period, the CTL response against $\mathrm{M}$ protein was significantly above that against the control antigen cytochrome $\mathrm{c}$ (fig 1f). However, hyperimmunization with D471 failed to elicit a CTL response against myosin, suggesting that repeated exposure to killed pathogen was not sufficient to induce an immune response against the autoantigen myosin. Thus, our results clearly demonstrate that the streptococcal M protein, either soluble or cell-associated, is not capable of inducing a myosinreactive CTL response in adult BALB/c mice.

Myosin-reactive CTL in neonatal BALB/c mice immunized with Streptococcus pyogenes:

The lymphocyte repertoire in mouse and man changes dramatically as a function of age with respect to antigen specificity $(23,24)$. It is also known that perturbations of the immune system in neonatal stages of development can have long-lasting effects $(25,26)$. While the mechanism of pathogenesis in most autoimmune diseases remain unclear, it is recognized that the initiating events may occur long before the disease symptoms are manifest. We therefore proceeded to test whether S. pyogenes might stimulate myosin-reactive CTL cells in neonatal mice.

Newborn BALB/c mice were immunized by the intraperitoneal route with heat-killed Streptococcus pyogenes or purified recombinant M protein within one week of birth and sacrificed seven days following immunization for analysis of antigen-specific CTL. As shown in figure 2a, in mice immunized with D471, we detected a CTL response against M protein. Interestingly, we also detected a CTL response against myosin. These results indicate that Streptococcus pyogenes can indeed induce the priming of autoreactive and potentially harmful 
CTL in laboratory mice. They further establish that age at exposure to $S$. pyogenes is critical in the capacity to mount an autoreactive CTL response.

In mice immunized within one week of birth with $5 \mu \mathrm{g}$ of recombinant $\mathrm{M}$ protein, a strong CTL response against M protein was noted (fig $2 b$ ). The percent M protein-specific lysis in this group of mice for each of the E:T ratios tested was comparable to or better than that observed in mice immunized with heat-killed D471 (note difference in $\mathrm{x}$-axis scale, 2a versus 2b). However, while the percent myosin-specific lysis of target cells by splenocytes from this group of mice was clearly above background, it was not comparable to that observed in mice immunized with D471. Two explanations for this observation are considered. Firstly, it is possible that the myosin-reactive CTL are induced by some other streptococcal antigen and that the $\mathrm{M}$ protein alone is not sufficient to induce maximal CTL response against myosin. Alternately, uptake and processing of the streptococcus by host macrophages may result in the processing and presentation of unique M protein CTL epitopes that may not be optimally generated following extracellular degradation of soluble M protein. Such epitopes may be critical in the elicitation of myosin-reactive CTL.

To investigate whether group A streptococcus might induce myosin-reactive CTL in the absence of M protein, we utilized strain UAB152, a variant of D471 derived by insertional inactivation of the emm6 gene. CTL responses against M protein as well as myosin were absent in mice immunized within one week of birth with a heat-killed preparation of strain UAB152 (fig 2c). While these findings do not exclude the role of other streptococcal antigens in the induction of a CTL response against myosin, the obligate role of $\mathrm{M}$ protein is underscored. 


\section{Kinetics of myosin-reactive CTL in neonatal BALB/c mice}

This next set of studies was conducted to compare the kinetics of elicitation of CTL reactive toward $\mathrm{M}$ protein and myosin following immunization with D471 in order to gain insight into the relationship between the two antigens. We immunized newborn BALB/c mice within 3 days of birth with D471. They were sacrificed on different days to assay the CTL responses against $\mathrm{M}$ protein and myosin. Four days following immunization with D471, the lytic response of splenocytes against P815 cells pulsed with tryptic digests of the M protein or myosin was indistinguishable from non-specific lysis of target cells loaded with cytochrome c (fig 3a and 3f). M protein-specific lysis was significantly above background on days 7, 10 and 13 following immunization (fig 3b, c, d, respectively), with peak response on day 7 (Fig 3b). By day 18 the capacity for M protein-specific lysis had dropped to background levels (fig 3e). On day 7 of the response, anti-CD8 and anti-CD4 antibodies produced about $70-80 \%$ and $10-15 \%$ inhibition of antigen-specific lysis of target cells respectively (fig $3 \mathrm{~b}$ ). On days 10 and $13,90 \%$ or greater of the lytic response was inhibited in the presence of anti-CD 8 antibody (fig $3 c$ and $3 d$ ). These findings establish that M protein-specific lysis is induced primarily by CD8-bearing cells following exposure of newborn BALB/c mice to heat-killed Streptococcus pyogenes by the systemic route. The kinetics of the response indicates that the antigen (M protein) is rapidly eliminated.

Interestingly, capacity for lysis of myosin pulsed target cells was also observed in the same group of mice as above with kinetics identical to that of M protein specific CTL (fig 3f-j). Lytic indices for myosin-specific lysis for all the E:T ratios on days 7, 10 and 13 of the response were comparable to those for M protein-specific lysis. (Day 7 - 12.3:10.9, Day 10 - 5.4; 4.6, Day 13 - 5: 4.2) Furthermore, the extent of inhibition of antigen-specific lysis achieved in the 
presence of anti-CD8 or anti-CD4 antibodies on days 7, 10 and 13 is identical for both antigens. These observations suggest the existence of shared CTL epitope(s) between the two antigens.

Capacity of D471 to prime a CTL response against myosin is lost at weaning:

Having established that administration of heat-killed Streptococcus pyogenes to neonatal mice is required for the generation of myosin-reactive $\mathrm{CTL}$ in $\mathrm{BALB} / \mathrm{c}$ mice, we chose to define the age limits to which this capacity might be restricted. Groups of mice were primed with D471 at $10^{7}$ heat-killed organisms per gram of body weight on days 10,20 or 30 after birth and boosted at 6 to 7 weeks of age with $2 * 10^{8} \mathrm{D} 471$. They were sacrificed 7 days later for analysis of the immune response. As shown in Figure 4, no significant differences were noted in the CTL response against M protein in mice primed with D471 on days 10, 22 (weaning age) or 30 (fig 4a-c). In contrast, CTL response against myosin was highest in mice primed on day 10 (fig 4a) and this was equivalent to that seen in mice primed within three days of life (compare with fig 5a). In mice primed on day 22, the myosin-specific CTL response was weaker, (lytic index $=$ 3.4) yet significantly above than that in mice primed with D471 on day 30 (fig 4b). In the latter group the myosin-specific lytic response at all E:T ratios was indistinguishable from non-specific lysis (fig 4c). Thus, priming for an optimum CTL response against myosin was best achieved by immunizing with D471 within the first 10 days of life. The capacity to elicit myosin-reactive CTL declined with increasing age and was lost in mice 30 days of age or older. These findings demonstrate the significance of host age in the capacity of the group A streptococcus to successfully initiate a CTL response against myosin. 
Myosin-reactive memory CTL can be reactivated with soluble M protein and vice versa

In further attempts to explore the relationship between the streptococcal M protein and mammalian myosin, we examined the secondary CTL response in BALB/c mice primed during the first week of life with $10^{7}$ heat-killed D471. As shown in figure 5a, in mice primed with D471, the CTL response against the M protein as well as against myosin was reactivated following an intraperitoneal booster with $10^{8}$ heat-killed D471 given at 4 months of age. An equivalent dose of the variant strain UAB152 lacking the M protein failed to reactivate CTL against both the M protein and myosin (fig $5 b$ ). These results confirm the requirement for $\mathrm{M}$ protein in the stimulation of myosin-reactive CTL. The absence of a CTL response against myosin in this group of mice (fig $5 \mathrm{~b}$ ) and in a group boosted with $100 \mu \mathrm{g}$ of the control antigen bovine cytochrome c (results not shown) suggests the absence of chronic stimulation of specific CTL by endogenous myosin.

Interestingly, a booster of $100 \mu \mathrm{g}$ of purified recombinant $\mathrm{M}$ protein in mice primed with D471 reactivated not only the M protein-reactive CTL as expected, but also myosin-reactive CTL (fig 5c). The lytic indices for myosin-specific lysis in experiments shown in fig $5 \mathrm{a}$ and $5 \mathrm{~b}$ are 5.5 and 1.0 respectively. Additionally, immunization with $100 \mu \mathrm{g}$ of mouse muscle extract induced a CTL response against myosin as well as M protein (fig $5 \mathrm{~d}$ ). These findings strongly support the idea that cross-priming between M protein and myosin results from existence of cross-reactive CTL epitope(s) rather than through indirect mechanisms. 


\section{M protein-reactive CTLs elicited in neonatal mice cross-react with myosin}

Our results thus far suggest that the myosin-reactive CTL response elicited in neonatal mice may be due to antigen cross-reaction to streptococcal M protein. In order to rule out the possible involvement of endogenous myosin in our experiment, we conducted the following experiment. $\mathrm{CD}^{+}$splenocytes were enriched from adult and neonatal mice immunized with D471 by magnetic sorting as described in material and methods. The enriched cells were assayed directly for lysis of antigen labeled target cells or were restimulated in vitro with enzymatic digests of recombinant $\mathrm{M}$ protein or cytochrome $\mathrm{c}$ for five days. As shown, $\mathrm{CD} 8^{+}$spleen cells from mice immunized as adults with D471 were capable of lysing P815 cells labeled with tryptic digests of M protein but not myosin or cytochrome c (fig 6a). A comparison with figure 1d shows and $8-10$ fold enrichment of $M$ protein reactive CTL. The CTL response measured against both $\mathrm{M}$ protein and myosin in cultured cells were inhibited by addition of anti-CD8 but not anti-CD4 to the assay (data not shown). $\mathrm{CD} 8^{+}$splenocytes obtained from unimmunized age matched control mice and cultured with either recombinant $\mathrm{M}$ protein or cytochrome $\mathrm{c}$ failed to lyse P815 pulsed with tryptic digests of recombinant M protein, myosin or cytochrome c (results not shown).

Culture of $\mathrm{CD}^{+}$splenocytes from adult mice immunized with D471 in the presence of M protein selectively enriched the specific $\mathrm{CD}^{+}$cells and maintained them functionally active (fig 6b) whereas, culture with digest of cytochrome $\mathrm{c}$ led to a loss of CTL activity against M protein (fig 6c). This finding suggests that presence of antigen, in this case M protein, was necessary to maintain functional activity in vitro.

$\mathrm{CD}^{+}$spleen cells from neonatal mice immunized with D471 were capable of lysing P815 cells labeled with either tryptic digests of M protein or myosin but not cytochrome c (fig 6d). 
Following culture with M protein for 5 days, the CTL response against both M protein and myosin was maintained (fig 6e) whereas, culture in the presence of tryptic digests of cytochrome $\mathrm{c}$ led to a loss of response against $\mathrm{M}$ protein as well as myosin (fig 6f). The logical interpretation of these results is that the myosin-reactive CTL response following neonatal exposure to D471 results from cross-reaction of CTL against M protein.

\section{DISCUSSION}

It is becoming increasingly evident that $\mathrm{T}$ cells are potential mediators of the pathology witnessed in rheumatic fever. Due to the shared structural characteristics and epitopes $(27,28)$, it has been hypothesized that $\mathrm{T}$ cells elicited against streptococcal $\mathrm{M}$ protein cross-react with the host protein myosin. Patients with ARF demonstrate lymphocytic infiltrates in cardiac tissue (5, 6), however, there are conflicting reports of their ability to cross-react with streptococcal preparations and cardiac proteins. Guilherme et al. (10) reported that T cell clones isolated from cardiac valve samples of rheumatic fever patients demonstrated cross-reactivity between type 5 M protein and heart tissue protein extracts. Yet, Yoshinaga et al. (12) were unable to demonstrate such cross-reactivity with their $\mathrm{T}$ cell lines isolated from cardiac tissue of RF patients. el-Demellawy et al. (18) has demonstrated that PBL from ARF patients recognize a 50 $\mathrm{kDa}$ and $54 \mathrm{kDa}$ protein of myocardial extracts and that the proliferative response may be intensified by pre-culturing cells with GAS extracts. Cloning of PBL from active and chronic cases of ARF has yielded conflicting results as well. The T cell lines of both $\mathrm{CD} 4^{+}$and $\mathrm{CD} 8^{+}$ phenotypes produced by Pruskakorn et al. (14) that cross-reacted between M protein and myosin were isolated from healthy individuals. Further study of human lymphocytes have shown that peptic preparations of certain serotypes of $\mathrm{M}$ protein have a mitogenic effect on a particular 
subset of naive human lymphocytes $(16,29)$ and this stimulation has the potential to invoke cytotoxic activity against cultured human heart cells $(19,30)$. These studies have allowed for thehypothesis that the superantigenic ability of $\mathrm{M}$ protein is able to augment the immune response against streptococcal antigens and, therefore, the cross-reactive immune response to host antigens, if one is primed. However, despite these promising studies, having cross-reactive $\mathrm{T}$ cells may not be sufficient to cause disease, in that, $\mathrm{M}$ protein-reactive and myosin crossreactive $\mathrm{T}$ cells were isolated from normal human subjects with no history of ARF (14).

In depth evaluation of such a hypothesis is hindered by the lack of a good animal model system. While it has been possible to induce viral mediated autoimmune diseases, such as experimental allergic encephalomyelitis and Coxsackie B3 myocarditis, in laboratory animals $(31,32)$, immunization of adult animals with Streptococcus pyogenes or components thereof usually does not induce autoreactive T cells (15). Hyperimmunization of guinea pigs or rabbits with Group A streptococcal preparations has been shown to induce the elicitation of cytotoxic responses against cardiac cells $(30,33,34)$. Cromartie et al. (34) demonstrated the ability to induce cardiac lesions in mice reminiscent of ARF, however in this case an inflammatory response to antigen deposited in the tissue was adjudged responsible for the pathology.

Based on our previous observation that immunizing neonatal, but not adult, mice with whole heat-killed S. pyogenes strain D471 induces the production of antibodies against the group specific determinant and that cross-react with myosin, we undertook this study to determine the extent this immunization strategy could elicit a T cell response. Specifically, we wanted to determine if immunization of neonatal mice with D471 could elicit CTL responses against the suspect host antigen, myosin, and if so, determine the capacity of $\mathrm{M}$ protein in the induction of such a response. $\mathrm{CD} 8^{+} \mathrm{T}$ cells have been shown to play an important role in the pathogenesis of 
several tissues targeted autoimmune diseases $(35,36)$. Our model includes an extracellular organism and therefore, the induction of a CTL response may not be as evident. Harding et al. $(37,38)$ and Rock et al. $(39)$ have demonstrated the ability of extracellular antigens to be presented via class I MHC. In addition, S. pyogenes has been shown to be capable of binding and entering and residing in host epithelium in patients with recurrent tonsillitis and in carriers (40). As such, S. pyogenes may spend some time as a viable intracellular pathogen and elicit a CTL response. Since we have employed heat-killed vaccine in our studies, our findings suggest that other mechanisms may also be involved in the generation of a CTL response against this organism.

Based on studies conducted to date, we know very little about the capacity of neonates to respond to various antigens. Studies in the area have employed the trial and error approach using distinct antigens. Of note are recent studies that have attempted to identify conditions conducive to the generation of optimal immune responses, in neonates. Utilizing the hen egg lysozyme (HEL) model for neonatal tolerance induction $(25,40)$, neonates were shown capable of eliciting an antigen-specific proliferative Th cell response. In addition, Sarzotti et al. (42) and Siegrist et al. (43) demonstrated the ability of neonatal mice to mount a protective CTL response using two distinct viral models. Furthermore, Pilarski et al. found that mice have detectable anti-allogenic CTL responses within three days of birth (44). Our data clearly shows that neonatal mice can mount CTL responses against bacterial antigens.

Results shown in figure 2 demonstrate the ability of mice neonatally treated with whole heat-killed S. pyogenes to elicit a CTL response against both M protein and myosin. The specificity of this response was confirmed by the lack of response against the unrelated control antigen cytochrome c. Examination of the kinetics of this response (fig 3) reveals that both the 
$\mathrm{M}$ protein and myosin CTL responses peak at seven days following exposure to antigen and diminish after eighteen days. This super-imposable kinetics of the responses against two distinct antigens suggests the presence of cross-reactive determinants shared by the two proteins. If the CTL response against myosin was induced by an indirect mechanism, one would expect the kinetics of this response to be distinct from that of M protein specific CTL. The capacity of M protein to maintain and enrich for the myosin reactive CTL in vitro further supports the existence of a shared CTL epitope. We intend to investigate the molecular basis for this cross-reactivity using synthetic peptides.

Another key finding in this study is the age dependence of the ability to mount a myosinreactive response following exposure to $S$. pyogenes. First, adult mice are quite capable of mounting a CTL response against myosin when immunized with purified rabbit myosin, yet immunization with S. pyogenes or M protein does not lead to the elicitation of myosin-reactive CTL in adult mice. Second, as shown in figure 4, the level of measurable lytic response against M protein was maintained despite the age of immunization, however, the level of the lytic response against myosin decreased steadily with the age of the mouse. A possible explanation for this is that the population of dual reactive $\mathrm{CD} 8^{+} \mathrm{T}$ cells prevailing early during ontogeny is replaced by $\mathrm{M}$ protein specific cells as a function of age. The myosin-reactive $\mathrm{CD} 8^{+}$cells may be deleted, anergized or merely outnumbered by those specific for M protein. This finding is reminiscent of earlier reports that demonstrate the ontogenic development of dominant idiotypes associated with bacterial polysaccharide antigens $(45$ - 47) and the loss of certain TCR V $\beta$ upon negative selection by endogenous viruses $(48,49)$. Thus a growing body of evidence suggests that autoreactive lymphocytes may be most easily activated during early life before the immune system is fully mature. Together, these findings help shape the theories about how autoimmune 
diseases develop. It is now believed that most autoimmune diseases originate in early life and are manifest as pathological conditions much later.

We have demonstrated here that in mice immunized with $S$. pyogenes early in life the myosin-reactive CTL remain as memory cells fully capable of a response when restimulated by either M protein or myosin much later in life. Interestingly, the myosin-reactive CTL pose no harm to the host suggesting that in this model system endogenous myosin is not released and that the epitopes recognized by these CTL are not presented by the host during their lifetime. Peak incidence of ARF is known to occur between the ages of five and fifteen, a time when the immune system is thought to be mature. Perhaps additional events, which may include reexposure to $S$. pyogenes, are necessary to precipitate the pathology of sequelae such as ARF. Our model system has thus permitted identification of potentially harmful CTL that can be induced by S. pyogenes prior to the manifestation of the autoimmune sequelae. Being able to detect such harmful lymphocytes before autoimmune diseases become debilitating would greatly benefit the design of intervention strategies. 

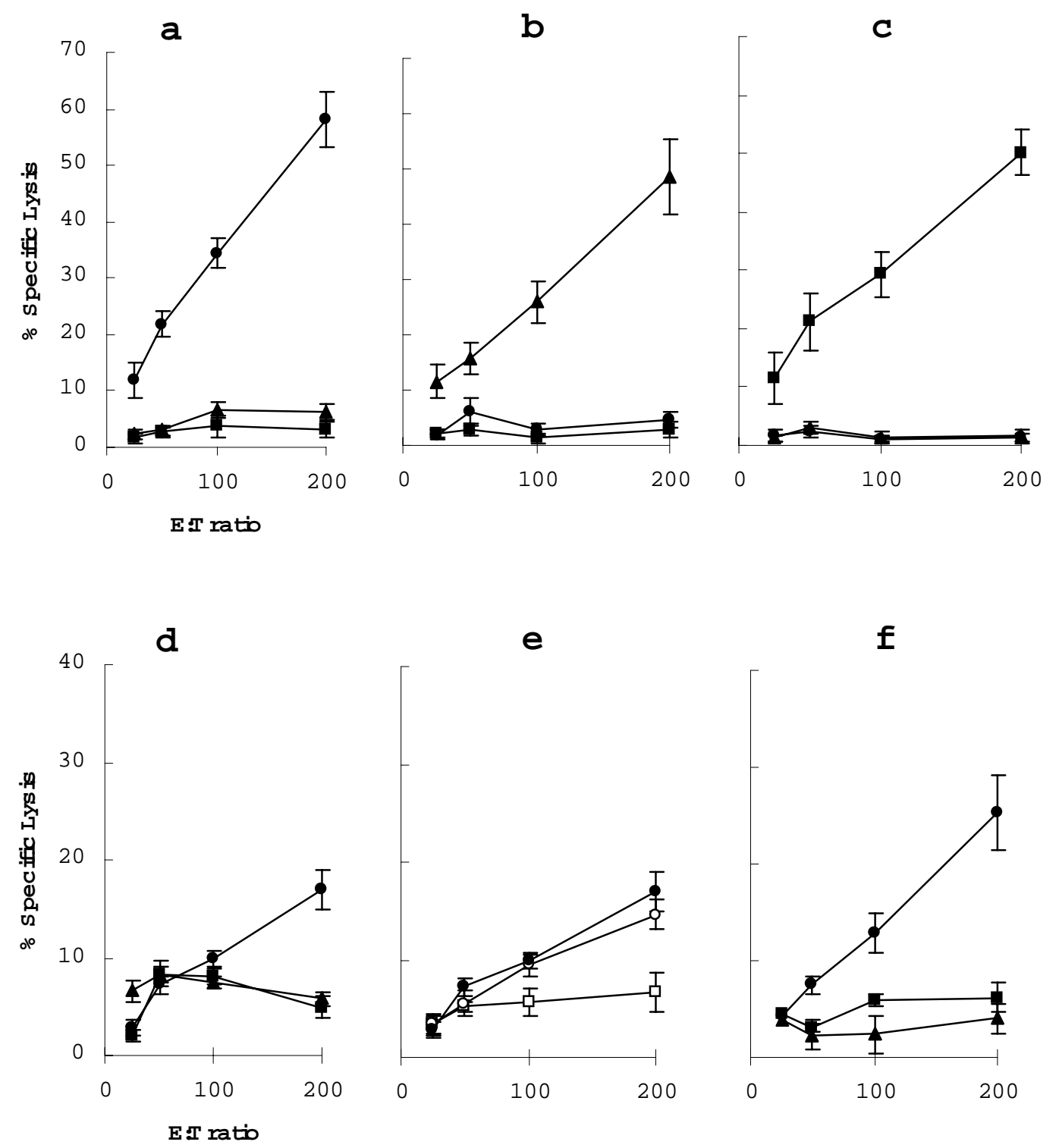

Figure 1. Analysis of cytolytic T cell responses induced in adult primed BALB/c mice. Groups of six to eight mice were immunized at least twice intraperitoneally (i.p.) with either $200 \mu \mathrm{g}$ of either recombinant $\mathrm{M}$ protein type 6 (a), crude mouse skeletal myosin extract (b) or bovine cytochrome c (c), or $2 * 10^{8}$ heat-killed D471 either twice $(\mathrm{d}, \mathrm{e})$ or four times $(\mathrm{f})$ as outlined in material and methods. Within 7 - 10 days following the last immunization spleen cells were harvested and assayed for cytolytic responses against P815 target cells labeled with tryptic digests of either recombinant M protein type 6 (MP) (O), cytochrome c (Cyt c) ( $\square$ ) or commercially prepared rabbit myosin (MY) ( $\mathbf{\Delta})$ starting at a 200:1 effector to target cell ratio. Assays in figure 1e demonstrate the lose of $M$ protein specific lysis in the presence of anti-CD4 (O) or anti-CD8 ( $\square$ ) monoclonal antibodies. Percent lysis is represented on the y-axis and the effector to target cell ratio is represented on the $\mathrm{x}$-axis. Error bars represent the standard error. 

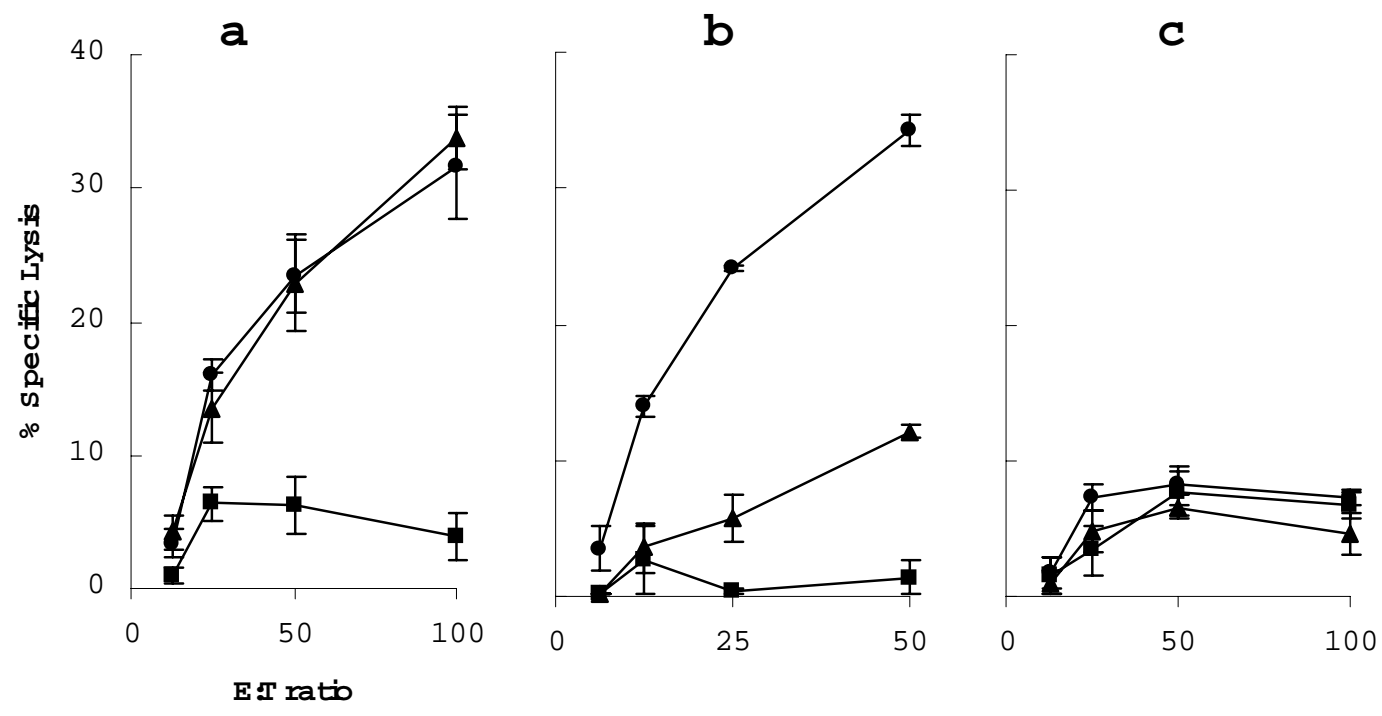

Figure 2. Analysis of myosin-specific CTL responses in BALB/c mice challenged as neonates with heat-killed S. pyogenes. Neonatal mice in groups of four were immunized i.p. within 7 days post partum with $2 * 10^{7}$ heat-killed D471 or UAB152 (a and c, respectively) or with $5 \mu \mathrm{g}$ of recombinant MP (b). Spleen cells were harvested and assayed for antigen specific CTL responses against MP $(\boldsymbol{\bullet})$, Cyt c $(\boldsymbol{\square})$, or MY $(\mathbf{\Delta})$. The y-axis represents percent lysis and the effector to target cell ratio is represented on the x-axis. Each point is the geometric mean for that group while the error bars represent the standard error. 


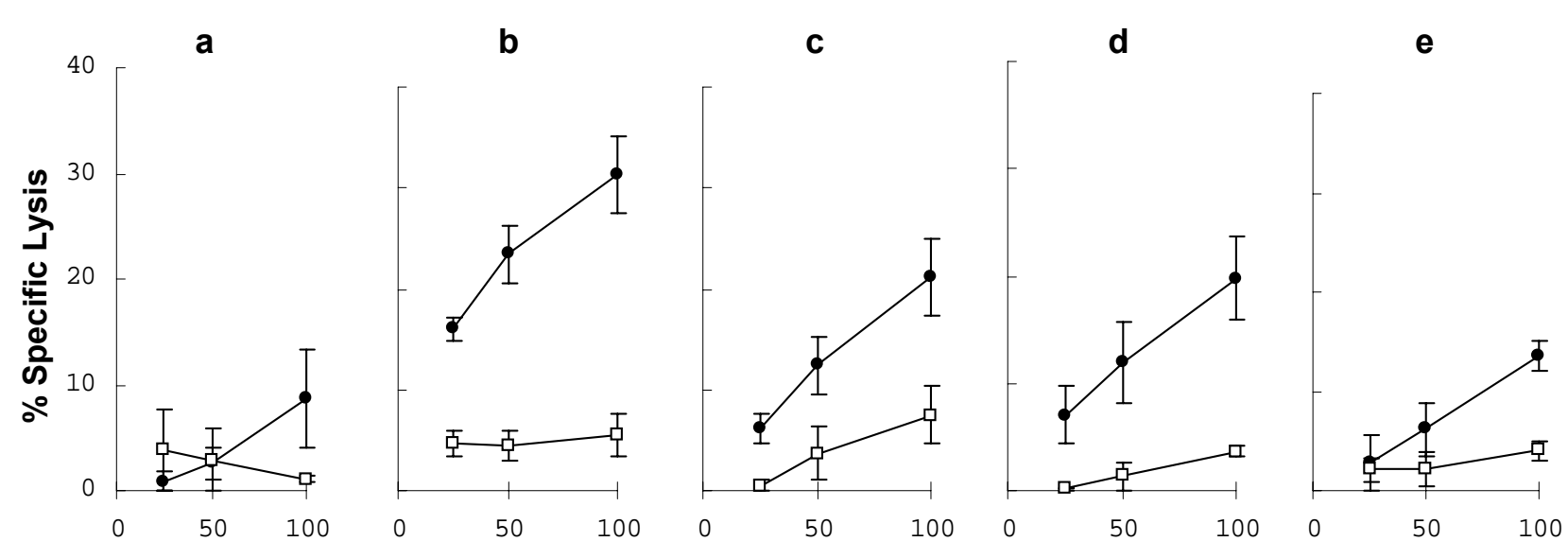

\section{E:T ratio}
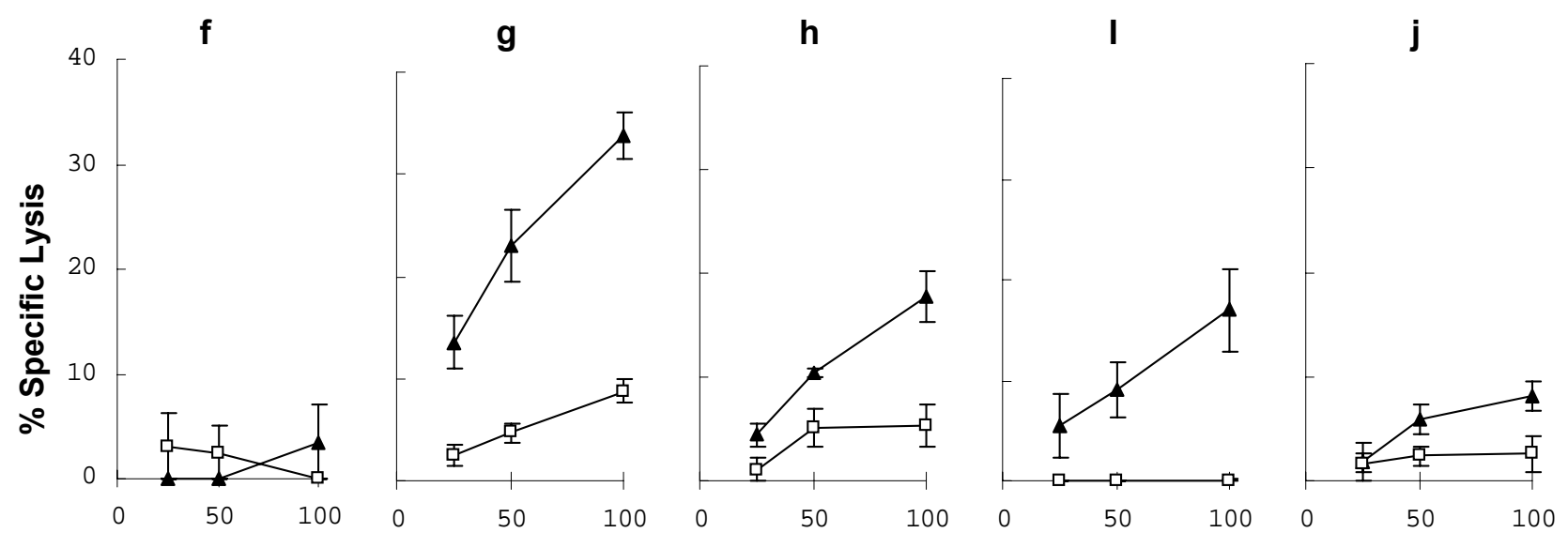

\section{E:T ratio}

Figure 3. Kinetics of the myosin-specific CTL response elicited in BALB/c mice primed as neonates with heat-killed D471. Groups of four mice were immunized i.p. within 48 hours of birth with $2 * 10^{7}$ heat-killed D471 and spleen cells were harvested at various timepoints including day $4(\mathrm{a}, \mathrm{f})$, day $7(\mathrm{~b}, \mathrm{~g})$, day $10(\mathrm{c}, \mathrm{h})$, day $13(\mathrm{~d}, \mathrm{i})$, and day $18(\mathrm{e}, \mathrm{j})$ following immunization. Assays were conducted with E:T ratios starting at 100:1 to measure the MP $(\mathbf{O})(\mathrm{a}-\mathrm{e})$ and MY (A) $(\mathrm{f}-\mathrm{j})$ specific CTL responses, as well as, to determine if the responses could be inhibited by the addition to the assay of anti-CD8 ( $\square$ ) monoclonal antibody. 

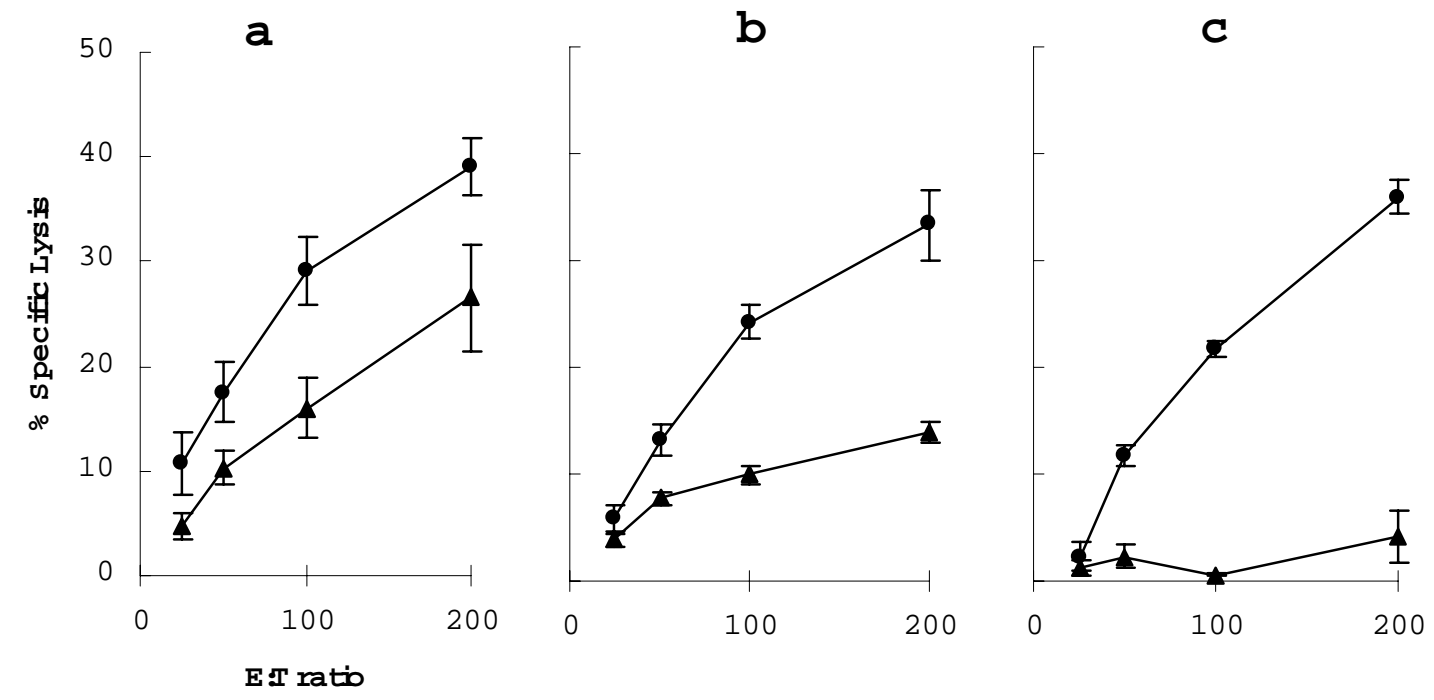

Figure 4. The role of age in the induction of a myosin specific CTL response. Groups of 5 mice were immunized with $2 * 10^{7}$ heat-killed D471 at either day 10, day 22 or day 30 post partum. CTL assays were performed on spleens cells for antigen specific responses against MP (O), or MY ( $\boldsymbol{\Delta})$. Lytic responses to target cells loaded with tryptic digest of the irrelevant control antigen cytochrome c are not shown. Error bars represent standard error. 

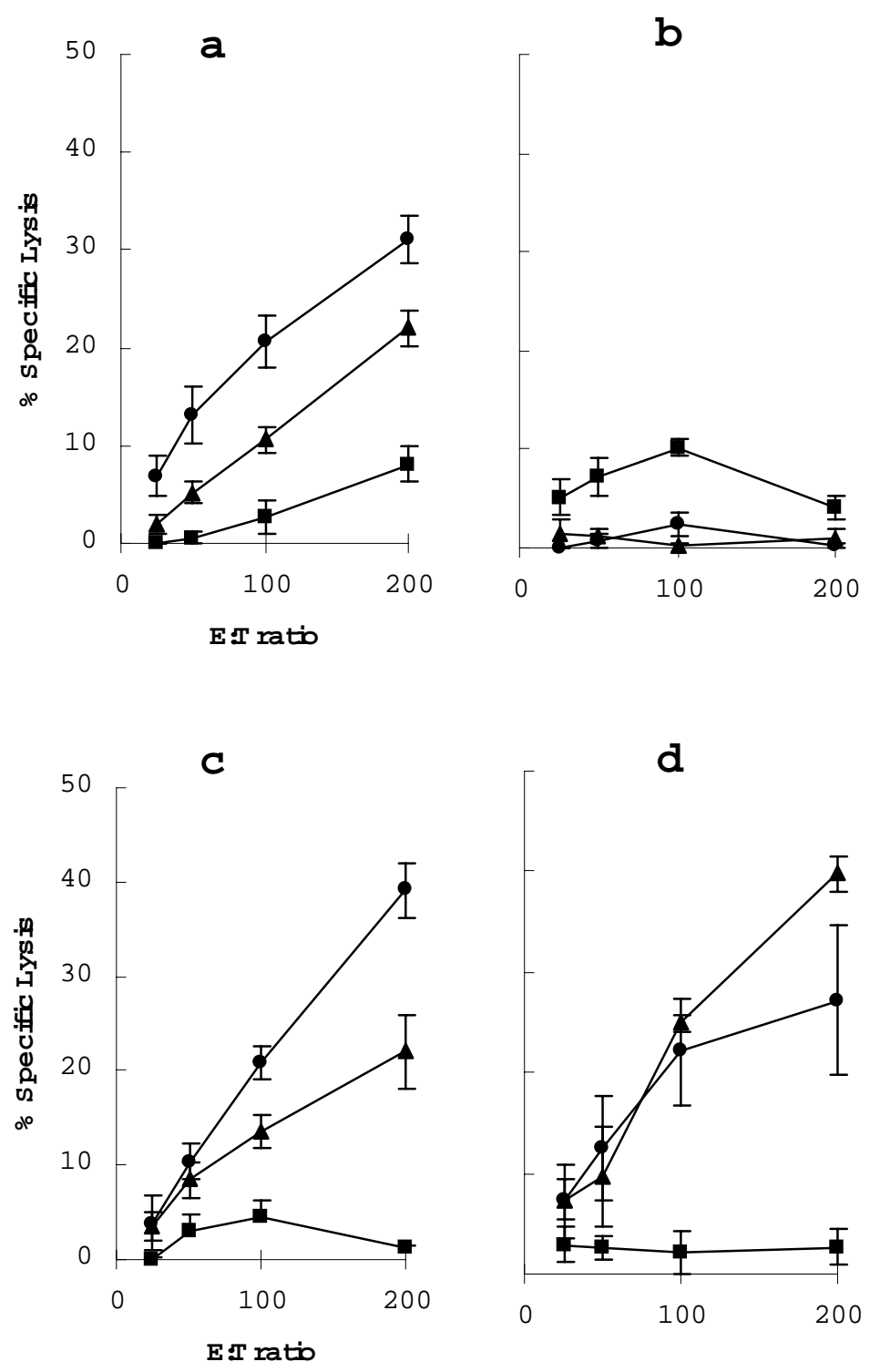

Figure 5. Requirement of $M$ protein during neonatal exposure of $S$. pyogenes for the induction of a myosin-specific CTL response. Groups of 3 - 5 mice were initially immunized i.p. within 7 days of birth with $2 * 10^{7}$ heat-killed D471 and boosted as adults with either an immunogenic dose of either D471 (a), UAB152 (b), mouse myosin extract (d) or recombinant M protein (c). Within 7 days of the last immunization spleen cells were harvested and assayed for CTL responses against MP (O), MY ( $\mathbf{\Delta})$ or Cyt c ( $\mathbf{\square})$. Bars represent standard error. 

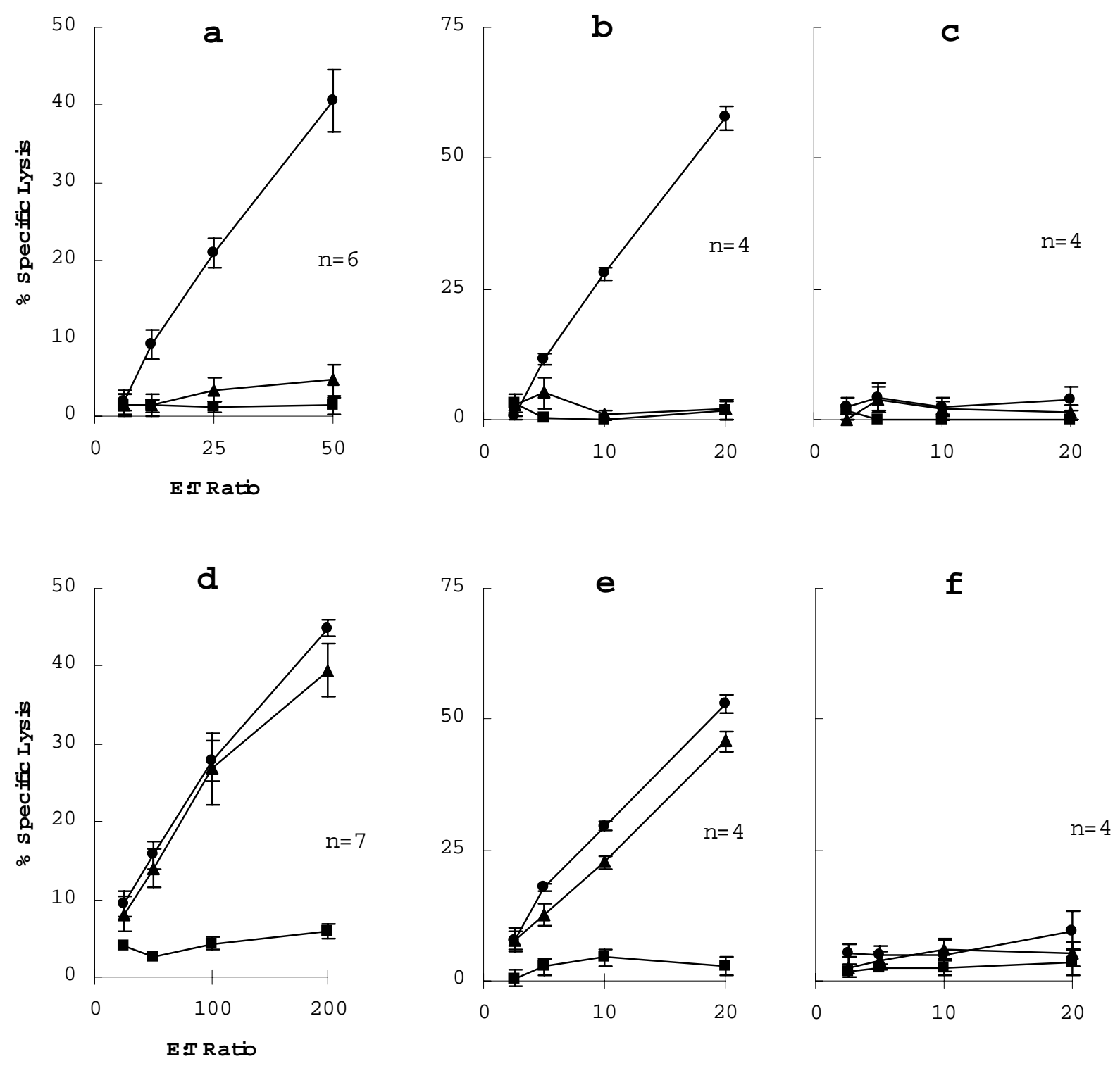

Figure 6: $\mathrm{CTL}$ activity of $\mathrm{CD} 8^{+}$enriched splenocytes before and after culturing with recombinant streptococcal M protein. Mice were immunized as adults (a - c) with $100 \mu \mathrm{g}$ of M6 or within three days of birth with $2 * 10^{7}$ heat-killed D471 (d - f). Splenocytes were harvested and enriched for $\mathrm{CD} 8^{+}$cells as outlined in material and methods. Enriched cells were either assayed directly (a, d) against MP $(\bullet)$, MY $(\boldsymbol{\Delta})$ or Cyt c $(\boldsymbol{\square})$ or placed into culture with tryptic digests of M6 (b, e) or Cyt c (c, f) for five days before being assayed against the same antigens. Percent specific lysis is represented on the y-axis and the effector to target cell ratio on the $\mathrm{x}$-axis. $\mathrm{y}$-axis error bars represent standard error and the $\mathrm{n}$ value indicates the number of experimental groups represented in each graph. 


\section{REFERENCES}

1. Stevens, D. 1992. Invasive Group A streptococcus infections. Clin. Infect. Dis. 14:2-13.

2. Stollerman, G. 1991. Rheumatogenic streptococci and autoimmunity. Clin. Immunol. Immunopath. 61:131-142.

3. Ayoub, E. M., and C. S. Chun. 1990. Nonsuppurative complications of group A streptococcal infection. Adv. Pediatr. Infect. Dis. 5:69-92.

4. Dajani, A. S. 1992. Guidelines for the diagnosis of rheumatic fever. Jones Criteria, 1992 update. Special writing group of the Committee on Rheumatic Fever, Endocarditis, and Kawasaki Disease of the Council on Cardiovascular Disease in the Young of the American Heart Association. JAMA 268:2069-2073.

5. Raizada, V., R. C. J. Williams, P. Chopra, N. Gopinath, K. Prakash, K. B. Sharma, K. M. Cherian, S. Panday, R. Arora, M. Nigam, J. B. Zabriskie, and G. Husby. 1983.

Tissue distribution of lymphocytes in rheumatic heart valves as defined by monoclonal anti-T cell antibodies. Am. J. Med. 74:90-96.

6. Kenemy, E., T. Grieve, R. Marcus, P. Sareli, and J. B. Zabriskie. 1989. Identification of mononuclear cells and T cell subsets in rheumatic valvulitis. Clin. Immunol. Immunopath. 52:225-237.

7. Cairns, L. M. 1988. The immunology of rheumatic fever. N Z Med J 101:388-391.

8. Cunningham, M., and S. Russell. 1983. Study of heart-reactive antibody in antisera and hybridoma culture fluid against Group A Streptococci. Infect. Immun. 42:531-538.

9. Eichbaum, Q. G., E. J. Hughes, J. E. Epstein, and D. W. Beatty. 1995. Rheumatic fever: autoantibodies against a variety of cardiac, nuclear, and streptococcal antigens. Ann. Rheum. Dis. 54:740-743.

10. Guilherme, L., E. Cunha-Neto, V. Coelho, R. Snitcowsky, P. M. A. Pomerantzeff, R. V. Assis, F. Pedra, J. Neumann, A. Goldberg, M. E. Patarroyo, F. Pileggi, and J. Kalil. 1995. Human heart-infiltrating $T$ cell clones from rheumatic heart disease patients recognize both streptococcal and cardiac proteins. Circulation 92:415-420.

11. Friedman, I., A. Laufer, N. Ron, and A. Davies. 1971. Experimental myocarditis: In vitro and in vivo studies of lymphocytes sensitized to heart extracts and group A streptococci. Immunol. 20:225-232.

12. Yoshinaga, M., F. Figueroa, M. R. Wahid, R. H. Marcus, E. Suh, and J. B. Zabriskie. 1995. Antigenic specificity of lymphocytes isolated form valvular specimens of rheumatic fever patients. J. Autoimmun. 8:601-613. 
13. Cunningham, M. W., J. M. McCormack, and P. G. Fenderson. 1989. Human and murine antibodies cross-reactive with streptococcal M protein and myosin recognize the sequence GLN-LYS-SER-LYS-GLN in M protein. J. Immunol. 143:2677-2683.

14. Pruskakorn, S., B. Currie, E. Brandt, C. Phornphutkl, H. Somchai, A. Manmontri, J. Robinson, M. Kehoe, A. Galbraith, and M. Good. 1994. Identification of T cell autoepitopes that cross-react with the C-terminal segment of the M protein of Group A streptococci. Int. Immunol. 6:1235-1244.

15. Robinson, J. H., and M. A. Kehoe. 1992. Group A streptococcal M proteins: virulence factors and protective antigens. Immunol. Today 13:362-367.

16. Tomai, M., M. Kotb, G. Majumdar, and E. H. Beachey. 1990. Superantigenicity of streptococcal M protein. J. Exp. Med. 172:359-362.

17. Tomai, M., J. Aelion, M. Dockter, G. Majumdar, D. Spinella, and M. Kotb. 1991. T cell receptor $\mathrm{V}$ gene usage by human $\mathrm{T}$ cells stimulated with the superantigen streptococcal $\mathrm{M}$ protein. J. Exp. Med. 174:285-288.

18. el-Demellawy, M., R. el-Ridi, N. Guirguis, M. Abdel Alim, A. Kotby, and M. Kotb. 1997. Preferential recognition of human myocardial antigens by T lymphocytes from rheumatic heart disease patients. Infect. Immun. 65:2197-2205.

19. Dale, J. B., and E. H. Beachey. 1987. Human cytotoxicity T lymphocytes evoked by Group A streptococcal M proteins. J. Exp. Med. 166:1825-1835.

20. Butler-Brown, G., and R. Whalen. 1984. Myosin isozyme transitions occurring during the postnatal development of the rat soleus muscle. Dev. Biol. 102:324-334.

21. Ralph, P., M.A. Moore, K. Nilsson. 1976. Lysozyme synthesis by established human murine histiocytic lymphoma cell lines. J. Exp. Med. 143:1528-1533.

22. Bryant, J., R. Day, T. L. Whiteside, R. B. Herberman. 1992. Calculation of lytic units for the expression of cell-mediated cytotoxicity. J. Immunol. Methods. 146:91-103.

23. Maverakis, E., J. T. Beech, S. S. Wilson, A. Quinn, B. Pederson, and E. E. Sercarz. 2000. T cell receptor complementarity determining region 3 length analysis reveals the absence of a characteristic public $\mathrm{T}$ cell repertoire in neonatal tolerance: The response in the "tolerant" mouse within the residual repertoire is quantitatively similar but qualitatively different. J. Exp. Med. 191:695-702.

24. Piguet, P. F., C. Irle, E. Kollatte, and P. Vassalli. 1981. Post-thymic T lymphocyte maturation during ontogenesis. J. Exp. Med.:581-593. 
25. Singh, R. R., B. Hahn, and E. Sercarz. 1996. Neonatal peptide exposure can prime T cells and upon subsequent immunization, induce their immune deviation: Implications for antibody vs. T cell mediated autoimmunity. J. Exp. Med. 183:1613-1621.

26. Adkins, B., and R. Du. 1998. Newborn mice develop balanced Th1/Th2 primary effector responses in vivo but are biased to Th2 secondary responses. J. Immunol. 160:4217-4224.

27. Manjula, B. N., and V. A. Fischetti. 1980. Tropomyosin-like seven residue periodicity in three immunologically distinct streptococcal $\mathrm{M}$ proteins and its implications for the antiphagocytic property of the molecule. J. Exp. Med. 151:695-708.

28. Manjula, B. N., B. L. Trus, and V. A. Fischetti. 1985. Presence of two distinct regions in the coiled-coil structure of the streptococcal Pep M5 protein: relationship to mammalian coiled-coil proteins and implications to its biological properties. Proc. Natl. Acad. Sci., USA 82:1064-1068.

29. Kotb, M., H. S. Courtney, J. B. Dale, and E. H. Beachey. 1989. Cellular and biochemical responses of human T lymphocytes stimulated with streptococcal M proteins. J. Immunol. 142:966-970.

30. Yang, L., P. Soprey, M. Wittner, and E. Fox. 1977. Streptococcal-induced cell mediated immune destruction of cardiac myofibers in vitro. J. Exp. Med. 146:344-360.

31. Dal Canto, M. C., R. W. Melvold, B. S. Kim, and S. D. Miller. 1995. Two models of multiple sclerosis: experimental allergic encephalomyelitis (EAE) and Theiler's murine encephalomyelitis virus (TMEV) infection. A pathological and immunological comparison. Microsc. Res. Tech. 32:215-229.

32. Rose, N. R., A. Herskowitz, and D. A. Neumann. 1993. Autoimmunity in myocarditis: models and mechanisms. Clin. Immunol. Immunopath. 68:95-99.

33. Dos Reis, G., M. Gaspar, and M. Barcinski. 1982. Immune recognition in the streptococcal carditis of mice: The role of macrophages in the generation of heart-reactive lymphocytes. J. Immunol. 128:1514-1521.

34. Cromartie, W., and J. Craddock. 1966. Rheumatic-like cardiac lesions in mice. Science 154:285-287.

35. Jiang, H., S. I. Zhang, and B. Pernis. 1992. Role of $\mathrm{CD}^{+} \mathrm{T}$ cells in murine experimental allergic encephalomyelitis. Science 256:1213-1215.

36. Wang, B., A. Gonzalez, C. Benoist, and D. Mathis. 1996. The role of CD ${ }^{+}$T cells in the initiation of insulin-dependent diabetes mellitus. Eur. J. Immunol. 26:1762-1769. 
37. Harding, C. V. 1996. Class I MHC presentation of exogenous antigens. J. Clin. Immunol. 16:90-96.

38. Pfeifer, J. D., M. J. Wick, R. L. Roberts, K. Findlay, S. J. Normark, and C. V. Harding. 1993. Phagocytic processing of bacterial antigens for class I MHC presentation to T cells. Nature 361:359-362.

39. Kovacsovics-Bankowski, M., and K. L. Rock. 1995. A phagosome-to-cytosol pathway for exogenous antigens presented on MHC class I molecules. Science 267:243-246.

40. Hagman, M. M., J. B. Dale, and D. L. Stevens. 1999. Comparison of adherence to and penetration of a human laryngeal epithelial cell line by group A streptococci of various $\mathrm{M}$ protein types. FEMS Immunol. Med. Microbiol. 23:195-204.

41. Forsthuber, T., H. Yip, and P. Lehmann. 1996. Induction of Th1 and Th2 immunity in neonatal mice. Science 271:1728-1730.

42. Sarzotti, M., D. Robbins, and P. Hoffman. 1996. Induction of protective CTL responses in newborn mice by a murine retrovirus. Science 271:1726-1728.

43. Siegrist, C., F. Saddallah, C. Tougne, X. Martinez, J. Kovarik, and P. Lambert. 1998. Induction of neonatal Th1 and CTL responses by live viral vaccines: a role for replication patterns within antigen presenting cells? Vaccine 16:1473-1478.

44. Pilarski, L. 1977. Ontogeny of cell-mediated immunity. I. Early development of alloantigenspecific cytotoxic T-cell precursors in postnatal mice. J. Exp. Med. 146:887-892.

45. Vakil, M., D. E. Briles, J. F. Kearney. 1991. Antigen-independent selection of T15 idiotype during B-cell ontogeny in mice. Dev. Immunol. 1:203-212.

46. Klinman, N. R. 1976. The acquisition of b-cell competence and diversity. Am. J. Pathol. 85:693-703.

47. Bona, C., R. Lieberman, C. Chien, J. Mond, K. Stein, S. House, I. Green, W. Paul. 1978. Immune response to levan. I. Kinetics and ontogeny of anti-levan and anti-inulin antibody response and of expression of cross-reactive idiotype. J. Immunol. 120:1436-1442.

48. Ignatowicz, L., J. Kappler, and P. Marrack. 1992. The effects of chronic infection with a superantigen-producing virus. J. Exp. Med. 175:917-923.

49. Scherer, M. T., L. Ignatowicz, A. Pullen, J. Kappler, and P. Marrack. 1995. The use of mammary tumor virus (Mtv)-negative and single-Mtv mice to evaluate the effects of endogenous viral superantigens on the T cell repertoire. J. Exp. Med. 182:1493-1504. 
Myosin-reactive CTL are induced in neonatal mice by the C-terminal conserved region of the streptococcal $M$ protein

Cynthia Cunningham and Meenal Elliott 


\begin{abstract}
Previously, we have shown that neonatal, but not adult, BALB/c mice primed with heatkilled Streptococcus pyogenes strain D471 (serotype M6) develop a cytotoxic T cell response to both streptococcal M protein type 6 (MP) and mammalian myosin. To determine if the elicitation of a myosin-reactive CTL response is exclusive to rheumatogenic serotypes of $S$. pyogenes, neonatal BALB/c mice were immunized with non-rheumatogenic streptococcal strains B737 (M49), H3 (M12) and J17A4 (M-type unknown). Mice immunized with J17A4 mounted a myosin-reactive CTL response comparable to that elicited by D471, and mice treated with B737 or H3 mounted a weaker myosin-reactive cytolytic response than that elicited by D471 and J17A4. Screening for cytolytic responses against myosin purified from hearts and two hindlimb muscles suggested that myosin-reactive CTL induced by D471 and J17A4, but not B737 and H3, are primarily mediated against neonatal cardiac myosin. This myosin-reactive cytolytic response was seen in conjunction with a response against the carboxy-terminal conserved region of $\mathrm{M}$ protein. Furthermore, mice primed with recombinant protein consisting of the carboxy terminal region of MP or D471 treated with pepsin to cleave away the variable amino terminus of M protein elicited a response to myosin, whereas, mice treated with the variable amino-terminal region of $\mathrm{M}$ protein did not. Taken together, these results suggest that carboxy terminal region of $\mathrm{M}$ protein, which is under consideration as a vaccine candidate, contains an epitope that is capable of inducing a myosin-specific CTL response in neonatal BALB/c mice.
\end{abstract}




\section{INTRODUCTION}

Group A streptococcus is a common human pathogen that primarily causes skin and nasopharyngeal infections (1). One of the potential consequences of an untreated streptococcal pharyngeal infection is acute rheumatic fever (ARF), an autoimmune manifestation that primarily targets the joints and heart (4 - 6). While it is widely accepted that ARF is the result of an immune response evoked by GAS $(4-6,13-15)$, the exact mechanism by which the infection triggers disease in a susceptible host remains unclear. Virulence factors expressed by GAS are known to share epitopes with mammalian proteins and it has been suggested that this molecular mimicry has the potential to elicit auto-reactive responses that may initiate tissue destruction (7 13). Such virulence factor is the anti-phagocytic factor M protein, an alpha helical coiled-coil surface protein of which exists more than 80 different serotypes based upon the antigentically variable amino terminal region $(2,3)$. Antigenic determinants within the carboxy terminal $\mathrm{C}$ repeat region allow most $\mathrm{M}$ protein serotypes to fall into one of two major classes of $\mathrm{M}$ protein. At the molecular level, specific amino acids marking key residues within the $\mathrm{C}$ repeat region distinguish class I M protein from class II (42). Nearly all serotypes of GAS that have been associated with ARF have been shown to express class I M protein (42).

In vitro and in vivo studies have shown that $\mathrm{M}$ protein has the potential to induce cytotoxic $\mathrm{T}$ cell responses that have the capacity to kill myocardial cells (16 - 18). Furthermore, extensive in vitro studies suggest that ARF patients can harbor lymphocytes that exhibit crossreactive responses to both $M$ protein and cardiac proteins (19 - 21). M protein serotypes that have been associated with ARF, especially M5, have been shown to act as superantigens to human $\mathrm{T}$ cells displaying particular $\mathrm{V} \beta$ gene elements (24 - 26), however, this has been disputed 
$(22,23)$ and numbers of $T$ cells expressing these $\mathrm{V} \beta$ are not elevated in patients with RHD (27). Furthermore, peptides from the conserved region of M5 have been shown to induce human T cells to cross-react with cardiac proteins $(2,29,30)$. In attempts to design an effective safe vaccine for GAS, Good et al. and Robinson et al. have used M5 peptides to map the major CD4 T cell epitopes of M protein, especially the conserved carboxy terminal region (29 - 31). While they have been able to identify immunogenicity of M5 peptides that fail to induce myosinreactive $\mathrm{T}$ cell responses in adult mice, these peptides have not been tested in neonatal mice. Our previous studies and this one indicate that myosin-specific $\mathrm{T}$ cell responses are easily induced in neonatal mice (28).

Since the peak incidence of ARF and AGN in humans is in children of school age and preschool age, respectively, the focus of our research has been to identify abnormal immune responses induced by $S$. pyogenes in neonatal inbred mice and characterize the basis for these responses at a molecular level. We have previously observed that neonatal, but not adult mice immunized with heat-killed D471 (M6 serotype), develop cytotoxic T cell responses against mammalian myosin and that $\mathrm{M}$ protein is required for the induction of this response (28). Also, these neonatally treated mice develop myosin cross-reactive antibodies that recognize the cardiac specific isoforms of myosin (37). We have undertaken the current study to determine if the CTL response elicited by $S$. pyogenes could distinguish endogenous (mouse) isoforms of cardiac myosin from skeletal isoforms and to determine which region of $\mathrm{M}$ protein was responsible for the induction of this myosin-reactive CTL response. We report that $S$. pyogenes can elicit a CTL response in neonatal mice that preferentially recognizes the cardiac isoforms of mouse myosin. In addition, our results indicate that it is the conserved carboxy-terminal region of $\mathrm{M}$ protein is capable of inducing a CTL response to myosin, however, in both neonatal and adult mice. These 
results are important in light of the fact that the carboxy-terminal of $\mathrm{M}$ protein it is currently being considered as a candidate for a GAS vaccine (29 - 33).

\section{MATERIAL AND METHODS}

Mice:

BALB/c mice were purchased from Jackson Laboratories and bred in our animal facilities.

Immunization with heat-killed S. pyogenes:

S. pyogenes strains D471 (serotype M6), UAB152 (chapter2), H3 (M12), J17A4 (non-typable) and B737 (M49) (ATCC) were grown overnight in Todd-Hewitt broth and heat-killed with incubation at $65^{\circ} \mathrm{C}$ for 1 hour. They were then washed five times in $0.85 \%$ saline adjusted to a

density of $10^{9}-10^{10} / \mathrm{ml}$ and stored at $-20^{\circ} \mathrm{C}$. To prepare $\mathrm{D} 471^{*}$, heat-killed culture was adjusted to $\mathrm{pH} 2.0$ with $\mathrm{HCl}$ and treated pepsin for 1 hour at $37^{\circ} \mathrm{C}$, neutralized with $\mathrm{NaOH}$, and washed and resuspended in $0.85 \%$ saline (32). Neonatal mice were immunized by intraperitoneal route (i.p.) with either $5 * 10^{6}$ heat-killed $S$. pyogenes strains D471, D471*, UAB152, H3, J17A4 or B737 diluted in $50 \mathrm{ml}$ Dulbecco's saline. Controls received saline only. The mice were subsequently boosted i.p. at 3 weeks of age with $10^{8}$ organisms of the corresponding heat-killed vaccine in $0.1 \mathrm{ml}$ of Dulbecco's saline.

Cloning of M protein and its fragments:

Cloning, expression, and purification of MP6 have been described (28). The amino and carboxy terminal $\mathrm{M}$ protein fragments $\mathrm{AB}$ and $\mathrm{C}$ were generated by subcloning the Nco1 Bsp1286I (AB region) and Bsp1286I - Xho1 (C region) into pET20b(+) and transformed in 
BL21(DE3):pLysS. Cells were grown to $\mathrm{OD}_{600}$ of 0.5 and induced with IPTG for one hour, harvested by centrifugation and lysed by resuspension in $8 \mathrm{M}$ urea. The his-tagged recombinant proteins were purified using Ni-NTA super flow resin (Qiagen). The purified proteins were dialyzed extensively against Dulbecco's PBS and stored at $-20^{\circ} \mathrm{C}$.

\section{Preparation of mouse myosin:}

Myosin was prepared from mouse skeletal (gastrocnemius and soleus) and hearts (1 day old mice) or heart ventricle tissue (adult mice) essentially as described by Margossian et al. (33). Briefly, crude muscle extracts were prepared by mincing tissue in four volumes/wt extraction buffer $\left(0.3 \mathrm{KCl}, 0.15 \mathrm{M} \mathrm{KH}_{2} \mathrm{PO}_{4}(\mathrm{pH} 6.5), 0.02 \mathrm{M}\right.$ EDTA, and $\left.5 \mathrm{mM} \mathrm{MgCl}_{2}\right)$ and incubated on ice for $15 \mathrm{~min}$. Samples were precipitated with 10 volumes of cold deionized water and placed at $4^{\circ} \mathrm{C}$ for at least 3 hours or overnight. Precipitate was collected with centrifugation at $9000 \mathrm{rpm}$ for $25 \mathrm{~min}$ at $4^{\circ} \mathrm{C}$, resuspended in a minimal volume of $1.0 \mathrm{M} \mathrm{KCl}, 25 \mathrm{mM}$ EDTA, $0.06 \mathrm{M}$, $\mathrm{KH}_{2} \mathrm{PO}_{4}\left(\mathrm{pH}\right.$ 6.5) buffer, and dialyzed against 30 volumes of $0.6 \mathrm{M} \mathrm{KCl}, 25 \mathrm{mM} \mathrm{KH}_{2} \mathrm{PO}_{4}(\mathrm{pH}$ 6.5), $10 \mathrm{mM}$ EDTA, $1 \mathrm{mM}$ DTT buffer. The precipitation and dialysis were repeated once more. Samples were filter sterilized and protein concentrations were determined by $D_{c}$ protein colormetric assay (Bio-Rad). The samples were then aliquoted and stored in aliquots at $-20^{\circ} \mathrm{C}$.

\section{Electrophoresis of myosin:}

Mouse myosin preparations were electrophoresed onto either standard 8\% SDS-PAGE gels as previously described (34) or $8 \%$ acrylamide gels with $30 \%$ glycerol using a Mini-PROTEAN II electrophoresis system (Bio-Rad). Preparation and execution of $8 \%$ acrylamide gels with 30\% glycerol were carried out as previously described (36), however, with the addition of 2- 
mercaptoethanol in the running buffer of the upper reservoir at a final concentration of $10 \mathrm{mM}$ (50). Following electrophoresis gels were stained with either Coomassie G-250 (Bio-Rad) or silver stain (Bio-Rad Silver Stain Plus Kit).

CTL assay:

CTL assays were carried out as described before (28). Briefly, P815 cells were pulsed with tryptic digests of $\mathrm{M}$ protein, $\mathrm{AB}, \mathrm{CD}$, the mouse myosins or the control protein cytochrome $\mathrm{c}$ at 1 $\mathrm{mg} / 2 * 10^{5}$ cells. Single cell suspensions of effector spleen cells were plated with MHC matched P815 cells at an E/T ratios of 200, 100, 50 25, unless otherwise noted, in phenol red-free RPMI with $2.5 \%$ fetal calf serum and incubated at $37^{\circ} \mathrm{C}$ for approximately 5 hours. Controls included spontaneous release of effector and target cells, maximum release of targets and media background. Supernatants were harvested and assayed using a non-radioactive colorimetric cytotoxicity assay kit (Cytotox96, Promega). Absorbance was read at $490 \mathrm{~nm}$. Percent lysis was calculated as follows:

Experimental release- Effector spontaneous release - Target spontaneous release Target maximum release - Target spontaneous release

\section{RESULTS}

Enrichment of myosin heavy chain isoforms from mouse muscle

The relative distribution of distinct isoforms in various muscles in inbred mice has been described (39 - 41). We isolated myosin from BALB/c mice from two hindlimb muscles of adult mice and from hearts of newborn and adult mice (figure 1). Myosin was enriched from crude extracts (fig. 1a), and although the myosin preparations are not completely free of contaminants (fig. 1b) we were able to achieve preparations with greater than $90 \%$ homogeneity. To visually 
determine the myosin isoform composition of each enriched myosin sample they were electrophoresed under stringent conditions that take advantage of the subtle molecular differences between the isoforms and allow adequate separation. In figure $1 \mathrm{~b}$, the enriched myosin samples were electrophoresed onto an $8 \%$ acrylamide gel containing $30 \%$ glycerol for 24 hours as described in material and methods. As seen in figure $1 \mathrm{~b}$ (lane 1) the neonatal heart contains both alpha and beta myosin isoforms, while the adult ventricular tissue (lane 2) is composed of solely of alpha myosin. The gastrocnemius (lane 3) is composed predominantly of the type IIb and type IIx/IId isoforms with a small amount of IIa and almost type I isoform. On the other hand, the soleus (lane 4) contains approximately an equal amount type I than type IIa with a negligible amount of the type IIb and IIx/IId isoforms. Therefore, we could determine whether the myosin CTL epitopes are shared by most mouse myosin isoforms or are restricted to isoforms expressed in specific muscle tissues. Therefore, the adult heart ventricle will serve as an indicator for responses specific for alpha cardiac myosin and can be compared to responses observed against the neonatal heart and soleus to determine reactivity against the beta cardiac isoform. Responses that recognize the gastrocnemius and not the soleus can most likely be attributed to the IIb isoform, while responses against both the gastrocnemius and soleus would suggest that the response is recognizing an isoform shared between them.

\section{CTL primed by streptococcal M protein recognize the cardiac isoforms of mouse myosin}

Mice were immunized within one week of birth with D471 or UAB152 (MP - variant of D471) and sacrificed seven days following the booster (material and methods). Splenocytes were harvested and assayed for the presence of CTL as outlined in material and methods. Previous results have shown us that D471 can induce a CTL response against rabbit myosin (28), 
therefore, this experiment would test whether mouse myosin would be recognized by the M protein reactive CTL. As shown in figure 2, immunization with D471 is capable of inducing a CTL response against mouse myosin thus confirming that the endogenous mouse myosin can be recognized by myosin-reactive CTL primed by $S$. pyogenes. The CTL response induced by D471 against myosin from the neonatal heart and soleus is comparable to that measured against rabbit myosin, and greater in magnitude than that against the gastrocnemius and adult heart ventricular myosin. These results show that the myosin-reactive CTL response is capable of recognizing all mouse myosin isoforms to varying degrees, but because the response against the neonatal heart and soleus is greater, this would suggest that the myosin-reactive CTL response preferentially recognizes the beta (type I) myosin isoform. Immunizing mice with UAB152 does not induce a CTL response against myosin, whether of rabbit or mouse origin, thus indicating that the CTL responses against the mouse myosin induced by D471 are specific and mediated by M protein.

Myosin-specific CTL may be primed by non-rheumatogenic S. pyogenes serotypes

Strain D471 represents the M6 serotype, which is commonly associated with ARF. The association of this strain with CTL response against cardiac myosin suggests a possible contribution to the pathology associated with ARF and rheumatic heart disease (RHD). We therefore chose to test whether other serotypes of S. pyogenes, particularly those not associated with ARF, were capable of inducing a myosin reactive CTL response against mouse cardiac myosin. We selected strains H3 (serotype M12) and B737 (M49), isolated from the nasopharynx and skin of patients presenting with AGN, respectively. Other strains expressing the M12 or M49 protein have not been associated with ARF. As previously discussed, $S$. pyogenes serotypes 
M6 and M12 belong to class I while M49 belongs to class II (42). In addition, we chose strain J17A4, a non-M typable strain from.

Newborn mice were immunized as described above and in material and methods and CTL assays were performed seven days following boosters at 3 - 4 weeks of age. As shown in figure 3, in mice immunized with J17A4 mounted a CTL response to MP6 that is comparable to that mounted by D471 (fig. 2), while H3 and B737 mounted a weaker response. This is not surprising since the M proteins are antigentically distinct with small regions of shared homology. Both J17A4 and H3 could induce a CTL response against rabbit, however, B737 did not. Mice immunized with J17A4 mounted a CTL response to cardiac myosin isolated from neonatal mice comparable in magnitude to that seen in mice immunized with D471. However, the CTL response against myosin from soleus was poor. In comparison, mice immunized with $\mathrm{H} 3$ or B737, we failed to detect strong CTL responses against any of the mouse myosins. Thus, at least one non-rheumatogenic strain of $S$. pyogenes was capable of inducing a CTL response against neonatal cardiac myosin.

The conserved region of $M$ protein is responsible for myosin-reactive CTL response in mice To investigate further the role of $\mathrm{M}$ protein in the induction of myosin-reactive CTL, we generated subclones of the plasmid containing the cloned emm6 gene to express the amino terminal half of the $\mathrm{MP}_{6}$ containing the $\mathrm{A}$ and $\mathrm{B}$ repeats separate from the carboxy terminal half containing the $\mathrm{C}$ repeat region and the region associated with the cell wall polysaccharide. The resulting recombinant proteins designated $\mathrm{AB}_{6}$ and $\mathrm{C}_{6}$ were purified and used to immunize neonatal mice. In addition, we prepared $\mathrm{D} 471 *$ by treatment with pepsin as described in material and methods. Since pepsin cleaves $\mathrm{M}_{6}$ protein between the $\mathrm{B}$ and $\mathrm{C}$ repeat regions this removed 
the $\mathrm{A}$ and $\mathrm{B}$ repeat regions of the $\mathrm{M}_{6}$ protein from the whole cell preparation. Thus the $\mathrm{D} 471^{*}$ represented a whole cell preparation containing the carboxy terminal conserved region of MP. Newborn BALB/c mice were immunized within a week of birth with D471, D471*, purified $\mathrm{AB}_{6}$ or $\mathrm{C}_{6}$. Within five to seven days following the second immunization splenocytes were removed and assayed for the presence of CTL against M protein and mouse myosin. None of the immunizing antigens induced responses to the irrelevant control antigen cytochrome c (fig 4a), while all groups mounted responses of similar magnitude against recombinant M protein (fig $4 \mathrm{~b}$ ). As shown in figures $4 \mathrm{c}$ and $4 \mathrm{~d}$, in mice immunized with D471, equivalent CTL response against both $\mathrm{AB}_{6}$ and $\mathrm{C}_{6}$ were detected. Thus, $\mathrm{CTL}$ epitopes are present in both the variable amino terminal half and constant carboxy terminal half of MP. Immunization with D471* induced a CTL response against $\mathrm{C}_{6}$ region that is comparable to the response induced by $\mathrm{C}_{6}$ itself (fig. $4 \mathrm{~d}$ ) and weak responses against $\mathrm{AB}_{6}$ (fig. $4 \mathrm{c}$ ). These results indicate that the pepsin treatment of the vaccine (D471) prior to immunization was sufficient in removing most, if not all, of the $\mathrm{AB}_{6}$ region. Immunization with $\mathrm{AB}_{6}$ induced a $\mathrm{CTL}$ response against itself (fig. $4 \mathrm{c}$ ) and a weak response against $\mathrm{C}_{6}$ (fig. $4 \mathrm{~d}$ ), whereas, immunization with $\mathrm{C}_{6}$ induced a CTL response to itself and weak response to $\mathrm{AB}_{6}$.

We next assayed the splenocytes for responses against mouse myosin (fig $4 \mathrm{e}-\mathrm{h}$ ). Mice immunized with D471 elicited a response to neonatal heart (fig. 4e) and soleus (fig. 4h) and a weaker response to adult heart ventricle (fig. 4f) and gastrocnemius (fig. 4g). One the other hand, mice immunized with D471* exhibited CTL responses of greater magnitude against gastrocnemius (fig. 4g) and soleus (fig. 4h) and a weaker response to the cardiac samples (fig $4 \mathrm{e}$ f). Immunization with $\mathrm{C}_{6}$ induces a response to all mouse myosin samples with the greatest response against the adult heart ventricle (fig $4 \mathrm{f}$ ). Immunization with $\mathrm{AB}_{6}$ does not induce a 
CTL response to the mouse myosin. Although we were able to measure responses against myosin in mice immunized with $\mathrm{C}_{6}$ or $\mathrm{D} 471^{*}$ they did not discriminate between the mouse myosin isolated from different muscle as much as the CTL responses induced by D471. Likewise, the myosin CTL response generated in the mice immunized with $\mathrm{C}_{6}$ or D471* was of lesser magnitude as those measured in D471 primed mice.

\section{Capacity of $M$ protein $C$ region to induce a myosin-reactive CTL response in adult mice}

Previous experiments conducted in our laboratory have shown that immunization of adult mice with D471 or whole recombinant M protein leads to a CTL response against M protein with no measurable response against rabbit myosin (28). Since the carboxy terminal half of M protein can elicit a myosin reactive CTL response in neonatal mice, we then wanted to determine if this response was also dependent on age as that seen with D471 immunization. Adult mice were immunized intraperitoneally with $50 \mu \mathrm{g}$ of recombinant $\mathrm{AB}_{6}$ or $\mathrm{C}_{6}$ and within seven days of the last immunization the splenocytes were harvested and assayed for CTL responses against mouse myosin. Both groups of mice developed a CTL response against M protein as measured by target cells loaded with recombinant $\mathrm{MP}_{6}$ with no background response to the irrelevant control antigen (fig 5a). Mice immunized with $\mathrm{AB}_{6}$ did not develop CTL responses against the mouse myosin (fig. 5b). Immunization with the recombinant $\mathrm{C}$ fragment induced a CTL response against the mouse myosin, however, with no significant discrimination between the cardiac and skeletal isoforms (fig 5b). This CTL response against mouse myosin is comparable to that induced in the neonatal mice demonstrated in figure 4 (panels e - h), again underscoring the involvement of the $\mathrm{C}$ region. A possible explanation for these results could be that extracellular degradation of 
whole recombinant $\mathrm{M}$ protein and the $\mathrm{C}$ region does not yield the same epitopes. The results obtained from mice immunized as neonate or adults with the $\mathrm{C}$ region suggest that an epitope exists within the $\mathrm{C}$ region of $\mathrm{M}$ protein that is capable of inducing a myosin-specific $\mathrm{CTL}$ response.

\section{DISCUSSION}

For several years researchers have attempted to determine the mechanisms of poststreptococcal autoimmune events by both analyzing human tissue and developing animals model systems. While the argument for a role of cross-reactive antibodies received attention first and is still being debated $(7,8,13,37,43,44,48)$, it is becoming increasingly clear that the pathology of ARF is mediated by T cells $(4,16-21,52,53)$. In both active and chronic cases of ARF, these infiltrates are found to be mostly macrophages and T lymphocytes of which the CD4 ${ }^{+}$ population out numbers the $\mathrm{CD}^{+}$population $4: 1(14,15)$. Analysis into the distribution of peripheral blood lymphocytes (PBL) of ARF patients compared to controls indicate that T cells from ARF patients are activated and that there is a sustained increase in the number of CD4 $4^{+} \mathrm{T}$ cells and B cells (45). Extensive studies conducted with the mouse model of experimental autoimmune myocarditis indicate that $\mathrm{CD}^{+} \mathrm{T}$ cells are necessary to initiate the response but the pathological outcome is mediated by $\mathrm{CD}^{+} \mathrm{T}$ cells $(46-48)$.

Various groups have tried to ascertain what the antigenic specificity of these lymphocytes and if antigen cross-reactivity is involved. In vitro and in vivo studies have shown that streptococcal proteins, especially the M protein, can induce the differentiation of cytotoxic $\mathrm{T}$ lymphocytes with the capacity to kill myocardial cells and cell lines $(16,17)$. Demellawy et al. has demonstrated that PBL from ARF patients recognize a $50 \mathrm{kDa}$ and $54 \mathrm{kDa}$ protein of 
myocardial extracts and that the proliferative response may be intensified by pre-culturing cells with GAS extracts (21). Cloning of lymphocytic infiltrates, however, have yielded conflicting results. Guilherme et al. have been able to isolate clones that cross-react with M protein and myosin, however, Yoshinaga et al. could not, even though they demonstrated that the T cell lines from ARF patients preferentially react with lysates of streptococcal strains associated with ARF but not strains associated nephritis or non-pathogenic streptococci $(19,20)$. Cloning of PBL from active and chronic cases of ARF has given no clearer answer either. The $\mathrm{T}$ cell lines produced by Pruksakorn et al. that cross-reacted between M protein and myosin were isolated from healthy individuals (49). While this study may not confirm the presence of cross-reactive lymphocytes, it does indicate that precursor myosin reactive $\mathrm{T}$ cells can exist in the periphery. Still the question of how these $\mathrm{T}$ cells are recruited remains. One possible explanation that has been put forth by Kotb et al. suggests that $\mathrm{T}$ cell responses initiated against microbial antigens and superantigens can generate high levels of inflammatory cytokines that ultimately lead to localized tissue destruction and subsequent release of self-antigen that allows for the expansion of autoreactive $\mathrm{T}$ cells (50). Certain serotypes of $\mathrm{M}$ protein that have been associated with ARF have been shown to have superantigenic affects on particular subsets of human lymphocytes (24 - 26), however, this has not be correlated to $\mathrm{V} \beta$ gene usage in ARF patients (27). In support of Kotb's hypothesis, local cardiac tissue damage initiated by GAS has been demonstrated previously in mice by Cromartie et al. (51). However, while the cardiac lesions they observed were a direct result of an inflammatory response due to antigen localization it departs from the human condition in several aspects. First, the lesions were detectable within two days, second, streptococcal antigens are not detectable in biopsied valvular tissue from ARF patients $(14,15)$, and lastly, the cellular infiltrates they observed in the mouse cardiac tissue were 
predominantly macrophages but not lymphocytes which have been well documented in the human disease.

Most animal model systems designed to address the questions regarding this disease have been unable to yield any information explain the underlying mechanisms. Immunizing mice with streptococcal heat-killed vaccines or streptococcal cell wall or membrane preparations will induce anti-streptococcal antibodies that cross-react with mammalian proteins, including myosin $(7,8,37,43)$, but no pathology has been linked with such an antibody response. Furthermore, it has been demonstrated in laboratory animals that whole cell GAS preparations can induce cell mediated cytotoxicity to cultured heart cells $(18,52)$. Evidence may suggest that this autoreactive immune response is attributed to $\mathrm{M}$ protein $(9-11,17,24-26,49,53)$, however, immunizing adult mice with $\mathrm{M}$ protein and $\mathrm{M}$ protein peptides usually yields a protective $\mathrm{T}$ cell response with no evidence of cross-reaction with myosin $(28$ - 30). Nonetheless, we have previously demonstrated the capacity of heat-killed D471, serotype M6, to induce lytic T cell responses to both $\mathrm{M}$ protein and myosin in neonatal but not adult mice, suggesting that the myosin-reactive CTL response is age dependent (28). However, this ability to induce a response to myosin is not exclusive to the M6 serotype. The results of the current study have demonstrated the ability of streptococcal strains representing serotypes M49 and M4 to elicit a myosin-reactive CTL response in neonatally immunized mice. Furthermore, our results suggest that $\mathrm{M}$ protein plays an important role in the induction of a myosin reactive response, in that, mice immunized with UAB152 (M- variant of D471) do not mount a lytic response to myosin.

In light of these results we decided to have a closer look at the role M protein plays in the induction of a myosin-specific lytic response. This is an important issue since studies are currently being conducted with mice to develop a GAS vaccine using peptides from the $\mathrm{C}$ region 
of $\mathrm{M}$ protein (29 - 31), with the intention of developing a vaccine that will induce a protective immune response to most serotypes of $S$. pyogenes without the deleterious side effect of inducing an autoimmune response. Our results indicate that the conserved $\mathrm{C}$ region of $\mathrm{M}$ protein contains an epitope that can induce a myosin-reactive response in both adult and neonatal mice. The location of this punitive epitope has yet to be determined but it draws into question the safety of using the $\mathrm{C}$ region of $\mathrm{M}$ protein as a potential vaccine candidate. Furthermore, the results of our study are in agreement with work conducted by Pruksakorn et al. (49), who showed that human peripheral blood lymphocytic lines stimulated with peptides from the $\mathrm{C}$ region of $\mathrm{M}$ protein cross-reacted to heart proteins.

While we did not see any overt pathology with these mice, these results indicate that streptococcal M protein, especially the conserved $\mathrm{C}$ region, can play a central role in the induction of an auto-reactive T cell response and requires further study. 


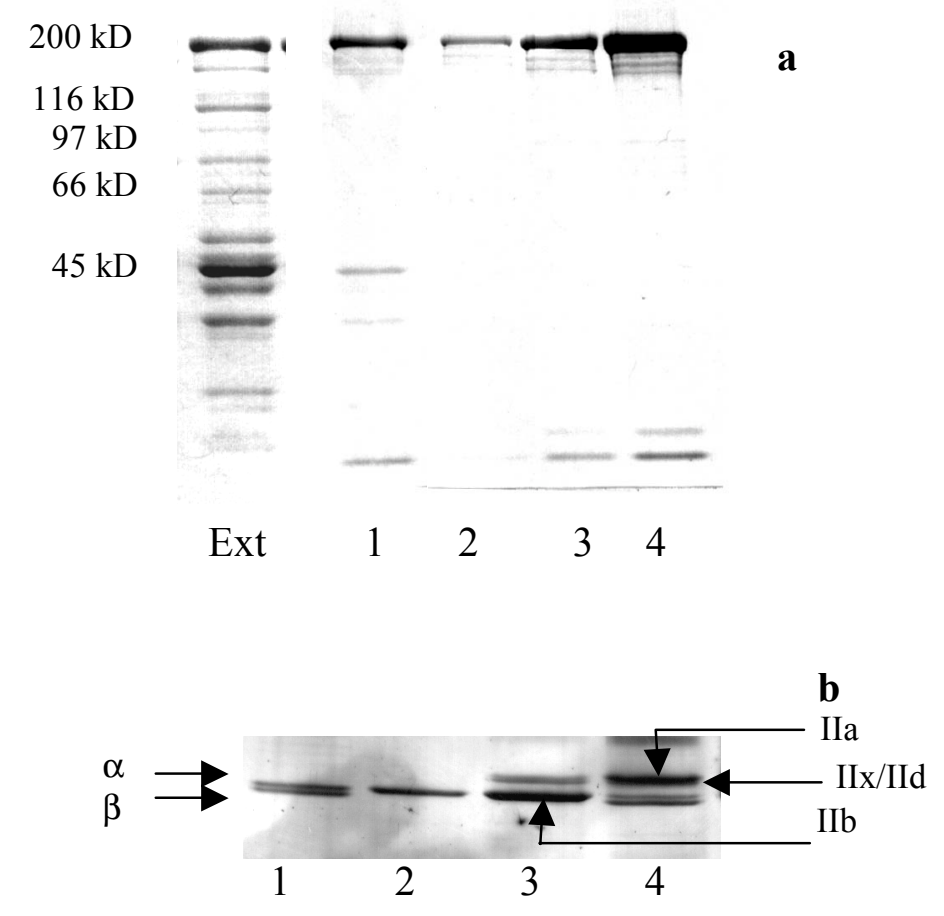

Figure 1. Electrophoretic separation of mouse myosin. Myosin was extracted from mouse skeletal and cardiac tissue and electrophoresed onto either $8 \%$ SDS-PAGE (a) or 8\% acrylamide SDS-PAGE with $30 \%$ glycerol (b) as described in material and methods. For comparison of the protein content, crude muscle extract is shown in 1a (EXT), otherwise, for each gel: Lane 1; one day heart, lane 2; adult heart ventricle, lane 3; adult gastrocnemius and lane 4; adult soleus. Electrophoresis of samples onto $8 \%$ acrylamide SDS-PAGE with $30 \%$ glycerol in figure b was conducted to determine relative representative amounts of each myosin heavy chain isoform (see text for isoform definitions). 


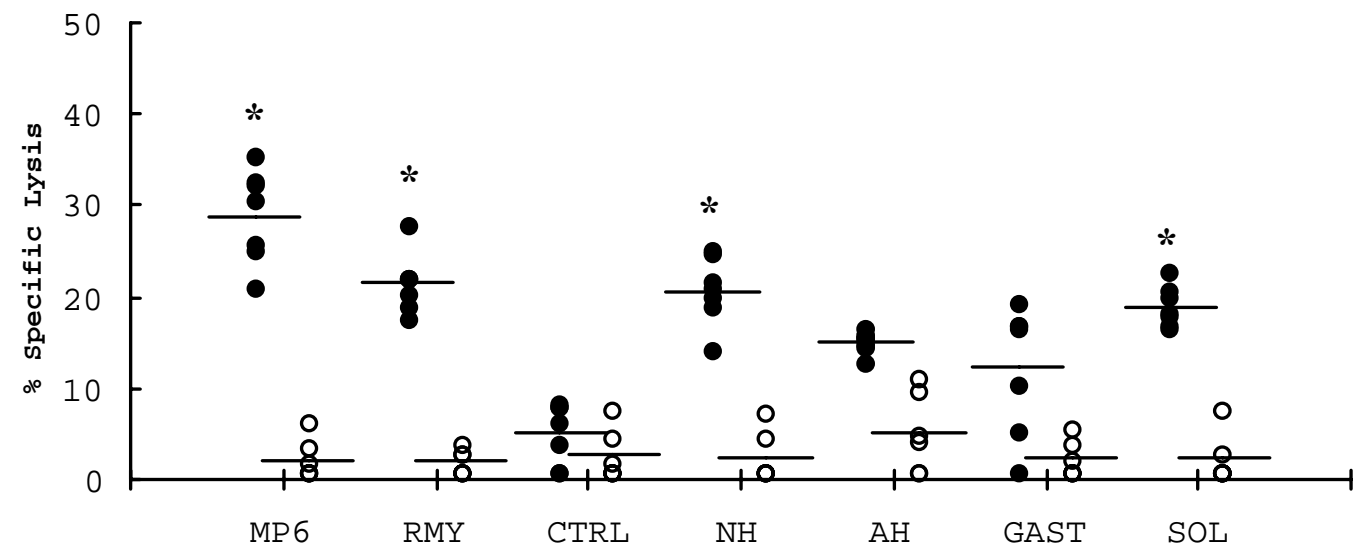

Figure 2. Cytolytic activity against myosin primed in neonatal mice requires M protein. Groups of $5-6 \mathrm{BALB} / \mathrm{c}$ mice were primed within 5 days of birth and boosted at 4 weeks of age as described in material and methods with D471 $(\bullet)$ or UAB152 (O). Splenocytes were harvested and assayed within seven days of last immunization. Data are shown as percent antigen-specific lysis (y-axis) of P815 cells labeled with tryptic digests of recombinant M6 protein (MP ${ }_{6}$ ), rabbit myosin (RMY), bovine cytochrome c (CTRL), and purified mouse myosin from neonatal heart $(\mathrm{NH})$, adult heart ventricle (AH), adult gastrocnemius (GAST), and adult soleus (SOL) muscles. Each symbol represents the calculated antigen specific lysis generated by spleen cells from an individual mouse at E:T ratios of 100:1. Horizontal bars represent geometric mean. Asterisks indicate statistical significance based upon a $p$-value $<0.0001$ as calculated by two-way ANOVA. 


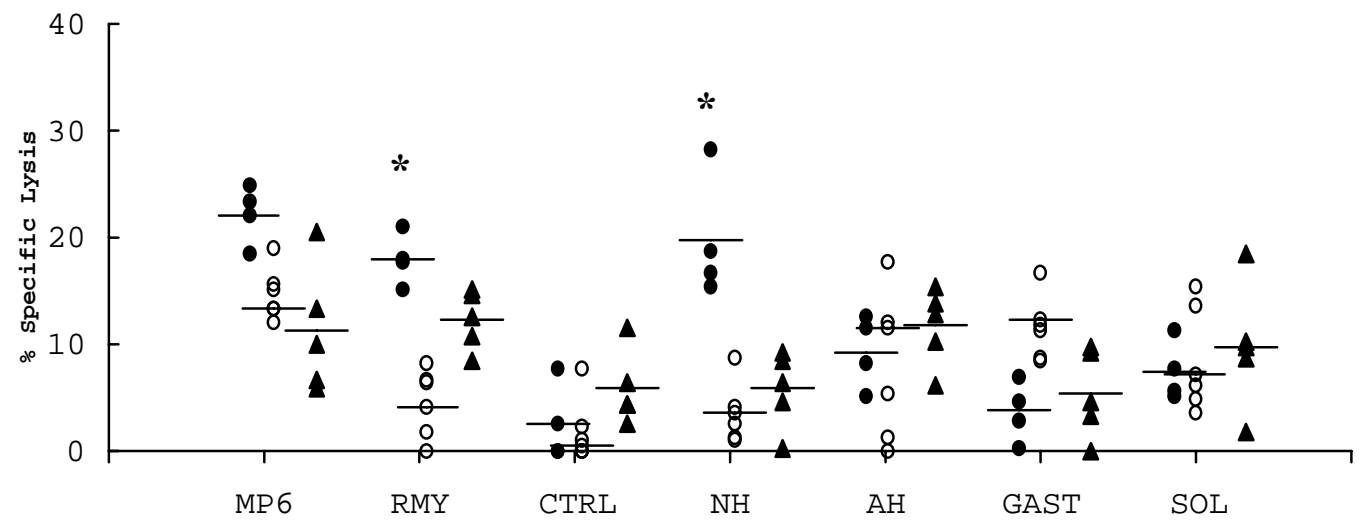

Figure 3. Priming of myosin-specific CTL responses in mice with non-rheumatogenic strains of S. pyogenes. BALB/c mice in groups of $4-6$ immunized within 5 days of birth and boosted at 3 - 4 weeks of age with J17A4 $(\mathbf{O})$, B737 (O) or H3 (A). Data represent percent antigen-specific lysis (y-axis) versus E:T ratio (x-axis) of P815 cells labeled of antigen at an effector to target ratio of 100:1. See legend of figure two for definition of antigen abbreviations. Each symbol represents the calculated antigen specific lysis generated by spleen cells from an individual mouse. Horizontal lines of each set represent the geometric means. Asterisks indicate statistical significance based upon a p-value $<0.0001$ as calculated by two-way ANOVA. 

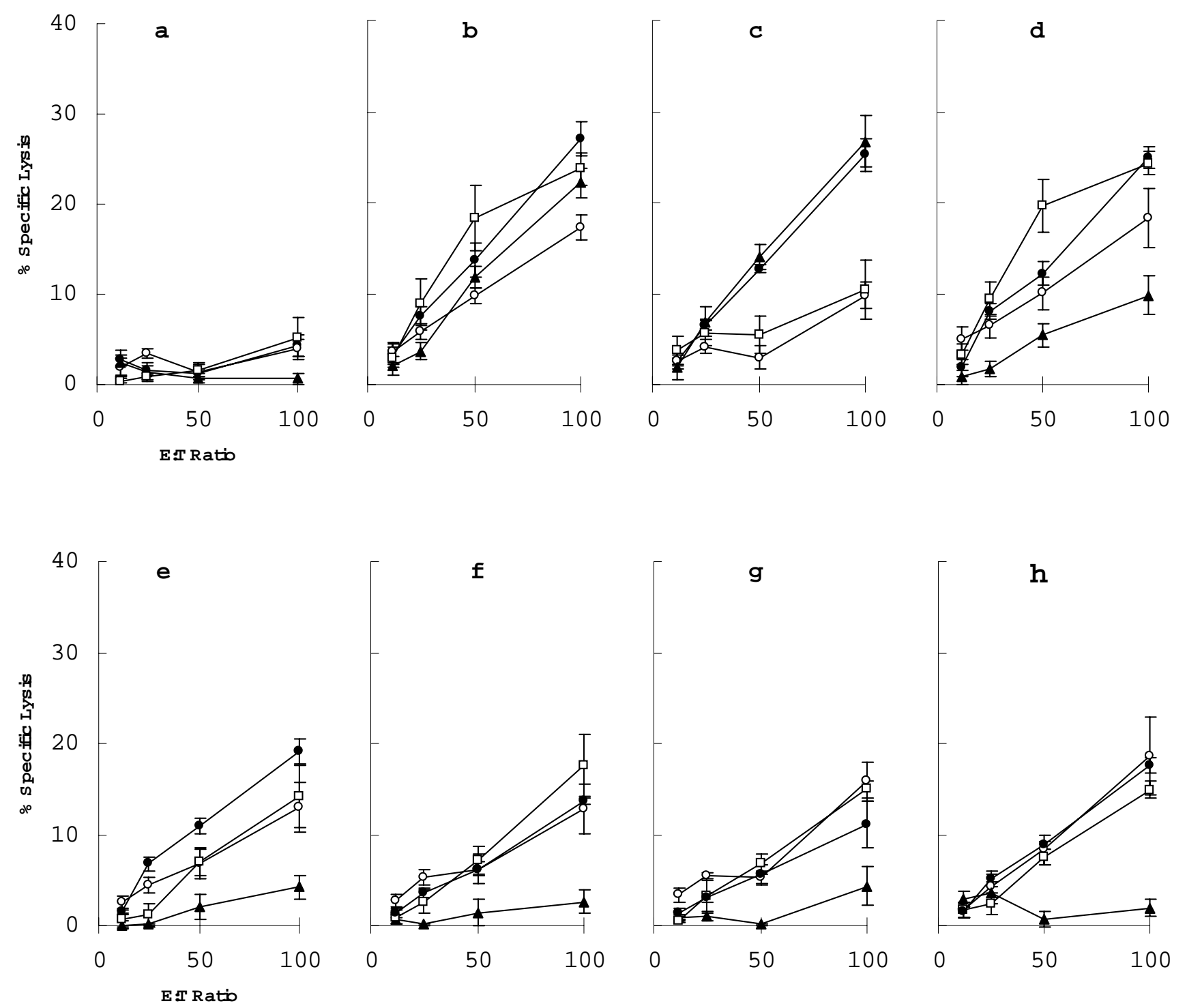

Figure 4. Priming of myosin-specific CTL response in neonatal mice with the conserved region of M protein. Mice were immunized as neonates with D471 (O), D471*(O), $\mathrm{AB}_{6}(\mathbf{\Delta})$ or $\mathrm{C}_{6}$ ( $\square$ ) and boosted at $4-5$ weeks of age with the corresponding immunogen as described in material and methods. Data represent percent antigen-specific lysis (y-axis) versus E:T ratio (xaxis) of P815 cells labeled with bovine cytochrome c (panel a), $\mathrm{MP}_{6}$ (panel b), M protein fragments $\mathrm{AB}_{6}$ (panel c) or $\mathrm{C}_{6}$ (panel d), mouse neonatal heart myosin (panel e), adult heart ventricle myosin (panel f), adult gastrocnemius myosin (panel g), and adult soleus myosin(panel h). y-axis error bars represent standard error. 

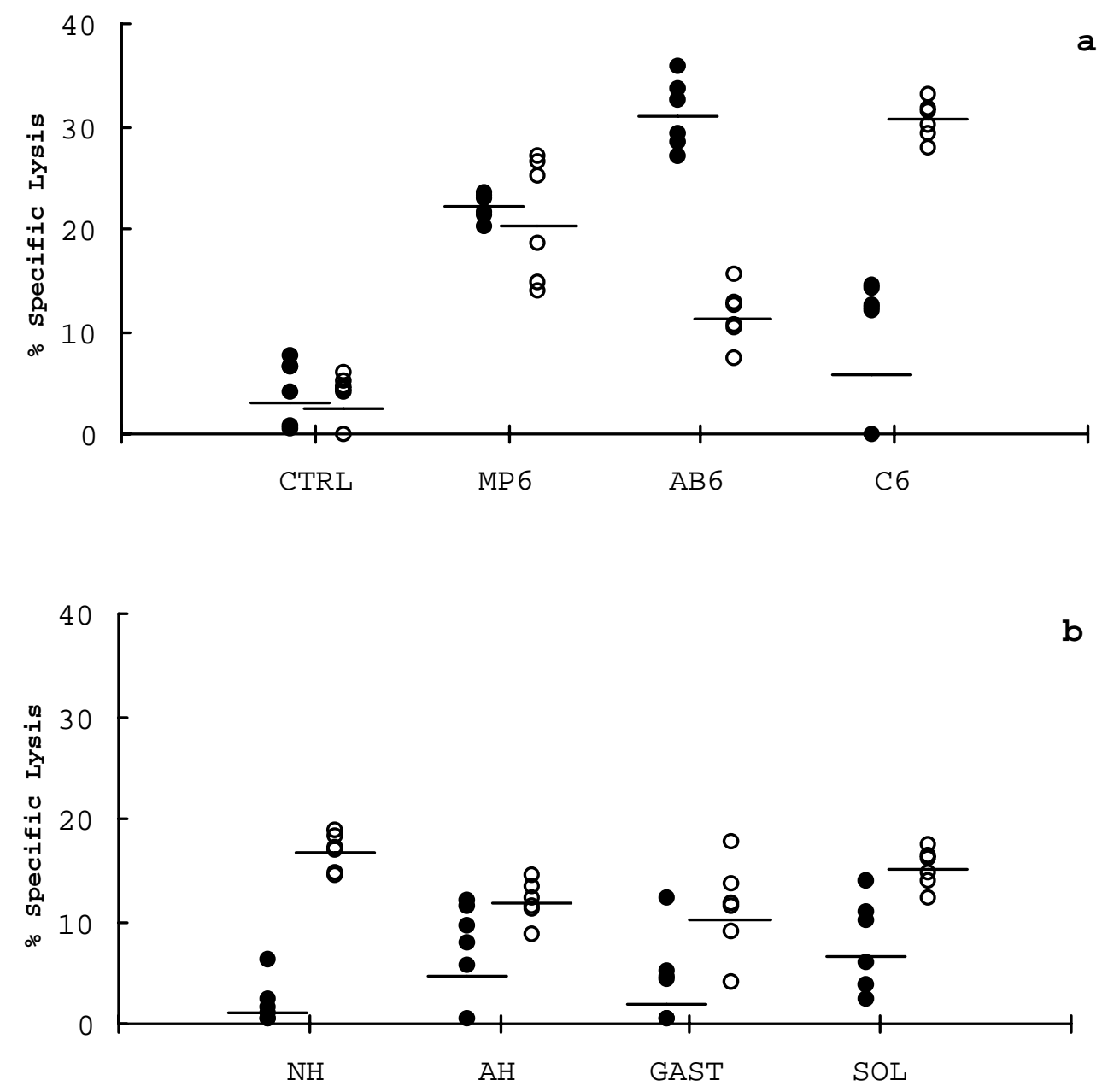

Figure 5 Priming of a myosin-specific CTL response in adult mice with the conserved region of $M$ protein. $C T L$ responses in adult mice immunized and boosted with $M$ protein fragments $\mathrm{AB}_{6}$ (O) or $\mathrm{C}_{6}(\mathrm{O})$ as described in material and methods. Data represent percent antigen-specific lysis (y-axis) of P815 cells labeled with antigens listed and defined in legend of figure two at an E:T ratio of 100:1. Panel a includes responses against streptococcal antigens while panel $b$ depicts CTL responses against mouse myosin. Each symbol represents the calculated antigen specific lysis generated by spleen cells from an individual mouse. Horizontal lines represent geometric mean. 


\section{REFERENCES}

1. Stevens, D. L. 1992. Invasive group A streptococcal infections. Clin. Infect. Dis. 14:2.

2. Robinson, J. H., Kehoe, M. A. 1992. Group A streptococcal M proteins: Virulence factors and protective antigens. Immunol. Today. 13:362.

3. Phillips, GN., P.F. Flicker, C. Cohen, B.N. Manjula, V.A. Fischetti. 1981. Streptococcal M protein: $\alpha$-helical coiled-coil structure and arrangement on the cell surface. Proc. Natl. Acad. Sci. USA. 78:4698.

4. Senitzer, D., E. H. Freimer. 1984. Autoimmune mechanisms in the pathogenesis of rheumatic fever. Rev. Infect. Dis. 6:832.

5. Stollerman, G. H. 1991. Rheumatogenic streptococci and autoimmunity. Clin. Immunol. Immunopath. 61:131.

6. Bisno, A. L. 1991. Group A streptococcal infections and acute rheumatic fever. N. Engl. J. Med. 325:783.

7. Shikhman, AR., N. S. Greenspan, M. W. Cunningham. 1993. A subset of mouse monoclonal antibodies cross-reactive with cytoskeletal proteins and group A streptococcal $\mathrm{M}$ proteins recognizes N-acetyl- $\beta$-D-glucosamine. J. Immunol. 151:3902.

8. Shikhman A. R., M. W. Cunningham. 1994. Immunological mimicry between N-acetyl- $\beta$ D-glucosamine and cytokeratin peptides. J. Immunol. 152:4375.

9. Manjula, BN., B. L. Trus, V. A. Fischetti. 1985. Presence of two distinct regions in the coiled-coil structure of the streptococcal Pep M5 protein: Relationship to mammalian coiledcoil proteins and implications to its biological properties. Proc. Natl. Acad. Sci. USA. 82:1064.

10. Hosein, B., M. McCarty, V. A. Fischetti. 1979. Amino acid sequence and physicochemical similarities between streptococcal M protein and mammalian tropomyosin. Proc. Natl. Acad. Sci. USA. 76:3765.

11. Manjula, BN., V. A. Fischetti. 1986. Sequence homology of group A streptococcal pepM5 protein with other coiled-coil proteins. Biochem. Biophys. Res. Comm. 140:684.

12. Barnett, L. A., and M. W. Cunningham. 1991. A new heart-cross-reactive antigen in Streptococcus pyogenes is not M protein. J. Infect. Dis. 162:875.

13. Dale, JB., E. H. Beachey. 1985. Epitopes of streptococcal M proteins shared with cardiac myosin. J. Exp. Med. 162:583. 
14. Kenemy, E., T. Grieve, R. Marcus, P. Sareli, J. Zabriskie. 1989. Identification of mononuclear cells and T cell subsets in rheumatic valvulitis. Clin. Immunol. Immunopath. $52: 225$.

15. Raizada, V., R. C. Williams Jr., P. Chopra, N. Gopinath, K. Prokash, K. B. Sharma, K. M. Cherian, S. Panday, R. Anora, M. Nigam, J. B. Zabriskie, G. Husby. 1983. Tissue distribution of lymphocytes in rheumatic heart valves as defined by monoclonal anti-T cell antibodies. Am. J. Med. 74:90.

16. Dale, J., E. Beachey. 1987. Human cytotoxicity T lymphocytes evoked by Group A streptococcal M proteins. J. Exp. Med. 166:1825.

17. Kotb, M., H. S. Courtney, J. B. Dale, E. H. Beachey. 1989. Cellular and biochemical responses of human $\mathrm{T}$ lymphocytes stimulated with streptococcal M proteins. J. Immunol. 142:966.

18. Friedman, I., A. Laufer, N. Ron, A. M. Davies. 1971. Experimental myocarditis: in vitro and in vivo studies of lymphocytes sensitized to heart extracts and group A streptococci. Immunol. 20:225.

19. Guilherme, L., E. Cunha-Neto, V. Coelho, R. Snitcowsky, P. Pomerantzeff, R. Assis, F. Pedra, J. Neumann, A. Goldberg, M. Patarroyo, F. Pileggi, J. Kalil. 1995. Human heartinfiltrating $\mathrm{T}$ cell clones from rheumatic heart disease patients recognize both streptococcal and cardiac proteins. Circulation 92:415.

20. Yoshinaga, M., F. Figueroa, M. Wahid, R. Marcus, E. Suh, J. Zabriskie. 1995. Antigenic specificity of lymphocytes isolated form valvular specimens of rheumatic fever patients. $J$. Autoimmun. 8:601.

21. El-Demellawy, M., R. El-Ridi, N. L.Guirguis, M. Abdel Aim, A. Kotby, M. Kotb. 1997. Preferential recognition of human myocardial antigens by T lymphocytes from rheumatic heart disease patients. Infect. Immun. 65:2197.

22. Degnan, B., J. Taylor, C. Hawkes, U. O'Shea, J. Smith, J. H. Robinson, M. A. Kehoe, A. Boylston, J. A. Goodacre. 1997. Streptococcus pyogenes type $5 \mathrm{M}$ protein is an antigen, not a superantigen, for human T cells. Human Immunol. 53:206.

23. Fleischer, B., K. Schmidt, D. Gerlach, W. Kohler. 1992. Separation of T-cell-stimulating activity from streptococcal M protein. Infect. Immun. 60:1767.

24. Tomai, M. A., J. A. Aelion, M. E. Dockter, G. Majumdar, D. G. Spinella M. Kotb. 1991. $\mathrm{T}$ cell receptor $\mathrm{V}$ gene usage by human $\mathrm{T}$ cells stimulated with the superantigen streptococcal M protein. J. Exp. Med. 174:285. 
25. Tomai, M. A., P. M. Schlievert, M. Kotb. 1992. Distinct T-cell receptor V $\beta$ gene usage by human T lymphocytes stimulated with the streptococcal pyrogenic exotoxins and pep M5 protein. Infect. Immun. 60:701.

26. Wantanabe-Ohnishi, R., J. Aelion, L. LeGros, M. A. Tomai, E. V. Sokurenko, D. Newton, J. Takahara, S. Irino, S. Rashed, M. Kotb. 1994. Characterization of unique human TCR V $\beta$ specificities for a family of streptococcal superantigens represented by rheumatogenic serotypes of M protein. J. Immunol. 152:2066.

27. Abbott, W. G. H., M. A. Skinner, L. Voss, D. Lennon, P. L. J. Tan, J. D. Fraser, I. J. Simpson, R. Ameratunga, A. Geursen. 1996. Repertoire of transcribed peripheral blood T cell receptor beta chain variable region genes in acute rheumatic fever. Infect. Immun. $64: 2842$.

28. Cunningham C., M. Elliott. Induction of myosin-reactive CTL in mice following immunization with heat-killed Streptococcus pyogenes. In preparation.

29. Robinson, J. H., M. C. Case, M. A. Kehoe. 1993. Characterization of a conserved helper T cell epitope from group A streptococcal M proteins. Infect. Immun. 61:1062.

30. Hayman, W. A., E. R. Brandt, W. A. Relf, J. Cooper, A. Saul, M. F. Good. 1997. Mapping the minimal murine $\mathrm{T}$ cell and $\mathrm{B}$ cell epitopes within a peptide vaccine candidate from the conserved region of the M protein of group A streptococcus. Int. Immunol. 9:1723.

31. Pruksakorn, S., A., B. Currie, E. R. Brandt, D. Martin, Galbraith, C. Phornphukul, S. Hunsakunachai, A. Manmontri, M. F. Good. 1994. Towards a vaccine for rheumatic fever: identification of a conserved epitope on M protein of group A streptococci. Lancet. 344:639.

32. Krause, R. M. 1970. The search for antibodies with molecular uniformity. Adv. Immunol. $12: 1$.

33. Margossian, S. S., S. Lowey. Preparation of myosin and its subfragments from rabbit skeletal muscle. Methods Enzymol. 85ptB:55.

34. Laemmli, U. K. 1970. Cleavage of structural proteins during the assembly of the head of bacteriophage T4. Nature 227: 680.

35. Talmadge, R. J., R. R. Roy. 1993. Electrophoretic separation of rat skeletal muscle myosin heavy chain isoforms. J. Appl. Physiol. 75:2337.

36. Blough, E. R., E. R. Rennie, F. Zhang, P. J. Reiser. 1996. Enhanced electrophoretic separation and resolution of myosin heavy chains in mammalian and avian skeletal muscles. Anal. Biochem. 233:31. 
37. Cunningham, C., M. Pearce, M. Elliott. Antibodies induced by heat-killed Streptococcus pyogenes in neonatal versus adult BALB/c mice recognize distinct isoforms of mouse skeletal myosin. In preparation.

38. Harrington, W. F., M. E. Rodgers. 1984. Myosin. Ann. Rev. Biochem. 53:35.

39. Weiss, A. and L. A. Leinwand. 1996. The mammalian myosin heavy chain gene family. Annu. Rev. Cell Dev. Biol. 12:417.

40. Schiaffino, S., C. Reggiani. 1994. Myosin isoforms in mammalian skeletal muscle. J. Appl. Physiol. 77:493.

41. Lompre, A. M., J. J. Mercadier, C. Wisnewsky, P. Bouveret, C. Pantaloni, A. D’ Albis, K. Schwartz. 1981. Species and age dependent changes in the relative amounts of cardiac myosin isoenzymes in mammals. Dev. Biol. 84:286.

42. Bessen, D., K. F. Jones, V. A. Fischetti. 1989. Evidence for two distinct classes of streptococcal M protein and their relationship to rheumatic fever. J. Exp. Med. 169:269.

43. Cunningham, M. W., N. K. Hall, K. K. Krisher, A. M. Spanier. 1986. A study of antigroup A streptococcal monoclonal antibodies cross-reactive with myosin. J. Immunol. 136:293.

44. Schwab J. H., R. R. Brown. 1973. Heart autoantibodies in mice: genetics, bacterial, and age determinants. J. Immunol. 111:682.

45. Morris, K., C. Mohan, P. L. Wahi, I. S. Anand, N.K. Ganguly. 1993. Increase in activated $\mathrm{T}$ cells and reduction in suppressor/cytotoxic $\mathrm{T}$ cells in acute rheumatic fever and active rheumatic heart disease: a longitudinal study. J. Infect. Dis. 167:979.

46. Smith S. C., P. M. Allen. 1993. The role of T cells in myosin induced autoimmune myocarditis. Clin. Immunol. Immunopath. 68:100.

47. Rose, N. R., S. L. Hill. 1996. The pathogenesis of post-infectious myocarditis. Clin. Immunol. Immunopath. 80:S92.

48. Neu, N., B. Ploier, C. Ofner. 1990. Cardiac myosin induces myocarditis heart autoantibodies are not involved in the induction of the disease. J. Immunol. 145:4094.

49. Pruksakorn, S., B. Currie, E. Brandt, C. Phornphutkul, S. Hunsakunachai, A. Manmontri, J. H. Robinson, M. A. Kehoe, A. Galbraith, M. F. Good. 1994. Identification of $\mathrm{T}$ cell autoepitopes that cross-react with the C-terminal segment of the $\mathrm{M}$ protein of group A streptococci. Int. Immunol. 6:1235. 
50. Kotb, M. 1994. Infection and autoimmunity: a story of the host, the pathogen, and the copathogen. Clin. Immunol. Immunopath. 74:10.

51. Cromartie, W. J., J. G. Craddock. 1966. Rheumatic-like cardiac lesions in mice. Science 154:285.

52. Yang, L. C., P. R. Soprey, M. K. Wittner, E. N. Fox. 1977. Streptococcal induced cell mediated immune destruction of cardiac myofibers in vitro. J. Exp. Med. 146:344.

53. Cunningham, M. W., S. M. Antone, M. Smart, R. Liu, S. Kosanke. 1997. Molecular analysis of human cardiac myosin cross reactive B and T cell epitopes of the group A streptococcal M5 protein. Infect. Immun. 65: 3913. 


\section{Addendum}

Induction of the myosin-reactive CTL responses in mice with heat-killed

Streptococcus pyogenes: The role of age, haplotype, route of immunization and presence of B lymphocytes 


\section{INTRODUCTION}

In previous studies outlined in chapter one we have observed that BALB/c mice immunized as neonates with heat-killed Streptococcus pyogenes are capable of eliciting a myosin cross-reactive antibody response that is reminiscent of that in acute rheumatic fever patients (ARF). We have also observed a myosin-reactive CTL response following neonatal systemic challenge of heat-killed S. pyogenes (chapter 2). In addition, we observed that the potential M protein epitope responsible for eliciting a myosin-reactive CTL response is found within the carboxy conserved region (chapter 3), a region under intense investigation as a potential vaccine candidate (1-3). Additionally, we wanted to examine various aspects of the host that may affect the development of the myosin-reactive CTL response including the MHC haplotype, the route of infection and the necessity of the B lymphocyte compartment.

All studies thus far have been conducted with BALB/c mice, hence experiments were performed with mice representing other MHC haplotypes to test their ability to develop a myosin-reactive CTL responses following exposure to $S$. pyogenes. Next, we addressed the potential role route of immunization has since all previous studies were conducted with systemic immunizations and most post-streptococcal autoimmune complications follow nasopharyngeal infection. Therefore, these studies would include experiments involving priming through the intranasal route, an immunization route most comparable to human nasopharnygeal infection.

In our neonatal systemically immunized mice we have a concurrent myosin cross-reactive antibody and CTL response. While it is believed that $\mathrm{CD} 8^{+}$lymphocytes can mediate tissue specific cytolytic damage in ARF and other autoimmune processes (4-10), with the exception of SLE no role has been found for the cross-reactive antibody response $(7,11,12)$. B lymphocytes can function as antigen presenting cells (APC) and present exogenous antigen, such as 
bacterium, by the classical MHC class II pathway, and non-classically via MHC class I pathway (13-15). In addition, Lin et al. (16) has shown that autoreactive B cells can function as APC and initiate autoreactive $\mathrm{T}$ cell responses. We conducted a series of experiments to determine what effect the presence of the B lymphocyte compartment has on the capacity to elicit the myosinreactive CTL response. A portion of the following experiments were performed with BALB/c mice, however, since the immunoglobulin heavy chain knock-out mutation $\left(\mathrm{Igh}^{-/}\right)$is on the C57Bl/6 background we also performed repetitive experiments with $\mathrm{C} 57 \mathrm{Bl} / 6$ mice to acquire control data for $\operatorname{Igh}^{-/}$experiments.

\section{MATERIAL and METHODS}

Mice. BALB/c, C57Bl/6, DBA/2J, and CBA/J mice were purchased from Jackson Laboratory, Bar Harbor, ME and bred at WVU animal facility. Mice were immunized with $10^{7}$ heat-killed $S$. pyogenes per gram of body weight or $200 \mu \mathrm{g}$ or $5 \mu \mathrm{g}$ of recombinant $\mathrm{M}$ protein and it subfragments for adult and neonatal mice, respectively. The volumes were maintained at 50-100 $\mu 1$ (neonatal) or $200 \mu 1$ (adult) per mouse by the intraperitoneal route or in $5 \mu 1$ (neonatal) or 20 $\mu 1$ (adult) per mouse divided equally between two nostrils.

Preparation of antigens. Streptococcus pyogenes strains D471 (serotype M6) and UAB152 (a derivative of D471 containing insertional inactivation of the emm6 gene) were grown from single colonies in 2 liters of Todd-Hewitt broth without aeration in the presence of $7.5 \% \mathrm{CO}_{2}$ until growth ceased. The cultures were pasteurized by incubation in a $56^{\circ} \mathrm{C}$ waterbath for 1.5 hours at which point cells were centrifuged, washed 5 times with $500 \mathrm{ml}$ of $0.85 \%$ saline and resuspended in $0.85 \%$ saline. The cells were frozen at $-20^{\circ} \mathrm{C}$ in $5 \mathrm{ml}$ aliquots after adjusting the cell density to $\mathrm{OD}_{600}$ of $2.0 / \mathrm{ml}\left(2 * 10^{8}\right.$ bacteria / $\left.\mathrm{ml}\right)$. Both strains were a gift from Dr. 
Hollingshead (UAB). D471* was prepared as previously described (chapter 3). Plasmid TR06 containing the M6 gene was gift of Dr. Hollingshead. This plasmid contains residues 1 to 413 of the mature M6 protein cloned into the NcoI and XhoI sites of pET20b+ (Novagen). The recombinant M6 protein with a carboxy-terminal His-6 tag was expressed in BL21:(DE3), pLysS by induction with Iptg for $1 \mathrm{hr}$ and was purified from periplasmic extracts by adsorption to $\mathrm{Ni}$ NTA-sepharose (Qiagen). Cloning, expression, and purification of $\mathrm{AB}_{6}$ and $\mathrm{C}_{6}$ have been described (chapter 3).

Non-radioactive assay for antigen specific CTL activity. Assay antigens M protein, rabbit myosin and bovine cytochrome c were adjusted to a final concentration of $1 \mathrm{mg} / \mathrm{ml}$ in sterile Dulbecco's phosphate buffered saline, to which, trypsin (Sigma chemical Co., St. Louis, MO) was added at $10 \mathrm{mg} / \mathrm{mg}$ protein. Proteolysis was carried out overnight at $37^{\circ} \mathrm{C}$ and digested samples were stored at $-20^{\circ} \mathrm{C}$. CTL assays were conducted as previously described (chapter 2). Briefly, single cell suspensions were processed from spleens in serum-free RPMI1640, washed once and resuspended in phenol red-free RPMI with 5\% fetal calf serum. Target cells of the corresponding haplotype (P815 (H-2d), EL4 $\left(H-2^{b}\right)$, CBA.D1 $\left.\left(H-2^{k}\right)\right)$ were incubated with tryptic peptides of antigen for a minimum of 20 minutes in serum-free, phenol red-free RPMI1640 at a concentration of $2 * 10^{5} / \mathrm{ml}$. Effector cells (splenocytes) were plated with the peptide labeled target cells at various ratios in phenol-red free RPMI in 96-well microtiter plates for each antigen tested. The assay plates were incubated at $37^{\circ} \mathrm{C}$ for approximately 5 hours in the presence of 7.5 $\% \mathrm{CO}_{2}$. Cytotoxicity was measured using Promega Cytox 96 assay substrate as outlined in manufacturers instructions. Absorbance values and percent lysis were determine as before (chapter 2). 


\section{RESULTS and DISCUSSION}

\section{Myosin-reactive CTL response in C57Bl/6 mice following immunization with heat-killed $S$.}

pyogenes as a factor of age and $M$ protein. In $\mathrm{BALB} / \mathrm{c}$ both the age of the animal at the time of immunization and the presence of M protein were key factors in the induction of the CTL response against myosin. In order to carry out the next set of experiments designed to study the effects of immunization route and the role of B lymphocytes in the induction of a myosin reactive CTL response, we needed to ascertain whether $\mathrm{C} 57 \mathrm{Bl} / 6$ mice are capable of responding to systemic challenge of heat-killed $\mathrm{D} 471$ in a similar manner as BALB/c mice. To this end, groups of $4-6 \mathrm{C} 57 \mathrm{Bl} / 6$ mice were immunized within 3 days post partum or at 6 weeks of age with heatkilled D471 (fig 1a and 1d) as described in material and methods. As shown in figure 1a, C57Bl/6 mice immunized as either adult or neonates with D471 elicit comparable CTL responses against $\mathrm{M}$ protein. In comparison to the response elicited in BALB/c mice (chapter 2), adult C57B1/6 mice primed with D471 elicits a CTL response against M protein of greater magnitude, whereas the M protein specific CTL response in neonatal mice remained relatively comparable. In agreement with the BALB/c data previously acquired (chapter 2), $\mathrm{C} 57 \mathrm{Bl} / 6$ mice are capable of generating a myosin specific CTL response if immunized systemically with D471 as neonates but not adults (fig 1d). No CTL responses were observed against the irrelevant control protein cytochrome $\mathrm{c}$ in either group of adult or neonatal mice immunized with D471 (data not shown).

Next, we wanted to determine whether the myosin-reactive CTL response in C57Bl/6 mice exhibits a similar requirement for $\mathrm{M}$ protein as previously observed in BALB/c mice. Mice were immunized as neonates or adults with UAB152 (fig $1 \mathrm{~b}$ and 1e). As previously observed in 
$\mathrm{BALB} / \mathrm{c}$ mice, $\mathrm{C} 57 \mathrm{Bl} / 6$ mice immunized with $\mathrm{UAB} 152$ were incapable of responding against either M protein (fig 1b) or myosin (fig 1e) whether immunized as neonates or adults. To begin further analysis into the involvement of M protein with the myosin-reactive CTL response, mice were immunized as adults or neonates with $\mathrm{D} 471^{*}$, a preparation of D471 treated with pepsin to remove the antigenically variable amino terminus leaving the more conserved carboxy terminus remaining. As shown in figure 1, C57B1/6 mice immunized as neonates with $\mathrm{D} 471$ * elicit a response against both $\mathrm{M}$ protein (fig 1c) and myosin (fig 1f), whereas adult mice elicit a response only against $\mathrm{M}$ protein (fig 1c and 1f). These results demonstrate that $\mathrm{C} 57 \mathrm{Bl} / 6$ mice immunized as neonates with heat-killed S. pyogenes are capable of eliciting a myosin-reactive CTL response. Further, this response is dependent upon M protein and the potential epitope for such a crossreactive response appears to lie within the carboxy terminal region. Again, all of the results are in agreement with results obtained previously with $\mathrm{BALB} / \mathrm{c}$ mice.

\section{$M$ protein is required but not exclusively responsible for the myosin-reactive CTL}

response. As previously established with $\mathrm{BALB} / \mathrm{c}$ mice and demonstrated in figure 1 with C57B1/6 mice, $\mathrm{M}$ protein is required to induce the myosin-reactive CTL response. We have also demonstrated that the potential M protein epitope necessary to induce the myosin-reactive CTL response lies within the carboxy terminal region (fig 1f). To investigate further the role of $\mathrm{M}$ protein in the induction of myosin-reactive CTL responses used recombinant M protein subfragments $\mathrm{AB}_{6}$ and $\mathrm{C}_{6}$ for immunization.

Experiments conducted with $\mathrm{BALB} / \mathrm{c}$ mice suggested that the $\mathrm{C}$ region but not the $\mathrm{A}$ and $\mathrm{B}$ of $\mathrm{M}$ protein is sufficient for the elicitation of the myosin-reactive response in both neonatal and adult mice (chapter 3). However, as shown in figure 2, immunization of adult C57B1/6 mice with either $\mathrm{AB}_{6}$ (fig 2a) or $\mathrm{C}_{6}$ (fig $2 \mathrm{~b}$ ) results in lytic responses against $\mathrm{M}$ protein, as well as 
respective immunizing subfragments (data not shown) without the induction of a lytic response against myosin. Further, immunizing neonatal mice with the recombinant fragments of $\mathrm{M}$ protein (fig 2c) or $\mathrm{C}_{6}$ (fig 2d) does not elicit a CTL response against myosin above background levels despite the measurable levels of $\mathrm{M}$ protein specific lytic response. A potential reason for the disparity of the results between these two strains of mice is their differing haplotype backgrounds. Thus it is conceivable that the epitopes processed and presented from the recombinant $\mathrm{M}$ protein and $\mathrm{C}_{6}$ within the $\mathrm{BALB} / \mathrm{c}$ mice that allow cross-priming are not being presented in $\mathrm{C} 57 \mathrm{Bl} / 6$.

\section{The myosin-reactive CTL response cannot be elicited by the intranasal route. All} experiments conducted thus far in both $\mathrm{BALB} / \mathrm{c}$ and $\mathrm{C} 57 \mathrm{Bl} / 6$ mice have followed systemic challenge, however, with the exception of AGN, most post-streptococcal autoimmune diseases are known to follow nasopharyngeal infection. In an effort to determine what role the route of infection may play in the development of a CTL response against myosin, groups of mice were immunized as either as adults (fig 3a and 3b) or neonates (fig 3c and 3d) with D471 by the intraperitoneal route (i.p.) (fig 3a and 3c) or the intranasal route (i.n.) (fig 3b and 3d) as outlined in material and methods. Both spleens and cervical lymph nodes were harvested for assay 7 or 10 days following the last i.p. or i.n. immunization, respectively. As previously observed, immunization of adult mice with D471 by the i.p. route invokes a M protein response but no response to either the irrelevant control protein or myosin (fig 3a). However, immunization of adult mice by the intranasal route is unable to elicit the response against $\mathrm{M}$ protein (fig 3b). As expected, immunization of neonatal mice with D471 by the i.p. route elicits a CTL response against both $\mathrm{M}$ protein and myosin (fig 3c). In contrast, neonatal mice primed with D471 by the intranasal route do not mount a CTL response against either M protein or myosin (fig 3d). 
Similar results were obtained with BALB/c mice immunized intranasally with D471 as either adults or neonates (data not shown).

The lack of measurable CTL responses in intranasally challenged mice could be attributed to several factors. First, the immunization may not allow for either a local or systemic response to be primed, perhaps as a result of inadequate antigen processing and presentation. Preliminary observations suggest that no response to either M protein or myosin were detectable with CLN lymphocytes either (data not shown). Second, immunization by the intranasal route may instead initiate tolerance, either as a result of the nature of the antigen or the antigenic dose.

\section{Intranasal immunization with $S$. pyogenes during the neonatal period primes for a systemic} myosin-reactive response. We next wanted to test the hypothesis that perhaps as a means for priming an autoimmune event, an individual is first exposed to the organism by the nasopharyngeal route and an initial, potentially autoreactive immune response is primed which may be subsequently boosted by systemic challenge of the organism. Although in our mice immunization by the intranasal route alone did not prime an immune response, it does not negate the possibility that an initial intranasal priming event may alter the systemic response following subsequent systemic challenge. To conduct the experiment, mice were immunized within the first three days of life by the intranasal route with heat-killed D471, UAB152, or D471* as described in material and methods. After reaching $4-6$ weeks of age the mice were challenged intraperitoneally with the respective streptococcal vaccine or recombinant M protein. Seven days following the last immunization splenocytes were harvested and assayed for lytic activity against M protein, myosin and an irrelevant control antigen.

As shown in figure 4, mice immunized with D471 (fig 4a) or D471* (fig 4b) intranasally as neonates and boosted as adults with D471 i.p. mount a measurable CTL response against M 
protein but the response against myosin is barely above background. Mice intranasally challenged with D471 or D471* and boosted i.p. with M protein (fig 4c and 4d, respectively) mount an antigen specific CTL response against M protein, however, in addition to the antigen specific response, these mice mounted a CTL response against myosin. This indicates that i.n. challenge with heat-killed streptococcal vaccine does not induce systemic tolerance against $\mathrm{M}$ protein. Further, since systemic challenge with M protein in adult animals primes only for an antigen specific CTL response (chapter 2 and data not shown) the elicitation of a myosin-reactive CTL response following the $\mathrm{M}$ protein systemic challenge in this set of experiments must be a consequence of the neonatal intranasal challenge with S. pyogenes. Unlike D471 and D471*, intranasal immunization with UAB152 does not allow for a myosin-reactive CTL response following systemic challenge with M protein (data not shown). These results suggest that not only is M protein required during the initial intranasal exposure but also that epitopes within the C-region of M protein are most likely responsible. Additionally, the need for subsequent systemic challenge with $\mathrm{M}$ protein to initiate the myosin-reactive response is further established by the fact that mice primed intranasally with D471 as neonates and boosted i.n. with M protein elicit a weak response to M protein and no response to myosin (fig 4e).

Role of B lymphocytes in the elicitation of the myosin-reactive CTL response. B cells are known to function as antigen presenting cells and it has been demonstrated that autoreactive $\mathrm{B}$ cells can function as an APC and initiate autoreactive T cell responses (16). Also, B cells have been shown to be capable of processing and presenting exogenous antigen via class I MHC (13, 15). Such autoantigen presentation by B cells is believe to occur by receptor mediated uptake of the antigen via the surface immunoglobulin $(13,15,16)$. In the laboratory, we have observed that mice immunized as neonates with D471 i.p. exhibit life-long myosin cross-reactive antibody 
responses, therefore, the next set of experiments were designed as a preliminary study to determine if these autoreactive $\mathrm{B}$ cell serve a role in the elicitation of the myosin-reactive CTL response. To perform these experiments we obtained C57Bl/6 immunoglobulin heavy chain knockout mice $\left(\mathrm{Igh}^{-/}\right)$that are unable to produce antibody or express a functional immunoglobulin receptor on their surface. Experiments were carried out by immunizing groups

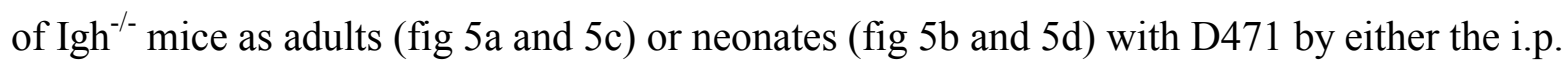
route (fig $5 \mathrm{a}$ and $5 \mathrm{~b}$ ) or the i.n. route (fig $5 \mathrm{c}$ and $5 \mathrm{~d}$ ). $\mathrm{Igh}^{-/-}$mice immunized as adults with D471 by either by the i.p. route (fig 5a) or i.n. route (fig 5c) mounted a response against $\mathrm{M}$ protein that is comparable in magnitude to that measured in wild-type $\mathrm{C} 57 \mathrm{Bl} / 6$ mice (fig 3a, 3b). Likewise for the myosin-reactive CTL response in $\operatorname{Igh}^{-/-}$mice immunized as neonates with D471 i.p. (fig 5b) or i.n. (fig 5d) when comparing the magnitude of the response in wild-type C57Bl/6 mice (fig 3c, 3d). Despite the lack of functional B cells, no obvious deficiencies with the lytic responses were observed. Thus, this preliminary study suggests that the B lymphocyte compartment does not play any obvious role in the capacity of mice to elicit a myosin-reactive CTL response following neonatal systemic challenge with S. pyogenes.

Influence of MHC haplotype on the development of myosin-reactive CTL response. Host genetics has long been suspected a factor in the susceptibility to post-streptococcal autoimmune complications (17-20). Preliminary studies were then conducted to determine what affect if any, the MHC haplotype may have on the development of a myosin-reactive CTL response following neonatal immunization with D471 and UAB152. To conduct the experiment, mouse strains $\mathrm{C} 57 \mathrm{Bl} / 6$ and $\mathrm{CBA} / \mathrm{J}$ were chosen to represent the $\mathrm{H}-2^{\mathrm{b}}$ and $\mathrm{H}-2^{\mathrm{k}}$ haplotypes, respectively. Experiments with BALB/c mice indicate the ability of mice with the $\mathrm{H}-2^{\mathrm{d}}$ haplotype to respond against myosin, however, mouse strain DBA/2 $\left(\mathrm{H}-2^{\mathrm{d}}\right)$ was also selected to serve as a control for 
the data generated from the BALB/c mice. Mouse strains, AKR/J, 129/J, representing haplotypes $\mathrm{H}-2^{\mathrm{b}}$ and $\mathrm{H}-2^{\mathrm{k}}$ respectively, were also chosen for this study as a means to serve as duplicate controls for data generated in $\mathrm{C} 57 \mathrm{Bl} / 6$ and $\mathrm{CBA} / \mathrm{J}$ mice. However, we were unable to acquire adequate numbers of neonates with these strains to perform our experiments.

First, we immunized groups of at least six C57Bl/6, DBA/2J and CBA/J mice, as adults i.p. at least twice with heat-killed D471 or UAB152. As we have previously documented with $\mathrm{BALB} / \mathrm{c}$ mice, none of these strains demonstrated CTL responses to myosin (data not shown) following adult administration with either heat-killed vaccine and therefore served as a controls for the experiment. Next, groups of neonatal mice representing each strain were immunized i.p. with either D471 or UAB152 and boosted as adults with the same vaccine. Within sevens days following the adult boosting splenocytes were harvested and assayed for cytolytic activity against P815 cells labeled with tryptic digests of recombinant M protein, rabbit skeletal myosin or the irrelevant control protein cytochrome c. Results of the cytolytic assays are summarized in table 1. The resultant data, albeit preliminary, suggests that the haplotype may play a role. $\mathrm{CBA} / \mathrm{J}$ mice $\left(\mathrm{H}-2^{\mathrm{k}}\right)$ are unable to elicit a myosin-reactive CTL response following neonatal immunization with $\mathrm{D} 471$, while $\mathrm{C} 57 \mathrm{Bl} / 6\left(\mathrm{H}-2^{\mathrm{b}}\right)$ respond to both vaccines in the same manner as BALB/c mice. As anticipated, DBA/2J mice elicit a myosin-reactive CTL response following neonatal priming with D471. However, unlike BALB/c, this strain also developed a detectable myosin-reactive CTL response following neonatal immunization with UAB152, suggesting that streptococcal antigens other than M protein may initiate a myosin-reactive CTL response. Again, these results are preliminary and require further examination.

Conclusion. The data presented within the addendum were compiled as a means to better understand the induction of a myosin-reactive CTL response in neonatal mice following 
immunization with heat-killed S. pyogenes vaccine. They represent the efforts undertaken to determine what aspects of the host and organism were key in the induction of an autoreactive CTL response. Together these data suggest that on the part of the host, genetic background may play a role in the susceptibility of developing autoreactive CTL responses. We have shown that mice of the $\mathrm{H}-2^{\mathrm{d}}(\mathrm{BALB} / \mathrm{c}$ and $\mathrm{DBA} / 2 \mathrm{~J})$ and $\mathrm{H}-2^{\mathrm{b}}(\mathrm{C} 57 \mathrm{~B} 1 / 6)$ background are capable of eliciting a myosin-reactive CTL response following neonatal but not adult immunization with wild-type $S$. pyogenes, while $\mathrm{CBA} / \mathrm{J}$ mice $\left(\mathrm{H}-2^{\mathrm{k}}\right)$ were unable regardless of age of immunization. However, because we were unable to obtain enough neonates from AKR/J and 129/J mice, we were unable to duplicate the results obtained with $\mathrm{C} 57 \mathrm{Bl} / 6$ and $\mathrm{CBA} / \mathrm{J}$ mice.

We have shown that intranasal immunization, a route of immunization most closely related to natural infection, in itself cannot induce autoreactive CTL responses but can alter the subsequent systemic response following i.p. challenge with $\mathrm{M}$ protein from one that is antigen specific to a myosin cross-reactive CTL response. These results suggest that local (intranasal) exposure to $S$. pyogenes may be able to have a lasting effect upon subsequent systemic responses. In the last set of experiments we attempted to discern a role for the autoreactive B cells within our immunized mice. We wanted to determine if the B cells could potentially act as antigen presenting cells, present host antigen and have a down-stream effect upon the autoreactive $\mathrm{T}$ cell responses. However, upon repeating experiments in $\mathrm{Igh}^{-/-}$mice, we were unable to detect any differences in the subsequent myosin-reactive CTL responses, which is not unlike what has been previously reported (21). 
These results provide clues into the requirements for the elicitation of a myosin-reactive CTL response. It appears that the genetic background of an individual can have an effect on the development of such a response, as well as, the route of immunization. Interestingly, according to our results in appears that in order to develop a CTL response to myosin, the necessary streptococcal antigen, M protein, must access the host systemically. 

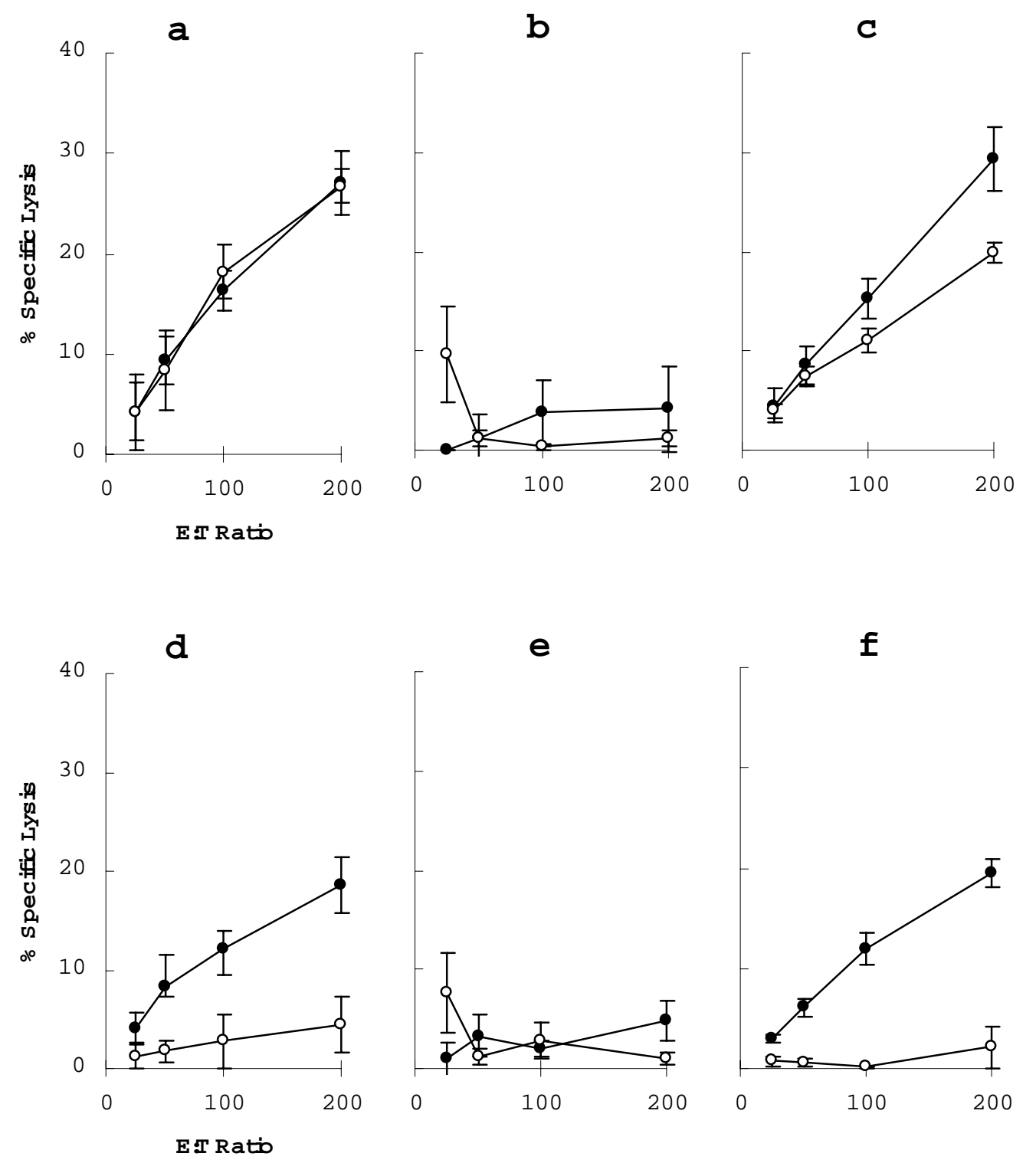

Figure 1. C57B1/6 mice are capable of eliciting a myosin-reactive CTL response following neonatal i.p. immunization with $S$. pyogenes. Groups of 4 to 6 mice were immunized by the i.p. route at least twice as adults $(\bigcirc)$ or within three days of birth $(\mathbf{O})$ with D471 (a, d), UAB152 (b, e), or D471* (c, f). Within seven days following the last immunization splenocytes were harvest and assayed for lytic activity against EL4 cells labeled with M protein (a, b, c) or myosin (d, e, f). Each animal was assayed individually and each point within the graph represents the combined geometric mean for each group. y-axis error bars represent the standard error. 

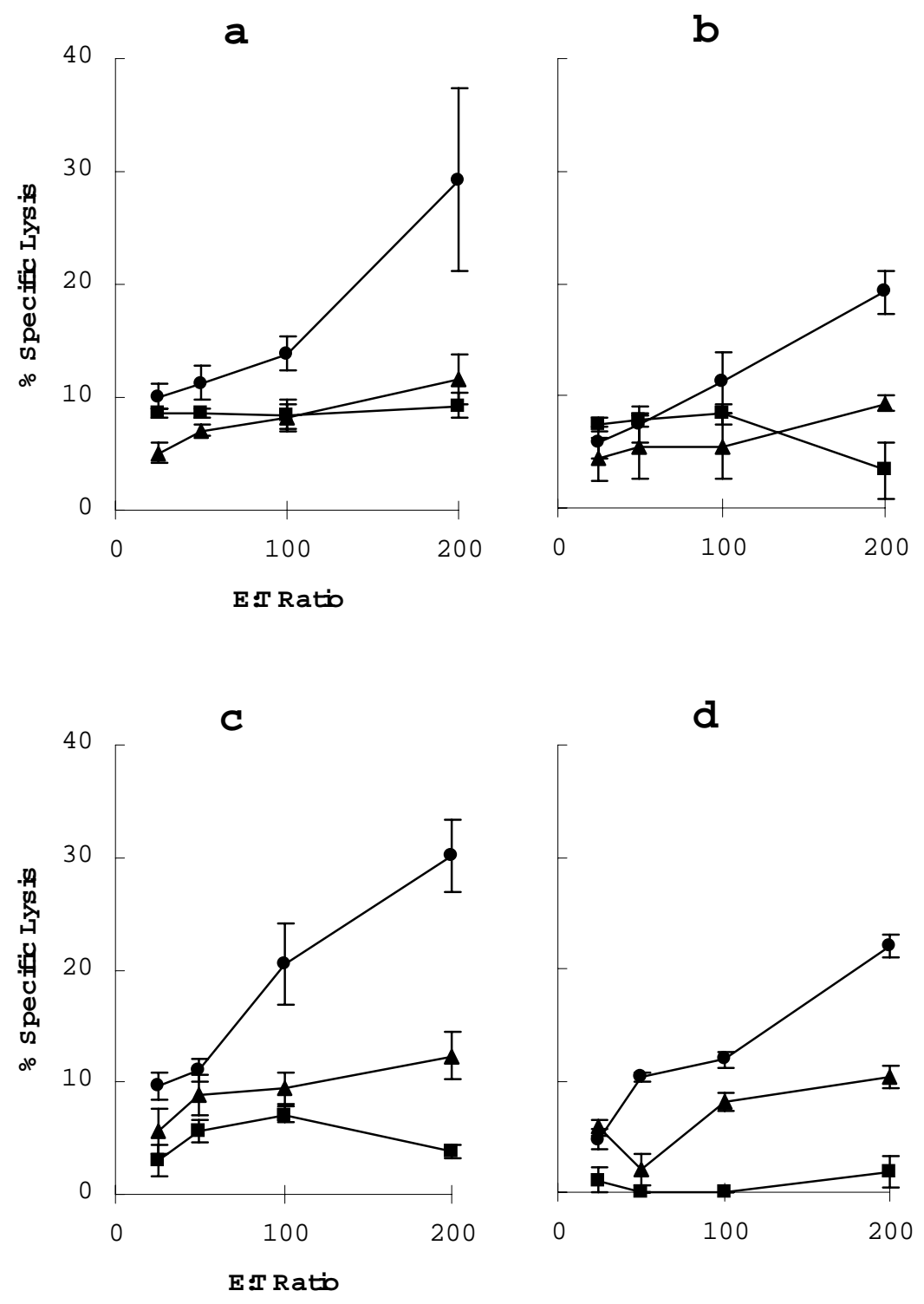

Figure 2. M protein is required but not exclusively responsible for the myosin-reactive CTL response. C57Bl/6 mice were immunized i.p. at least twice as adults with $200 \mu \mathrm{g}$ of recombinant $M$ protein subfragments $\mathrm{AB}_{6}(\mathrm{a})$ or $\mathrm{C}_{6}$ (b) or within three days of birth with $5 \mu \mathrm{g}$ of recombinant $\mathrm{M}$ protein (c) or $\mathrm{M}$ protein fragment $\mathrm{C}_{6}(\mathrm{~d})$ and boosted as adults. Within seven days following the last immunization splenocytes were harvested and assayed for lytic activity against $\mathrm{M}$ protein $(\boldsymbol{O})$, irrelevant control cytochrome c ( $\boldsymbol{\square})$ or myosin $(\boldsymbol{\Delta})$. Each graph represents the combined geometric mean for each group and the y-axis error bars represent the standard error. 

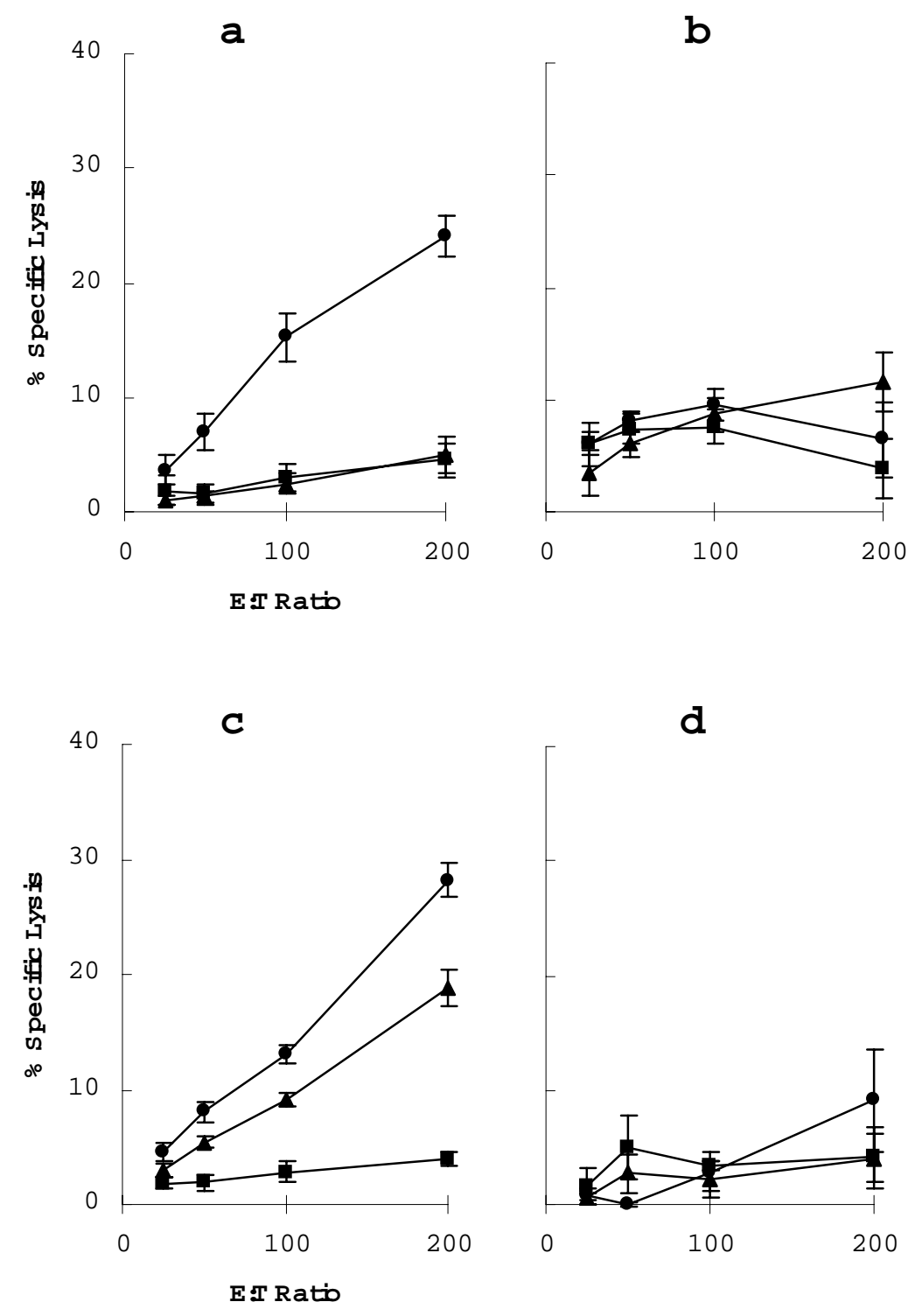

Figure 3. The myosin-reactive CTL response cannot be elicited by the intranasal route of immunization. Groups of four $\mathrm{C} 57 \mathrm{Bl} / 6$ mice were immunized with $\mathrm{D} 471$ as adults $(\mathrm{a}, \mathrm{b})$ or neonates $(c, d)$ by the i.p. route $(a, c)$ or i.n. route $(b, d)$ as described in material and methods. Splenocytes were harvested for cytolytic activity within seven days following the last i.p. immunization or ten days of the last i.n. immunization. Lytic activity was monitored against EL4 cells labeled with M protein $(\mathbf{O})$, cytochrome c $(\boldsymbol{\square})$ or myosin $(\boldsymbol{\Delta})$. 

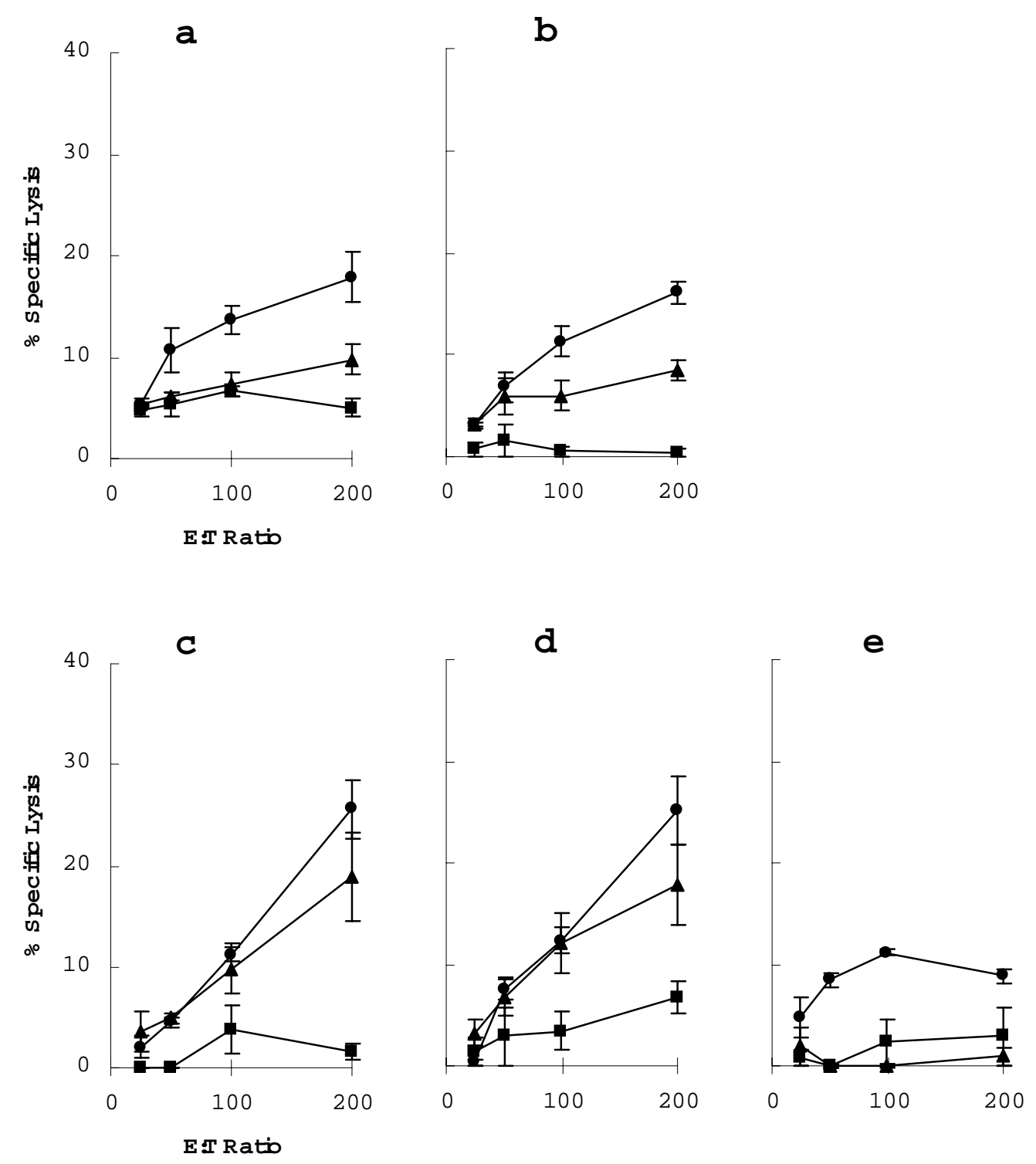

Figure 4. Intranasal immunization with $S$. pyogenes during the neonatal period primes for a systemic myosin-reactive CTL response. Groups of four to six C57Bl/6 mice were immunized by the i.n. route within three days post partum with either $2 * 10^{7} \mathrm{D} 471$ (a, c, e) or with D471* (b, d) and subsequently boosted as adults i.p. with $2 * 10^{8} \mathrm{D} 471$ (a, b) or $200 \mu \mathrm{g} \mathrm{M}$ protein (c, d) or i.n. with M protein (e). Seven to ten days following the last booster, splenocytes were assayed for lytic activity against EL4 cells labeled with M protein $(\mathbf{O})$, cytochrome c ( $\mathbf{\square})$ or myosin $(\boldsymbol{\Delta})$. Each animal was assayed individually and each point within the graph represents the combined geometric mean for each group. y-axis error bars represent the standard error. 

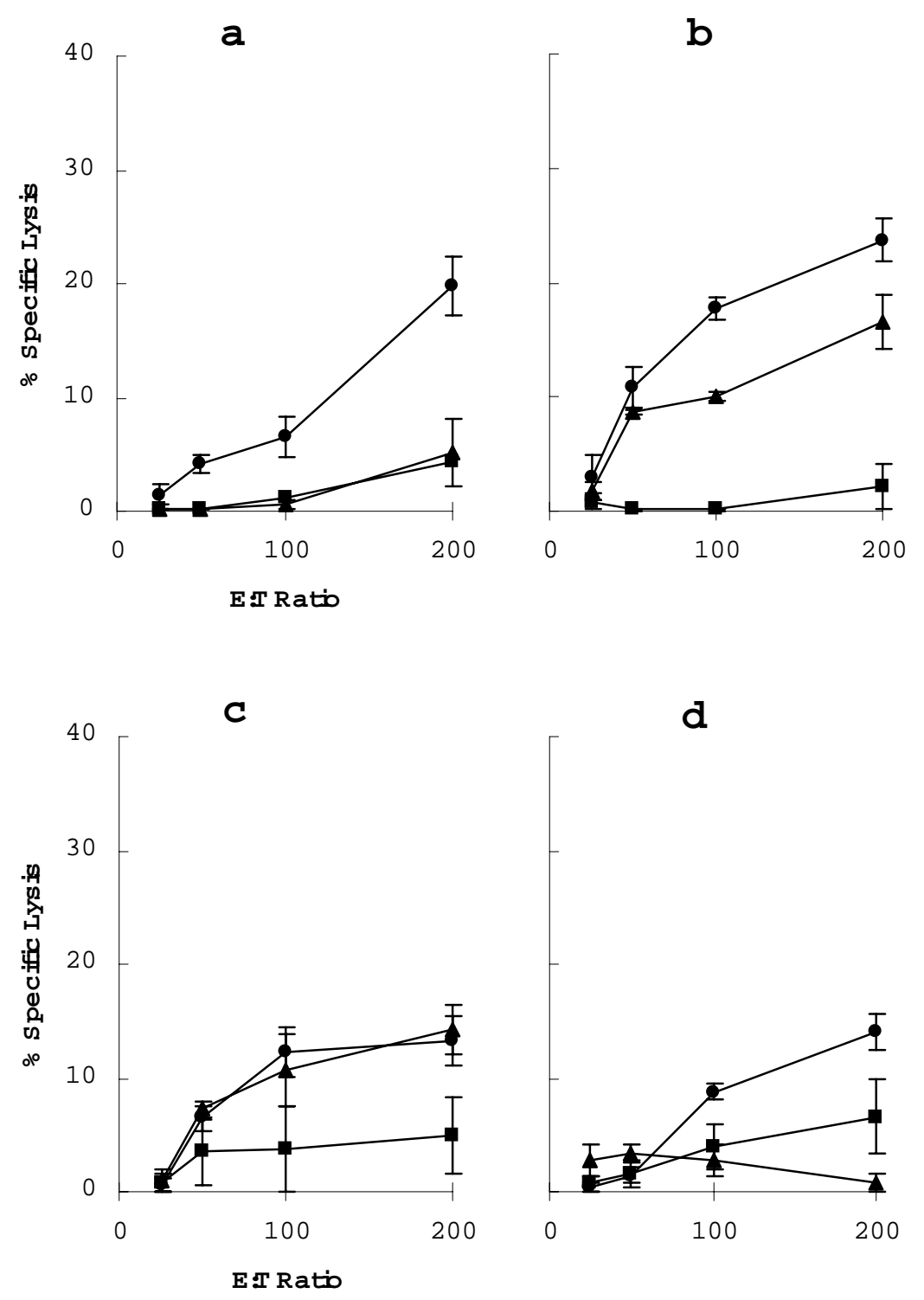

Figure 5. Role of B lymphocytes in the elicitation of the myosin-reactive CTL response. Groups of three to four C57B1/6 $\mathrm{Igh}^{-/-}$mice were immunized as outlined in material and methods with D471 by either the i.p. $(a, b)$ or i.n. $(c, d)$ route as adults $(a, c)$ or within three days post partum $(b, d)$. Splenocytes were harvested and assayed for lytic activity against M protein (-), myosin $(\boldsymbol{A})$ or cytochrome c ( $\mathbf{\square})$ as described in legend of figure 3. 
Table1. Potential role of genetics in the elicitation of a myosin-specific CTL response following neonatal immunization with $S$. pyogenes

\begin{tabular}{ccccc} 
Mouse strain $^{\mathrm{a}}$ & \multicolumn{2}{c}{$\mathrm{D} 471(\mathrm{M}+)$} & \multicolumn{2}{c}{ UAB152 (M-) } \\
& MP $^{\mathrm{b}}$ & MYO & MP & MYO \\
\hline \hline BALB/c $\left(\mathrm{H}-2^{\mathrm{d}}\right)$ & $+^{\mathrm{c}}$ & + & - & - \\
$\mathrm{C} 57 \mathrm{~B} 16\left(\mathrm{H}-2^{\mathrm{b}}\right)$ & + & + & - & - \\
$\mathrm{DBA} / 2\left(\mathrm{H}-2^{\mathrm{d}}\right)$ & + & + & - & + \\
$\mathrm{CBA} / \mathrm{J}\left(\mathrm{H}-2^{\mathrm{k}}\right)$ & + & - & - & - \\
\hline
\end{tabular}

${ }^{a}$ Groups of at least 4 mice were immunized i.p. within three days post partum with either heat-killed D471 or UAB152 vaccine and boosted once as adults i.p. with the same vaccine. The representative MHC haplotype is indicated within the parentheses.

${ }^{\mathrm{b}}$ Splenocytes were harvested within seven days of the final adult boosting immunization as assayed lytic activity against MHC matched target cells labeled with digests of M protein (MP), commercially prepared rabbit skeletal myosin (MYO) and the irrelevant control protein cytochrome c (not shown). All lysis against cytochrome c was negligible.

${ }^{\mathrm{c}}$ Results are represented with plus signs $(+)$ to indicate percent lysis above $20 \%$ or minus signs (-) indicating less than $10 \%$ lysis. All results represent the specific lysis at the effector to target cell ratio of $200: 1$. 


\section{REFERENCES}

1. Pruskakorn, S., B. Currie, E. Brandt, D. Martin, A. Galbraith, H. Phornphutkl, A. Manmontri, and M. Good. 1994b. Towards a Vaccine for Rheumatic Fever: identification of a conserved target epitope on M protein group A streptococci. Lancet 344:639-642.

2. Robinson, J. H., M. C. Case, and M. A. Kehoe. 1993. Characterization of a Conserved Helper T cell epitope from Group A streptococcal M proteins. Infect. Immun. 61:1062-1068.

3. Hayman, W. A., E. R. Brandt, W. A. Relf, J. Cooper, A. Saul, and G. M. F. 1997. Mapping the minimal murine $\mathrm{T}$ cell and $\mathrm{B}$ cell epitopes within a peptide vaccine candidate from the conserved region of the $\mathrm{M}$ protein of group A streptococcus. Int. Immunol. 9:17231733.

4. Yoshinaga, M., F. Figueroa, M. R. Wahid, R. H. Marcus, E. Suh, and J. B. Zabriskie. 1995. Antigenic specificity of lymphocytes isolated form valvular specimens of rheumatic fever patients. J. Autoimmunity 8:601-613.

5. Yang, L., P. Soprey, M. Wittner, and E. Fox. 1977. Streptococcal-induced cell mediated immune destruction of cardiac myofibers in vitro. J. Exp. Med. 146:344-360.

6. Smith, S., and P. Allen. 1993. The role of T cells in myosin-induced autoimmune myocarditis. Clin. Immunol. Immunopath. 68:100-106.

7. Rose, N., B. Ploier, and C. Ofner. 1990. Cardiac myosin-induced myocarditis. Heart autoantibodies are not involved in the induction of the disease. J. Immunol. 145:4094-4100.

8. Rodriguez, M., A. J. Dunkel, R. L. Thiemann, J. Leibowitz, M. Zijlstra, and R. Jaenisch. 1993. Abrogation of resistance to Theiler's virus-induced demyelination in $\mathrm{H}-2^{\mathrm{b}}$ mice deficient in beta 2-microglobulin. J. Immunol. 151:266-276.

9. Wang, B., A. Gonzalez, C. Benoist, and D. Mathis. 1996. The role of CD $8^{+}$T cells in the initiation of insulin-dependent diabetes mellitus. Eur. J. Immunol. 26:1762-1769.

10. Jiang, H., S. I. Zhang, and B. Pernis. 1992. Role of $C D 8^{+}$T cells in murine experimental allergic encephalomyelitis. Science 256:1213-1215.

11. Maddison, P. J. 1999. Autoantibodies in SLE. Disease associations. Adv. Exp. Med. Biol. 455:141-145.

12. Zabriskie, J. B., and J. E. Friedman. 1983. The role of heart binding antibodies in rheumatic fever. Adv. Exp. Biol. 161:457-470. 
13. Rock, K. L., L. Rothstein, S. Gamble, and C. Fleischacker. 1993. Characterization of antigen presenting cells that present exogenous antigens in association with class I MHC molecules. J. Immunol. 150:438-446.

14. Pfeifer, J. D., M. J. Wick, R. L. Roberts, K. Findlay, S. J. Normark, and C. V. Harding. 1993. Phagocytic processing of bacterial antigens for class I MHC presentation to T cells. Nature 361:359-362.

15. Harding, C. V. 1996. Class I MHC presentation of exogenous antigens. J. Clin. Immunol. 16:90-96.

16. Lin, R., M. J. Mamula, J. A. Hardin, and C. A. Janeway Jr. 1991. Induction of autoreactive B cells allows priming of autoreactive T cells. J. Exp. Med. 173:1433-1439.

17. Ertug, M. H. 1993. HLA-DR antigens in rheumatic fever and rheumatic heart disease patients. Br. J. Rheumatol. 32:347 -348.

18. Falk, J. A., J. L. Fleischman, J. B. Zabriskie, and R. E. Falk. 1973. A study of HL-A antigen phenotype in rheumatic fever and rheumatic heart disease patients. Tissue Antigens 3:173-178.

19. Gerbase-DeLima, M., L. C. Scala, J. Temin, D. V. Santos, and P. A. Otto. 1994. Rheumatic fever and the HLA complex. A cosegregation study. Circulation 89:138-141.

20. Gibofsky, A., A. Khanna, E. Suh, and J. B. Zabriskie. 1991. The genetics of rheumatic fever: relationship to streptococcal infection and autoimmune disease. J. Rheumatol. Suppl. 30:1-5.

21. Asano, M. S., and R. Ahmed. 1996. CD8 T cell memory in B cell-deficient mice. J. Exp. Med. 183:2165-2174. 


\section{General Discussion}

Non-suppurative autoimmune complications such as acute rheumatic fever and glomerulonephritis are potential outcomes following infection with Streptococcus pyogenes, especially for children. Research has focused onto two major hypotheses as to the induction of host cross-reactive immune responses. The first hypothesis suggests that hyper-immune responsiveness against various streptococcal antigens may trigger or exacerbate an existing quiescent autoimmune response (Ayoub 1991; Kotb 1998). Proponents have argued a role for the numerous streptococcal superantigens and drawn attention to the elevated serum antibody titers witnessed in post-streptococcal autoimmune patients. The second major hypothesis argues that the autoimmune responses are due to direct antigen cross-reactivity between streptococcal and host components (Dale and Beachy 1985b; Cunningham et al. 1989; Yoshinaga et al. 1995). Advocates of the latter theory have focused primarily on the major immunodominant antigen, $\mathrm{M}$ protein, and the group specific carbohydrate, $\mathrm{N}$-acetylglucosamine.

The work presented within this dissertation has addressed the requirements of both the host and the immunizing organism for the induction of host cross-reactive immune responses in mice. First, we investigated the qualitative differences between the antibody response generated in mice as a function of age and $\mathrm{M}$ protein. Next, we performed a series of studies designed to investigate the capacity of S. pyogenes to induce host cross-reactive cytotoxic T cell responses in mice. Then, we attempted to determine what factors may play a role in the development of the cytotoxic $\mathrm{T}$ cell responses, including age and genetic background of the mice, the route of infection and the obligate role of $\mathrm{M}$ protein. 
Characterization of myosin cross-reactive monoclonal antibodies. Antibodies recognizing mammalian myosin are a hallmark characteristic of childhood post-streptococcal autoimmune complications. Antibody deposits have been described in biopsied tissue from ARF patients (Kaplan 1960; Kaplan et al. 1964b; Kemeny et al. 1989) as well as, serum anti-streptococcal antibodies that cross-react with myosin (Cunningham and Russell 1983; Cunningham et al. 1989). Immunizing laboratory animals with streptococcal cell wall or membrane preparations elicit antibody responses against various mammalian proteins, including myosin and keratin (Dale and Beachy 1985a; Dale and Beachy 1985b; Cunningham and Swerlick 1986; Kraus et al. 1990; Cunningham et al. 1992; Vashishtha and Fischetti 1993). However, despite their presence in humans and the ability to be induced in animals, assessing a role for such antibodies has proven difficult. Likewise, the requirements for their elicitation are not well understood.

Our results would suggest that both the age of the animal and the presence of $\mathrm{M}$ protein maintain a pivotal role in the development of a myosin cross-reactive antibody response. We have observed that in BALB/c mice a single neonatal immunization with heat-killed $S$. pyogenes vaccine will induce persistent antibody titers against the group specific determinant $\mathrm{N}$ acetylglucosamine, a portion of which cross-react with myosin. Interestingly, while immunizing adult $\mathrm{BALB} / \mathrm{c}$ mice with the vaccine does not elicit a cross-reactive antibody response, giving a secondary challenge with recombinant $\mathrm{M}$ protein or mouse skeletal myosin will induce the development of myosin cross-reactive antibody responses. Western blot analysis of representative hybridomas indicate that the cross-reactive antibodies produced in mice immunized as neonates with S. pyogenes recognize GlcNAc and cross-react predominantly with the cardiac isoforms of mouse myosin. In contrast, antibodies elicited in mice immunized as 
adults with S. pyogenes and boosted with either myosin or M protein recognize most cardiac and skeletal isoforms of mouse myosin.

The myosin cross-reactive antibodies elicited following a single neonatal exposure to $S$. pyogenes have been shown to persist within the sera up to 60 weeks beyond the immunization. Maintaining this serum antibody response is unique to the neonatal animal and is characteristic of the exaggerated antibody response in post-streptococcal autoimmunity patients (Appleton et al. 1985; Ayoub 1991). Considering that the cross-reactive antibodies predominantly recognize GlcNAc, a classical $\mathrm{T}$ independent antigen, the sustainment of the response is probably not likely due to lymphocytic memory. Therefore, it is conceivable that the cross-reactive antibody response is maintained as the result of cross-recognition to host antigens. Additionally, it may be postulated that the antibody response is chronically stimulated due to exposure to enteric commensal organisms in a manner similar to the immune response maintained against blood group antigens (Drach et al. 1972, Yang and Boettcher 1992).

We have demonstrated that age and $\mathrm{M}$ protein are two requirements for a myosin crossreactive antibody response, however the role for the autoreactive B cells and their antibody remains in question. Antibody deposition does occur in target tissue and is known to have a role in mediating tissue damage in certain autoimmune diseases, including post-streptococcal autoimmune glomerulonephritis (Richards 1991) and systemic lupus erythematosus (Maddison 1999). Also, these autoreactive B cells producing cross-reactive antibodies may potentially serve as a means to induce autoreactive $T$ cell responses (Lin et al. 1991; Chan et al. 1999). However, CTL studies conducted by us and others (Asano and Ahmed 1996) using $\operatorname{Igh}^{-/-}$mice indicate that B cells has no direct significance on the ability to either mount a primary or memory CTL response. 


\section{Requirements for the induction of a myosin-reactive cytotoxic $T$ cell response in mice. The}

pathology associated with ARF is believed to be primarily the result of a cellular mediated immune response. While it can be demonstrated that biopsied cardiac tissue from ARF patients contain extensive lymphocytic infiltrates (Raizada et al. 1983; Kemeny et al. 1994), it remains to be determined if these cells are recruited due to their ability to cross-react with host antigens (Manjula and Fischetti 1980; Guilherme et al. 1995; el-Demellawy et al. 1997) or as a by-product of an overzealous immune response (Cairns 1988; Alarcon-Riquelme et al. 1990; Bhatnagar et al. 1999).

It has been our observation that neonatal immunization with heat-killed $S$. pyogenes elicits a myosin-reactive cytotoxic T cell response. Producing a T cell response against an extracellular antigen in neonatal mice can present some obstacles. First, it has been traditionally viewed that neonatal immunization will not elicit a productive immune response either due to the induction of tolerance (Billingham et al. 1953) or immune deviation (Singh et al. 1996; Adkins and Du 1998). Neonates are capable of eliciting protective CTL responses, whether antiallogenic (Pilarski 1977), against viral challenge (Sarzotti et al. 1996; Siegrist et al. 1998) or following DNA vaccination (Pertmer and Robinson 1999). Furthermore, neonatally thymectomized mice produce a Th1 response upon challenge with soluble protein later in life suggesting that $\mathrm{T}$ cells have fully mature capacity as early as day one of life (Adkins and Du 1998). Secondly, the ability of an exogenous antigen like GAS to enter the class I processing and presentation pathway is not completely understood. Observations have been made indicating that extracellular particulate antigens, whether protein coated beads or extracellular bacteria, can be processed and presented via class I by activated macrophages in vitro (Pfeifer et al. 1993; Rock et al. 1993; Kovacsovics-Bankowski and Rock 1995; Harding 1996). 
Based on our observation, the myosin-reactive CTL response induced in neonatal mice is primarily the result of antigenic cross-reactivity to streptococcal M protein. A large body of literature exists detailing the importance of $\mathrm{M}$ protein in streptococcal infections and subsequent autoimmune complications. M protein is known to share antigenic determinants with myosin (Manjula and Fischetti 1980; Manjula et al. 1985; Manjula and Fischetti 1986) and myocarditis can be induced in $\mathrm{MRL} / /^{++}$mice with an M protein peptide sharing homology with myosin (Huber and Cunningham 1996). Furthermore, several laboratory studies have shown that M protein has the potential to induce cytotoxic $\mathrm{T}$ cell responses with the capacity to kill myocardial cells (Friedman et al. 1971; Yang et al. 1977; Dale and Beachey 1987; Kotb et al. 1989; el-Demellawy et al. 1997). In addition to underscoring the importance of M protein, we have also demonstrated that the potential cross-reactive epitopes lies within the carboxy terminal region or, more specifically the $\mathrm{C}$ sequence repeat region. $\mathrm{M}$ protein is classified into two major classes based upon C region sequence where class I is more associated with autoimmunity (Bessen et al. 1989). We also have found that streptococcal strains expressing class I M protein were more capable of eliciting myosin-reactive CTL responses. These observations are important considering the efforts underway to develop a streptococcal vaccine designed with $\mathrm{M}$ protein conserved region (Robinson et al. 1993; Pruskakorn et al. 1994a; Pruskakorn et al. 1994b).

Our observations support the hypothesis of autoimmunity as a result of antigenic crossreactivity however, we also wanted to address other conditions, apart from age of immunization, which may contribute to autoimmune susceptibility. The potential role genetics may play in the development of post-streptococcal autoimmune complications has been the focus of much research, not only as a factor that dictates hyperimmunity to streptococcal infections (Greenberg et al. 1981; Hafez et al. 1990) but also as a correlation factor for the susceptibility to post- 
streptococcal autoimmune diseases (Greenberg et al. 1975; Gibofsky et al. 1991; Ertug 1993). In a preliminary study we have shown the genetic background, or MHC haplotype, of the animal can dictate the ability to develop a CTL response against myosin as a result of neonatal immunization with $S$. pyogenes. While we were able to elicit a myosin-reactive CTL response in three strains of mice representing two distinct haplotypes, further experimentation with other backgrounds is desirable.

The route of immunization appears to be another important factor pertaining to the capability to elicit a myosin-reactive CTL response. We have observed in BALB/c and C57Bl/6, two distinct genetic backgrounds, that systemic immunization of neonatal mice with $S$. pyogenes vaccine will elicit a myosin specific CTL response. Immunizing these mice intranasally with $S$. pyogenes, as a means to mimic the natural infectious route, does not yield a measurable CTL response to either $\mathrm{M}$ protein or myosin, unless a systemic booster of vaccine or $\mathrm{M}$ protein is administered later in life. These results have potential application to the human situation, in that, where streptococcal skin infections may lead to only AGN, streptococcal throat infections may lead to one of several autoimmune disorders including ARF, AGN, and psoriasis. Taken together, this would suggest that an initial intranasal or nasopharyngeal exposure to antigen may stimulate a potentially cross-reactive systemic immune response that can be restimulated and detected following systemic challenge with $S$. pyogenes or an antigenic component thereof, namely M protein.

Conclusion. Despite the extent to which the cross-reactive antibody and cytolytic response can be induced, we did not observe any pathological outcome however it does indicate the capability of $S$. pyogenes to overcome the immunological privilege of host proteins. Further these results do not definitively explain the mechanism underlying the elicitation of a myosin-reactive CTL 
response following neonatal exposure to wild-type S. pyogenes, they do provide clues into the requirements to the development such a response. Accordingly, it appears that the most important factors are the age of the animal at the initial immunization and the presence of $\mathrm{M}$ protein. Other factors potentially regulating the elicitation of a myosin CTL response include the genetic background of the animal and route of immunization. Taken together our results would suggest that in a genetically susceptible individual local exposure to the organism has a lasting, potentially deleterious, effect upon a subsequent systemic immune response and if the necessary streptococcal antigens, namely M protein, gain access systemically the primed autoreactive immune response will be activated and potentially initiate the pathology characteristic of poststreptococcal autoimmune diseases. 


\section{General References}

Abbott, W. G., M. A. Skinner, L. Voss, D. Lennon, P. L. Tan, J. D. Fraser, I. J. Simpson, R. Ameratunga and A. Geursen. 1996. Repertoire of transcribed peripheral blood T-cell receptor beta chain variable-region genes in acute rheumatic fever. Infect. Immun. 64:2842-2845.

Abe, J., J. Forrester, T. Nakahara, J. A. Lafferty, B. L. Kotzin and D. Y. Leung. 1991. Selective stimulation of human $\mathrm{T}$ cells with streptococcal erythrogenic toxins A and B. J. Immunol. 146:3747-3750.

Adkins, B. and R. Du. 1998. Newborn mice develop balanced Th1/Th2 primary effector responses in vivo but are biased to Th2 secondary responses. J. Immunol. 160:4217 - 4224.

Adkins, B., A. Ghanei and K. Hamilton. 1994. Up-regulation of murine neonatal T helper cell responses by accessory cell factors. J. Immunol. 153:3378-3385.

Alarcon-Riquelme, M. E., D. Alarcon-Segovia, A. Loredo-Abdala and J. Alcocer-Varela. 1990. T lymphocyte subsets, suppressor and contrasuppressor cell functions, and production of interleukin-2 in the peripheral blood of rheumatic fever patients and their apparently healthy siblings. Clin. Immunol. Immunopath. 55:120-128.

Amoils, B., R. C. Morrison, A. A. Wadee, R. Marcus, D. Ninin, P. King, P. Sareli, S. Levin and A. R. Rabson. 1986. Aberrant expression of HLA-DR antigen on valvular fibroblasts from patients with active rheumatic carditis. Clin. Exp. Immunol. 66:88-94.

Anastasiou-Nana, M. I., J. L. Anderson, J. F. Carlquist and J. N. Nanas. 1986. HLA-DR typing and lymphocyte subset evaluation in rheumatic heart disease: a search for immune response factors. Am. Heart. J. 112:992-997.

Anthony, B. F., E. L. Kaplan and L. W. Wannamaker. 1969. Attack rate of acute nephritis after type 49 streptococcal infection of skin and the respiratory tract. J. Clin. Invest. 48:16971704.

Appleton, R. S., V. E. Benjamin, D. Tamer and E. M. Ayoub. 1985. Specificity of persistence of antibody to the streptococcal group A carbohydrate in rheumatic valvular heart disease. J. Lab. Clin. Med. 105(1):114-119.

Arulanandam, B. P., V. H. Van Cleave and D. W. Metzger. 1999. IL-12 is a potent neonatal vaccine adjuvant. Eur. J. Immunol. 29:256-264.

Asano, M. S. and R. Ahmed. 1996. CD8 T cell memory in B cell-deficient mice. J. Exp. Med. 183:2165-2174. 
Astori, M., D. Finke, O. Karapetian and H. Acha-Orbea. 1998. Development of T-B collaboration in neonatal mice. Int. Immunol. 11:445-451.

Ayoub, E. M. 1991. Host-parasite interaction in the pathogenesis of rheumatic fever. J. Rheumatol. 18:6-13.

Ayoub, E. M., D. J. Barrett, M. N. K. and J. P. Krischer. 1986. Association of class II human histocompatibility leukocyte antigens with rheumatic fever. J. Clin. Invest. 77: 2019-2026.

Ayoub, E. M. and C. S. Chun. 1990. Nonsuppurative complications of group A streptococcal infection. Adv. Pediatr. Infect. Dis. 5:69-92.

Baker, B. S., A. F. Swain, H. Valdimarsson and L. Fry. 1984a. T cell subpopulations in the blood and skin of patients with psoriasis. Brit. J. Dermatol. 110:37-44.

Baker, B. S., A. F. Swain and L. Fry. 1984b. Epidermal T lymphocytes and HLA-DR expression in psoriasis. Brit. J. Dermatol. 110:555-564.

Baker, B. S., A. V. Powles, H. Valdimarsson and L. Fry. 1988. An altered response by psoriatic keratinocytes to gamma interferon. Scand. J. Immunol. 28:735-740.

Baker, B. S. and L. Fry. 1992. The immunology of psoriasis. Brit. J. Dermatol. 126:1-9.

Baker, B. S., S. Bokth, A. V. Powles, J. J. Garioch, H. Lewis, H. Valdimarsson and L. Fry. 1993. Group A streptococcal antigen-specific T lymphocytes in guttate psoriatic lesions. Brit. J. Dermatol. 128:493-499.

Bata-Csorgo, Z., C. Hammerberg and J. J. Voorhees. 1995. Kinetics and regulation of human keratinocyte stem cell growth in short-term primary ex vivo culture. Cooperative growth factors from psoriatic lesional $\mathrm{T}$ lymphocytes stimulate proliferation among psoriatic uninvolved, but not normal, stem keratinocytes. J. Clin. Invest. 95:317-327.

Beachey, E. H. and W. A. Simpson. 1982. The adherence of group A streptococci to oropharyngeal cells: the lipoteichoic acid adhesin and fibronectin receptor. Infection 10:107-111.

Beachey, E. H., W. A. Simpson, I. Ofek, D. L. Hasty, J. B. Dale and E. Whitnack. 1983. Attachment of Streptococcus pyogenes to mammalian cells. Rev. Infect. Dis. 5:S670-677.

Beachey, E. H. and G. H. Stollerman. 1973. Mediation of cytotoxic effects of streptococcal M protein by nontype-specific antibody in human sera. J. Clin. Invest. 52:2563-2567.

Bennett, S. R., F. R. Carbone, F. Karamalis, J. F. A. P. Miller, and W. R. Heath. 1997. Induction of a CD8 cytotoxic T lymphocyte response by cross-priming requires cognate CD4 help. J. Exp. Med. 186:65-70. 
Bennett, S. R., F. R. Carbone, F. Karamalis, J. F. A. P. Miller, and W. R. Heath. 1998. Help for inducing cytotoxic $\mathrm{T}$ cell responses by cross-priming is mediated via CD40 signaling. Nature 393:478-480.

Berrios, X., F. Quesney, A. Morales, J. Blazques, E. Lagomarsino and A. L. Bisno. 1986. Acute rhuematic fever and post streptococcal glomerulonephritis in an open population: comparative studies of epidemiology and bacteriology. J. Clin. Med. 108:535-542.

Bessen, D. 1994. Localization of immunoglobulin A-binding sites within M or M-like proteins of group A streptococci. Infect. Immun. 62:1968-1974.

Bessen, D. and V. A. Fischetti. 1990. A human IgG receptor of group A streptococci is associated with tissue site of infection and streptococcal class. J. Infect. Dis. 161:747-754.

Bessen, D., K. Jones and V. Fischetti. 1989. Evidence for two distinct classes of streptococcal M protein and their relationship to rheumatic fever. J. Exp. Med. 169:269-283.

Bevan, M. J. 1976. Minor H antigens introduced on H-2 different stimulting cells cross-react at the cytotoxic T cell level during in vivo priming. J. Immunol. 117:2233-2238.

Bhatia, R., J. Narula, K. S. Reddy, M. Koicha, A. N. Malaviya, R. B. Pothineni, R. Tandon and M. L. Bhatia. 1989. Lymphocyte subsets in acute rheumatic fever and rheumatic heart disease. Clin. Cardiol. 12:34-38.

Bhatnagar, A., A. Grover and N. K. Ganguly. 1999. Superantigen-induced T cell responses in acute rheumatic fever and chronic rheumatic heart disease patients. Clin. Exp. Immunol. 116: 100-106.

Billingham, M. A., L. Brent and P. B. Medawar. 1953. Actively acquired tolerance of foreign cells. Nature 172: 603-606.

Bjerke, J. R., H. K. Krough and R. Matre. 1978. Characterization of mononuclear cell infiltrate in psoriatic lesions. J. Invest. Dermatol. 71:340-343.

Bohach, G. A., D. J. Fast, R. D. Nelson and P. M. Schlievert. 1989. Staphylococcal and streptococcal pyrogenic toxins involved in toxic shock syndrome and related illnesses. Crit. Rev. Microbiol. 17: 251-272.

Boyle, M. D. 1995. Variation of multifunctional surface binding proteins - a virulence strategy for group A streptococci? J. Theor. Biol. 173:415-426.

Braun, D. G., B. Kindred and E. B. Jacobson. 1972. Streptococcal group A carbohydrate antibodies in mice: evidence for strain differences in magnitude and restriction of the response, and for thymus dependence. Eur. J. Immunol. 2:138-143. 
Cairns, L. M. 1988. The immunology of rheumatic fever. N Z Med J 101:388-391.

Caparon, M., D. Stephens, A. Olsen and J. Scott. 1991. Role of M protein in adherence of group A streptococci. Infect. Immun. 59:1811-1817.

Caughey, D. E., R. Douglas, W. Wilson and I. B. Hassall. 1975. HL-A antigens in Europeans and Maoris with rheumatic fever and rheumatic heart disease. J. Rheumatol. 2: 319-322.

Cavelti, P. A. 1945. Autoantibodies in rheumatic fever. Proc. Soc. Exp. Biol. Med. 60:379-84.

Cedervall, T., P. Akesson, L. Stenberg, A. Herrmann and B. Akerstrom. 1995. Allosteric and temperature effects on the plasma protein binding by streptococcal M protein family members. Scand J Immunol 42:433-441.

Chan, O. T., M. P. Madaio and M. J. Shlomchik. 1999. The central and multiple roles of B cells in lupus pathogenesis. Immunol. Rev. 169:107-121.

Christophers, E. 1996. The immunopathology of psoriasis. Int. Arch. Allergy Immunol. 110:199-206.

Cleary, P. and D. Retnoningrum. 1994. Group A streptococcal immunoglobulin-binding proteins: adhesins, molecular mimicry or sensory proteins? Trends Microbiol. 2:131-136.

Coburn, A. F. and R. H. Pauli. 1935. Studies of the immune response of the rheumatic subject and its relationship to activity of the rheumatic process: IV. Characteristics of strains of hemolytic streptococcus, effective and noneffective in initiating rheumatic activity. J. Clin. Invest. 14:755-762.

Collis, W. R. F. 1932. Discussion on some problems concerning the prevention and treatment of acute rheumatic infection. Proc. R. Soc. Med. 25:1631-1636.

Congeni, B., C. Rizzo and J. Congeni. 1987. Outbreak of acute rheumatic fever in northeast Ohio. J. Pediatr. 111:176-179.

Cunningham, M., S. Antone, J. Gulizia, B. McManus, V. Fischetti and C. Gauntt. 1992. Cytotoxic and viral neutralizing antibodies cross react with streptococcal M protein, enteroviruses, and human cardiac myosin. Proc. Natl. Acad. Sci., USA 89:1320-1324.

Cunningham, M., K. Krisher and D. Graves. 1984. Murine monoclonal antibodies reactive with human heart and Group A streptococcal membrane antigens. Infect. Immun. 46:34-41.

Cunningham, M., J. McCormack, P. Fenderson, M. Ho, E. Beachey and J. Dale. 1989. Human and murine antibodies cross-reactive with streptococcal $\mathrm{M}$ proteins and myosin recognize the sequence Gln-Lys-Ser-Lys-Gln in M proteins. The Journal of Immunology 143: 2677-2683. 
Cunningham, M. and S. Russell. 1983. Study of heart-reactive antibody in antisera and hybridoma culture fluid against Group A Streptococci. Infect. Immun. 42:531-538.

Cunningham, M. and R. Swerlick. 1986. Polyspecificity of antistreptococcal murine monoclonal antibodies and their implications in autoimmunity. J. Exp. Med. 164:998-1012.

Cunningham, M. W., J. M. McCormack, L. R. Talaber, J. B. Harley, E. M. Ayoub, R. S. Muneer, L. T. Chun and D. V. Reddy. 1988. Human monoclonal antibodies reactive with antigens of the Group A Streptococcus and human heart. J. Immunol. 141:2760-2766.

Dajani, A. S. 1992. Guidelines for the diagnosis of rheumatic fever. Jones Criteria, 1992 update. Special Writing Group of the Committee on Rheumatic Fever, Endocarditis, and Kawasaki Disease of the Council on Cardiovascular Disease in the Young of the American Heart Association. JAMA 268:2069-2073.

Dale, J. and E. Beachy. 1985a. Epitopes of streptococcal M proteins shared with cardiac myosin. J. Exp. Med. 162:583-591.

Dale, J. B. and E. Beachy. 1985b. Multiple, heart cross-reactive epitopes of streptococcal M proteins. J. Exp. Med. 161:113-122.

Dale, J. B. and E. Beachey. 1987. Human cytotoxicity T lymphocytes evoked by Group A streptococcal M proteins. J. Exp. Med. 166:1825-1835.

Dale, J., W. A. Simpson, I. Ofek and E. H. Beachey. 1981. Blastogenic responses of human lymphocytes to structurally defined polypeptide fragments of streptococcal M protein. J. Immunol. 126(4):1499-1505.

Dale, J., R. Washburn, M. Marques and M. Wessels. 1996. Hyaluronate capsule and surface $\mathrm{M}$ protein in resistance to opsonization of group A streptococci. Infect. Immun. 64:1495-1501.

Degnan, B., J. Taylor, C. Hawkes, U. O'Shea, J. Smith, J. H. Robinson, M. A. Kehoe, A. Boylston and J. A. Goodacre. 1997. Streptococcus pyogenes type 5 M protein is an antigen, not a superantigen, for human T cells. Hum. Immunol. 53:206-215.

Delvig, A. A., M. A. Kehoe and J. H. Robinson. 1997. Phagocytic processing of two M protein T-cell epitopes from viable group A streptococci. Biochem. Soc. Trans. 25:205S.

Dillon, H. C. J. and M. S. Reeves. 1974. Streptococcal immune responses in nephritis after skin infections. Am. J. Med. 56:333-346.

Donermeyer, D. L., K. W. Beisel, P. M. Allen and S. C. Smith. 1995. Myocarditis-inducing epitope of myosin binds constitutively and stably to $\mathrm{I}^{-\mathrm{A}^{\mathrm{k}}}$ on antigen-presenting cells in the heart. J. Exp. Med. 182:1291-1300. 
Drach, G.W., W. P. Reed, and R. C. Williams Jr. 1972. Antigens common to human and bacterial cells. II. E. coli 014, the common Enterobacteriaceae antigen, blood groups A and B, and E. coli 086. J. Lab. Clin. Med. 79:38-46.

Dudding, B. A. and E. M. Ayoub. 1968. Persistence of streptococcal group A antibody in patients with rheumatic valvular disease. J. Exp. Med. 128:1081-1098.

Eichbaum, Q. G., E. J. Hughes, J. E. Epstein and D. W. Beatty. 1995. Rheumatic fever: autoantibodies against a variety of cardiac, nuclear, and streptococcal antigens. Ann. Rheum. Dis. 54:740-743.

El Kohly, A., D. N. Fraser and N. Guirguis. 1980. A controlled study of penicillin therapy of group A streptococcal acquisitions in Egyptian families. J. Infect. Dis. 141:759-771.

el-Demellawy, M., R. el-Ridi, N. Guirguis, M. Abdel Alim, A. Kotby and M. Kotb. 1997. Preferential recognition of human myocardial antigens by $\mathrm{T}$ lymphocytes from rheumatic heart disease patients. Infect. Immun. 65:2197-2205.

Emmrich, F., B. Schilling and K. Eichmann. 1985. Human immune response to group A streptococcal carbohydrate (A-CHO). I. Quantitative and qualitative analysis of the A-CHOspecific B cell population responding in vitro to polyclonal and specific activation. J. Exp. Med. 161:547-562.

England, R. J. A., D. R. Strachan and L. C. Knight. 1997. Streptococcal tonsillitis and its association with psoriasis: a review. Clin. Otolaryngol. 22:532-535.

Ertug, M. H. 1993. HLA-DR antigens in rheumatic fever and rheumatic heart disease patients. Br. J. Rheumatol. 32:347 -348.

Falk, J. A., J. L. Fleischman, J. B. Zabriskie and R. E. Falk. 1973. A study of HL-A antigen phenotype in rheumatic fever and rheumatic heart disease patients. Tissue Antigens 3:173-178.

Feeney, A. J. 1991. Junctional sequences of fetal T cell receptor beta chains have few $\mathrm{N}$ regions. J. Exp. Med. 174:115-124.

Fierlbeck, G. and G. Rassner. 1990. Treatment of psoriasis and psoriatic arthritis with interferon gamma. J. Invest. Dermatol. 95:138-141.

Fischetti, V., K. F. Jones and J. R. Scott. 1985. Size variation of the M protein in group A streptococci. J. Exp. Med. 161:1384-1401.

Fischetti, V. A. 1983. Requirements for the opsonic activity of human IgG directed to type 6 group A streptococci: net basic charge and intact Fc region. J. Immunol. 130:896-902. 
Fischetti, V. A. 1989. Streptococcal M protein: Molecular design and biological behavior. Clin. Microbiol. Rev. 2:285-314.

Fischetti, V. A. and M. Windels. 1988. Mapping the immunodeterminants of the complete streptococcal M6 protein molecule. J. Immunol. 141:3592-3599.

Fitzsimons, E. and C. F. Lange. 1991. Hybridomas to specific streptococcal antigen induce tissue pathology in vivo; autoimmune mechanisms for post-streptococcal sequelae.

Autoimmunity 10:115-124.

Fitzsimons, E., M. Weber and C. F. Lange. 1987. The isolation of cross-reactive monoclonal antibodies: Hybridomas to streptococcal antigen cross-reactive with mammalian basement membrane. Hybridoma 6:61-69.

Fleischer, B., K. Schmidt, D. Gerlach and W. Kohler. 1992. Separation of T-cell-stimulating activity from streptococcal M protein. Infect. Immun. 60:1767-1770.

Forsthuber, T., H. Yip and P. Lehmann. 1996. Induction of Th1 and Th2 Immunity in Neonatal Mice. Science 271:1728-1730.

Fraser, W. J., Z. Haffejee, D. Jankelow, A. Wadee and C. K. 1997. Rheumatic Aschoff nodules revisited. II: Cytokine expression corroborates recently proposed sequential stages. Histopathology 31:460-464.

Friedman, I., A. Laufer, N. Ron and A. Davies. 1971. Experimental myocarditis: In vitro and in vivo studies of lymphocytes sensitized to heart extracts and group A streptococci. Immunol. 20:225-232.

Ganguly, N. K., I. S. Anand, M. Koicha, S. Jindal and P. L. Wahi. 1992. Frequency of D8/17 B lymphocyte alloantigen in north Indian patients with rheumatic heart disease. Immunol. Cell. Biol. 70:9-14.

Gerbase-DeLima, M., L. C. Scala, J. Temin, D. V. Santos and P. A. Otto. 1994. Rheumatic fever and the HLA complex. A cosegregation study. Circulation 89:138-141.

Giardina, A. C. and S. Heaton. 1988. Acute rheumatic fever in New York City. NY State J. Med. 88:385-386.

Gibofsky, A., A. Khanna, E. Suh and J. B. Zabriskie. 1991. The genetics of rheumatic fever: relationship to streptococcal infection and autoimmune disease. J. Rheumatol. Suppl. 30:1-5.

Goldstein, I., B. Halpern and L. Robert. 1967. Immunological relationship between streptococcus A polysaccharide and the structural glycoproteins of heart valve. Nature 213:44-47. 
Gordis, L. 1985. The virtual disappearance of rheumatic fever in the United States: Lessons in the rise and fall of disease. Circulation 72:1155-1156.

Gottlieb, S. L., P. Gilleaudeal and R. Johnson. 1996. Response of psoriasis to a lymphocyte selective toxin (DAB389IL-2) suggests a primary immune, but not keratinocyte, pathogenesis basis. Nature Med. 1:442-447.

Greenberg, L. J., P. W. Bradley, R. L. Chopyk and J. M. Lalouel. 1980. Immunogenetics of response to a purified antigen from group A streptococci. I. Complex segregation analysis. Immunogenetics 11:145-146.

Greenberg, L. J., P. W. Bradley, R. L. Chopyk and J. M. Lalouel. 1981. Genetic control of response to streptococcal antigens: implication of two HLA-linked complementary loci. Transplant Proc. 13:992-994.

Greenberg, L. J., E. D. Gray and E. J. Yunis. 1975. Association of HL-A5 and immune responsiveness in vitro to streptococcal antigens. J. Exp. Med. 141:935-943.

Griffiths, C. E. M., A. V. Powles, J. N. Leonard, L. Fry, B. S. Baker and H. Valdimarsson. 1986. Clearance of psoriasis with low dose cyclosporin. Br. J. Med. 293:731-732.

Griffiths, S. P. and W. M. Gersony. 1990. Acute rheumatic fever in New York City (19691988): A comparative study of two decades. J. Pediatr. 116:882-887.

Guilherme, L., E. Cunha-Neto, V. Coelho, R. Snitcowsky, P. M. A. Pomerantzeff, R. V. Assis, F. Pedra, J. Neumann, A. Goldberg, M. E. Patarroyo, F. Pileggi and J. Kalil. 1995. Human heart-infiltrating $\mathrm{T}$ cell clones from rheumatic heart disease patients recognize both streptococcal and cardiac proteins. Circulation 92:415-420.

Guilherme, L., W. Weidebach, M. H. Kiss, R. Snitcowsky and J. Kalil. 1991. Association of human leukocyte class II antigens with rheumatic fever or rheumatic heart disease in a Brazilian population. Circulation 83:1995-1998.

Hafez, M., A. Abdalla, F. el-Shennawy, Y. al-Tonbary, A. Sheaishaa, Z. el-Morsi, S. Tawfik, A. Settien and M. Abou el-Khair. 1990. Immunogenetic study of the response to streptococcal carbohydrate antigen of the cell wall in rheumatic fever. Annals of Rheumatic Diseases 49:708-714.

Hagman, M. M., J. B. Dale and D. L. Stevens. 1999. Comparison of adherence to and penetration of a human laryngeal epithelial cell line by group A streptococci of various M protein types. FEMS Immunol. Med. Microbiol. 23:195-204.

Halbert, S. P., R. Bircher and E. Dahle. 1961. The analysis of streptococcal infections. V. Cardiotoxicity of streptolysin O for rabbits in vivo. J. Exp. Med. 113:759-65. 
Hanski, E. and M. Caparon. 1992. Protein F, a fibronectin-binding protein, is an adhesin of the group A streptococcus Streptococcus pyogenes. Proc. Natl. Acad. Sci., USA 89:6172-6176.

Harding, C. V. 1996. Class I MHC presentation of exogenous antigens. J. Clin. Immunol. 16:90-96.

Harris, S. L., L. Craig, J. S. Mehroke, M. Rashed, M. B. Zwick, K. Kenar, E. J. Toone, N. Greenspan, F. I. Auzanneau, J. R. Marino-Albernas, B. M. Pinto and J. K. Scott. 1997. Exploring the basis of peptide-carbohydrate cross-reactivity: evidence for discrimination by peptides between closely related anti-carbohydrate antibodies. Proc. Natl. Acad. Sci., USA 94:2454-2459.

Hasty, D. and H. Courtney. 1996. Group A streptococcal adhesion. All of the theories are correct. Adv. Exp. Med. Biol. 408:81-94.

Heath, W. R. and F. R. Carbone. 1999. Cytotoxic T lymphocyte activation by cross-priming. Curr. Opin. Immunol. 11:314-318.

Hoffman, T. M., L. A. Rhodes, L. A. Pyles, A. A. Balian, W. A. Neal and S. Einzig. 1997. Childhood acute rheumatic fever: A comparison of recent resurgence areas to cases in West Virginia. WV Med. J. 93: 260-263.

Hollander, E., G. DelGiudice-Asch, L. Simon, J. Schmeidler, C. Cartwright, C. M. DeCaria, J. Kwon, C. Cunningham-Rundles, F. Chapman and J. B. Zabriskie. 1999. B lymphocyte antigen D8/17 and repetitive behaviors in autism. Am. J. Psychiatry 156:317-320.

Hollingshead, S. K., V. A. Fischetti and J. R. Scott. 1986. Complete nucleotide sequence of type $6 \mathrm{M}$ protein of the group A streptococcus: repetitive structure and membrane anchor. J. Biol. Chem. 261:1677-1686.

Holm, S. E. 1988. The pathogenesis of acute post-streptococcal glomerulonephritis in new lights. APMIS 96:189-193.

Homer, C. and S. T. Shulman. 1991. Clinical aspects of acute rheumatic fever. J. Rheumatol. 18:2-13.

Horaud, T., A. Bouvet, R. Leclercq, H. de Montclos and M. Sicard, Eds. 1997. Streptococci and the Host. Adv. Exp. Med. Biol. New York, Plenum Press.

Horstmann, R. D., H. J. Sievertsen, J. Knobloch and V. A. Fischetti. 1988. Antiphagocytic activity of streptococcal $\mathrm{M}$ protein: selective binding of complement control protein factor $\mathrm{H}$. Proc. Natl. Acad. Sci., USA 85:1657-1661.

Horstmann, R. D., H. J. Sievertsen, M. Leippe and V. A. Fischetti. 1992. Role of fibrinogen in complement inhibition by streptococcal M protein. Infect. Immun. 60: 5036-5041. 
Hosein, B., M. McCarty and V. A. Fischetti. 1979. Amino acid sequence and physicochemical similarities between streptococcal $\mathrm{M}$ protein and mammalian tropomyosin. Proc. Natl. Acad. Sci., USA 76:3765-3768.

Hryniewicz, W., W. D. Gray, J. R. Tagg, L. W. Wannamaker, K. Kanclerski and N. Laible. 1978. Streptolysin S: purification and properties. Zbl. Bakt. Hyg. I. Abt. Orig. A. 242:327-328.

Huber, S. A. and M. W. Cunningham. 1996. Streptococcal M protein peptide with similarity to myosin induces $\mathrm{CD} 4{ }^{+} \mathrm{T}$ cell-dependent myocarditis in $\mathrm{MRL} /{ }^{++}$mice and induces partial tolerance against coxsakie viral myocarditis. J. Immunol. 156:3528-3534.

Husby, G., I. van de Rijn, J. B. Zabriskie, Z. H. Abdin and R. C. J. Williams. 1976. Antibodies reacting with cytoplasm of subthalamic and caudate nuclei neurons in chorea and acute rheumatic fever. J. Exp. Med. 144:1094-1110.

Husmann, L. K., D. L. Yung, S. K. Hollingshead and J. R. Scott. 1997. Role of putative virulence factors of Streptococcus pyogenes in mouse models of long-term throat colonization and pneumonia. Infect. Immun. 65:1422-1430.

Johnson, D. R., D. L. Stevens and E. L. Kaplan. 1992. Epidemiologic analysis of group A streptococcal serotypes associated with severe systemic infection, rheumatic fever or uncomplicated pharyngitis. J. Infect. Dis. 66:374-382.

Jones, K. F. and V. A. Fischetti. 1988. The importance of the location of antibody binding on the M6 protein for opsonization and phagocytosis of group A M6 streptococci. J. Exp. Med. 167: 1114-1123.

Kaplan, E. L., B. F. Anthony, S. S. Chapman, E. M. Ayoub and L. W. Wannamaker. 1970. The influence of the site of infection on the immune response to group A streptococci. J. Clin. Invest. 49:1405-1414.

Kaplan, M. H. 1960. The concept of autoantibodies in rheumatic fever and in the post commissurotomy state. Ann. NY Acad. Sci. 86:974-991.

Kaplan, M. H. 1963. Immunologic relation of streptococcal and tissue antigens. I. Properties of an antigen in certain strains of group A streptococci exhibiting an immunologic cross-reaction with human heart tissue. J. Immunol. 90:595-606.

Kaplan, M. H. and M. L. Suchy. 1964a. Immunologic relation of streptococcal and tissue antigens. II. Cross-reaction of antisera to mammalian heart tissue with a cell wall constituent of certain strains of Group A streptococci. J. Exp. Med. 119:643-649.

Kaplan, M. H., R. Bolande, L. Rakita and J. Blair. 1964b. Presence of bound immunoglobulins and complement in the myocardium of acute rheumatic fever. N. Engl. J. Med. 271:637-645. 
Kaplan, M. H. and J. D. Frengley. 1969. Autoimmunity to the heart in cardiac disease. Current concepts of the relation of autoimmunity to rheumatic fever, postcardiotomy and postinfarction syndromes and cardiomyopathies. American Journal of Cardiology 24:459-473.

Kasp-Grochowska, E., D. Kingston and L. E. Glynn. 1972a. Immunology of bovine heart valves. I. Cross-reaction with the C-polysaccharide of Streptococcus pyogenes. Ann. Rheum. Dis. 31:282-289.

Kasp-Grochowska, E., D. Kingston and L. E. Glynn. 1972b. Immunology of bovine heart valves. II. Reaction with connective tissue components. Ann. Rheum. Dis. 31:290-297.

Ke, Y. and J. A. Kapp. 1996. Exogenous antigens gain access to the major histocompatibility complex class I processing pathway in B cells by receptor-mediated uptake. J. Exp. Med. 184: 179-184.

Kehoe, M. A. 1991. New aspects of Streptococcus pyogenes pathogenicity. Rev. Med. Microbiol. 2:147-152.

Kemeny, E., T. Grieve, R. Marcus, P. Sareli and J. B. Zabriskie. 1989. Identification of mononuclear cells and $\mathrm{T}$ cell subsets in rheumatic valvulitis. Clin. Immunol. Immunopath. 52: 225-237.

Kemeny, E., G. Husby, R. C. Williams and J. B. Zabriskie. 1994. Tissue Distribution of Antigens Defined by Monoclonal Antibody D8/17 Reacting with B Lymphocytes of Patients with Rheumatic Heart Disease. Clin. Immunol. Immunopath. 72(1):35-43.

Kendall, F., M. Heidelberger and M. Dawson. 1937. A serologically inactive polysaccharide elaborated by mucoid strains of group A hemolytic streptococcus. J. Biol. Chem. 118:61-82.

Kennedy, H. L. and S. K. Das. 1976. Postmyocardial infarction (Dressler's) syndrome: report of a case with immunological and viral studies. Am. Heart. J. 91:233-239.

Kingston, D. and L. E. Glynn. 1971. A cross-reaction between Str. pyogenes and human fibroblasts, endothelial cells and astrocytes. Immunol. 21:1003-1016.

Klinman, D. M., S. Banks, A. Hartman and A. D. Steinberg. 1988. Natural autoantibodies and conventional antibodies exhibit degrees of antigenic cross-reactivity. J. Clin. Invest. 82:652-661. Kotb, M. 1998. Superantigens of gram-positive bacteria: structure-function analyses and their implications for biological activity. Curr. Opin. Microbiol. 1:56-65.

Kotb, M., H. S. Courtney, J. B. Dale and E. H. Beachey. 1989. Cellular and biochemical responses of human T lymphocytes stimulated with streptococcal M proteins. J. Immunol. 142: 966-970. 
Kovacsovics-Bankowski, M. and K. L. Rock. 1995. A phagosome-to-cytosol pathway for exogenous antigens presented on MHC class I molecules. Science 267:243-246.

Kraus, W. and E. H. Beachey. 1988. Renal autoimmune epitope of group A streptococci specified by M protein tetrapeptide Ile-Arg-Leu-Arg. Proc. Natl. Acad. Sci., USA 85:4516-4520.

Kraus, W., J. Dale and E. Beachy. 1990. Identification of an epitope of type 1 streptococcal M protein that is shared with a $43 \mathrm{kDa}$ protein of human myocardium and renal glomeruli. J. Immunol. 145:4089-4093.

Krisher, K. and M. W. Cunningham. 1985. Myosin: a link between streptococci and heart. Science 227:413-415.

Kurts, C., J. F. A. P. Miller, R. Subramanium, F. R. Carbone and W. R. Heath. 1998. Major histocompatibility complex class I-restricted cross-presentation is biased towards high dose antigens and those released during cellular destruction. J. Exp. Med. 188:409-414.

Kutukculer, N. and N. Narin. 1995. Plasma interleukin-7 (IL-7) and IL-8 concentrations in acute rheumatic fever and chronic rheumatic heart disease. Scand. J. Rheumatol. 24:383-385.

Lancefield, R. 1962. Current Knowledge of Type-Specific antigens of Group A Streptococci. J. Immunol. 89:307-313.

Land, M. A. and A. L. Bisno. 1983. Acute rheumatic fever: A vanishing disease in suburbia. JAMA 249:895-898.

Lange, C. F. 1995. Tracking the in vivo localization of streptococcal cell membrane (SCM) monoclonal antibodies: potential model for post-streptococcal sequelae. Res. Commun. Mol. Pathol. Pharmacol. 89:241-255.

Lee, R. E., A. A. Gaspari and M. T. Lotze. 1988. Interleukin 2 and psoriasis. Brit. J. Dermatol. 110:555-564.

Leung, D. Y. M., M. Gately and A. Trumble. 1995b. Bacterial superantigens induce T cell expression of the skin-selective homing receptor the cutaneous lymphocyte-associated antigen (CLA). J. Exp. Med. 181:747-753.

Leung, D. Y. M., B. J. Travers and R. Giorno. 1995a. Evidence for a streptococcal superantigen-driven process in acute guttate psoriasis. J. Clin. Invest. 96:2106-2112.

Levin, D. and H. Gershon. 1989. Antigen presentation by neonatal murine spleen cells. Cell. Immunol. 120:132-144.

Lewis, H. M., B. S. Baker and S. Bokth. 1993. Restricted T cell receptor V $\beta$ usage in the skin of patients with guttate and chronic plaque psoriasis. Brit. J. Dermatol. 129:514-520. 
Lichtman, M. and R. Weed. 1970. Electrophoretic mobility and N-acetyl neuraminic acid content of human normal and leukemic lymphocytes and granulocytes. Blood 35:12-22.

Lin, R., M. J. Mamula, J. A. Hardin and C. A. Janeway Jr. 1991. Induction of autoreactive B cells allows priming of autoreactive T cells. J. Exp. Med. 173:1433-1439.

Lottenberg, R., C. C. Broder and M. D. Boyle. 1987. Identification of a specific receptor for plasmin on a group A streptococcus. Infect. Immun. 55:1914-1918.

Lueker, R. D., Z. H. Abdin and R. C. J. Williams. 1975. Peripheral blood T and B lymphocytes during acute rheumatic fever. J. Clin. Invest. 55:975-985.

Maddison, P. J. 1999. Autoantibodies in SLE. Disease associations. Adv. Exp. Med. Biol. 455: 141-145.

Maharaj, B., M. G. Hammond, B. Appadoo, W. P. Leary and D. J. Pudifin. 1987. HLA-A, $\mathrm{B}, \mathrm{DR}$, and DQ antigens in black patients with severe chronic rheumatic heart disease. Circulation 76:259-261.

Manjula, B. and V. Fischetti. 1980. Tropomyosin-like seven residue periodicity in three immunologically distinct streptococcal $\mathrm{M}$ proteins and its implications for the antiphagocytic property of the molecule. J. Exp. Med. 151:695-708.

Manjula, B. and V. Fischetti. 1986. Sequence homology of group A streptococcal pepM5 protein with other coiled-coil proteins. Biochem. Biophys. Res. Commun. 140:684-690.

Manjula, B. N., B. L. Trus and V. A. Fischetti. 1985. Presence of two distinct regions in the coiled-coil structure of the streptococcal Pep M5 protein: relationship to mammalian coiled-coil proteins and implications to its biological properties. Proc. Natl. Acad. Sci., USA 82:1064-1068.

Markowitz, A. S. and C. F. J. Lange. 1964. Streptococcal related glomerulonephritis. I. Isolation, immunochemistry and comparative chemistry of soluble fractions from type 12 nephritogenic streptococci and human glomeruli. J. Immunol. 92:565-571.

Marrack, P. and J. W. Kappler. 1990. The staphylococcal enterotoxins and their relatives. Science 248:705-711.

Maxted, W. R. 1956. The indirect bactericidal test as a means of identifying antibody to the M antigen of Streptococcus pyogenes. Brit. J. Exp. Pathol. 37:415-422.

McFadden, J., H. Valdimarsson and L. Fry. 1991. Cross-reactivity between streptococcal M surface antigen and human skin. Brit. J. Dermatol. 125:433-437. 
Miller, L. C., E. D. Gray, M. Mansour, Z. H. Abdin, R. Kamel, S. Zaher and W. E. Regelmann. 1989. Cytokines and immunoglobulin in rheumatic heart disease: production by blood and tonsillar mononuclear cells. J. Rheumatol. 16:1436-1442.

Morel, P., J. P. Revillard, J. F. Nicolas, J. Wijdenes, H. Rizova and J. Thivolet. 1992. AntiCD4 monoclonal antibody therapy in severe psoriasis. Autoimmunity 5: 465-77.

Mori, K., Y. Ito, N. Kamikawaji and T. Sasazuki. 1997. Elevated IgG titer against the C region of streptococcal $\mathrm{M}$ protein and its immunodeterminants in patients with post-streptococcal acute glomerulonephritis. J. Pediatr. 131:293-299.

Morris, J. E., J. T. Hoyer and S. K. Pierce. 1992. Antigen presentation for T cell interleukin-2 secretion is a late acquisition of neonatal B cells. Eur. J. Immunol. 22:2923-2928.

Morris, K., C. Mohan, P. L. Wahi, A. I. S. and N. K. Ganguly. 1993a. Increase in activated T cells and reduction in suppressor/cytotoxic $\mathrm{T}$ cells in acute rheumatic fever and active rheumatic heart disease: a longitudinal study. J. Infect. Dis. 167:979-983.

Morris, K., C. Mohan, P. L. Wahi, I. S. Anand and N. K. Ganguly. 1993b. Enhancement of IL-1, IL-2 production and IL-2 receptor generation in patients with acute rheumatic fever and active rheumatic heart disease; a prospective study. Clin. Exp. Immunol. 91:429-436.

Morrissey, P. J., D. Bradley, S. O. Sharrow and A. Singer. 1983. T cell tolerance to non-H-2encoded stimulatory alloantigens is induced intrathymically but not prethymically. J. Exp. Med. 158:365-377.

Narin, N., N. Kutukculer, R. Ozyurek, A. R. Bakiler, A. Parlar and M. Arcasoy. 1995. subsets and plasma IL-1 alpha, IL-2, and TNF-alpha concentrations in acute rheumatic fever and chronic rheumatic heart disease. Clin. Immunol. Immunopath. 77:172-176.

Neu, N., C. Pummerer, T. Rieker and P. Berger. 1993. T cells in cardiac myosin-induced myocarditis. Clin. Immunol. Immunopath. 68:107-110.

Nilson, B., I. Frick, P. Akesson, S. Forsen, L. Bjorck, B. Akerstrom and M. Wikstrom. 1995. Structure and stability of protein H and the M1 protein from Streptococcus pyogenes. Implications for other surface proteins of gram-positive bacteria. Biochemistry 34:13688-13698.

Nordstrand, A., M. Norgren, J. J. Ferretti and S. E. Holm. 1998. Streptokinase as a mediator of acute post-streptococcal glomerulonephritis in an experimental mouse model. Infect. Immun. 66:315-321.

Nordstrand, A., M. Norgren and S. E. Holm. 1996. An experimental model for acute poststreptococcal glomerulonephritis in mice. APMIS 104:805-816. 
O'Connor, S. P., D. Darip, K. Fraley, C. M. Nelson, E. L. Kaplan and P. P. Cleary. 1991. The human antibody response to streptococcal C5a peptidase. J. Infect. Dis. 163:109-116.

O'Toole, P., L. Stenberg, M. Rissler and G. Lindahl. 1992. Two major classes in the M protein family in group A streptococci. Proc. Natl. Acad. Sci., U.S.A. 89:8661-8665.

Okada, N., M. K. Liszewski, J. P. Atkinson and M. Caparon. 1995. Membrane cofactor protein (CD46) is a keratinocyte receptor for the M protein of the group A streptococcus. Proc. Natl. Acad. Sci., USA 92:2489-2493.

Okada, N., A. P. Pentland, P. Falk and M. G. Caparon. 1994. M protein and protein F act as important determinants of cell-specific tropism of Streptococcus pyogenes in skin tissue. J. Clin. Invest. 94:965-977.

Patarroyo, M. E., R. J. Winchester, A. Vejerano, A. Gibofsky, F. Chalem, J. B. Zabriskie and H. G. Kunkel. 1979. Association of a B-cell alloantigen with susceptibility to rheumatic fever. Nature 278:173-174.

Perez-Lorenzo, R., J. F. Zambrano-Zaragoza, A. Saul, L. Jimenez-Zamudio, E. ReyesMaldonado and E. Garcia-Latorre. 1998. Autoantibodies to autologous skin in guttate and plaque forms of psoriasis and cross-reaction of skin antigens with streptococcal antigens. Int. J. Dermatol. 37:524-531.

Pertmer, T. M. and H. L. Robinson. 1999. Studies on antibody responses following neonatal immunization with influenza hemagglutinin DNA or protein. Virology 257:406-414.

Petty, R. E. and D. W. Hunt. 1998. Neonatal dendritic cells. Vaccine 16:1378-1382.

Pfeifer, J. D., M. J. Wick, R. L. Roberts, K. Findlay, S. J. Normark and C. V. Harding. 1993. Phagocytic processing of bacterial antigens for class I MHC presentation to T cells. Nature 361:359-362.

Phillips, G., P. Flicker, C. Cohen, B. Manjula and V. Fischetti. 1981. Streptococcal M protein: alpha-helical coiled-coil structure and arrangement on the cell surface. Proceedings from the National Academy of Science USA 78:4689-4693.

Pilarski, L. 1977. Ontogeny of cell-mediated immunity. I. Early development of alloantigenspecific cytotoxic T-cell precursors in postnatal mice. J. Exp. Med. 146:887-892.

Prehm, S., C. Herrington, V. Nickel, W. Volker, N. I. Briko, E. I. Blinnikova, A. Schmiedel and P. Prehm. 1995. Antibodies against proteins of streptococcal hyaluronate synthase bind to human fibroblasts and are present in patients with rheumatic fever. J. Anat. 187:271-277.

Prinz, J. C. 1997. Psoriasis vulgaris, streptococci, and the immune system: a riddle to be solved soon? Scand. J. Immunol. 45:583-586. 
Prinz, J. C., B. Gross and S. Vollmer. 1994. T cell clones from psoriasis skin lesions can promote keratinocyte proliferation in vitro. Eur. J. Immunol. 24:593-598.

Pruskakorn, S., B. Currie, E. Brandt, C. Phornphutkl, H. Somchai, A. Manmontri, J. Robinson, M. Kehoe, A. Galbraith and M. Good. 1994a. Identification of T cell autoepitopes that cross-react with the $\mathrm{C}$-terminal segment of the $\mathrm{M}$ protein of Group A streptococci. Int. Immunol. 6:1235-1244.

Pruskakorn, S., B. Currie, E. Brandt, D. Martin, A. Galbraith, H. Phornphutkl, A. Manmontri and M. Good. 1994b. Towards a Vaccine for Rheumatic Fever: identification of a conserved target epitope on M protein group A streptococci. Lancet 344:639-642.

Pruskakorn, S., A. Galbraith, R. Houghten and M. Good. 1992. Conserved T and B cell epitopes on the M protein of Group A Streptococci: Induction of bactericidal antibodies. J. Immunol. 149:2729-2735.

Pummerer, C., P. Berger, M. Fruhwirth, C. Ofner and N. Neu. 1991. Cellular infiltrate, major histocompatibility antigen expression and immunopathogenic mechanisms in cardiac myosin-induced myocarditis. Lab. Invest. 65:538-547.

Pummerer, C. L., G. Grassl, M. Sailer, K. W. Bachmaier, J. M. Penninger and N. Neu. 1996. Cardiac myosin-induced myocarditis: target recognition by autoreactive $\mathrm{T}$ cells requires prior activation of cardiac interstitial cells. Lab. Invest. 74:845-852.

Quinn, R. W., R. V. Zwaag and P. N. Lowry. 1985. Acquisition of group A streptococcal M protein antibodies. Pediatr. Infect. Dis. J. 4:374-378.

Raizada, V., R. C. J. Williams, P. Chopra, N. Gopinath, K. Prakash, K. B. Sharma, K. M. Cherian, S. Panday, R. Arora, M. Nigam, J. B. Zabriskie and G. Husby. 1983. Tissue distribution of lymphocytes in rheumatic heart valves as defined by monoclonal anti-T cell antibodies. Am. J. Med. 74:90-96.

Rajajee, S., P. R. Narayanan, S. G. Moses and N. Sundaravalli. 1984. Cell mediated immunity in post-streptococcal glomerulonephritis. Indian Pediatr. 21:615-621.

Rajapakse, C. N., K. Halim, I. Al-Orainey, A. Al-Nozha and A. K. MAl-Aska. 1987. A genetic marker for rheumatic heart disease. Br. Heart J. 58:659-662.

Read, S. E., V. A. Fischetti, V. Utermohlen, R. E. Falk and J. B. Zabriskie. 1974. Cellular reactivity studies to streptococcal antigens. Migration inhibition studies in patients with streptococcal infections and rheumatic fever. J. Clin. Invest. 54:439-450.

Read, S. E. and J. B. Zabriskie. 1977a. Streptococcal Diseases and the Immune Response. New York, Academic Press. 
Read, S. E., H. Reid, T. Poon-King, V. A. Fischetti, J. B. Zabriskie and F. T. Rapaport. 1977b. HLA and predisposition to the nonsuppurative sequelae of group A streptococcal infections. Transplant Proc. 9:543-546.

Richards, J. 1991. Acute post-streptococcal glomerulonephritis. W V Med J 87:61-65.

Ridge, J. P., E. Fuchs and P. Matzinger. 1996. Neonatal tolerance revisited: Turning on newborn T cells with dendritic cells. Science 271:1723-1726.

Robinson, J. H., M. C. Case and M. A. Kehoe. 1993. Characterization of a conserved helper T cell epitope from Group A streptococcal M proteins. Infect. Immun. 61:1062-1068.

Rock, K. L., L. Rothstein, S. Gamble and C. Fleischacker. 1993. Characterization of antigenpresenting cells that present exogenous antigens in association with class I MHC molecules. J. Immunol. 150:438-446.

Rose, N., B. Ploier and C. Ofner. 1990. Cardiac myosin-induced myocarditis. Heart autoantibodies are not involved in the induction of the disease. J. Immunol. 145:4094-4100.

Rossiter, B. A., C. Alfonso, M. A. Kehoe and J. H. Robinson. 1994. Processing of viable group A streptococci leads to major histocompatibility complex class II presentation of T cell epitopes from the major protective antigen. Eur. J. Immunol. 24:1244-1247.

Ryc, M., E. Beachey and E. Whitnack. 1989. Ultrastructural localization of the fibrinogenbinding domain of streptococcal M protein. Infect. Immun. 57:2397-2404.

Sarzotti, M., D. Robbins and P. Hoffman. 1996. Induction of Protective CTL Responses in Newborn Mice by a Murine Retrovirus. Science 271:1726-1728.

Scheynius, A., J. Fransson, C. Johansson, H. Hammar, B. Baker, L. Fry and H. Valdimarsson. 1992. Expression of interferon-gamma receptors in normal and psoriatic skin. J. Invest. Dermatol. 98:255-258.

Schlievert, P., A. Assimacopoulos and P. Cleary. 1996. Severe invasive group A streptococcal disease: clinical description and mechanisms of pathogenesis. Journal of Laboratory and Clinical Medicine 127:13-22.

Schrager, H. M., S. Alberti, C. Cywes, G. J. Dougherty and M. R. Wessels. 1998. Hyaluronic acid capsule modulates $M$ protein-mediated adherence and acts as a ligand for attachment of group A Streptococcus to CD44 on human keratinocytes. J. Clin. Invest. 101:1708-1716.

Scwartz, B., R. Facklam and R. Brieman. 1990. Changing epidemiology of group A streptococcal infection in the USA. Lancet 336:1167-1171. 
Shikhman, A. R. and M. W. Cunningham. 1994. Immunological mimicry between N-acetylbeta-D-glucosamine and cytokeratin peptides. Evidence for a microbially driven anti-keratin antibody response. J. Immunol. 152:4375-4387.

Shulman, S. T., E. M. Ayoub, B. E. Victorica, I. H. Gessner, D. F. Tamer and F. A. Hernandez. 1974a. Differences in antibody response to streptococcal antigens in children with rheumatic and non-rheumatic mitral valve disease. Circulation 50:1244-1251.

Siegel, A. C., E. E. Johnson and G. H. Stollerman. 1961. Controlled studies of streptococcal pharyngitis in a pediatric population. 2. Behavior of the type specific immune response. N. Engl. J. Med. 265:566-570.

Siegrist, C., F. Saddallah, C. Tougne, X. Martinez, J. Kovarik and P. Lambert. 1998. Induction of neonatal Th1 and CTL responses by live viral vaccines: a role for replication patterns within antigen presenting cells? Vaccine 16:1473-1478.

Sigmundsdottir, H., B. Sigurgeirsson, M. Troye-Blomberg, M. F. Good, H. Valdimarsson and I. Jonsdottir. 1997. Circulating T cells of patients with active psoriasis respond to streptococcal M-peptides sharing sequences with human epidermal keratins. Scand. J. Immunol. 45:688-697.

Simpson, W. A. and E. H. Beachey. 1983. Adherence of group A streptococci to fibronectin on oral epithelial cells. Infect. Immun. 39:275-279.

Singh, R. R., B. Hahn and E. Sercarz. 1996. Neonatal peptide exposure can prime T cells and upon subsequent immunization, induce their immune deviation: Implications for antibody vs. T cell mediated autoimmunity. J. Exp. Med. 183:1613-1621.

Smith, S. and P. Allen. 1992. Expression of myosin-class II major histocompatibility complexes in the normal myocardium occurs before induction of autoimmune myocarditis. Proc. Natl. Acad. Sci., USA 89:9131-9135.

Smith, S. and P. Allen. 1993. The role of T cells in myosin-induced autoimmune myocarditis. Clin. Immunol. Immunopath. 68(2):100-106.

Sorger, K. 1986. Postinfectious glomerulonephritis. Subtypes, clinico-pathological correlations, and follow-up studies. Veroff Pathol. 125:1-105.

Speziale, P., M. Hook, L. M. Switalski and T. Wadstrom. 1984. Fibronectin binding to a Streptococcus pyogenes strain. J. Bacteriol. 157:420-427.

Stehbens, W. E. and J. M. Zuccollo. 1999. Anitschkow myocytes or cardiac histiocytes in human hearts. Pathology 31:98-101. 
Stetson, C. A., C. H. Rammelkamp and R. M. Krause. 1955. Epidemic acute nephritis: Studies on etiology, natural history and prevention. Medicine 34:431-450.

Stevens, D. 1992. Invasive Group A streptococcus infections. Clin. Infect. Dis. 14:2-13.

Stollerman, G. 1991. Rheumatogenic streptococci and autoimmunity. Clin. Immunol. Immunopath. 61:131-142.

Stollerman, G. H. 1975. Rheumatic Fever and Streptococcal Infection. New York, Grune and Stratton.

Svensson, M., B. Stockinger and W. M. J. 1997. Bone marrow-derived dendritic cells can process bacteria for MHC-I and MHC-II presentation to T cells. J. Immunol. 158:4229-4236.

Swedom, S. E., H. L. Leonard, B. B. Mittleman, A. J. Allen, J. L. Rapoport, S. P. Dow, M. E. Kanter, F. Chapman and J. Zabriskie. 1997. Identification of children with pediatric autoimmune neuropsychiatric disorders associated with streptococcal infections by a marker associated with rheumatic fever. Am. J. Psychiatry 154:110-112.

Thompson, A., S. P. Halbert and U. Smith. 1970. The toxicity of streptolysin O for beating mammalian heart cells in tissue culture. J. Exp. Med. 131:745-763.

Tomai, M., J. Aelion, M. Dockter, G. Majumdar, D. Spinella and M. Kotb. 1991. T cell receptor $\mathrm{V}$ gene usage by human $\mathrm{T}$ cells stimulated with the superantigen streptococcal $\mathrm{M}$ protein. J. Exp. Med. 174:285-288.

Tomai, M., M. Kotb, G. Majumdar and E. H. Beachey. 1990. Superantigenicity of streptococcal M protein. J. Exp. Med. 172:359-362.

Tomai, M., P. Schlievert and M. Kotb. 1992. Distinct T cell receptor V gene usage by human $\mathrm{T}$ lymphocytes stimulated with the streptococcal pyrogenic exotoxins and pepM5 protein. Infect. Immun. 60:701-705.

Valdimarrson, H., H. Sigmundsdottir and I. Jonsdottir. 1997. Is psoriasis induced by streptococcal superantigens and maintained by M-protein-specific T cells that cross-react with keratin. Immunol. 107:21-24.

van de Rijn, I., J. B. Zabriskie and M. McCarty. 1977. Group A streptococcal antigens crossreactive with myocardium. Purification of heart-reactive antibody and isolation and characterization of the streptococcal antigen. J. Exp. Med. 146:579-599.

Vashishtha, A. and V. Fischetti. 1993. Surface-exposed conserved region of the streptococcal $\mathrm{M}$ protein induces antibodies cross-reactive with denatured forms of myosin. J. Immunol. 150:4693-4701. 
Veasy, G. L. and H. R. Hill. 1997. Immunologic and clinical correlations in rheumatic fever and rheumatic heart disease. Pediatr. Infect. Dis. J. 16:400-407.

Veasy, L. G., S. E. Wiedmeier, G. S. Orsmond, H. D. Ruttenberg, M. M. Boucek, S. J. Roth, V. F. Tait, J. A. Thompson, J. A. Daly and E. L. Kaplan. 1987. Resurgence of acute rheumatic fever in the intermountain area of the United States. N. Engl. J. Med. 16:421-427.

Vollmer, S., A. Menssen, P. Trommler and J. C. Prinz. 1994. T lymphocytes derived from skin lesions of patients with psoriasis vulgaris express a novel cytokine pattern that is distinct from that of T helper type 1 and T helper type 2 cells. Eur. J. Immunol. 24:2377-2382.

Wagner, B. M. 1960. Studies in rheumatic fever: III. Histochemical reactivity of the Aschoff body. Ann. NY Acad. Sci. 86:992-1008.

Wald, E. R., E. Dashefsky and C. Feidt. 1987. Acute rheumatic fever in Western Pennsylvania and the tristate area. Pediatr. 80:371-374.

Watanabe-Ohnishi, R., J. Aelion, L. LeGros, M. A. Tomai, E. V. Sokurenko, D. Newton, J. Takahara, S. Irino, S. Rashed and M. Kotb. 1994. Characterization of unique human TCR V beta specificities for a family of streptococcal superantigens represented by rheumatogenic serotypes of M protein. J. Immunol. 152:2066-2073.

Watanabi-Ohnishi, R., D. Low, A. McGeer, D. Stevens, P. Schlievert, B. Kreiswirth and M. Kotb. 1995. Selective depletion of V $\beta$-bearing T cells in patients with severe invasive Group A streptococcal infections and streptoccal toxic shock syndrome. J. Infect. Dis. 171:74-84.

Westlake, R. M., T. P. Graham and K. M. Edwards. 1990. An outbreak of acute rheumatic fever in Tennessee. Pediatr. Infect. Dis. J. 9:97-100.

Wexler, D. E., D. E. Chenoweth and P. P. Cleary. 1985. Mechanism of action of the group A streptococcal C5a inactivator. Proc. Natl. Acad. Sci., USA 28:8144-8148.

Whitnack, E., A. L. Bisno and E. H. Beachey. 1981. Hyaluronate capsule prevents attachment of group A streptococci to mouse peritoneal macrophages. Infect. Immun. 31:985-991.

Williams, R. and R. Gibbons. 1972. Inhibition of bacterial adherence by secretory immunoglobulin A: a mechanism of antigen disposal. Science 177:697-699.

Williams, R. C. J., V. Raizada, K. Prakash, I. van de Rijn, J. B. Zabriskie, J. D. Stobo and K. B. Sharma. 1982. Changes in T-lymphocyte subsets during acute rheumatic fever. J. Clin. Immunol. 2:166-172.

Winkelstein, J. A. 1981. The role of complement in the host's defense against Streptococcus pneumoniae. Rev. Infect. Dis. 3:289-298. 
Yang, L., P. Soprey, M. Wittner and E. Fox. 1977. Streptococcal-induced cell mediated immune destruction of cardiac myofibers in vitro. J. Exp. Med. 146:344-360.

Yang, N., and B. Boettcher.1992. Development of human ABO blood group A antigen on Escherichia coli Y1089 and Y1090. Immunol. Cell. Biol.70:411-6.

Yegin, O., M. Coskun and H. Ertug. 1997. Cytokines in acute rheumatic fever. Eur. J. Pediatr. 156:25-29.

Yewdell, J. W., C. C. Norbury, and J. R. Bennick. 1999. Mechanisms of exogenous antigen presentation by $\mathrm{MHC}$ class I molecules in vitro and in vivo: implications for generating CD8+ $\mathrm{T}$ cell responses to infectious agents, tumors, transplants, and vaccines. Adv. Immunol. 73:1-77.

Yoshinaga, M., F. Figueroa, M. R. Wahid, R. H. Marcus, E. Suh and J. B. Zabriskie. 1995. Antigenic specificity of lymphocytes isolated form valvular specimens of rheumatic fever patients. J. Autoimmun. 8:601-613.

Yoshinoya, S. and R. M. Pope. 1980. Detection of immune complexes in acute rheumatic fever and their relationship to HLA-B5. J. Clin. Invest. 65: 136-45.

Zabriskie, J. B. and E. H. Freimer. 1966. An immunological relationship between the group A streptococcus and mammalian muscle. J. Exp. Med. 124: 661-78.

Zabriskie, J. B., D. Lavenchy, R. C. J. Williams, S. M. Fu, C. A. Yeadon, M. Fotino and D. G. Braun. 1985. Rheumatic fever-associated B cell alloantigens as identified by monoclonal antibodies. Arthritis Rheum 28: 1047-51.

Zarconi, J. and M. C. Smith. 1988. Glomerulonephritis: Bacterial, viral, and other infectious causes. Postgrad. Med. 84: 239-251.

Zipfel, P. F., J. Hellwage, M. A. Friese, G. Hegasy, S. T. Jokiranta and S. Meri. 1999. Factor $\mathrm{H}$ and disease: a complement regulator affects vital body functions. Mol. Immunol. 36: 241-8. 